\title{
Organizational structures, gender roles and performance of smallholders in Africa - \\ Insights from the Nigerian shrimp and prawn sector
}

Dissertation to obtain a Ph.D. degree in the Graduate School Forest and Agricultural Sciences (GFA)

at the Department of Agricultural Economics and Rural Development

Faculty of Agricultural Sciences

Georg-August-University Göttingen, Germany

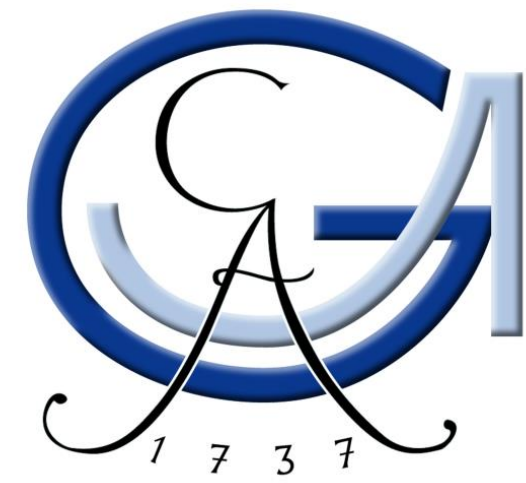

presented by

Ayobami Adetoyinbo

born in Ibadan, Nigeria

Göttingen, May 2020 
First supervisor: Prof. Dr. Ludwig Theuvsen

Second supervisor: Dr. Verena Otter

Third supervisor: Prof. Dr. Achim Spiller

Fourth supervisor: Prof. Dr. Jacques Trienekens

Date of dissertation: 18 May 2020 


\section{Summary}

Agriculture is important for most of the world's poor population not only as a source of income but defense against hunger. Over the last three decades, agricultural supply chain organizational structures in developing countries have increasingly become complex and transformed because of the emergence of competitive, fast-moving business environments. These changes have particularly affected several food value chains, creating in some cases positive effects, and resulting in the exclusion of smallholders who are unable to meet specific supply chain requirements. This counteracts the achievement of development goals by disrupting associated distributional effects to excluded smallholders in developing countries. Evidence suggests that affected smallholders respond by switching marketing channels and shifting to organizational network relationships. This consequently intensifies the formation of dualistic systems in which both modern and local value chains coexist. However, since the mid-1990s, the focus of development analysts and researchers has been on the expansion and inclusion of smallholders in modern value chains. This has resulted in total neglect of local value chains, which remain a significant source of income for many rural populations and ensure effective food delivery that meets culturally diverse needs in developing countries. Only recently has agribusinesses' and development analysts' attention been placed on local value chains yet, some key knowledge and research areas remain unaddressed.

Indeed, our understanding of how local value chains are organized and function within dualistic systems remains generally limited. In particular, little is known about the role of socially constructed concepts such as gender-relations and decision-making power in driving value additions. Understanding these fundamentals is important for the postulation of policies for agricultural and local value chain upgrading and equitable distribution of wealth. Besides, smallholders continuously face external and internal contingencies that affect their competitiveness along food systems. Theory posits that the effects of changing business environments on smallholder performance can be mitigated by fitting supply chain network that includes vertical, horizontal and lateral relationships. However, the associations between these constructs as postulated theoretically remain generally underexplored, especially for smallholders in African food sectors. Frameworks and empirical analyses that holistically and simultaneously analyze these associations are rare. Furthermore, over the last two decades, there has been increasing attention of donors, governments and researchers to strengthen collection actions 
through producer groups in developing countries. Producer groups are widely viewed as valuable institutional arrangements for smallholders to cope with/overcome market inefficiencies arising from changing business environments. However, little is known about the effect of membership in producer groups on smallholder performance in fishery subsectors. Overall, bridging these gaps is important to understand and posit practical implications on how to promote alternative development models and smallholders' opportunities in dynamic food systems.

On this account, this dissertation fills these gaps by analyzing the links between organizational structures, gender roles, and performance of smallholders in African local value chains. The dissertation consists of three main papers that are based on two types of data from the Nigerian shrimp and prawn sector. First, qualitative data was obtained between December 2017 and January 2018 from 48 respondents in three States namely; Akwa-Ibom, Delta and Lagos. The second data includes two sets of quantitative data obtained from the survey of 405 producers and 238 processors in Akwa-Ibom, Ondo and Lagos States between May and August 2018.

The first paper aims to uncover how local value chains in dualistic food systems are organized, depicting the predominant governance themes, gender roles for value addition, and necessary upgrading strategies for smallholders in Africa. Failure of existing studies to capture the evolution and multiplicity of governance structures, and hidden social constructs has resulted in mixed findings on the organization and drivers of local value chains. Using qualitative data obtained from 3 in-depth focus group discussions and 21 key informant interviews, we rely on the global value chain approach to map local value chain's organization distinctively from modern value chains. We make a conceptual contribution by extending this approach to include a gendered dimension of the value web approach, which we developed. This allows for simultaneous analysis of the roles of governance schemes and hidden gender relations in driving local value chains.

Our main results reveal that competitive traders, the mutual dependence between production and processing segments and strategic business activities of female processors were crucial for the chain's functioning. Results from the Net-maps show that the predominant marketing channel is long: producer-women processors/marketer-trader-retailer-consumer, however, analysis of the governance dimensions shows the importance of the relational governance between producers and women processors that allows for better coordination of supply and marketing activities at the supply-base. Further analysis of the gendered value-web highlights the vital roles women play 
in ensuring value additions and smooth flow of products along the chain. Women processors act as financial buffers for producers, points of contact and precursors to all midstream value additions in the value web.

The second paper builds on the results and implications of the first paper. Here, we suggest a comprehensive quantitative research framework to determine the relationship between changing business contingencies, organizational supply chain networks and smallholder performance. While supply chain contingencies and organizational complexities have been widely studied in organizational theory literature, it only became a subject of quantitative analysis in recent times. Still, several conceptual and research shortcomings exist in the literature such as the neglect of the concurrent fit of organizational strategies to both external and internal contingencies, lack of comprehensive analysis of organizational networks, and less focus on multiple tiers. Hence, we use a variance-based structural equation model to analyze the quantitative data from producers and women processors. We first take a cue from contingent resource-based theory and netchain approach to conceptualize the influence of both external (market turbulence, technological progress, distrust and power asymmetry) and internal (human and financial resources) contingencies on organizational relationships and performance, extending an existing empirical model. We then empirically test the so-called "Contingency-Netchain-Performance" (CNP) framework, on two tiers to derive valid and comprehensive evidence comparable across the tiers.

Results from the estimations indicate that both external and internal contingencies significantly influence adaptational change in organization supply chain network, which in turn contributes to smallholders' performance. All the smallholders' external contingencies influence the formation of tighter vertical coordination but their influences differ on horizontal and lateral relationships. More importantly, results reveal that smallholders' internal contingencies concurrently influence their organizational network structures and performance. However, the influence of both external and internal contingencies on organizational networks seems to differ across tiers while supply chain vertical relationships tend to intensify the formation of closer network structures. Several conceptual, theoretical and practical contributions emerged from the successful application of the CNP framework in this study.

In the third paper, we examined the selectivity-corrected role of fisher groups on the capture and technical efficiency of artisanal shrimpers in Africa. We empirically identify factors that influence shrimpers' decision to belong to fisher groups and estimate the effect of membership on 
capture and technical efficiency. Methodological augmentation using Greene's stochastic production frontier method and propensity score matching that correct for selection bias, allows us to account for different technological set if any, and sample selection bias from both observed and unobserved factors. We use quantitative data of 353 producers that operate outboard engines, comprising of 95 members and 258 non-members. We found that the overall participation in fisher groups is positively determined by shrimpers' socioeconomic characteristics; female participation in shrimp-related groups; and infrastructural facilities like credit and tarmacked roads. The stochastic results reveal that technical efficiency scores remain consistently higher for members regardless of how biases were corrected. Although technical efficiency scores for members and nonmembers tend to be over-estimated if selectivity is not appropriately controlled, our findings suggest that participation in fisher groups is important for smallholders with belowaverage performance and positively related to increases in catch and technical efficiency.

Important lessons and conclusions were derived from the results of this dissertation. The papers confirm that organizational network structures matter for smallholders' upgrading and local value chain development in Nigeria. Our results confirm strong influences from highly dynamic external and internal contingencies on the formation of dense and complex organizational network structures in which vertical and network relationships are dependent. By aligning their organizational network structure to fit changing external and internal contingencies, smallholders can create and remain competitive within dualistic sectors. However, associated concepts such as gender roles and internal contingencies across mutually dependent tiers are important to upgrade smallholders' activities. Furthermore, fisher groups is a valuable institutional arrangement as they tend to improve shrimpers' capture and technical efficiency, and might be crucial for attaining equitable distributional effects to smallholders with below-average economic performances. Relevant policy implications for smallholders' upgrading and local value chain development, as well as limitations of the study, are discussed in the papers. 


\section{Acknowledgements}

"Veni Vidi Vici".

I would like to express my immeasurable appreciation and deepest gratitude to everyone who had contributed one way or the other to the success of Ph.D. program. I would like to thank my supervisory committee. I am deeply grateful to Prof. Dr. Ludwig Theuvsen for providing me with the opportunity to pursue my Ph.D. program, as well as immense support and trust in my research work. Ludwig, your feedback has been priceless and has contributed a great deal to my scientific development. My profound gratitude goes to Dr. Verena Otter for the unwavering backing, scientific feedback, and opportunities provided during my Ph.D. program. Thank you for your esteemed inputs on my work and soothing suggestions during turbulent and uncertain periods. I also thank Prof. Dr. Achim Spiller for acting as the third member of my thesis committee and discussant for my first GlobalFood doctoral seminar. His scientific feedback on my proposal has gone a long way in shaping the overall design and successful completion of my thesis. I am indebted to Prof. Dr. Jacques Trienekens for providing me with top-notched recommendations and for always having his door open to me during my research stay in Wageningen. I also appreciate the platform you gave me to engage with colleagues at the Business Management and Organization group.

I am deeply grateful to Prof. Victoria Salin, Prof. Brent Ross, and Dr. Aleks Schaefer for organizing and providing me with the opportunity to make seminar presentations at the Department of Agricultural Economics, Texas A\&M University and Michigan State University.

I will like to thank my friends who have made my life in Germany and studies in Goettingen exciting. "Ich möchte Herrn Andreas Holzwarth - meinem ehemaligen Vermieter - für seine Unterstützung während meines Masterstudiums in Hohenheim und darüber hinaus danken“. I appreciate all members of the GlobalFood RTG for their supports and insightful comments on my research work. It has been a great opportunity and joy to share several special moments with you within and outside the office. I am also thankful to all my colleagues at the Chair of Agribusiness Management. I am particularly grateful to Dirk for providing me with a soft landing in Goettingen and most especially teaching me how to ride a bicycle! I would also like to thank my mates Makaiko, Dela, Cansin, and Collins for their support through the years.

I am grateful to everyone that contributed to the success of my field survey. I thank officials of the Nigerian Institute for Oceanography and Marine Research and Akwa-Ibom Ministry of 
Agriculture for facilitating the data collection process in Lagos, Delta, and Akwa-Ibom States. I am particularly thankful to Prof. Victor Okoruwa, the current Director of Academic Planning at the University of Ibadan for hosting and supporting me during the field survey. I also thank Sayo Ojo, Mrs. Mercy Eke, Steve Akinbulumo, Mr. Samuel, Mr. Shina and Prince Ernest for managing and co-supervising the data collection activities. I appreciate all the survey respondents, the experts, and managers of the fishing companies in Nigeria. My sincere thanks go to the enumerators, field assistants, and drivers. Their effort, tenacity and hard work to cope with the difficult terrains were crucial for collecting the data presented and analyzed in this dissertation.

I acknowledge the financial support from the German Research Foundation (DFG) through the GlobalFood RTG and the Chair of Agribusiness Management at the University of Goettingen. Without this, it would have been difficult to cover all costs associated with fieldwork, software, and participation in international conferences. More importantly, my gratitude goes to GlobalFood's coordination team that includes Dr. Melanie Grosse, Mrs. Katrin Pape, and Ms. Ann-Kathrin Fahlbusch as well as Frau Martina Reichmann for making the bureaucratic process less tedious.

My profound appreciation goes to my family who stood by me through the course of my Ph.D. program. My mum, sisters (Kemi, Funke, and Joke), in-laws (bros. Gbadedo, Dele and Kehinde), nephews (Bolu, Taye, Kehinde, Tomi, and Darasimi), and nieces (Mary and Josephine) deserve huge gratitude for their encouragement and support during my Ph.D. program.

Finally, my deepest and heartfelt gratitude goes to my wife, heartbeat, and joy - Bolade temi ni kan). Words cannot express how appreciative I am for the unending encouragement and love you showered me, which have kept me going when the journey got tough. I love you, babe! 
I dedicate this dissertation to my late father and sister, Lawrence Adetoyinbo and Ronke Adebiyi. 


\section{Table of contents}

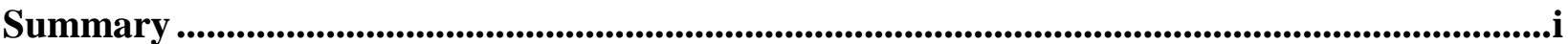

Acknowledgements.............................................................................................................................

Table of contents............................................................................................................................... viii

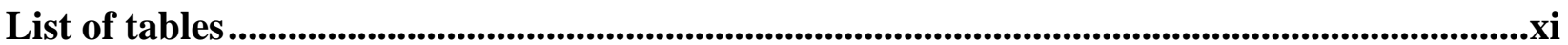

List of figures ................................................................................................................................................... xii

List of acronyms ................................................................................................................................................. xiii

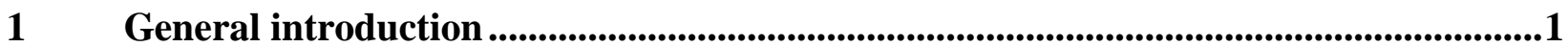

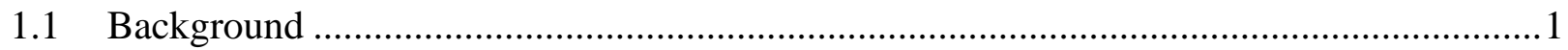

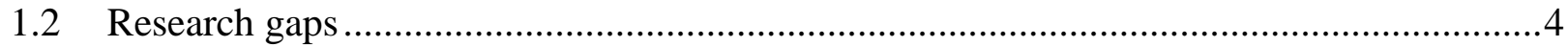

1.2.1 Local value chains and organizational structures in dualistic sectors .........................

1.2.2 Organizational structures, contingencies, and performance of smallholders ...............6

1.2.3 Collective action and smallholders' productivity and technical efficiency .................8

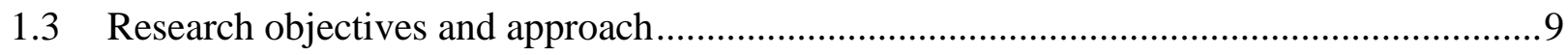

2 Organizational Structures, gender roles and upgrading strategies for smallholders in developing countries' local value chains.....................................................................................11

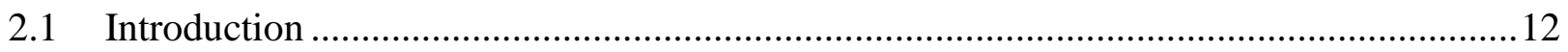

2.2 Conceptual framework …………………………...................................................14

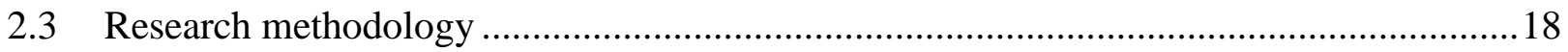

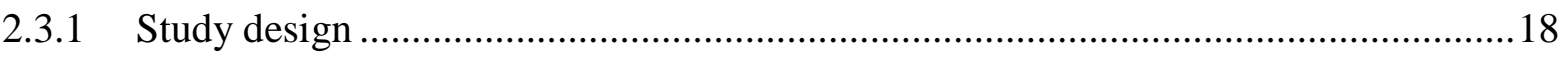

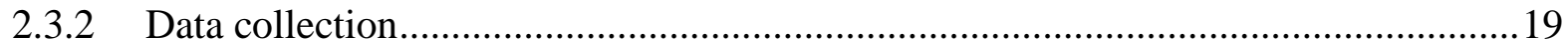

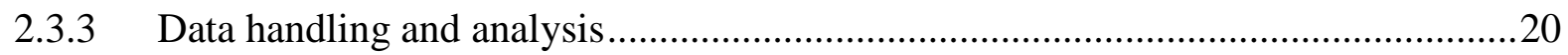

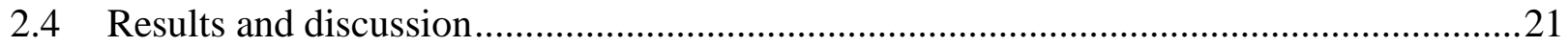

2.4.1 Organization of the Nigerian shrimp and prawn value chain...................................21

2.4.2 Connecting landing sites to the markets: drivers of LVC and MVC ........................23

2.4.3 Third dimension: benefit distribution among actors in the LVC ..............................29

2.4.4 Fourth dimension: smallholders' upgrading strategies in the LVC ..........................30

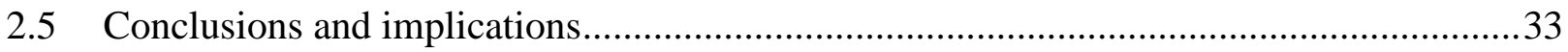

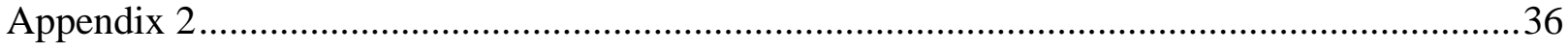

3 Contingent resource-based view of food netchain organization and firm performance across tiers: A comprehensive quantitative framework .......................................................38 


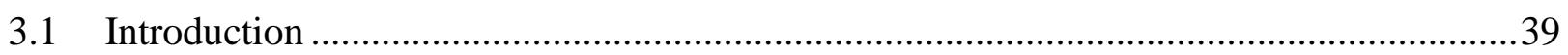

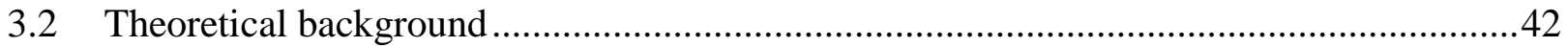

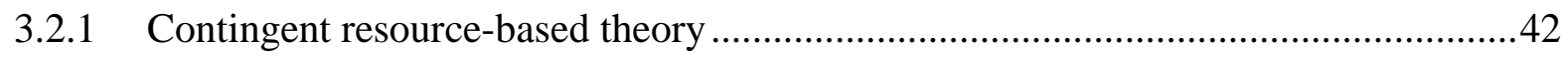

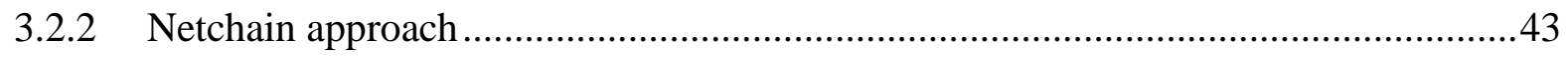

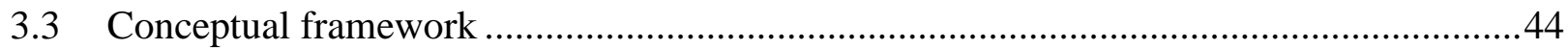

3.3.1 Effects of external contingencies on organizational SC network relationships .........44

3.3.2 Effects of internal contingencies on organizational SC network relationships..........47

3.3.3 Effects among different organizational SC network relationships.............................48

3.3.4 Effects of organizational SC network structures on firms' performance ....................49

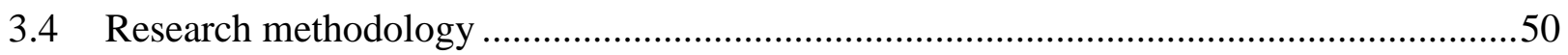

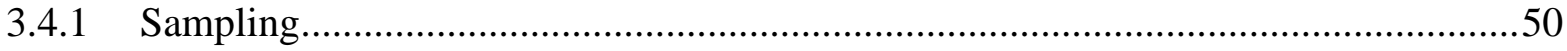

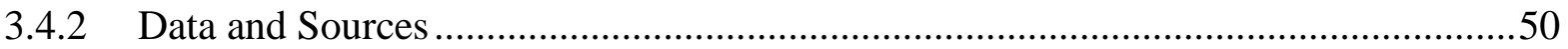

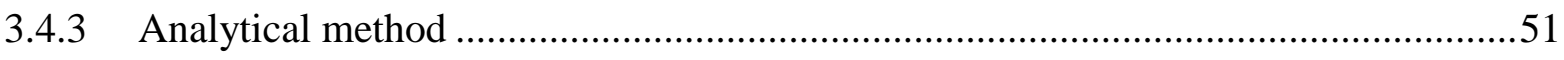

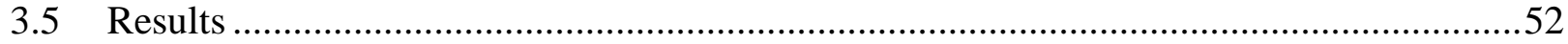

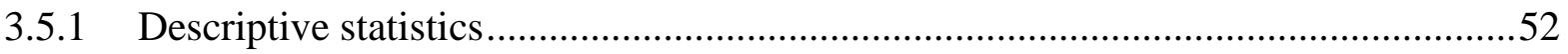

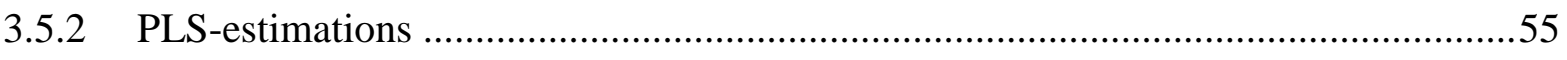

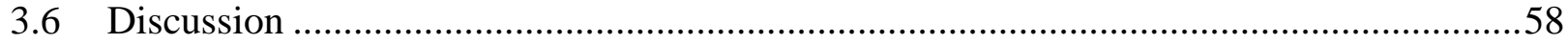

3.6.1 External contingencies and organizational SC network relationships .......................58

3.6.2 Internal contingencies and organizational SC network relationships ........................59

3.6.3 Influence among different organizational SC network relationships .........................60

3.6.4 Organizational relationships and performance of mutually-dependent producers and

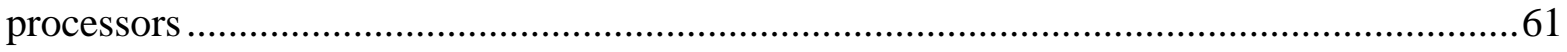

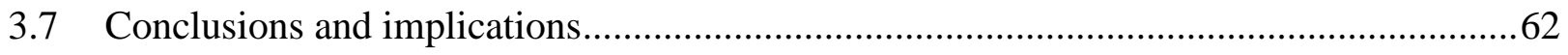

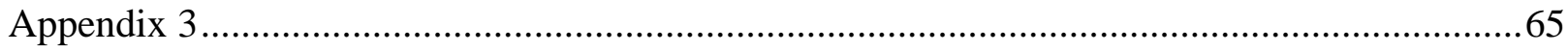

4 Can producer groups improve technical efficiency among artisanal shrimpers in Nigeria? A study accounting for observed and unobserved selectivity .........................70

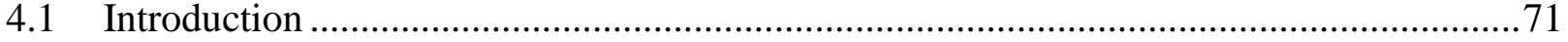

4.2 Shrimp production and artisanal fisher groups in Nigeria ................................................73

4.3 Conceptual framework and empirical specifications .......................................................75

4.3.1 Artisanal fishers' decisions to participate in producer group .....................................75

4.3.2 Stochastic production frontier model .....................................................................

4.3.3 Sample selection bias in stochastic production function model.................................77 


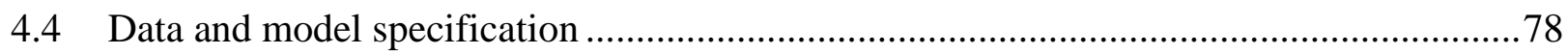

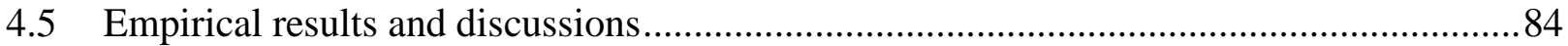

4.5.1 Estimates of producer group participation decisions ...........................................84

4.5.2 Stochastic production frontier estimates ...................................................... 86

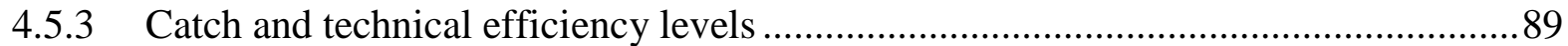

4.6 Concluding remarks and policy implications ......................................................91

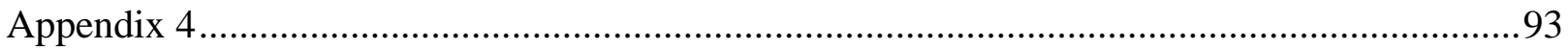

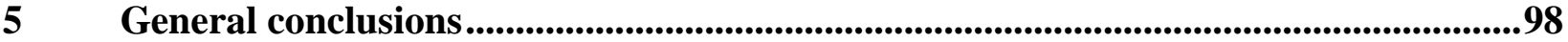

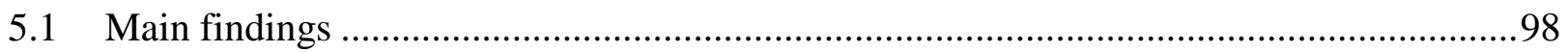

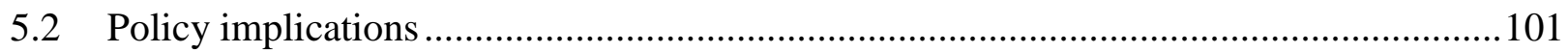

5.3 Limitations and suggestions for future research.................................................104

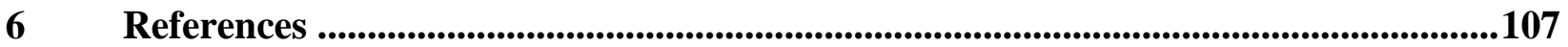

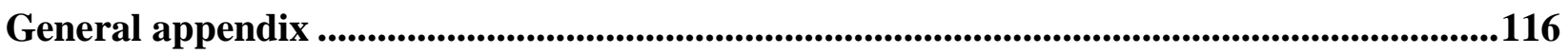

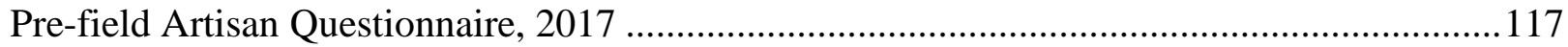

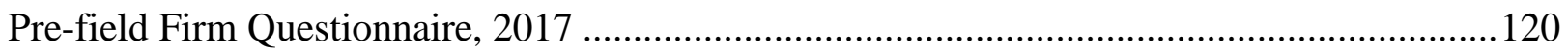

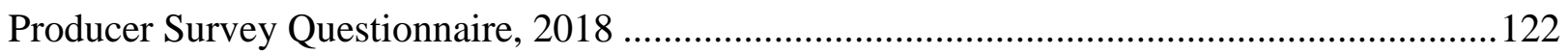

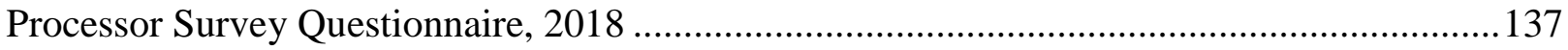




\section{List of tables}

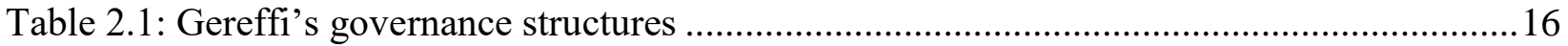

Table 2.2: Details of the participants in the FGDs and KIIs ……................................................ 18

Table 2.3: Constraints and opportunities in the production and processing segments....................31

Table A2.1: Constraints and opportunities in the mid and downstream of LVC ...........................37

Table 3.1: Producer and Processor Descriptive Statistics ...........................................................53

Table A3.1: Reliability and Discriminant Validity for the Producer Model..................................65

Table A3.2: Reliability and Discriminant Validity for the Processor Model..................................66

Table A3.3: Summary of the reflective measurement models .......................................................67

Table A3.4: Inter-construct Correlations for the Producer Model .................................................67

Table A3.5: Inter-construct Correlations for the Processor Model ...................................................68

Table A3.6: HTMT values for producer and processor models....................................................68

Table 4.1: Definition of selected variables............................................................................. 80

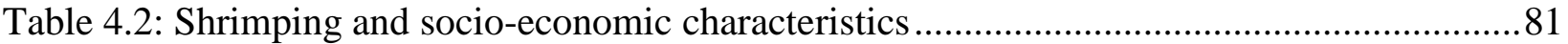

Table 4.3: Probit model estimates of the determinant of membership in producer group

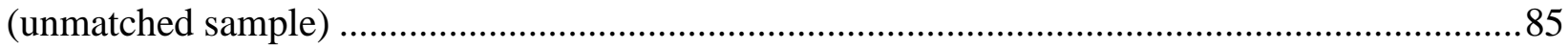

Table 4.4: Parameter estimates for conventional and sample selection SPF models: Unmatched sample

Table 4.5: Parameter estimates for conventional and sample selection SPF models: Matched sample

Table 4.6: Technical efficiency levels across the SPF models...................................................90

Table 4.7: Predicted frontier output for unmatched and matched samples .....................................91

Table A4.1: Hypothesis testing for Stochastic Production Frontier Models ....................................93

Table A4.2: Probit model estimates of determinant of membership in producer group (matched

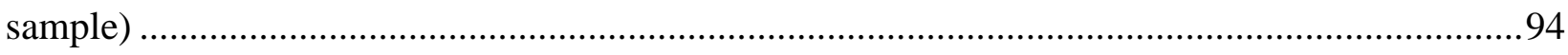

Table A4.3: Probit model addressing potential endogeneity (pooled and matched samples)........94

Table A4.4: Roles and reasons for participating in fisher groups .................................................95

Table A4.5: Metafrontier levels across the stochastic metafrontier (SMF) models........................95

Table A4.6: Endogenous switching regression for unmatched sample .........................................96

Table A4.7: Endogenous switching regression for matched sample ...............................................96

Table A4.8: Endogenous switching regression showing effects of fisher group on capture .........97 


\section{List of figures}

Figure 1.1: Nigerian shrimp and prawn capture and export based of FAO database ..................2

Figure 1.2: Poverty differences among households in MVCs and LVCs (Swinnen et al., 2013)....3

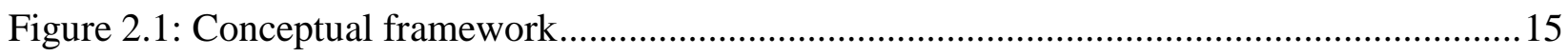

Figure 2.2: Shrimp and prawn value chain .........................................................................22

Figure 2.3: Governance typologies along the shrimp and prawn value chain ..........................25

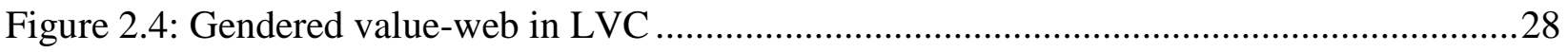

Figure A2.1: Distribution of additional margins in the value chain........................................36

Figure A2.2: Framework summarizing results and necessary upgrading strategies ....................36

Figure 3.1: Research framework integrating the contingent RBT and netchain approach ...........44

Figure 3.2: Research model with hypotheses for producers developed from Otter et al., (2014)..46

Figure 3.3: Research model with hypotheses for processors developed from Otter et al., (2014) 47

Figure 3.4: Producer model showing path coefficients ......................................................56

Figure 3.5: Processor model showing path coefficients.....................................................57

Figure A3.1: Sources of market turbulence and type of information from external actors ..........69

Figure 4.1: Map of Nigeria showing shrimping communities and membership distribution ........79

Figure A4.1: Common support property for the PSM model ................................................97 


\section{List of acronyms}

ARFAN Artisanal Fishers Association of Nigeria

ATA Agricultural Transformation Agenda

ATT Average Treatment on the Treated

AVE

Average Variance Extracted

CD

CR Composite Reliability

Cobb Douglas

ESR Endogenous Switching Regression

FGD Focus Group Discussion

GDP Gross Domestic Product

GVC Global Value Chain

KII Key Informant Interview

LGA Local Government Area

LR Log-likelihood Ratio

LVC Local Value Chain

MTE Metafrontier Technical Efficiency

MVC Modern Value Chain

NFDP National Fadama Development Project

NGO Non-Governmental Organization

PLS-SEM Partial Least Squares Structural Equation Modeling

PSM Propensity Score Matching

RBT Resource-based Theory

SC Supply Chain

SMF Stochastic Meta Frontier

SP Shrimp and prawn

SPF Stochastic Production Frontier

TE Technical Efficiency

VC Value Chain 


\section{General introduction}

Agriculture is important for most of the world's poor population not only as a source of income but defense against hunger. In most developing counties, the agricultural sector accounts for three-quarters of employment, one-third of Gross Domestic Product (GDP) and nearly four-times more increase in income than growth in other sectors (The World Bank, 2012). As a result, agricultural development has remained a powerful tool to reduce global poverty and improve economic development. The ongoing transformation of agricultural food systems is no more a quiet revolution as it is seen as a pro-poor arrangement in developing countries. Over the past three decades, many agrifood systems have become restructured, urbanized and globalized due to changes in consumption, competition and trade patterns (Mather, 2005; Qaim, 2017; Reardon et al., 2009). In the process, the overall organizational dimension of agrifood systems has become more heterogeneous and complex with several implications for smallholders (Dolan \& Humphrey, 2000; Mather, 2005; Mhlanga, 2010; Neven et al., 2009; Scoones et al., 2016).

\subsection{Background}

Nigeria, a lower-middle-income country in Africa, presents a suitable case of the ongoing agricultural transformation because it shares similar economic and agricultural characteristics with other developing countries. Despite the importance of the oil sector, agriculture has remained the main basis of the Nigerian economy, employing about 36.6 percent of the entire labor force. Although the value-added of the Nigerian agricultural sector is relatively high at about 21 percent of the Gross Domestic Product (GDP), it does not reflect in the livelihood of the population, as 53.5 percent of the population lives below the poverty line of $\$ 1.90$ per day (FAO, 2018; WorldFish, 2018). Like other developing countries, about 88 percent of Nigerian farmers and fishers are smallholders and face myriad contingencies that come from agricultural production and marketing. Farmers and fishers face typical problems relating to low productivity and technological advancement, limited commercialization, weak infrastructural and financial amenities, and limited institutional support. Thus, more than 72 percent of Nigeria's smallholders are poor and reside in rural areas (FAO, 2018).

What is never mentioned is the deepening poverty level in the coastal areas due to neglect of the fishery subsector (Zabbey et al., 2010). Fishery subsector is an important source of direct and indirect income to more than 28.2 million people in Nigeria, 70 percent of whom are women (WorldFish, 2018). Shrimp and prawn (SP) are some of the major valuable agricultural products 
in the subsector from which smallholders can better benefit (FAO, 2017a; NBS, 2016). However, SP production and marketing are impacted by several contingencies, including volatile supply and demand and high perishability (see Figure 1.1). With the growing global demand and dwindling SP supply in Asia and the Americas, more attention is paid to Africa countries to expand SP's frontier. As a result, the Nigerian SP subsector has undergone immense transformations in the last two decades (Figure 1.1). More prominently is the globalization of and introduction of stringent governance mechanisms and private standards by private companies in the subsector, which have resulted in the emergence of export and modern value chains (MVC).

While several positive effects relating to increasing productivity, income, and price have been stimulated by the organizational structures and institutional attributes inherent in the MVCs, another set of challenges and risks, particularly for smallholders and women have been created (Udong et al., 2009; Udong et al., 2010). Similar to other developing countries, poor smallholders not participating in MVCs struggle with economic marginalization over the years (Figure 1.2), just as the potentials and effects of attrition and exclusion from MVCs increase (FAO, 2007). This counteracts the achievement of a sustainable development goal aimed at reducing inequality, especially since modern and export retailers prefer to engage private companies that are more efficient.

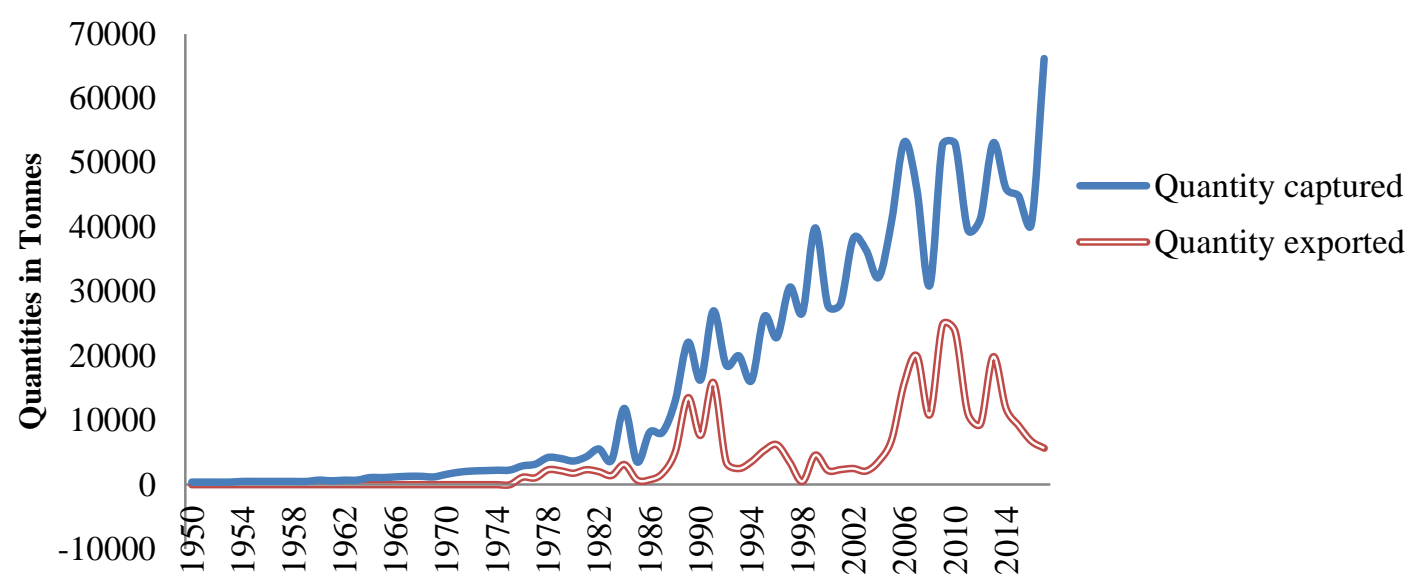

Figure 1.1: Nigerian shrimp and prawn capture and export-based of FAO database

The attrition and exclusion of smallholders from the MVC have resulted in a lock-in effect and forced smallholders to swap markets and/or modify their organizational relationships. This deepened the formation of dualistic systems in which local value chains (LVC) function parallel to MVCs. Unlike MVC, LVC is within the reach of poor smallholders and women, and so its development might be crucial in reducing poverty and economic marginalization inherent in 
Nigeria, which has the highest poor population in Africa (Figure 1.2). With the LVC driving overall SP supply (i.e. quantity captured minus exported in Figure 1.1) and accounting for over two-thirds of urban consumers' expenditures, many poor smallholders including women can benefit from stable demand by effectively connecting with the growing local and regional markets (Lie et al., 2012; Markelova et al., 2009). The issue remains how to develop the LVC and organize associated smallholders and women to deal with inherent contingencies and improve their performance.

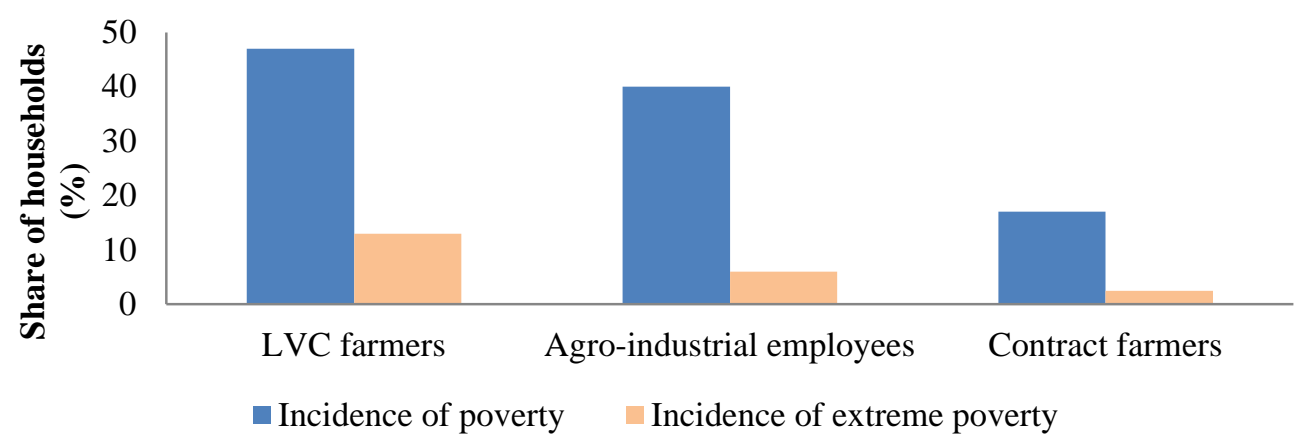

Figure 1.2: Poverty differences among households in MVCs and LVCs (Swinnen et al., 2013)

Indeed, evidence suggests that smallholders' benefit and success from the development of LVCs is partly based on their organizational structures (Corsi et al., 2017; Lie et al., 2012; Markelova et al., 2009). The unfavorable business situations that smallholders face in the Nigerian LVC require organizational adaptation to reduce associated transactional risks and costs. First, there is the option of implementing some coordination mechanisms, which go beyond the conventional open-market mechanism. Implementing higher coordination mechanisms is expected to improve smallholder's performance by fostering better risk and cost management along supplier-buyer relationships (Carbone et al., 2009; Codjo et al., 2016; Elomri, 2015; Handayati et al., 2015). Contract, information sharing, joint decision-making, and collective learning are peculiar coordination mechanism tools crucial to harmonize smallholders' activities and deal with dynamic business situations. Second, smallholders to a large extent can forge relational networks with players along the LVCs through collective actions and links to broad networks of government, donors and development agencies (Markelova et al., 2009). Besides, though still unclear how, this array of relationships can also be complementary in fostering smallholders' performance by leading to a boost in the market, creating more value additions and supporting higher profit and employment (FAO, 2014; Fayet \& Vermeulen, 2014; The WorldBank, 2013). 
Focusing and understanding smallholders' organizational structures is crucial to create alternative LVC-based development models, which will ensure the inclusiveness of poor smallholders and women, and improve their opportunities in light of persistent transformations in the SP subsector (Bernard \& Spielman, 2009; Maertens \& Swinnen, 2012). Women will particularly benefit from an inclusive organizational structure because their prominent marketization and commoditization activities along LVCs are often invisible and unvalued. There is an on-going argument whether women's activities along the SP LVC are livelihood strategies aimed at ensuring the survival of their families or fully involved in economic decisions (Udong et al., 2010). Gender-sensitive LVC development can increase women's yield by 20-30 percent, consequently raising agricultural output by 2.5-4 percent and reducing poor population by 12-17 percent (FAO, 2016a). Yet, various family and VC contingencies such as power asymmetry and socio-economic and cultural settings affect women's roles and integration in LVC development (Schumacher, 2014).

Research about LVC development with gender sensitivity is timely with the recent postulation of the Nigerian Agriculture Promotion Policy, which seeks to support smallholders and women, and engage the 20 percent of youth population (ages 15-24) who are unemployed in Agriculture (FMARD, 2016; WorldFish, 2018). Against this background, this dissertation uses a "genderlens" to analyze the neglected influence of smallholders' organizational structures on their performance in a developing country's LVC. With the case of the Nigerian shrimp and prawn subsector, transferability of results and implications seems likely since similar agricultural attributes are shared with other developing countries.

\section{$1.2 \quad$ Research gaps}

The promotion of smallholders' opportunities through LVC development has started attracting immense attention from agribusiness and development analysts in developing countries (Lie et al., 2012; Neven et al., 2009). There is a growing body of literature exploring the organizational structures of LVCs, particularly relating to inherent business contingencies and smallholder performance. Yet some conceptual and research gaps exist in this literature.

\subsubsection{Local value chains and organizational structures in dualistic sectors}

As mentioned above, several agricultural sectors in developing countries have undergone an enormous transformation in the last three decades, consequently evolving into dualistic sectors. 
This has prompted several studies to analyze various VCs in developing countries. Although several studies have analyzed LVCs in several cases of the world's developing countries, several research gaps still exist. Existing studies do not make a comprehensive analysis of LVCs that exist in dualistic sectors. For example, Ketema et al., (2016) used a multinomial model to determine factors that influence producer's milk channel choice in the dairy VC of Harar and Dire Dawa Areas of Eastern Ethiopia. Similarly, Ouma et al., (2017) used a multinomial logit model to identify the determinants of vertical integration among pig traders in Uganda. Hichaambwa and Tschirley, (2010) relied on a qualitative approach to understand how vegetables are moved into Lusaka by assessing the existing market structure. Lie et al., (2012) also qualitatively analyzed how smallholders use their capabilities to establish and sustainably manage the local dairy VC through Twawose goat cooperative in Tanzania. While these aforementioned studies focused on non-dualistic sectors, studies such as Mani et al., (2018) and Chagomoka et al., (2013) have analyzed LVCs in dualistic sectors. The latter studies however profiled actors and segments in such a way that there are no clear distinctions between LVCs and MVCs. Yet, it remains unclear how neglected LVCs are organized and function parallel to MVCs within a dualistic sector, such that a niche is created for smallholders, women and numerous localized wholesale and retail outlets.

Traditionally, governance analysis of VCs is essential to understand how they are controlled and coordinated (Gereffi et al., 2005; Hichaambwa \& Tschirley, 2010; Kaplinsky, 2000; Ouma et al., 2017; Wentink et al., 2017). Recent evidence has shown that VCs are driven through multiple interacting governance structures and social concepts that might be rather hidden (Gereffi \& Fernandez-Stark, 2016; Lie et al., 2012; Schumacher, 2014). Studies listed earlier have however failed to account for the evolution and multiplicity of governance structures, thus resulting in the identification of incomplete governance typologies as fundamental drivers of LVCs. Additionally, solely analyzing governance typologies creates another research gap in itself. Governance analysis focuses only on the coordination of LVCs, neglecting other key drivers, which are considered hidden. Hidden drivers that are socially constructed such as differentiated gender roles and relations and decision making power have received little attention in recent VC literature (FAO, 2016b; GIZ, 2013; Lie et al., 2012; Maertens \& Swinnen, 2009, 2012; Schumacher, 2014). The effort to comprehensively understand how LVCs in dualistic sectors are organized therefore remains a conceptual and empirical one. It would be interesting to first get in- 
depth insights into how neglected LVCs in dualistic sectors are organized along governance mechanisms and gender-relations. Analyzing these concepts is important to understand the role of social and economic components in shaping LVCs and postulating practical upgrading strategies for further LVC development in developing countries.

\subsubsection{Organizational structures, contingencies, and performance of smallholders}

During the last decade, research has paid increasing attention to smallholders' organizational structures and their effects on farm performance (Maertens \& Vande Velde, 2017; Ochieng et al., 2018; Ton et al., 2017). However, such studies lack a holistic view of different interorganizational relationships, even though smallholders in developing countries concurrently engage in several complex organizational network relationships. Many studies focused on vertical relationships that depict supplier-buyer relationships between smallholders and their trading partners. For instance, Barrett et al., (2012) studied the contracting arrangements between smallholders and commodity-processing firms in five developing countries. They highlighted different narratives explaining patterns of contracting and non-contracting and found its effects on smallholders' economic performance and welfare to be elusive. Conversely, Bellemare (2012) and Ton et al. (2017) found substantial positive income effects on household welfare, even though the poorest smallholders were rarely included. While these studies focused on MVCs, the reasons for indefinable and inconsistent effects of vertical relationships on smallholders' performance have remained unexplained so far.

Another stream of literature focuses on horizontal relationships that define collective interaction among competing smallholders. For example, Fischer and Qaim (2012) found positive income effects for active cooperative group members in Kenya. Collective groups are important in facilitating innovation adoption since they enhance efficient information flow. Similar results were also found by Verhofstadt and Maertens, (2014) and Ochieng et al., (2018) in Rwanda and Central Africa respectively. Although both vertical and horizontal relationships could be complementary in enhancing smallholder performance (Barrett et al., 2012; Ton et al., 2017), smallholders rely additionally on interactions with external stakeholders such as research institutes, extension agents and NGOs to organize themselves (Gramzow et al., 2018).

Until now, the conceptual associations between these organizational relationships are unclear while the debate on the organizational relationships that will improve smallholders' performance 
has remained open. Only strategic management studies such as Mesquita and Lazzarini, (2008) and Otter et al., (2014) have considered the simultaneous and holistic influence of organizational SC network structures on smallholders' performance. These gaps, therefore, spur the need to implement a more comprehensive and integrative model to analyze the organizational SC network structures of smallholders in neglected LVCs.

Besides having a holistic view of their organizational SC network structures, development and strategic management studies have struggled to concurrently establish the link between contingencies, SC organizational networks, and smallholders' performance. Studies relying on organizational theories have solely focused on forging a fit between external business contingencies and organizational strategies to maximize business performances (Gnizy et al., 2017; Otter et al., 2014). Conversely, non-holistic development studies made emphasis on the role of individual and business characteristics as sources of competitiveness and determinants of organizational strategies (Barrett et al., 2012; Forsman, 2004; Wang et al., 2015). In reality, smallholders face both external and internal contingencies.

Depicting this reality requires a complex framework, which is still subject to rigorous conceptual development and empirical application. Although several studies have attempted to bridge this research gap, the links between these key concepts have remained vague and underexplored in developing countries. For instance, Otter et al., (2014) relied on contingency theory and netchain approach to analyze the influence of the interplay of organizational relationships, determined by external contingencies on farmers' performance in Chile. They found evidence that external contingencies influence the interplay of organizational relationships though the role internal contingencies were neglected. Kayser et al., (2015) instead relied on industrial organization and resource-based theories to analyze the impact of external and internal factors on strategic management practices of agribusiness firms in Tanzania. They found that internal rather than external factors consistently influence organizational strategic actions. This study is flawed by the limitation of its definition of external factors and consideration of strategic management, which do not capture all organizational SC network relationships. Overall, the general lack of consistent directional links between contingencies and organizational strategies, and non-holistic consideration of both contingencies in existing literature suggests the need for further conceptual development and analysis (Gnizy et al., 2017; Wang et al., 2015). 


\subsubsection{Collective action and smallholders' productivity and technical efficiency}

In recent times, government and development scholars have focused on supporting the formation of producer/cooperative groups to help smallholders cope with and overcome complex market constraints such as high transaction costs in accessing input and output markets, lack of physical and financial infrastructure, high power asymmetry and limited technological advancement. Though most attention has been on farm-based subsectors, there is growing evidence that producer groups have positive effects on smallholder's overall economic performances and welfare (Ainembabazi et al., 2017; Chagwiza et al., 2016; Fischer \& Qaim, 2012; Ma et al., 2018; Mojo et al., 2017; Ochieng et al., 2018; Orsi et al., 2017; Verhofstadt \& Maertens, 2014). Insignificant and negative effects have also been documented (Bernard \& Taffesse, 2012; Bernard et al., 2008; Chagwiza et al., 2016; Fischer \& Qaim, 2012; Hellin et al., 2009; Mujawamariya et al., 2013). Similar patterns also exist for group membership effect on smallholders' productivity and technical efficiency, although empirical evidence has remained generally scarce and vague (Abate et al., 2014; Gedara et al., 2012; Hailu et al., 2015).

There are several explanations for these mixed findings in the literature. The first is the heterogeneity among producer groups. The fact that each producer group differs in their operational objectives (production versus marketing), leader and member characteristics, and location, etc. stresses the need to also study producer groups in nonfarm-based subsectors. For instance, the question regarding what factors influence smallholders' decision to participate in nonfarm-based producer groups has remained under-explored and unanswered.

Furthermore, the presence of selection bias is another prominent reason for biased and inconsistent findings. Indeed, selection into producer groups is often non-random as smallholders decide to participate in producer groups based on some observed and unobserved factors. Different methods and models have been applied to account for selectivity in the literature. The most common has been propensity score matching (PSM) which largely accounts for selectivity from observed attributes. However, PSM is flawed by its inability to account for selectivity from unobserved attributes (Abdulai \& Huffman, 2014; Fischer \& Qaim, 2012). Instead, several studies employed endogenous switching regression models which are known to produce inconsistent estimates as a result of misspecifications of the error term (Alene \& Manyong, 2007; Ma \& Abdulai, 2016). Over the last two decades, concerns on selectivity have been stressed in 
productivity and empirical economics literature (Greene, 2010). Yet, studies on productivity and efficiency often neglect selection bias (Abate et al., 2014; Gedara et al., 2012; Hailu et al., 2015).

In response, a new stochastic frontier model that corrects for sample selection from unobserved factors was suggested by Greene (2010). Over time, this approach has been further developed and implemented in several studies (Bravo-Ureta et al., 2012; De los Santos-Montero \& Bravo-Ureta, 2017). Only Abdul-Rahaman and Abdulai (2018) and Ma et al. (2018) have applied this approach in the context of membership in cooperative groups' effect on productivity and efficiency in farm-based subsectors. Thus, applying this approach to study smallholders in nonfarm-based LVCs is important to understand the immediate and unbiased effects of producer groups in the subsector and contribute to alternative practical implications on how to attain income and welfare equality in developing countries.

\subsection{Research objectives and approach}

The main research objective of this dissertation is to analyze the influence of organizational structures on the performance of smallholders in developing countries' LVCs. By addressing the aforementioned research gaps, this dissertation contributes to the propagation of alternative development models for smallholders excluded from MVCs and the attainment of gender equality in developing countries. This dissertation comprises three main chapters, each presenting one paper and addressing the aforementioned research gaps.

The first paper focuses on uncovering how LVCs in dualistic systems are organized, the predominant governance themes and gender roles for value addition, and necessary upgrading strategies for smallholders in developing countries. To do this, we build on the studies by Lie et al. (2012) and rely on the global value chain (GVC) approach to distinctively map and analyze how LVCs are organized and function parallel to MVCs in the presence of changing agrifood systems. We also identify the drivers of LVCs by concurrently analyzing the roles of governance and inherent gender relations in LVCs. With this, the paper makes a conceptual contribution by extending the GVC framework to include a gendered dimension of the value-web approach which we developed based on Virchow et al. (2014)'s study. Based on these analyses, we discuss and postulate concrete and novel managerial and policy implications needed to develop LVCs, improve the competitiveness of restricted smallholders and posit gender opportunities. This is a qualitative study that relies on empirical data collected from three focus group discussions, three net-maps and 21 interviews with 48 respondents in the Nigerian shrimp and prawn sector. 
The second paper builds on the results and implications of the first paper. The paper seeks to provide a comprehensive quantitative research framework for analyzing how SC external and internal contingencies jointly influence organizational SC network structures and performance across two mutually dependent tiers. We build on studies by Otter et al. (2014) and take a cue from contingent resource-based theory (Brush \& Artz, 1999; Lawrence \& Lorsch, 1967; Lazzarini et al., 2001) and netchain approach. With this, we make a conceptual contribution to the literature on the influence of external (market turbulence, technological progress, distrust and power asymmetry) and internal (human and financial resources) contingencies on organizational SC network relationships and performance. We then empirically test the resulting conceptual framework on multiple proxies of performance of 405 producers and 238 processors. This approach allows us to derive valid and comprehensive evidence comparable across tiers and contribute theoretically to the interpretation of the links among these concepts.

In the third paper, we estimated a stochastic production frontier models that correct for selectivity to analyze the role of producer groups in improving capture and technical efficiency of artisanal fishers - a nonfarm-based subsector in Africa. We make two empirical contributions by relying on studies such as Greene (2010) and Bravo-Ureta Greene and Solís, (2012) to estimate the effect of group membership on shrimper's capture and technical efficiency and identify factors that influence shrimpers' decision to belong to fisher groups. For the former, we make a methodological augmentation by using PSM and stochastic frontier methods to correct for sample selection bias from both observed and unobserved factors and account for different technological set. For this paper, we focus only on producers who operate outboard engines. Thus, we use quantitative data of 353 producers, comprising of 95 members and 258 nonmembers.

The rest of this dissertation is structured as follows: In Chapter 2, we present the first paper that focused on the organizational structure of LVCs in developing countries. Chapter 3 presents the second paper that analyzed the contingent resource-based and netchain perspectives of supply chain organization and performance, considering two mutually reliant tiers. Chapter 4 comprises the third paper and analyzes the effect of producer group membership on productivity and technical efficiency, accounting for possible selection bias from observed and unobserved factors. In Chapter 5, we summarize and discuss the key findings, policy implications and some limitations of the three papers above. 


\title{
2 Organizational Structures, gender roles and upgrading strategies for smallholders in developing countries' local value chains ${ }^{*}$
}

\begin{abstract}
To achieve the Sustainable Development Goals, research concepts and empirical evidence are needed to upgrade developing countries' smallholder activities within local value chains (LVCs). The study aims to uncover LVCs' (1) organization, (2) governance themes and gender roles for value addition and (3) smallholder upgrading strategies in developing countries' dualistic sectors. The global value chain (GVC) framework is extended towards a gendered value web approach that captures the importance of hidden gender roles and power relations. Empirical data obtained from three focus group discussions and 21 interviews in the Nigerian shrimp and prawn sector represent the basis for qualitative analysis. The results clearly indicate that, despite being buyerdriven by competitive traders, mutually reliant coordination between production and processing segments and strategic business activities of female processors are crucial for the LVCs' functioning. Based on these results, manifold managerial and policy implications are derived to upgrade and develop smallholder activities and products along the Nigerian shrimp and prawn LVC, which can also apply to other developing countries and cases.
\end{abstract}

Keywords: Governance themes, Gender, Global value chain framework, Value web approach, Smallholder upgrading strategies, Nigerian shrimp and prawn.

\footnotetext{
* A shorter version of this chapter is under revision in Business Strategy and Development. This chapter is coauthored with Verena Otter (VO). The authors' contributions are as follows: Ayobami Adetoyinbo (AA) conceptualized, designed the research and collected the data. AA analysed and interpreted the data. VO assisted in the interpretation of the results. AA wrote the paper and VO contributed with feedback and comments at various stages of the research and drafts.

Acknowledgments: The authors are grateful to the German Research Foundation (DFG) for providing financial support to this research through the GlobalFood Research Training Group (GRK 1666). We also appreciate all members of the GlobalFood Research Training Groups, in particular Dr. Lisa Jaeckering and Collins Asante-Addo, for their helpful comments on earlier version of this article.
} 


\subsection{Introduction}

The last decade has witnessed huge transformations in the food value chains of developing countries, such as rapidly increasing globalization, modernization and technologization. These transformations are often associated with distributional effects counteracting the achievement of the Sustainable Development Goals (Dürr, 2015; WTO, 2019). Smallholders respond to changing situations by switching their marketing channels or inter-organizational relationships (Lie et al., 2012; Schipmann \& Qaim, 2010; Teklehaimanot et al., 2017). This intensifies the formation of dualistic systems in which modern value chains (MVCs) and local value chains (LVCs) ${ }^{1}$ coexist.

Typically, MVCs are characterized by tighter governance structures. Contrarily, rampant spot market sourcing driven by specialized and competitive procurement agents in a "hub and spoke model" (Herring, 2015) and, in some cases, differentiated gender relations and roles (FAO, 2016a) characterize LVCs. Since the mid-1990s, the focus of development analysts and researchers in many developing countries has been on the expansion of food exports, the inclusion of smallholders in contract and standard-ridden MVCs and increasing their welfare through such participation (Maertens, 2012; Neven et al., 2009; Reardon et al., 2006; Schipmann \& Qaim, 2010). Even though LVCs represent a significant source of income for the rural population and ensure effective food delivery that meets the culturally diverse needs of urban and rural consumers in a developing country, only recently, has agribusinesses' and development analysts' attention been placed on LVCs (Dürr, 2015; Lie et al., 2012). This attention aims to promote alternative development models and smallholder opportunities in developing countries (Ketema et al., 2016; Lie et al., 2012; Maertens \& Swinnen, 2012).

Despite this trend, the existing scientific literature still shows threefold gaps that can potentially limit our understanding of LVCs' functioning in developing countries and the corresponding implications for further development. First, most studies on LVCs' organizational structures have focussed on non-dualistic sectors, while studies that did, have not distinguished LVCs from MVCs (Chagomoka et al., 2013; Lie et al., 2012). This has created a gap in the knowledge regarding how typical LVCs are organized and function in parallel to MVCs. Second, the existing literature has shown mixed findings regarding the fundamental drivers of LVCs. Most studies that have relied on LVC governance analysis to identify the key drivers have failed to capture the

\footnotetext{
${ }^{1}$ Series of value-adding activities that are mostly carried out by several informally coordinated actors, the products of which are meant for consumers within the same geographical location or region.
} 
evolution and multiplicity of governance structures (Ketema et al., 2016; Lie et al., 2012). This has resulted in the identification and analysis of incomplete LVC governance typologies and consequently limited the implications for LVC development. Clearly, many LVCs are driven by multiple and interacting governance structures (Gereffi \& Fernandez-Stark, 2016). Third, studies that have sought to determine LVCs' drivers have neglected hidden factors, like gender relations and roles and decision-making power, which are socially constructed (Lie et al., 2012). Indeed, there is a scarcity of conceptual approaches that integrate gender analyses into the concept of value chains (Schumacher, 2014).

The objective of this study is to uncover LVCs' (1) organization, (2) governance themes and gender roles for value addition and (3) smallholder upgrading strategies in developing countries' dualistic sectors. Using qualitative data obtained from the Nigerian shrimp and prawn subsector, this study seeks to achieve the sub-objectives in three ways. First, building on the research by Lie et al. (2012) and Maertens and Swinnen (2012), we rely on the global value chain (GVC) approach (Kaplinsky, 2000; Kaplinsky \& Morris, 2001) to map distinctively and investigate how LVCs are organized and function in parallel to MVCs in the face of globalization. Second, we extend the GVC framework by developing and adding the gendered dimension of the value web approach (Virchow et al., 2014) to analyse simultaneously the roles of governance and differentiated gendered relations in LVCs. Third, we draw out concrete and novel managerial and policy implications needed to further develop LVCs, improve the future competitiveness of smallholders and posit gendered opportunities. These managerial implications are of great importance for interested parties, such as smallholders and artisanal group leaders, while the policy implications are important for private firms and public stakeholders.

African countries are among those developing countries with a growing real GDP (approximately 3.8 per cent in 2018) that is largely driven by the increasing domestic demand (+6.7 per cent), but they still face development challenges regarding favorable business environments (AfDB, 2019). Apart from often obstructive foreign trade policies, the diversity and complexity of the African private sectors and the inefficient smallholder integration into regional production networks especially represent major pitfalls (AUC/OECD, 2019). The LVC in the Nigerian shrimp and prawn sector is of particular interest for this research because it shares peculiar sectoral and structural characteristics with many agrifood sectors in other developing and transition countries. The LVC exists in a dualistic system with MVCs and is characterized by numerous artisans - 
about 1.2 million (Bondad-Reantaso et al., 2012) - most of whom are poor, limited in scope and operations, informally organized and dwell in the rural coastal areas (Agbo \& Usoroh, 2015; Wategire \& Ike, 2015). Despite its importance as a source of livelihood for artisans and for fulfilling culturally diverse needs for consumers in the domestic markets, researchers and development analysts have paid very little attention to it. As a result, many smallholders in the LVC in the Nigerian shrimp and prawn sector, similar to many LVCs in other developing countries, continuously face the challenge of effectively coordinating their activities and remaining competitive in dualistic systems. Contrarily, the MVC in this dualistic system, which is dominated by industrial fishing companies, has attracted more attention because it provides opportunities to earn foreign exchange.

Uncharacteristically, both the MVC and the LVC command higher shrimp and prawn (SP) values per unit of catch, especially because the domestic demand for SP still outstrips the supply (Bondad-Reantaso et al., 2012). This suggests an opportunity to foster economic gains for the smallholders involved through upgrading and further expansion of the LVC. We expect that our results will help to clarify how LVCs that coexist with MVCs function and what strategies are needed for smallholder upgrading. Insights from this case can, therefore, be useful for other developing and transition countries, where LVCs are also underdeveloped and the smallholders involved are neglected.

The study is organized as follows. The next section describes the conceptual framework employed in the study. Second, the research methodology is elaborated, including the criteria for the selection of the study area and participants, data collection procedures, handling and analysis. Thirdly, the results and a discussion of the findings are presented, followed by the conclusions and implications.

\subsection{Conceptual framework}

This study is based on two concepts: the GVC approach by Kaplinsky (2000) and Kaplinsky and Morris (2001) and the value web by Virchow et al. (2014) (Figure 2.1). The GVC approach is useful for tracing patterns of production and linking geographically dispersed activities and actors in a chain (Kaplinsky, 2000; Kaplinsky \& Morris, 2001). Although the focus of the GVC approach crosses international boundaries, new evidence suggests the regionalization of GVCs (Gereffi \& Fernandez-Stark, 2016). Four dimensions (mapping; governance; benefit distribution; and upgrading in value chains), which have been further developed by Gereffi and 
Fernandez-Stark (2016) and Gereffi et al. (2005), have commonly been employed in the literature to analyse effectively and understand fully the broader issues of value chains. With the first GVC dimension, the systematic mapping of value chains, the entire input-output process that brings a product from conception to consumers is presented. The main actors and their activities or segments, specific characteristics and dynamics of segments, like preferred suppliers, are depicted with maps.

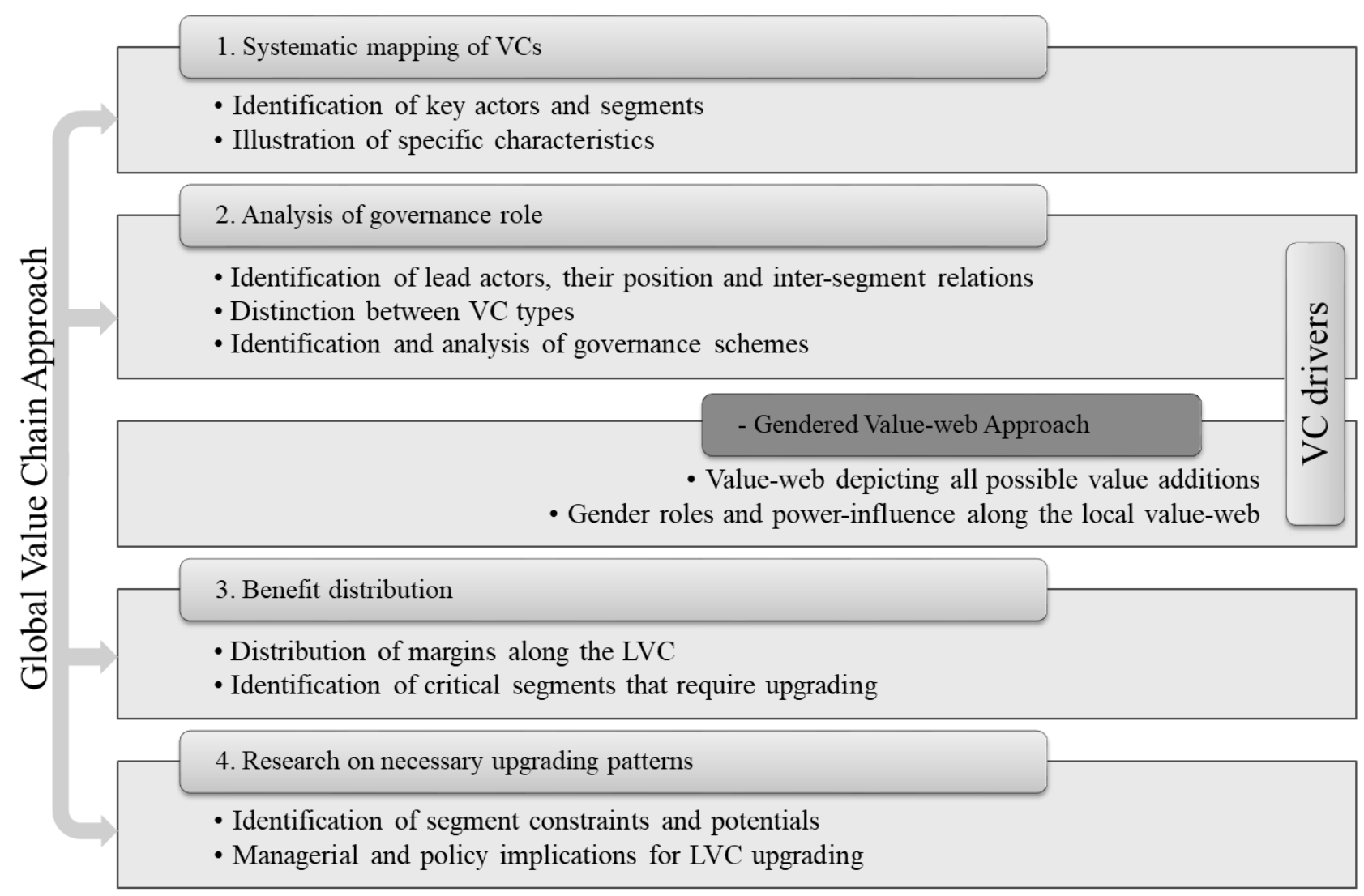

Figure 2.1: Conceptual framework

Source: Authors' illustration

The second dimension emphasizes the role of governance. Governance in the GVC approach ensures that interactions between actors reflect control and coordination (Kaplinsky, 2000). In LVC governance analysis, lead actors are first identified, reflecting on their position, interrelationships and influence sources (Gereffi \& Fernandez-Stark, 2016). Then, the distinction of value chains is made based on the type of lead actors identified. Producer-driven chains are mostly found in capital- and technology-intensive industries and controlled by large producers, while buyer-driven chains are mostly found in labour-intensive consumer goods industries and controlled by buyers (Kaplinsky, 2000; Kaplinsky \& Morris, 2001). Lastly, the inherent governance structures in each segment are identified from the five governance structures defined 
by Gereffi et al. (2005) based on the complexity and coding of information shared and the competence of the suppliers involved.

Table 2.1: Gereffi's governance structures

\begin{tabular}{|l|l|}
\hline Governance types & Description \\
\hline Market & $\begin{array}{l}\text { Typical of a spot market, the price mechanism is central, with little to no formal } \\
\text { cooperation between actors. Low power relationship asymmetry exists, since the cost of } \\
\text { switching to new partners is low. }\end{array}$ \\
\hline Modular & $\begin{array}{l}\text { Relationships between suppliers and buyers are tighter, with a high volume of information } \\
\text { flow beyond price and semi-low power asymmetry. Suppliers take full responsibility for } \\
\text { securing the generic processes/technologies needed to meet customers' specifications. }\end{array}$ \\
\hline Relational & $\begin{array}{l}\text { Interactions between suppliers and buyers are complex, with mutual dependence and high } \\
\text { asset specificity managed through reputation, family and ethnic ties. Nevertheless, the lead } \\
\text { actor can exert some levels of control in medium power asymmetry. Trust is built after } \\
\text { repeated interaction, so the cost of switching partners tends to be high. }\end{array}$ \\
\hline Captive & $\begin{array}{l}\text { Characterized by high power asymmetry in which small suppliers are dependent on one or } \\
\text { a few buyers. Producers face high switching costs by functioning under certain conditions } \\
\text { set by a buyer, while the lead actor, whose competence tends to be outside production, } \\
\text { exerts a high degree of monitoring and control. }\end{array}$ \\
\hline Hierarchy & $\begin{array}{l}\text { Products are complex and product characteristics are hard to transmit, so chains are } \\
\text { characterized by vertical integration and managerial control. }\end{array}$ \\
\hline
\end{tabular}

Source: Adapted from Gereffi and Fernandez-Stark (2016) and Gereffi et al. (2005).

The third dimension is the assessment of how benefits are distributed to pinpoint critical segments that require upgrading. Different measures have been used to describe the distribution of benefits along value chains. For instance, Lie et al. (2012) used three measures: profit, employment benefits and non-monetary benefits like knowledge. Adopting these measures in this study will be problematic because of actors' heterogeneity and data unavailability. However, price has become an important measure of value since the 1990s, because product processing and differentiation significantly add to the margins (Dolan \& Humphrey, 2000; Manning, 2015). Therefore, this study employs price as a measure of benefit distribution. Furthermore, the fourth dimension entails research on the necessary upgrading patterns. Four types of upgrading were identified by Kaplinsky and Morris (2001), namely process, which deals with how production efficiency can be increased; product, which entails enhancing products' quality by either producing new ones or improving old ones; function, which entails changing the scope and combination of the activities performed; and chain/inter-sectoral, which involves moving into new production activities.

The GVC approach has been applied to analyse different value chains across the world. Bassett et al. (2018) used the concept to determine the influence of power relations on the upgrading of the cashew value chain in Cote d'Ivoire, from the production segment to exporting. The authors argued that power relationships are more important than quality in ensuring the proper 
functioning of the chain and in setting producer prices. However, their study created a gap regarding the inner workings through which different actors influence the price-setting mechanism. Nguyen et al. (2017) bridged this gap by analysing the value chain of exported white-leg shrimp in Vietnam and drawing conclusions on its organizational structure and drivers. They argued that middlemen drive the chain and transfer risk to the producers in the price-setting mechanism. De Marchi et al. (2013) leveraged the concept to develop an integrated theoretical framework that allows for the analysis of environmental upgrading strategies in the Italian homefurnishing industry. Conversely, the GVC approach has been applied to analyse LVCs. Lie et al. (2012) applied a theoretical framework that is based on the GVC to identify possibilities for upgrading in a Tanzanian goat milk yogurt LVC. The study warned against several constraints that could impede the upgrading over time. Clearly, the latter studies fused the GVC approach with other frameworks to contextualize the organization and upgrading strategies for the actors along the chains.

We draw on these studies by extending the GVC framework to include the gender dimensions necessary to determine the role of gender relations in ensuring the proper functioning of LVCs. Schumacher (2014) reviewed the studies that have conceptualized gender relations in GVCs and offered insights into areas that are completely missing from the literature. According to the author, the analysis of differentiated gender roles in transnational networks highlighting gender decision-making power and influence is an important topical area that requires immediate attention. The FAO (2016) further developed a framework that captures gender issues in value chains and emphasized the importance of robust gender analysis in making effective recommendations about value chain upgrading strategies. The framework involves the inclusion of gender-sensitive information in the mapping of value chains. Apart from this, several studies have developed and delved into gender relations in value chains; however, contradictory findings on the roles and influence of women along value chains have been found (Barrientos et al., 2003; Schumacher, 2014). This gap appeared because studies employed approaches that are product specific and cannot deal with disaggregated gender information.

The value web approach offers a great advantage by depicting all the value additions possible within the sector (Scheiterle et al., 2018; Virchow et al., 2014). The multidimensional framework of the value web approach provides the study with an avenue to describe certain social factors that could drive or ensure synergy in the inter-linkage of different local values in the sector. 
Although the value web is an innovative approach that has commonly been employed in business and biomass-based literature (Scheiterle et al., 2018), the relevance of its "web perspective" makes it crucial as a concept to depict disaggregated gender-sensitive information innovatively in this study. We extend the GVC approach by adding the gendered value web to the second dimension of the GVC approach (governance analysis) to assess simultaneously the roles of governance and gender relations in driving and ensuring the functioning of LVCs (the second sub-objective of the study).

\subsection{Research methodology}

\subsubsection{Study design}

The study relies on qualitative primary data collected between December 2017 and January 2018 in Nigeria. The data collection involved three in-depth focus group discussions (FGDs) and twenty-one key informant interviews (KIIs). Questions that take into account the four dimensions of the GVC (systematic mapping, governance analysis, benefit distribution and upgrading strategies) and gender issues explained in Chapter 2 were asked during the FGDs and KIIs. To encourage a diverse and quite representative pool of respondents to participate, the study was conducted in several shrimping villages and markets across three States (Lagos, Akwa-Ibom and Delta) that were purposefully selected to gain insights across different socio-cultural zones.

The first pool of respondents was identified by experts from the Nigerian Institute for Oceanography and Marine Research (NIOMR). In all, eight categories of actors were selected through snowball sampling, as shown in Table 2.2. The data from artisanal producers and processors were obtained from two States - Badagry, Lagos, and Eket, Akwa-Ibom - because of their high level of shrimping activities. The data from traders, retailers and transporters were obtained from two large markets, namely Ibaka and Oron, Akwa-Ibom, and Warri, Delta, based on their high level of retailing and wholesaling activities. Additionally, a series of interviews with two fishing companies and experts (for triangulation) was conducted in Lagos.

Table 2.2: Details of the participants in the FGDs and KIIs

\begin{tabular}{|c|c|c|c|c|}
\hline $\begin{array}{c}\text { Data } \\
\text { identification }\end{array}$ & Participants & Type/frequency & $\begin{array}{l}\text { Type and number of participants } \\
\text { and years of experience }\end{array}$ & $\begin{array}{c}\text { Number and gender } \\
\text { of participants }\end{array}$ \\
\hline $\begin{array}{l}\text { A } \\
\text { B }\end{array}$ & Fishermen & $\begin{array}{c}2 \mathrm{FGD} \\
5 \mathrm{KII}\end{array}$ & $\begin{array}{l}24 \text { fisherfolk: } \\
5 \text { had > } 20 \text { years } \\
13 \text { had } 10-20 \text { years } \\
5 \text { had } 5-10 \text { years } \\
1 \text { had no experience (helper) }\end{array}$ & $25 \mathrm{M}$ \\
\hline $\begin{array}{l}\text { C } \\
\text { D }\end{array}$ & Processors & $\begin{array}{c}\text { 1FGD } \\
3 \mathrm{KII}\end{array}$ & $\begin{array}{l}8 \text { processors: } \\
1 \text { had }>10 \text { years }\end{array}$ & $8 \mathrm{~F}$ \\
\hline
\end{tabular}




\begin{tabular}{|c|c|c|c|c|}
\hline & & & 7 had 5-10 years & \\
\hline $\mathrm{E}$ & Collectors & $2 \mathrm{KII}$ & $\begin{array}{l}2 \text { local collectors } \\
2 \text { had }>5 \text { years }\end{array}$ & $2 \mathrm{~F}$ \\
\hline F & Logistics & $1 \mathrm{KII}$ & 3 transporters & $3 \mathrm{M}$ \\
\hline $\begin{array}{l}\mathrm{G} \\
\mathrm{H}\end{array}$ & Retailers & $\begin{array}{l}2 \mathrm{KII} \\
1 \mathrm{KII}\end{array}$ & $\begin{array}{l}2 \text { processed retailers } \\
1 \text { fresh retailer }\end{array}$ & $3 \mathrm{~F}$ \\
\hline $\begin{array}{l}\mathrm{I} \\
\mathrm{J}\end{array}$ & $\begin{array}{l}\text { Fishing } \\
\text { companies }\end{array}$ & $\begin{array}{l}1 \mathrm{KII} \\
1 \mathrm{KII}\end{array}$ & $\begin{array}{l}1 \text { company manager } \\
1 \text { marketing manager }\end{array}$ & $2 \mathrm{M}$ \\
\hline $\begin{array}{l}\mathrm{K} \\
\mathrm{L}\end{array}$ & Experts & $\begin{array}{l}1 \mathrm{KII} \\
1 \mathrm{KII}\end{array}$ & $\begin{array}{l}1 \text { researcher } \\
1 \text { field officer }\end{array}$ & $\begin{array}{l}1 \mathrm{M} \\
1 \mathrm{~F}\end{array}$ \\
\hline $\begin{array}{l}\mathrm{M} \\
\mathrm{N}\end{array}$ & Associations & $\begin{array}{l}1 \mathrm{KII} \\
2 \mathrm{KII}\end{array}$ & $\begin{array}{l}1 \text { group leader } \\
2 \text { settlement leaders }\end{array}$ & $3 \mathrm{M}$ \\
\hline
\end{tabular}

Source: Authors' illustration.

Notes: M: male and F: female.

\subsubsection{Data collection}

\section{Type of information obtained}

The FGDs and KIIs were guided by semi-structured questionnaires using open-ended questions to describe six themes that are relevant to analysing the four GVC dimensions and the gendered relations. These include information on the inputs; fish resources caught; main actors (indicating the relationship and governance mechanisms existing between actors); possible value addition to the SP (indicating associated price and quantity flow and market destinations); chain characteristics (indicating the historical evolution of the chain, contingent situations, difficulties and opportunities, etc.); and gender roles and power relations. Most FGDs and KIIs were conducted in local languages, except the KIIs with experts and fishing companies, which were conducted in English. The questions varied according to the category of the participants. For all the FGDs and KIIs, audio recorders and jotters were used to capture important details.

\section{The relevance of net-map to the study}

One important tool used during FGDs is the net map, which is often employed in participatory research methods (Scheiterle et al., 2018). The net map is advantageous because it helps us to visualize implicit knowledge and understand the interplay of complex value networks, power relations and actor roles. It allows us to involve respondents actively in the process of visualizing differentiated LVCs, gender relations and influences, which are rather difficult to depict through conventional methods. The implementation of net maps was adapted following the steps described by Schiffer and Hauck (2010). First, prior to the start of the FGDs, the research objectives and significance of the study were explained to the participants. Then, the net-mapping steps were described to the participants to ensure that everyone understood the procedure, while permission to record the sessions was obtained. The first GVC dimension - the mapping of the 
LVC - started with the identification and naming of key actors and activities by the participants. The same logic was applied thereafter in the mapping of the value web to determine all possible value-adding activities. Here, the names of actors and their activities ${ }^{2}$ were written on stickers and glued to A1-sized cardboard. Afterwards, all the stickers were linked by the participants using markers to depict a chain.

Next, the net map was modified either to rearrange it or to accommodate new actors/activities that had not been mentioned earlier, the quantity of catches and the price flow. Throughout each stage, the respondents were encouraged to argue their points until they agreed on a single conclusion, thereby increasing the reliability of the information obtained. The penultimate step involved the ranking of actors' power relations by the participants for the second GVC dimension. Questions regarding the importance and influence of each actor were asked to determine the power relations in the LVC. The participants were provided with flat button-like materials that could be piled up to form a tower. The number of materials in each tower was counted and noted for each actor named on the map. ${ }^{3}$ For the gendered value web, activities in which both men and women were influential were also ranked. Finally, we ended each session by discussing the LVC and the web structure.

\subsubsection{Data handling and analysis}

Content analysis of the qualitative data obtained was conducted following Mayring (2015). The first step of data analysis involved the transcription of audio recordings into a separate Word document template. The transcribed data were coded into nodes based on the broadly predefined thematic information listed in the "Study design" section. Important terms like codes, texts, metaphors, storylines and discourse coalition that reoccur in the data and are related to the themes were formed into nodes using Nvivo 12 plus. For the first sub-objective, relevant information presented in the net maps and data obtained from interviews were combined to portray the detailed LVC and MVC graphically. The key input-output components of these value chains were profiled to include the main activities/segments and key characteristics of the actors involved. Hence, the segments of the LVC and MVC were identified and differentiated by the value that they add to the product.

\footnotetext{
${ }^{2}$ Different activities depicted different LVC segments.

${ }^{3}$ The actors deemed to have the most influence had a maximum of eight layers, while those with the least power relations had none.
} 
For the second sub-objective concerning the identification of LVC drivers, information on different governance structures between each LVC segment and gendered roles in the value web were coded, illustrated graphically and analysed. The governance concepts to be analysed included governance schemes and lead actors, reflecting their roles, position and sources of power relations. An overview of the value-adding benefits accruing to each actor in the LVC is presented graphically to depict the third GVC dimension. For the third sub-objective, the data from FGDs and KIIs were further reviewed and coded based on the key constraints and opportunities for development in each segment of the LVC. This allowed for the derivation of segment-specific implications regarding necessary upgrading strategies as part of the fourth GVC dimension (Trienekens, 2011).

\subsection{Results and discussion}

\subsubsection{Organization of the Nigerian shrimp and prawn value chain}

In this section, we present the first dimension of the GVC approach by systematically mapping the value chain to address the first sub-objective. The Nigerian shrimp and prawn sector is organized along the two types of value chains, namely the MVC and the LVC, as presented in Figure 2.2. The MVC is dominated by industrial fishing companies, many of which are organized under the umbrella of the Nigerian Trawlers' Owners Association (NITOA) (Managers I\&J). Figure 2.2 shows that the MVC is structured to target export and modern domestic markets, because they can earn a premium for meeting export quality and quantity standards. About 85 per cent of the SP captured is exported, mainly to EU countries. Compliance with strict regulations and standards is strictly monitored and controlled by the Nigerian Federal Department of Fisheries. SP that cannot meet these standards is absorbed by the domestic markets (15 per cent of the total industrial capture). Most fishing companies sell through registered agents and not directly to final consumers (Company manager I). Overall, the producer-international marketsconsumer link represents the predominant market channel in the MVC.

The LVC is structured to target traditional domestic markets, firms and regional markets. ${ }^{4}$ The majority of the demand for SP comes from the traditional domestic market, comprising the urban and peri-urban market and the rural market. In this type of value chain, all the SP captured by

\footnotetext{
${ }^{4}$ Very negligible exports are also made to OECD countries but are not profiled.
} 
fishermen is sold off at the shore to fish mammies, ${ }^{5}$ who, in many cases, process and market the SP. Fish mammies, if not selling through their union after processing, prefer to sell to traders. ${ }^{6}$ Village collectors/brokers and large traders/wholesalers differ in their characteristics and activities (Collector E).

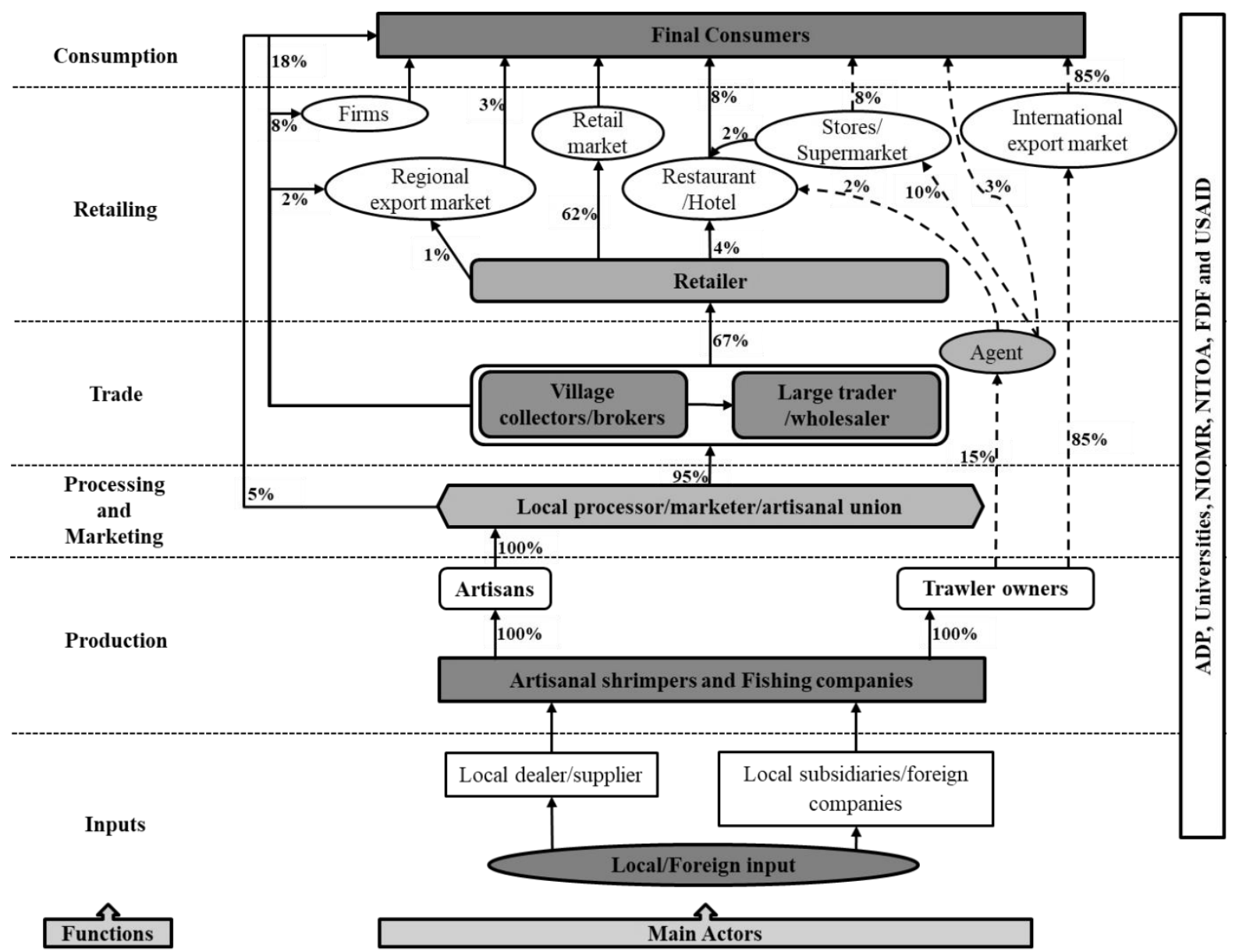

Figure 2.2: Shrimp and prawn value chain

Source: Authors' illustration based on FGD and KII

Notes: The flowchart indicates both LVC and MVC highlighting the sources of SP and their different marketing channels. The percentages depict the quantity flow of SP across tiers and were obtained based on participants' perceptions during FGDs and KIIs. Tick arrows are used to link actors and segments in LVCs while broken arrows depict MVC. Institutions that intervene to support and regulate the sector are listed in the box located on the right side of the figure. Lastly, several segments are listed on the left side of the chain, each separated by thin dotted lines.

Village collectors/brokers are often closer to landing sites, transact frequently with fish mammies, service markets around the landing sites and are sometimes missing along the LVC if the landing sites can easily be reached by large traders/wholesalers. Village collectors/brokers sell to large traders but not vice versa (Collector E). The study depicts these differences by profiling these actors separately but in the same segment, as shown in Figure 2.2. Of the total SP processed, 95 per cent is sold to traders who demand in bulk and with whom they have long-term

\footnotetext{
${ }^{5}$ The term "fish mammies" is used interchangeably with processors/marketers.

${ }^{6}$ Traders represent both village collectors/brokers and large traders/wholesalers.
} 
relationships. The remaining 5 per cent is bought by final consumers around the processing sites (Processor C). Traders sell about 67 per cent of the SP captured to retailers, while about 18 per cent is sold directly to the final consumers in the traditional domestic markets. Contrarily, retailers sell very significant quantities (62 per cent) directly to the final consumers through the local retail markets, while the remainder ends up in local restaurants and hotels (4 per cent) and regional markets, such as Cameroon (1 per cent).

The interviews with retailers indicated that industrial firms using SP as raw materials and regional export markets have sprung up and are being targeted along the LVC (Retailer G). This finding highlights further developments in the LVC from the situation in the past, in which the demand from firms and regional markets was missing (Agbo \& Usoroh, 2015). However, industrial firms demand SP in smaller quantities ( 8 per cent) through procurement agents who are well connected to the processors and village collectors (Processor C). Similarly, the quantity supplied by traders to the regional markets is quite negligible ( 2 per cent). Accordingly, the producer-processor-trader-retailer-consumer link represents the most important and predominantly used market channel in the LVC.

\subsubsection{Connecting landing sites to the markets: drivers of LVC and MVC}

In this section and section 4.3, the answers relating to the second sub-objective are presented. The study seeks to identify the key drivers that shape the LVC and ensure the smooth flow of SP by analysing the second GVC dimension and the gendered value web approach. To describe how the dualistic system works, we first present the drivers of MVC and later focus on LVC.

\section{Second dimension: governance themes and its role along the MVC}

Local fishing companies also adopt explicit higher degree of vertical coordination to reduce uncertainties and transaction costs. They can push and formally meet the demands and requirements of international export markets by fully integrating all vertical activities from the supply-base to distribution in the export-oriented chain (Manager I). This is an interesting finding as forward vertical integration across several segments is not common and premised in many other African export VCs (Maertens et al., 2012). The difference in levels of coordination arose for two main reasons. First, the export chain is a typical producer-driven chain that is only effectively controlled through vertical integration (Barrientos et al., 2003). Interviews with fishing companies indicate that export chain is characterized by capital and technology-intensive investments at the supply base. Consistent with other findings, fishing companies adopt this type 
of coordination mechanism to deal with high risk associated with asset specificity at the supplybase, and the complex nature of transactions in the chain (Ouma et al., 2017). Secondly, the export chain is characterized by high transaction complexity, which can only be understood and met by a few competent fishing companies that coordinate their activities better and have tighter relationships with buyers. Information about quality, specie, form, preservation method, and safety, as well as social and environmental conditions under which the shrimp is caught, is distinct to market niches and hard to codify.

Firms manage their chains more tightly when they face such complex transaction requirements, both to avert negative publicity for the chain and properly differentiate their products (Barrientos et al., 2003). While attainment of certain level of economies of scale and technological advancement are criteria for entry and locking of buyers in the chain, inability of many fishing companies to deal with this complexity could be one of the reasons why their number shrunk over the last two decades from 36 to 14 companies (Manager J). In addition, few lapses in government's policy and support for the sector, including inadequate offshore security infrastructure, and irregular supply are barriers to potential business development (Managers I-J). Final transaction with buyers in importing countries is done through a less-tighter linkage. Therefore, apart from functioning institutions and government regulations, vertical integration was another germane reason why the sector performs well in the export market.

Unlike the export MVC, the modern domestic market is characterized by modular governance, in which fishing companies take full responsibility of investing in generic machinery that limits transaction-specific costs for domestic customers. Although non-detailed and non-formalized agreements characterized company-agent relationship, fishing companies capture shrimp to meet agent's specifications using defined technical standards. Fishing companies take full responsibility for investing in generic machinery like shrimping vessels equipped with fish-hold and cold-room that limits transaction-specific costs for domestic customers. However, fishing companies curb possible agent's opportunistic behavior by committing them through forwardpayments (Manager J). The governance analysis of the MVC indicates a short, simple chain with complex organizations whereas the modern domestic chain is characterized by many intermediaries and less complex structure. Such arrangement allows for equitable distribution of benefits, as agents and retailers could earn comparable margins along the MVC (Manager J). 
However, just like the export market, fishing companies are dominant as they drive all the activities.

\section{Second dimension: governance themes and their role along the $L V C$}

Reflecting on the second dimension in the conceptual framework, the LVC is an unregulated buyer-driven chain in which traders dominate and drive the chain because they have better access to rich market information and higher purchasing and bargaining power. The power rankings made by the respondents during the FGDs indicate that traders drive the overall chain network. In addition, during the FGDs, fishermen described traders as "a group who has more power and influence" during negotiations and price-setting generally, because they drive the aggressive distribution of SP (Fisherman A). This is common in many African sectors in which intermediary traders are crucial to the proper functioning of value chains (Agbo \& Usoroh, 2015; Gereffi et al., 2005; Maertens et al., 2012).

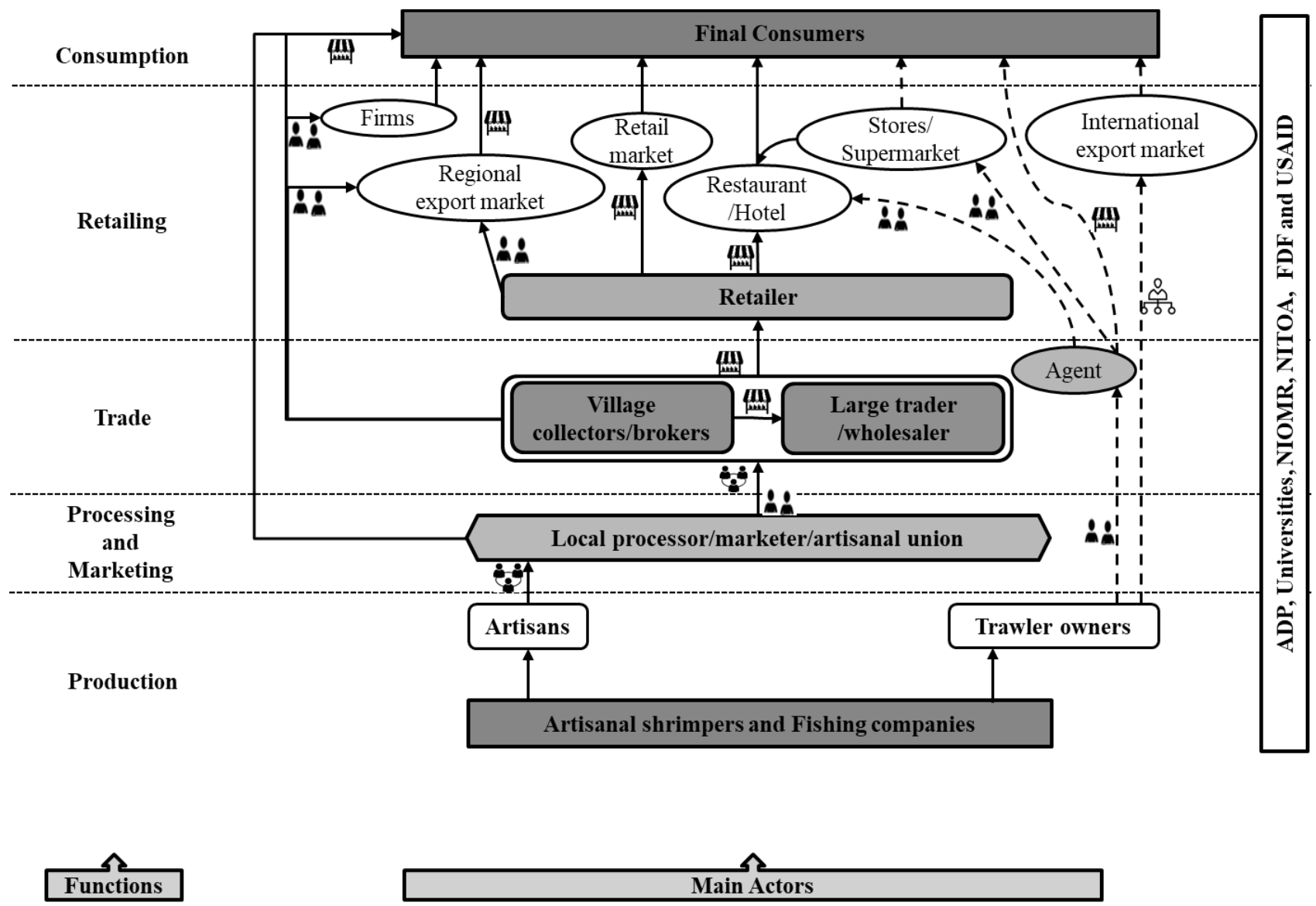

Figure 2.3: Governance typologies along the shrimp and prawn value chain Source: Authors' illustration based on FGD and KII

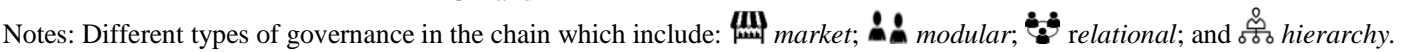


The dominance of the traders erupts from their relationships with multiple actors across tiers, as depicted in Figure 2.2. First, from both ends of the chain, traders can receive essential market information that is crucial for their business decision-making processes, especially for spatial integration and price determination. Traders engage in hub and spoke business models in which they source products from different origins, consolidate them and send them to different markets. Traders supplying firms and regional markets also adopt this model but with the more substantial relationship needed to meet certain specifications. Although Agbo and Usoroh (2015) concluded that a smooth and free flow of information exists, this study opines that traders often hold up essential market information as an advantage to themselves, which results in unsmooth and poor marketing information across tiers, especially for artisanal producers and processors (Processors C\&D). As noted during the FGDs with fishermen and processors, this causes a low level or even a lack of trust in fish mammy-trader relationships (Processor D).

Secondly, traders are faced with relatively less liquidity pressure and risk, so they are able to make more careful business decisions than artisans and shift negotiations in their favour. Conversely, most fish mammies sell at the mercy of traders who buy in bulk, due to their liquidity problems and the resultant pressure to sell quickly. Thirdly, traders have relatively larger working capital resources, since they can access several sources of income, including credit facilities.

As shown in Figure 2.3, the transactions in the LVC are mostly governed on the spot market in which the price is set by both the supplier and the buyer after they have both wielded their negotiating and bargaining power. An exception is the collective selling-price fixing and marketing by processors/marketers through unions in some shrimping communities. Although producer groups also exist, there were no indications of collective marketing (Leaders $M \& N$ ). Producer groups target their activities towards improving production-related activities, like employee sourcing and political lobbying (Leader M). With the governance mechanism "market" dominating the LVC, actors are faced with no entry barriers, thereby resulting in a relatively long and spatially diverse chain with simple interactions. In an attempt to avoid incurring additional transaction costs, fish mammies sell directly to traders at their processing site or nearest market hub. Over time, this could develop into a strategic and mutually dependent relationship.

Further, the interviews with processors indicated the evolution of the LVC towards the divisiveness of the production and processing segments. Around the mid-1990s, though on a very 
small scale, fish mammies dominated both the production and the processing segments of the LVC by shrimping or owning production inputs, processing and marketing (Agbo \& Usoroh, 2015). Over time, as the LVC developed, and as observed by Trienekens (2011), fishermen and fish mammies became specialized in the segments in which they have a comparative advantage (Leaders M\&N). Most fishermen now own their production inputs and shrimp under less exertion of the processor's control. Usually, typical producer-processor/marketer transactions in African LVCs are based on market governance (Simon et al., 2016) and in some cases on formal captive governance (Markelova \& Mwangi, 2010; Reardon et al., 2009).

The interviews with producers suggested an evolution in the upstream LVC in which producerprocessor relationships are rather based on relational governance (Table 2.1). Due to the transactional complexity arising from uncertainty at the supply base, fishermen form strategic bonds with fish mammies that are largely managed by reputation, family or ethnic ties and social and spatial proximity (Gereffi \& Fernandez-Stark, 2016; Gereffi et al., 2005). It is therefore common to see fishermen selling to fish mammies who are their wives or relations in the LVC. Although previous studies have not observed this relational governance (Agbo \& Usoroh, 2015), this study posits that it provoked the emergence of new processing and marketing segments in the LVC. The relational governance ensures that the activities of both producers and processors are to a certain extent synchronized and thus an important factor that drives the LVC. In this type of arrangement, as also observed in the Philippine tawilis chain (Trienekens, 2011), fishermen sell to the same processor(s) for years (Processors C\&D). While both parties' activities have distinct and mutually exclusive costs and benefits, shoreline prices or revenue-sharing formulas are often agreed when SPs are purchased or product credit is made, respectively. Both parties enjoy a certain level of autonomy, as they can switch to other actors temporarily to maximize their own gains. Despite this, the power ranking of actors during the FGDs with artisanal fishermen suggested that fish mammies are important drivers of the LVC (Fishermen A\&B). One fisherman said, "They (fish mammies) are very important in this system... They have the ability to influence certain things within the community and along the supply chain" (Fisherman A).

\section{Gendered value web in the LVC}

SP value $w^{7} b^{7}$ activities are generally undertaken on three levels, namely the shoreline level, at which most of the exchanges between producers and processors take place; the local processing-

\footnotetext{
${ }^{7}$ Here, the value web only captures all the possible value additions along the LVC.
} 
household consumer level, at which most of the local processing and consumption are performed after active marketing by the middlemen; and the industrial level. Fish mammies process SP by smoking on shelves constructed for this purpose or sun-drying. Several important trends that support the importance and influence of fish mammies along the LVC can be summarized from the gendered value web. First, the value web supports the existence of a strict division of labour and specialization based on gender comparative advantages, especially at the supply base. Men have a comparative advantage in shrimping mainly because of the physicality of driving plank canoes and drawing nets (Fishermen B), while offshore security was another reason expressed in some areas. However, "women are expert in drying SP ... Fishermen spend hours in the water and so rely on women to dry it, else SP will spoil" (Fisherman B).

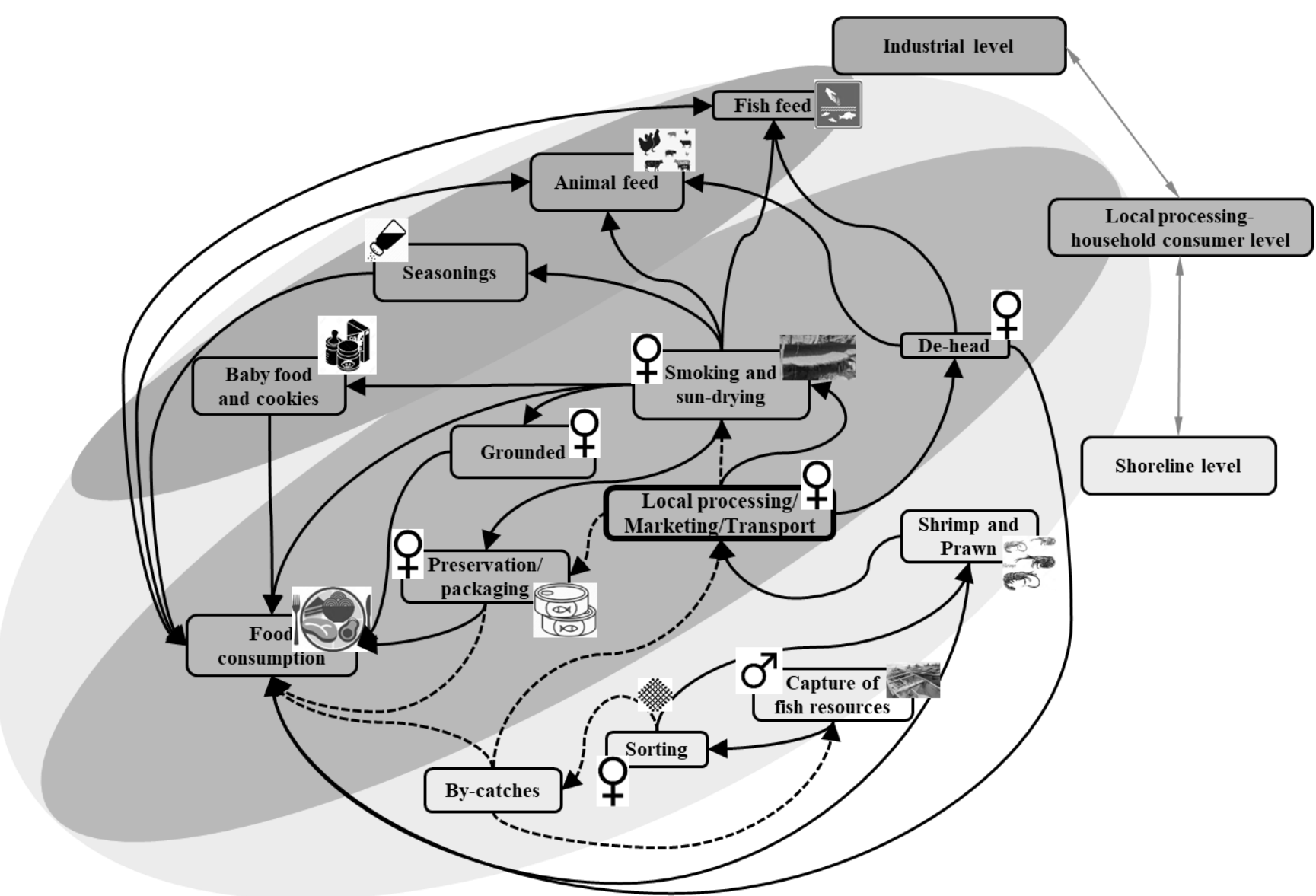

Figure 2.4: Gendered value-web in LVC

Source: Authors' illustration based on FGDs and KIIs

Notes: The study depicts the different types of value addition possible for SP in LVC. It also depicts gender dominance in different activities: 9 represents women dominance while $\sigma^{\top}$ depicts men dominance in the chain. Thick lines represent the flow of SP while the broken lines represent the flow of by-catches.

Second, fish mammies are important providers of a financial cushion for many fishermen who face high cash constraints from an uncertain supply by providing them with zero-interest credit, 
repayments of which are made in subsequent transactions. "That is why you have a lot of fishermen with very white hair ... If you get one basin, which is not up to your fuel cost, they (fish mammies) will buy the little basin you catch and pay your money before trading on it. That is why many women are wealthier than most of the men here" (Fisherman A). "It is those women who sometimes lend us money so that we can operate and they will take back their money after the sale of the SP" (Fisherman A). This has an important impact on the LVC, because a constant supply of SP can be attained from the supply base. Third, fish mammies encourage most industrial and local value additions for SP through their processing or handling activities. Smoking or sun-drying of SP is crucial to increase its shelf life, enhance handling and make it available in forms that are generally acceptable to most local buyers. This is particularly important for fishermen, as they are assured of consistent demand and no financial loss from the deterioration of SP after landing. As shown in Figure 2.4, all possible industrial value additions of SP come only after it has been processed by fish mammies.

Fourth, fish mammies serve as the face of the supply base and can determine the LVC's shape by deciding to sell to either traders or local consumers. Fish mammies are also crucial in determining what and how the benefits are distributed to the producers. The repayment time and margin that fishermen receive depends on how fish mammies fare in their negotiation with powerful middlemen, especially when exchanges between fishermen and fish mammies are based on predetermined sharing formula (Fishermen A). As a result, fishermen seek to transact with fish mammies who are agile, understand the business relationship and can provide a financial background (Fisherman A). Similar to newer findings in some African LVCs (FAO, 2016; Kamau \& Ngigi, 2013; Schumacher, 2014; Udong et al., 2009, 2010), interviews and discussions with several actors also prove that women and their roles are shifting from being totally inferior and dependent to being one of the major drivers of chains at and beyond the supply base. This is also clearly highlighted in Figure 2.4, in which women manage most value-adding activities beyond the supply base, even though the purchasing and bargaining power in the LVC could be independent of gender.

\subsubsection{Third dimension: benefit distribution among actors in the LVC}

The analysis, as well as the results shown in Figure A2.1, suggests inequitable benefit sharing in

the LVC. Generally, more benefits accrue to lead actors (Trienekens, 2011), in this case traders. If large traders/wholesalers sell to big cities, they earn three times (+200 per cent) the shoreline 
price $(\AA 800=2.20 \mathrm{USD})^{8}$ per $\mathrm{kg}$ received by fishermen. Retailers can also earn four times (+150-325 per cent) the shoreline price. Contrarily, fish mammies earn an additional 7 to 25 per cent depending on whether they transact with the final consumers or the traders. The strategic mutual reliance between fishermen and fish mammies means that the uneven benefit shares given to fish mammies also resonate with fishermen. It should be reiterated that the inequitable benefit shares of fish mammies cannot be regarded as indirect gender discrimination of fish mammies since the LVC is largely in women's realm; that is, most traders and retailers are also women. However, the result tilts towards the theory that smallholders generally suffer from more inequitable product market effects in the LVC than in MVCs (Barrientos et al., 2003; Maertens \& Swinnen, 2012; Schumacher, 2014). Therefore, further development of the LVC requires necessary upgrading strategies that will align the benefits better with the supply base.

\subsubsection{Fourth dimension: smallholders' upgrading strategies in the LVC}

This section addresses the third sub-objective. The presence of several challenges that still inhibit the LVC's development is obvious, even though there is the potential for producer and processor upgrading. Table 2.3 summarizes the key constraints and opportunities related to upgrading in the production and processing segments. The constraints at the supply base significantly revolve around market access and orientation, the unavailability of innovation resources and physical infrastructure and institutions (Trienekens, 2011).

\section{Public constraints and opportunities at the supply base}

The institutional supply-side pillars emphasize the roles that the government (public) and private sectors play in providing an enabling environment for artisanal fishermen and fish mammies (AUC/OECD, 2019; Trienekens, 2011). Fishermen lamented about the neglect by the government (Fishermen A-B). Artisanal fishermen lack access to a range of complementary assets, infrastructure, finance, technical assistance and skills that are required to improve their operational efficiency and product quality and effectively link them to the growing local demand. The lack of basic infrastructure, like tarmacked roads, has prevented many smallholders from selling directly to final consumers and limited the activities of private stakeholders. Apart from these, the regulation and enforcement of relevant laws to control pollution in water bodies and environmental degradation are lacking. These externalities negatively affect the supply (Fisherman A). Depending on the available locally fabricated inputs, fishermen expressed that

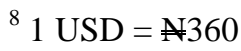


they are technically unable to deal with naturally occurring constraints like seasonality in the supply and bad ocean weather (Fisherman B).

Table 2.3: Constraints and opportunities in the production and processing segments

\begin{tabular}{|cll|}
\hline Segments & Key constraints & Opportunities \\
\hline Production & High natural seasonality/instability in & High domestic demand \\
& production & Increasing post-harvest value \\
& High seasonal demand & Collective action to upscale supply \\
& High asset specificity and costs & \\
& Conventional shrimping inputs & \\
& Lack of basic and financial infrastructure & \\
& Information asymmetry & \\
& Limited incentive to store SP further & Upscaling the quantity processed \\
Processing & Quality variability & Collective action to overcome constraints \\
& Lack of a cold chain & Increased processing hours \\
& Limited access to modern techniques & \\
& Low education and financial illiteracy & \\
& Lack of basic and financial infrastructure & \\
Insufficient working capital & Collective marketing and price determination \\
\hline Marketing & High transportation cost & Weekly traditional markets \\
& Information asymmetry & \\
& Limited market outlets & \\
& Low negotiating power & \\
& Huge competition & \\
& Limited marketing skills & \\
& Unstable demand and high price fluctuation & \\
\hline
\end{tabular}

Source: Authors' illustration based on the FGDs and KIIs.

Additionally, the lack of basic physical infrastructure often limits fish mammies, increases their processing and transportation costs and consequently results in uncompetitive market prices. Generally, higher costs are incurred in shrimping communities with no direct access to some basic infrastructural facilities, like electricity and tarmacked roads. The lack of electricity in many shrimping communities means that certain opportunities, like upscaling sales, longer hours of processing and cold processing, cannot be taken (Processor C). This significantly decreases their possibilities to target new markets and reduces their bargaining power. Additionally, similar to value chains in East Africa, a lack of access to modern processing facilities reduces fish mammies' incentives to improve and attain consistent quality (AUC/OECD, 2019). There are opportunities for quality upgrading that fish mammies can capture. However, they need to spend more time and effort to ensure that the product quality is uniform and the products are free of contaminants. Wealthy consumers in the urban and peri-urban areas are sensitive to product quality and willing to pay a premium for high-quality levels (Researcher K).

Institutionally, the government still needs to provide an enabling environment for private firms/stakeholders to act and make inclusive policy instruments to reposition and involve 
smallholders progressively along the LVC. Policy instruments that border on the provision of location, gender-sensitive infrastructural and financial facilities and modern technologies are generally absent in most shrimping communities. These are essential to improve the efficiency of smallholders and enhance equitable benefit sharing. There was no evidence of public-private coordination, which includes support from the network of fishing companies in MVCs and nonchain actors, in most communities. As a result, smallholders generally lack technical assistance, training and market information and find it hard to organize themselves better into groups (Trienekens, 2011). Furthermore, firms in the SP-based value web still need technical infrastructure, a skilled labour force and financial instruments that can support innovativeness, ensure a consistent demand and aid further research to develop markets (AUC/OECD, 2019).

\section{Organizational constraints and opportunities at the supply base}

On the institutional demand side, the smallholder producer-processor interface often lacks coordinated vertical and horizontal relationships, resulting in ineffective production and business decisions, high market information asymmetry and severe holdup problems (Adekambi et al., 2016; Watabaji et al., 2016). The interviews with fishermen revealed that they often supply SP continuously even when fish mammies have reached full capacity or when the demand is low. This often results in holdups and severe liquidity problems for fishermen, especially when exchanges with fish mammies are based on credit and profit-sharing formulae. Consequently, we found that smallholders are negatively affected by huge product holdups. Fishermen revealed that they experience less purchasing and bargaining power when the holdup of products is longer than expected (Fisherman B).

Furthermore, there is inefficient dissemination of the available market information to smallholders at the supply base, because traders hide information while several non-functional or uncoordinated horizontal relationships still exist in many shrimping communities. Hence, many smallholders are inefficient, incurring higher production and transaction costs (Wategire \& Ike, 2015). Additionally, information asymmetry from the unsynchronized and uncoordinated activities of neighbouring shrimping communities results in spatial price differences, of which traders often take advantage. The result shows that many fish mammies are not willing to adopt modern technologies, for example for smoking and drying SP, and show scepticism towards their effectiveness. "You cannot use any other technology to process SP effectively" (Processor D). However, there are opportunities to reduce the processing costs for fish mammies if modern 
techniques are used instead of the conventional method, which is unsustainable health-wise and environmentally (Fisherman A). Fish mammies' scepticism is compounded by the lack of access to extension services and government-sponsored training, which could teach and encourage them to discard conventional techniques. Lastly, we observed that the location of many processing sheds is often unfavourable, hard to reach or far from landing sites; thus, fish mammies incur higher costs to maintain sheds and transport SP.

Finally, the evidence from the interviews with middlemen and experts indicates that the midstream is also constrained by several challenges that resonate back to the supply base (Table A2.1). Among others, middlemen in the LVC face high market turbulence and transaction costs. As in other African LVCs, the major expense for middlemen is transportation. Middlemen often increase the price of SP to accommodate and compensate for the high transport costs incurred (Udong et al., 2010) or, as found in this case, transfer the risk to smallholders at the supply base by wielding their negotiating power to reduce smallholders' margins. Apart from the government providing an enabling environment, middlemen can alleviate these constraints through collective transportation, which helps to distribute the costs across several traders and marginally reduce the costs for individual traders. Consequently, this will reduce the amount of risks transferred to smallholder producers and processors.

\subsection{Conclusions and implications}

In this paper, we extend the GVC framework (Kaplinsky, 2000; Kaplinsky \& Morris, 2001) towards the gendered value web approach (Virchow et al., 2014) to uncover LVCs' (1) organization, (2) governance themes and gender roles for value addition and (3) smallholder upgrading strategies in developing countries' dualistic sectors using the example of the Nigerian shrimp and prawn sector. The LVC map indicates that the predominant marketing channel is a long chain of producer-processor/marketer-trader-retailer-consumer (see Figure 2.2). Against the background of LVCs, this study finds the LVC structure to be well defined and able to remain competitive despite facing uncertain external situations and neglect.

Historically, the LVC has evolved in response to these contingencies (Agbo \& Usoroh, 2015; Trienekens, 2011). From the analysis of the GVC governance dimension, the relevant drivers of the LVC were identified. The LVC, being a buyer-driven chain, is clearly driven by competitive traders who engage in an aggressive hub and spoke marketing model. The result shows that the coordination mechanisms and business strategy between producer and processor relationships 
evolved in response to a greater demand, an unstable supply, technological advancement and the highly perishable nature of SP at the supply base. This led to the emergence of a new segment at the supply base (processing and marketing), as observed in this study. Further in-depth governance analysis shows that strategic relational governance and business strategies between production and processing segments are crucial in ensuring a constant and smooth supply of SP from the LVC's supply base to the midstream (Figure A2.2). Furthermore, the analysis of the gendered value web highlights the vital roles that women play in ensuring a smooth flow of SP along the LVC (FAO, 2016; Kamau \& Ngigi, 2013; Schumacher, 2014; Udong et al., 2009, 2010). For example, female processors/marketers act as a financial buffer for many producers, a point of contact and a precursor to all midstream value additions in the value web.

Therefore, potential managerial and policy interventions for effective upstream upgrading and LVC development should simultaneously take into account segments that are mutually dependent and based on differentiated gender relations (Schumacher, 2014). As a strategic business plan, the study suggests an initial focus on the domestic and regional markets until rigorous process and product upgrading at the supply base are achieved.

To attain process upgrading, smallholder producers and processors at the supply base need to optimize the coordination and collaboration processes with their trading partners and competitors, respectively (Adekambi et al., 2016; Trienekens, 2011; Watabaji et al., 2016). We suggest better coordination of the producer-processor relationship in which concrete business strategies and plans for shrimping activities are made. Additionally, smallholders need to intensify the horizontal bonds. Existing groups need to be empowered to encompass strategic marketing objectives that benefit members, while new groups are needed in areas where they do not exist (AUC/OECD, 2019). In particular, collective marketing seems to be the imminent cost-effective approach for fish mammies. Collective price determination would also increase fish mammies' negotiating power since the price would be the same for buyers in the area (Dürr, 2015; Lie et al., 2012; Trienekens, 2011). Although this is clearly difficult, smallholders and groups in adjacent shrimping villages also need to coordinate better to integrate spatially and ensure uniform prices at neighbouring landing sites.

We posit that only after process upgrading is achieved can product upgrading begin at the supply base, in which smallholders shift to supply high-quality SP (Trienekens, 2011). In addition, a cold chain, further development of local processing and industries in the value web and the 
targeting of institutions, like a school feeding programme, are good business strategies to differentiate SP, maintain value and provide constant markets for a potential consistent supply from the supply base (Lie et al., 2012).

There are a few limitations to the study. First, the geographical scope of the study, focusing on just three States, means that certain hidden heterogeneous characteristics might affect the activities and that the choice of LVC governance schemes might have been omitted. Validation by external experts was performed, while the data were triangulated with several sources in different States to confirm the consensus. Our sampling method - snowball sampling potentially biased our selection of experienced and better-linked respondents. Despite these limitations, the data obtained enabled an understanding of the overall organizational structure and the derivation of necessary upgrading strategies for smallholders.

The upgrading strategies highlighted are, however, without implications for cost and sustainable production. Future research can determine the most cost-effective choice of upgrading for smallholders and assess the sustainability of the current production technique and efforts. Furthermore, the study identified an array of inter-relationships and governance measures that are important for the effective functioning of the LVC in the face of changing situations. Future research should pay simultaneous attention to segments with mutually dependent gender roles and determine the most effective inter-relationships and governance measures necessary to fit segment-specific situations and enhance the equitable benefit distribution. 


\section{Appendix 2}

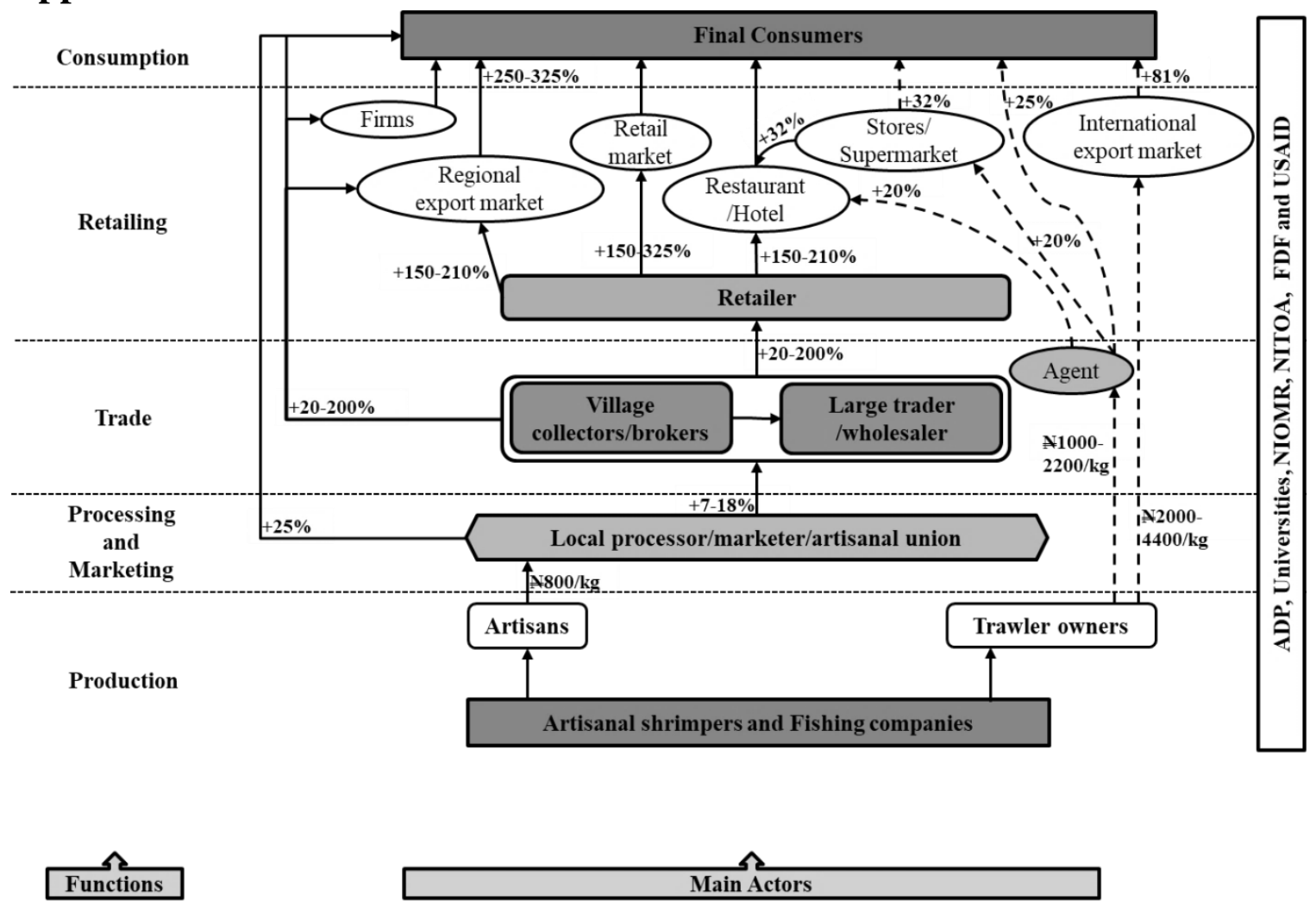

Figure A2.1: Distribution of additional margins in the value chain

Source: Authors' illustration based on FGDs and KIIs. SP shoreline prices are provided per kg while additional margin accruable to actors in each segment are in percentages.

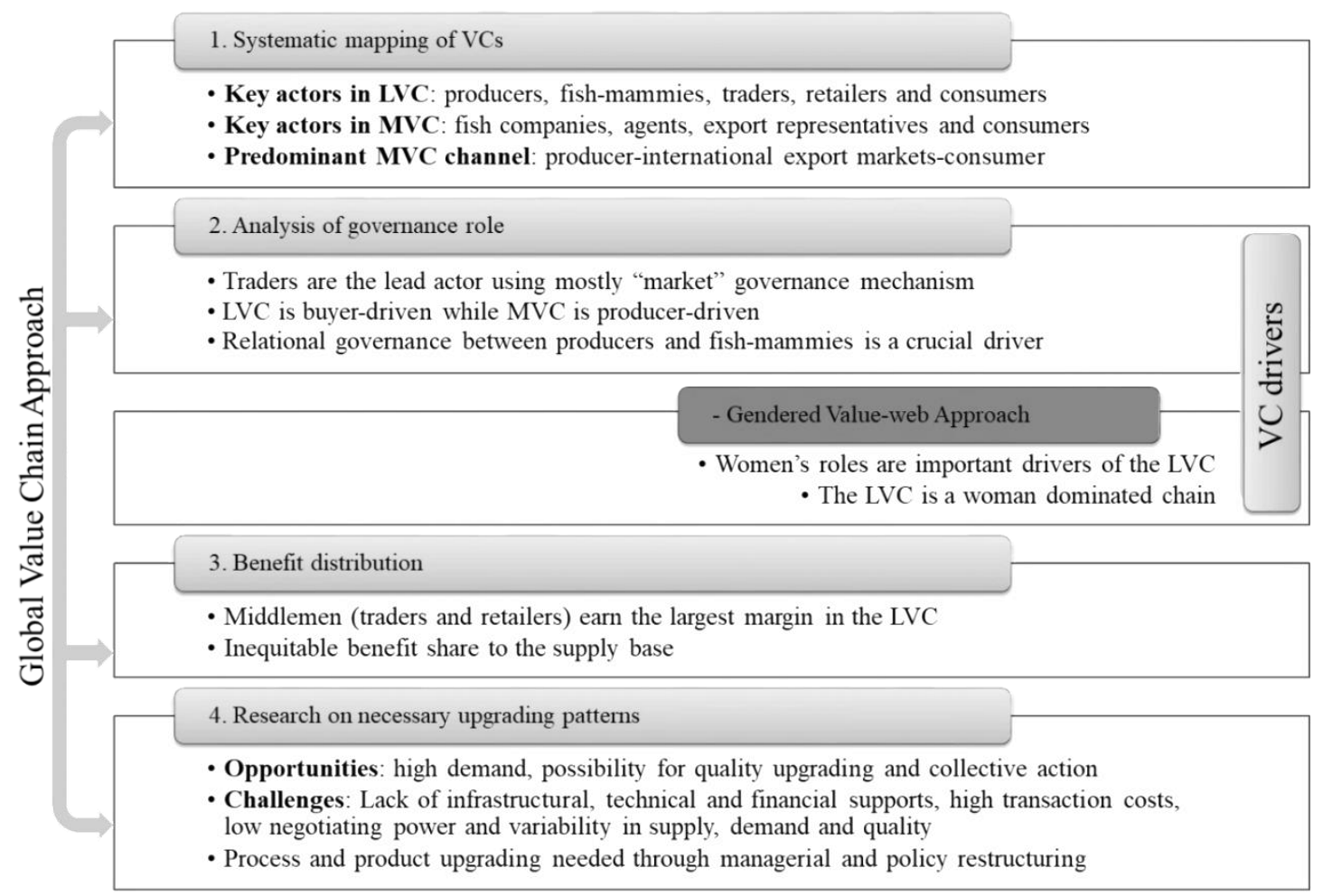

Figure A2.2: Framework summarizing results and necessary upgrading strategies 
Source: Authors' illustration

Table A2.1: Constraints and opportunities in the mid and downstream of LVC

\begin{tabular}{|c|c|c|}
\hline & Key Constraints & Opportunities \\
\hline Village collection/broking & $\begin{array}{l}\text { High transaction cost } \\
\text { High competition with other traders } \\
\text { Challenges to have a constant supply } \\
\text { and meet large local demand } \\
\text { Long distance to the collection site } \\
\text { Insufficient working capital } \\
\text { Wild price fluctuations }\end{array}$ & $\begin{array}{l}\text { Better local market information } \\
\text { High demand from local markets } \\
\text { Premium price } \\
\text { Several differentiation strategies } \\
\text { Possibility for cold chain }\end{array}$ \\
\hline Large trading/wholesaling & $\begin{array}{l}\text { Higher transaction cost } \\
\text { Lack of cold chain } \\
\text { Competition from other traders } \\
\text { Challenges to have a constant supply } \\
\text { and meet larger urban demand } \\
\text { Very long distance to the collection site } \\
\text { Infrastructural decay } \\
\text { Wild price fluctuations }\end{array}$ & $\begin{array}{l}\text { Better chain information } \\
\text { Huge demand } \\
\text { Premium price } \\
\text { Several differentiation strategies } \\
\text { Huge capital base }\end{array}$ \\
\hline Retailing & $\begin{array}{l}\text { Competition from other fish resources } \\
\text { Externalities } \\
\text { Limited marketing skills } \\
\text { Quality variability } \\
\text { Unknown market demand } \\
\text { Challenges to have a constant supply }\end{array}$ & $\begin{array}{l}\text { High demand from urban and peri-urban } \\
\text { areas } \\
\text { Possibility for cold chain }\end{array}$ \\
\hline \multicolumn{3}{|l|}{ Peri-urban markets ${ }^{9}$} \\
\hline $\begin{array}{l}\text { Local retail markets } \\
\text { Restaurants } \\
\text { Local kiosk } \\
\text { Institutions }\end{array}$ & $\begin{array}{l}\text { Competition from other fish resources } \\
\text { Spatial price difference } \\
\text { Limited local purchasing power } \\
\text { Challenges to have a constant supply } \\
\text { Limited marketing skills and } \\
\text { information } \\
\text { Unknown market demand } \\
\text { Quality variability }\end{array}$ & $\begin{array}{l}\text { Several differentiation strategies } \\
\text { Possibility for cold chain } \\
\text { Collective sourcing } \\
\text { Public school feeding program and hospitals } \\
\text { Government support } \\
\text { Premium price } \\
\text { Road-side food vendors }\end{array}$ \\
\hline \multicolumn{3}{|l|}{ Urban markets } \\
\hline $\begin{array}{c}\text { Restaurants } \\
\text { Large market hubs }\end{array}$ & $\begin{array}{l}\text { Competition from other fish resources } \\
\text { Challenges to have a constant supply } \\
\text { Stall rent } \\
\text { Quality variability } \\
\text { Huge competition }\end{array}$ & $\begin{array}{l}\text { Hotels and university cafeterias } \\
\text { Huge demand } \\
\text { Premium price } \\
\text { Collective sourcing to lower transaction cost } \\
\text { Huge demand }\end{array}$ \\
\hline
\end{tabular}

Source: Authors' illustration based on FGDs and KIIs

\footnotetext{
${ }^{9}$ To give an overview of shrimp retail markets, we based the section on the perception of the three retailers interviewed. Shrimp retail market is very diverse in Nigeria.
} 


\title{
3 Contingent resource-based view of food netchain organization and firm performance across tiers: A comprehensive quantitative framework ${ }^{*}$
}

\begin{abstract}
Much has been written in the literature on the effect of fast-moving business environments on organizational and supply chain (SC) management. Yet, empirical scientific findings on the quantitative effect of changing external and internal contingencies on today's globalized SC networks and performance are still fragmented into different organizational instruments, with some conflicting results remaining unexplained. As this also holds for the implications derived, actors' mal-adaptation delays and hampers the restoration of fit between business contingencies and complex organizational structure to maximize performance. This study addresses these deficiencies by providing a comprehensive quantitative research framework to examine how SC external and internal contingencies jointly influence organizational SC network structures and performance across mutually-dependent tiers. The so-called "ContingencyNetchain-Performance" (CNP) framework based on contingent resource-based theory and netchain approach was empirically tested on data obtained from a standardized survey of 405 artisanal producers and 238 processors in the Nigerian shrimp and prawn sector. Partial Least Squares-estimations indicate that both external and internal contingencies significantly influence adaptational change in organization supply chain network, which in turn contributes to smallholders' performance. All external contingencies influence the formation of tighter vertical coordination but differ on horizontal and lateral relationships. More importantly, results reveal that internal contingencies concurrently influence organizational network structures and smallholders' performance. Furthermore, the influence of both external and internal contingencies on organizational networks seems to differ across tiers however, supply chain vertical relationships tend to intensify the formation of closer network structures. Several theoretical and practical implications for SC organization management emerged from this study and are addressed to researchers, practitioners, and policymakers.
\end{abstract}

Keywords: Contingent resource-based view, supply chain network organization, Partial Least Squares estimation, Fishery, Nigeria

\footnotetext{
*This chapter is co-authored with Prof. Jacques Trienekens (JT) and Dr. Verena Otter (VO) and is a discussion paper to be submitted to the Journal of Supply Chain Management. The authors' contributions are as follows: Ayobami Adetoyinbo (AA) conceptualized, designed the research and collected the data. AA analyzed and interpreted the data. JT and VO assisted in the interpretation of the results. AA and VO wrote the paper. JT and VO commented at various stages of the research and revising of the paper.

Acknowledgments: The authors are grateful to the German Research Foundation (DFG) for providing financial support to this research through the GlobalFood Research Training Group (GRK 1666). We are also grateful to Prof. Bernhard Brummer and members of GlobalFood RTG and BMO group, Wageningen for their comments on earlier versions of this paper.
} 


\subsection{Introduction}

Organizational supply chain (SC) complexities arising from fast-moving business environments have been widely described in organizational theory literature (Donaldson, 2006; Pennings, 1992). The core paradigm of structural contingency theory defines this dependency as a fit situation between organization internal and external contingencies and the organizational structure creating the maximum performance possible. Conversely, SC performance as also those of its member firms dwindles with changing contingencies, worsening if non-, mal- and/or delayed adaptation further creates misfit in organizational SC network structures (Donaldson, 2006; Lawrence and Lorsch, 1967). Acknowledging this phenomenon, the concept of contingency continues to be central element and recurrent concern in many organizational and SC management literature over the last half-century (De Clercq et al., 2016; Flynn et al., 2016), though it only became a subject of sophisticated modeling as part of quantitative empirical analysis in recent times (Flynn et al., 2016; Otter et al., 2014). In line with organizational theory (Donaldson, 2006; Lawrence \& Lorsch, 1967), existing empirical studies give evidence that both internal (e.g. age and size) and external (e.g. market conditions) contingencies are likely major factors considered simultaneously by managers when deciding on organizational instruments as part of firms' strategies and thus, source of competitiveness (Cao et al., 2011; Flynn et al., 2016; Leuschner et al., 2013). However, contingency changes nowadays appear in much more diverse forms such as increasing deregulation, privatization and globalization (Reardon, 2015), evershorter innovation cycles and corresponding technological progress (Arora et al., 2016; Autry et al., 2010), which go hand in hand with rising business uncertainties (Flynn et al., 2016) and resource heterogeneity in SCs across multiple tiers (Brandon-Jones et al., 2014).

Structural complexities increase as firms seek to adapt to these changes by using a myriad of heterogeneous and complex strategic SC network instruments to maximize their performance (De Clercq et al., 2016; Johnston et al., 2004; Otter et al., 2014). Firms' SC network instruments convert into different types and/or combinations of complex relationships, which can be categorized into vertical, horizontal and lateral. While vertical relationships are supplier-buyer relationships of different intensities (e.g. duration of relationships, degree of formalization), horizontal relationships appear between actors on the same SC level (e.g. memberships in associations, strategic alliances) (Lazzarini et al., 2001; Otter et al., 2014). Lateral relationships represent bonds with actors, which are not directly involved in any type of production, processing 
and transportation of the good, i.e. stakeholders (Freeman, 1984). These different types of relationships might not be independent of each other in their occurrence (Lazzarini et al., 2001; Otter et al., 2014). Particularly, sectors including SCs with higher numbers of tiers that show different degrees of concentration, such as the agrifood sector, typically witness complex organizational adaptation to contingencies (Barrett et al., 2012; Hobbs \& Young, 2000).

Against this background, it more than ever assigns to academia the task of continuously suggesting theoretical and practical implications for firms on how to realign complex SC organization with predominant dynamic business environments and given resource base. However, until now the literature cannot paint the whole picture as the following conceptual gaps exist: First, existing empirical SC management research puts focus on external contingencies (Arora et al., 2016; De Clercq et al., 2016; Johnston et al., 2004; Otter et al., 2014; Wang et al., 2015). Yet, the concurrent fit of SC organizational strategies to both concurrent changes in external contingencies and internal contingencies in the sense of organization resource bundling is neglected in most quantitative organizational and SC management literature (Kayser et al., 2015; Leuschner et al., 2013). Second, also due to the long-lasting coexistence of SC- and network analysis until the early years of the current millennium (Lazzarini et al., 2001), up to now various literature exists only on particular single organizational instruments or relationships (Autry et al., 2010; Dries et al., 2014; Flynn et al., 2016; Johnston et al., 2004). The lack of comprehensive view on various types of organizational SC relationships as part of management strategies still leaves inconsistent or even conflicting results unexplained (Arora et al., 2016; Johnston et al., 2004; Kayser et al., 2015; Kwon \& Suh, 2004; Wang et al., 2015). Only Otter et al., (2014) simultaneously analyzed the influence of the interplay of all three types of relationships on firm performance. Third, existing studies typically focus on a single tier of the supply chain network (supplier) (Brandon-Jones et al., 2014; Flynn et al., 2016), though this limits implications on how to align SC organizations with changing business environments across mutually-dependent tiers (Mena et al., 2013).

To close these gaps, this study seeks to provide a comprehensive quantitative research framework for analyzing how SC external and internal contingencies jointly influence organizational SC network structures and performance across two mutually-dependent tiers. This objective is addressed by further developing the empirical model of Otter et al., (2014), which integrates netchain approach (Lazzarini et al., 2001) into contingency theory (Donaldson, 2006; Lawrence 
\& Lorsch, 1967), towards the inclusion of firm's internal contingencies based on the contingent resource-based theory (RBT) (Brush \& Artz, 1999). Partial Least Squares Structural Equation Modelling (PLS-SEM) is used to analyze primary data obtained from 643 smallholders over two tiers (production and processing) in the local food system of the Nigerian shrimp and prawn sector. Results from this study can tease out concrete conceptual insights for SC organizational management in highly dynamic industries of developing and industrialized countries.

Global food systems have witnessed immense transformation over the last decades whilst they emerged as key-sector for achieving the United Nations' Sustainable Development Goals (FAO, 2017b). This holds particularly true for local food systems in low and mid-income countries, as they are the main source of income for rural households (Barrett et al., 2012; FAO, 2017b; Reardon, 2015). The Nigerian shrimp and prawn sector as one of those local food systems is dominated by about 1.2 million artisans, most of whom rely on wild capture to supply about 15 metric tons, representing 80 percent of supply to the local markets (FAO, 2017a).

The supply-base of the food system is of particular interest because fisher folks experience highly dynamic external and internal contingencies, which are typical of agrifood systems in developing and transition countries (FAO, 2017b; Udong et al., 2010). Seasonality, extreme weather conditions and fast seafood perishability affect shrimping activities, causing high market uncertainties and volatilities for artisanal producers and processors. Besides, they face traders and influential competitors who have bargaining advantages, financial capability and market information access to transfer risks and earn higher values. Particularly producers perceive rapid technological changes to motorized canoes, engine capacities and gears due to the development in input markets, rising sea levels, and changing consumer demand (FAO, 2017b). Processors, however, are especially confronted with spatial market information asymmetry due to their remoteness and non-transparency of buyers (i.e. traders) along the SC, making them transact under low levels of trust downstream (Udong et al., 2010). Further, many of the artisans lack adequate human and financial capital such as skills, experience, and credit, needed to perform their activities and create/sustain competitive advantage (Udong et al., 2010). As a result, the food system perceives the progressive trend towards denser organizational SC networks. While many processors transact with traders in spot-markets, there are convincing indications for "relational governance" between producer-processors transactions which allows for better synchronization of activities, thereby fostering mutual dependency. Simultaneously, the role of 
producer and processing groups, as well as public extension agents and NGOs, are becoming prominent as alternative sources of information and support for the fisher folks (FAO, 2017b; Udong et al., 2010).

The study is organized as follows. Section 2 provides a detailed description of the theoretical background. The conceptual framework and research methodology are presented in sections 3 and 4, respectively. Lastly, results are presented in section 5 while sections 6 and 7 are dedicated to discuss the results and draw conclusions, respectively.

\subsection{Theoretical background}

\subsubsection{Contingent resource-based theory}

The contingent RBT follows the assumptions of contingency theory (Donaldson, 2006; Lawrence \& Lorsch, 1967) and RBT (Barney, 2001; Wernerfelt, 1984) by arguing that superior organizational performance is attained when firms align their organizational structures with their internal and external context variables (Brush \& Artz, 1999). Contingency theory provides a framework for organizational design and emphasizes that firms must adapt to their external business environment. The fit of firms' organizational SC network structures to their external contingencies will determine the significance and magnitude of competitive (dis)advantage (Donaldson, 2006; Hobbs \& Young, 2000). This forms three dimensions of the situation, response and performance indicators (Cao et al., 2011; Otter et al., 2014). Situations, which are in this context firms' external contingencies, and are not under the control of managers but continuously exert influence on organization (Zeithaml et al., 1988); responses are the organizational factors and strategies that are readjusted to the contingencies; while performances are a measure of fit between situations and responses.

RBT proponents assert that competitive advantage is an outcome of the creation and use of bundles of strategic resources and/or capabilities which are heterogeneous and immobile across firms (Aragón-Correa \& Sharma, 2003; Barney, 2001; Brandon-Jones et al., 2014; Cao et al., 2011; Grant, 1991). RBT's basic proposition is that firms may gain resource-based competitive advantage when their resource bundles are strategic that is, are valuable- $(\mathrm{V})$, rare- $(\mathrm{R})$, imperfectly imitable-(I) and can be fully exploited by an effective organization-(O) (Kozlenkova et al., 2014). Such "resources and capabilities" (internal contingencies) are central constructs in RBT. Extant RBT literature has helped categorize resources into tangible and intangible resources which could be financial, physical, human, technological, reputational and 
organizational (Brandon-Jones et al., 2014; Grant, 1991). While resources are inputs in the production process, capabilities are derived from the combined utilization of tangible resource bundles and are more likely to improve and sustain performance because they intangibly fulfill the VRIO conditions (Brush \& Artz, 1999). We further reinterpret the RBT by applying it to smallholder producer-processor and processor-trader exchanges. Employing RBT at the exchange-level is logical since transactions follow similar resource-based assumptions and logic as firm-level transactions on which RBT has been mainly applied (Kozlenkova et al., 2014). Despite the importance of RBT, as a stand-alone concept, it suffers from the inability to capture context-specific settings in which resources become valuable. This, in addition to an attempt to add a dynamic adaptation process, justifies the reason we implement the contingent RBT into our framework (Brandon-Jones et al., 2014; Cao et al., 2011).

\subsubsection{Netchain approach}

As Otter et al., (2014) did, we integrate the netchain approach into the framework to simultaneously disaggregate and capture different organizational relationships that exist within SC networks. The netchain approach developed by Lazzarini et al., (2001) incorporates SC and network analyses. Both represent different facets of organizational relationships since they are characterized by unique types of interdependencies. The netchain perspective suggests the design of interdependencies as the foundation for the formulation of organizational SC network strategies. SCs are characterized by "sequential" interdependence emphasizing vertical ties in which the output of certain SC actors serves as input for other (dependent) actors. Supply networks are characterized by "reciprocal" interdependence emphasizing horizontal ties in which actors collaborate with their competitors in the same vertical ties. Horizontal relationships involve strong social ties, dense networks, value co-creation and collective learning.

Netchain explicitly differentiates between vertical and horizontal relationships (Lazzarini et al., 2001), but does not include relationships with actors who are not actively part of creating and transporting the product. In this regard, we further take a cue from the stakeholder theory to add lateral ties (Freeman, 1984) which depict network cooperation between SC actors and external stakeholders. The general notion of stakeholder relationship is for organizations to pay attention to all and only relationships that affect and are affected by organization's achievements. Thus, lateral networks could exist to pressurize actors or to address complex problems by enhancing the overall innovation process and exchanging knowledge embodied in products and/or services 
(Freeman, 1984). This is evident in the top-down lateral relationships between SC actors and supporting external actors in many African food systems. Following the netchain approach, an analytical connection between SC and network analyses exists, suggesting that managers consider the nature of vertical coordination before making decisions on horizontal and lateral relationships (Lazzarini et al., 2001). Overall, based on these theories, we developed the “Contingency-Netchain-Performance (CNP) framework" (Figure 3.1).

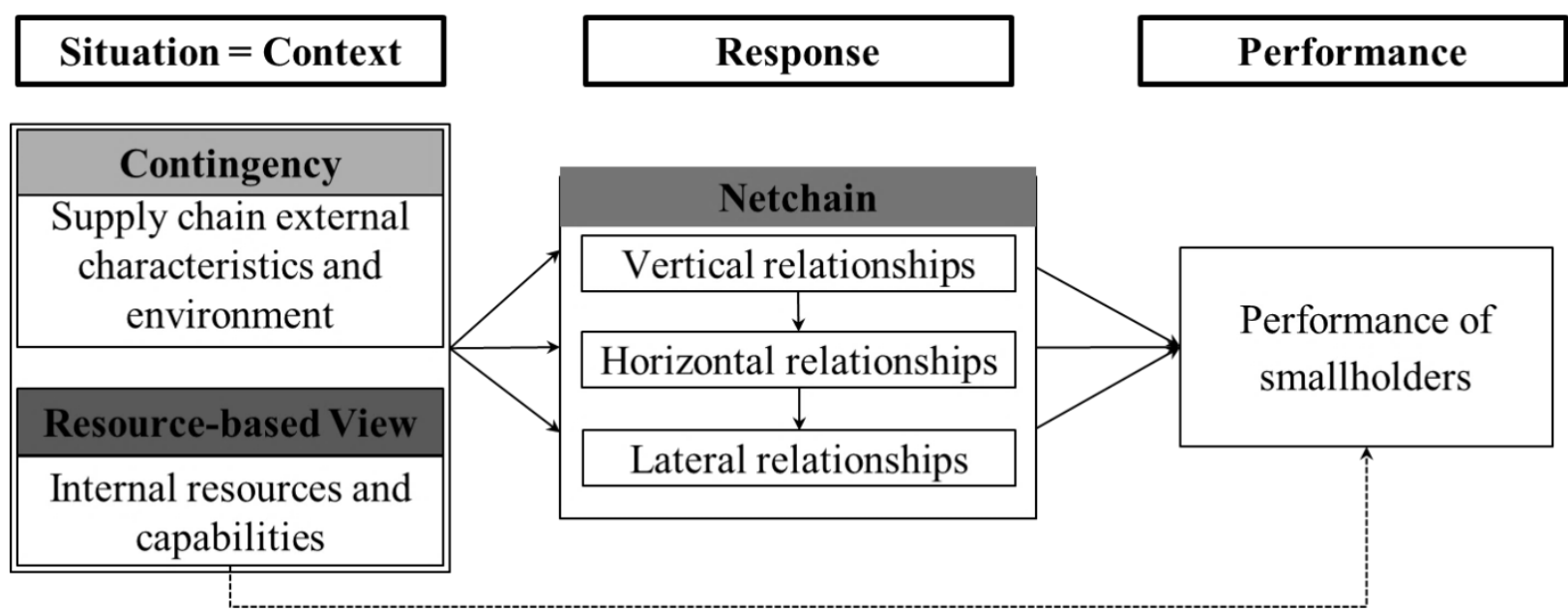

Figure 3.1: Research framework integrating the contingent RBT and netchain approach Source: Own elaboration based on Otter et al., (2014)

\subsection{Conceptual framework}

Based on the theoretical elaborations in Chapter 2, and the concepts adapted from De Clercq et al., (2016); Otter et al., (2014) and Wang et al., (2015), we carefully define external and internal contingencies, organizational structures, and performance constructs to have meaningful results.

\subsubsection{Effects of external contingencies on organizational SC network relationships}

Largely, organizational relationships in food SCs depend on the general business environment such as market situations, trust, technologies, regulations and legal framework, and power relations. Definition of external business environments can be obtained from the perception of decision-makers, in this case, smallholders. For the smallholders in developing countries' food sectors, more specifically in the Nigerian fishery sector, four predominant external contingencies (market turbulence, technological advancement, distrust and power asymmetry) were identified from past literature (Arora et al., 2016; Johnston et al., 2004; Otter et al., 2014) and a qualitative pre-study.

The term "market turbulence" refers to the rate of change in market forces, prices and customers" and stakeholders' composition and preferences (Arora et al., 2016). Market turbulence often 
erupts from production and market uncertainty that could strain logistics and quality management and be transferred across SC tiers (Figure A3.1) (Aramyam et al., 2006). Turbulent markets increasingly make predictions of supply, demand, and market trends difficult, disrupting actors' production and delivery schedules and increasing transaction costs. Actors facing turbulent markets are expected to manage this by intensifying their organizational SC network structures (Wang et al., 2015). Associated uncertainties and risks in highly turbulent markets can be mollified by enhancing information flow through the formation of (i) hybrid relationships that is centered on streamlining operations and logistics with trading partners, though could reduce autonomous adaptability and; (ii) closer network of horizontal and lateral relationships with competitors and supporting external actors, respectively (Reardon, 2015; Williamson, 1979).

H1a: Perceived market turbulence positively influence the tightness of vertical relationships

H2a: Perceived market turbulence positively influence the closeness of horizontal relationships

H3a: Perceived market turbulence positively influence the closeness of lateral relationships

Technological progress captures the rate of technological advances in the industry (Autry et al., 2010; De Clercq et al., 2016). In this study, technological progress is only considered for the production tier due to the fast technological progress with regards to shifting towards outboard engines with different capacities, driven by input market development and consumer demand (Figure 3.2). Frequent updates and volatile changes of technologies and degree of innovation increase the degree of asset specificity and the investment costs to adapt operations and, thus, might render existing SC network structures ineffectually. Smallholder producers would respond by either agglomerating, tightening organizational relationships, synchronizing and imitating competitor's activities and/or jointly securing and operating technology (Autry et al., 2010).

$\mathbf{H 1 b}^{1}$ : Perceived technological progress positively influences the tightness of vertical relationships $\mathbf{H 2 b}^{1}$ : Perceived technological progress positively influences the closeness of horizontal relationships $\mathbf{H 3 b}^{1}$ : Perceived technological progress positively influences the closeness of lateral relationships 


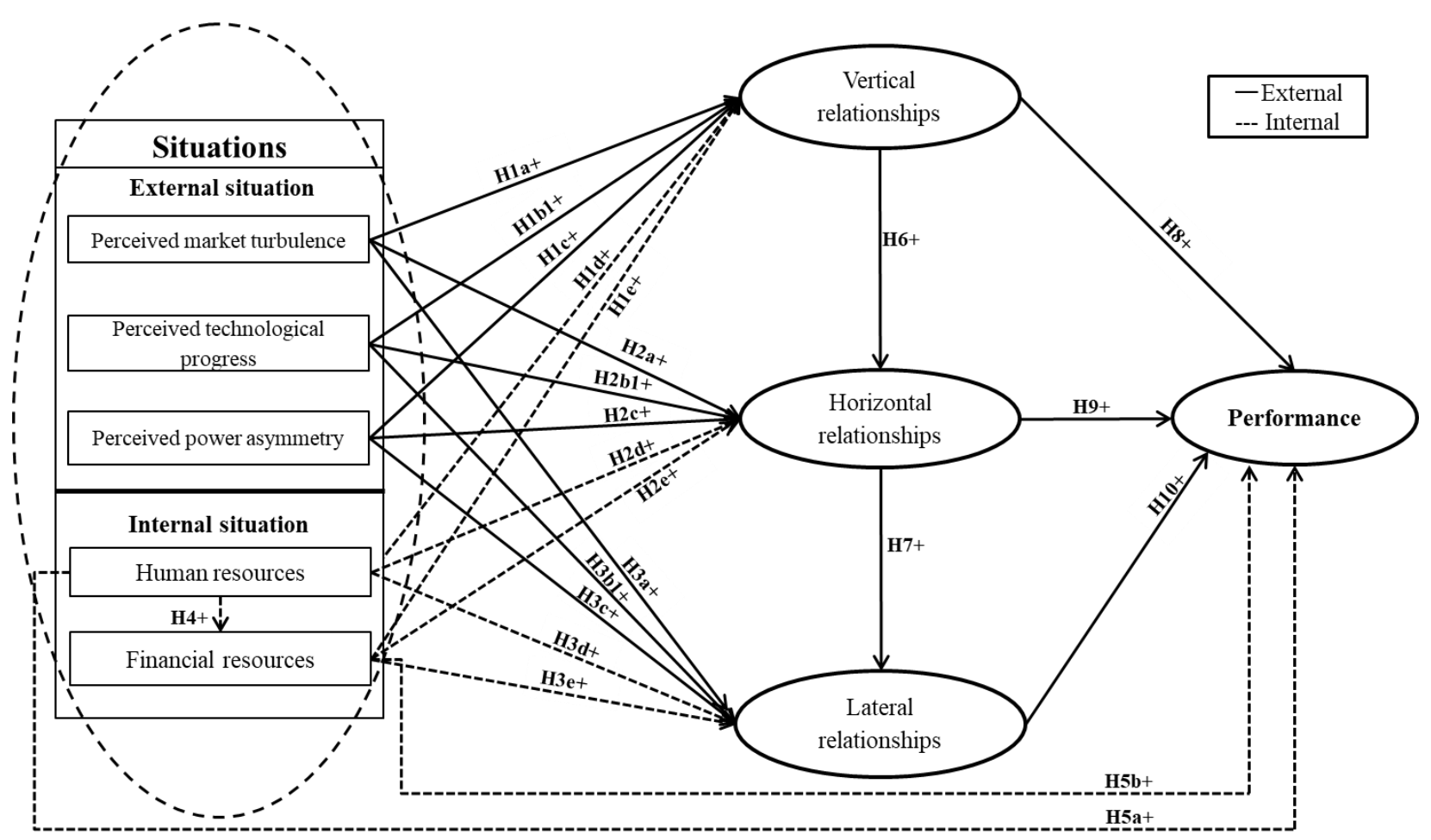

Figure 3.2: Research model with hypotheses for producers developed from Otter et al., (2014)

For shrimp processors, however, distrust levels during their interactions with the middle-men are a major contingency rather than technological progress since their activities are conducted manually (Figure 3.2). Trust, a reoccurring concept in the SC management literature, depicts the levels of confidence in trading partners' capabilities and actions, which cannot be controlled by individual SC actors (Johnston et al., 2004; Kwon \& Suh, 2004). The levels of trust determine actors' information exchange behaviors and influence the degree of commitment and collaborative-decisions in buyer-supplier and supplier-supplier relationships, thereby facilitating complexity in organizational structures (De Clercq et al., 2016; Johnston et al., 2004; Otter et al., 2014). Smallholders often face high distrust levels along SCs which increases behavioral uncertainty and risks among trading partners and consequently, higher transaction costs (Barrett et al., 2012; Williamson, 1979). From what is known in existing research, smallholders could reduce behavioral uncertainty from distrust by forming tighter/closer organizational relationships with buyers, producer groups or stakeholders such as public agencies and NGOs to enhance reliability and information sharing (Hobbs \& Young, 2000; Otter et al., 2014).

$\mathbf{H 1}^{2}$ : Perceived distrust positively influences the tightness of vertical relationships

$\mathbf{H}^{2} \mathbf{b}^{2}$ : Perceived distrust positively influences the closeness of horizontal relationships

$\mathbf{H 3 b}^{2}$ : Perceived distrust positively influences the closeness of lateral relationships 


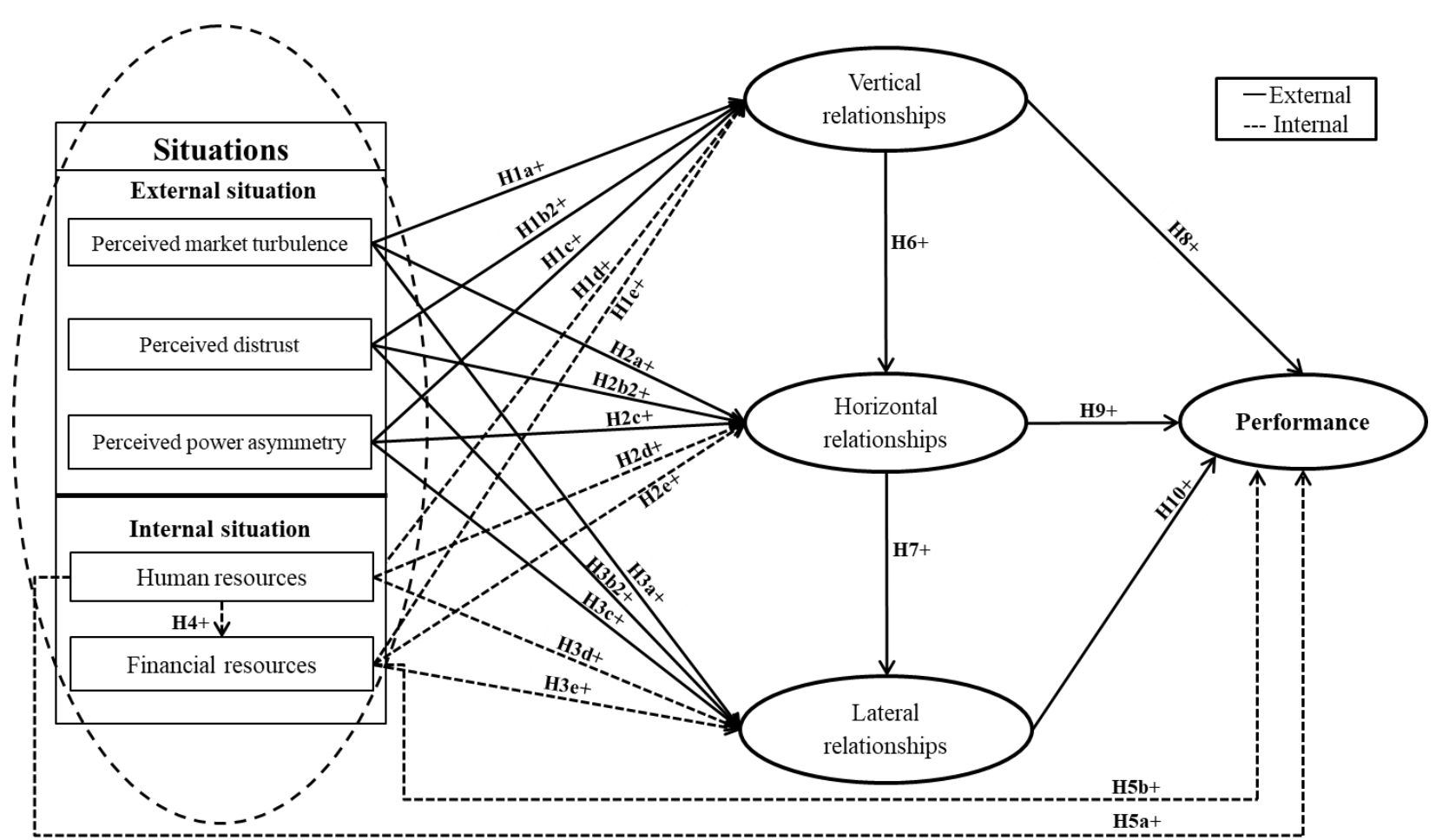

Figure 3.3: Research model with hypotheses for processors developed from Otter et al., (2014)

Lastly, though vast definitions of power exist in the literature (Otter et al., 2014; Reimann \& Ketchen, 2017), we define power as the "capacity to effect (or affect) organizational outcome" (Mintzberg, 1983). Influential actors in SCs require some sources of power with bargaining advantages which are skillfully used to claim higher share of value available in the transactions between actors (Reimann \& Ketchen, 2017). The globalization and urbanization of food systems in developing countries have increased the influence of middlemen, causing an inequitable shift in bargaining power and value share to smallholders (Reardon, 2015). As such, the concept of power has become important for smallholders, who could make a counter through the formation of closer organizational SC networks that allows for better coordination and cooperation among actors (Barrett et al., 2012; Mintzberg, 1983; Verhofstadt \& Maertens, 2014).

H1c: Perceived power asymmetry positively influences the tightness of vertical relationships

H2c: Perceived power asymmetry positively influences the closeness of horizontal relationships

H3c: Perceived power asymmetry positively influences the closeness of lateral relationships

\subsubsection{Effects of internal contingencies on organizational SC network relationships}

Internal contingencies are disaggregated into tangible and intangible resources (Barney, 2001; Wernerfelt, 1984). Smallholders in food systems face limited or lack access to tangible resources which limits resource bundling into capabilities (Udong et al., 2010). Thus, we focus on tangible 
resources rather than capabilities to capture predominant internal contingencies that fulfill the VRIO conditions. Smallholders' age, experience, and collaborative efforts can be proxies for human resources, thereby capturing relational capability in a way (Grant, 1991; Wang et al., 2015). Financial resources originate from smallholders' access and level of financial capital. They are unequally attained by smallholders in developing countries, with most generally endowed with low capital-base due to constraints by history and path-dependent strategies which makes imitation rather costly (Barrett et al., 2012; FAO, 2017b). This similarly holds for smallholders' experience and reputation, suggesting that these resources are heterogeneously distributed and imperfectly mobile across smallholders in this study. Thus, it can be expected that smallholders with better human resources would easily access financial capital and combine both productive resources to create relatively better performance. Smallholders with human and financial resources would be incentivized to form tighter SC networks to reduce production and marketing risks, create more values and optimally improve performance (Aragón-Correa \& Sharma, 2003; Barney, 2001; Brandon-Jones et al., 2014).

H1d, H2d, and H3d: Human resources positively influence the tightness/closeness of organizational relationships

H1e, H2e, and H3e: Financial resources positively influence the tightness/closeness of organizational relationships

H4: Access to human resources positively influence access to financial resources

H5a: Strategic human resources positively influence firm performance

H5b: Strategic financial resources positively influence firm performance

\subsubsection{Effects among different organizational SC network relationships}

Managers' decisions on the nature of network relationships are not independent of sequentially arranged vertical ties (Lazzarini et al., 2001). Though actors that forge tighter but informal vertical relationships could overcome some contingencies, this as a standalone coordination mechanism might not be sufficient to fit with all contingencies (Donaldson, 2006; Lawrence \& Lorsch, 1967). Smallholders in developing countries often collectively access input and output markets and obtain supplementary market information by forging producer groups/cooperatives. Thus, positive links between tighter vertical and closer horizontal relationships are assumed, though different findings are plausible in settings where there are fewer market imperfections (Lazzarini et al., 2001; Otter et al., 2014). Similarly, closer horizontal relationship is expected to facilitate collaborations with supporting stakeholders (lateral relationships) since this is often a 
major condition to initiate and establish contacts with government agencies, extension agents and NGOs in developing countries (Emmanuel et al., 2016; Gramzow et al., 2018). Lateral relationships with non-supporting stakeholders are not considered in this study since they are under-represented in this local food system.

H6: Tighter vertical relationships intensify the closeness of horizontal relationships

H7: Closer horizontal relationships intensify closeness of lateral relationships

\subsubsection{Effects of organizational SC network structures on firms' performance}

Organizational performance varies with the degree of fit between organizational SC networks and external and internal contingencies (Donaldson, 2006; Lawrence \& Lorsch, 1967). Tighter vertical relationships, a consequence of coordination mechanisms beyond market, guide interactions and can help mitigate business uncertainties and overcome market failure experienced in many developing countries (Dries et al., 2014; Williamson, 1979). The efficiency of smallholders' internal contingencies to generate competitive advantage can be improved by tighter vertical relationships (Barney, 2001; Grant, 1991), which has been found to positively influence performance in certain business situations (Leuschner et al., 2013; Otter et al., 2014).

Further, horizontal relationships afford individual actors to pool their financial and productive resources to attain economies of scale in commercializing products and purchasing inputs (Lazzarini et al., 2001). Smallholders in developing countries can promote intensification, increase market orientation and create values by sharing associated risks and costs collectively through producer groups/cooperatives which consequently improve individual performance (Gramzow et al., 2018; Verhofstadt \& Maertens, 2014). Stakeholders are important in organizational structures since they influence the success of business enterprises in modern turbulent environments (Freeman, 1984). Lateral relationships with stakeholders are forged to strengthen smallholders' competitiveness in many developing countries by enhancing access to public infrastructure, market information, knowledge, and technology (Emmanuel et al., 2016).

Positive performance effects could become evident for forming closer relationships to wellfunctioning institutions, although negative effects from mal-functioning institutions have been documented (Otter et al., 2014).

H8: Tighter vertical relationships positively influence smallholder performance

H9: Closer horizontal relationships positively influence smallholder performance

H10: Closer lateral relationships organizations positively influence smallholder performance 


\subsection{Research methodology}

This study uses primary cross-sectional data obtained between May and August 2018 in three major shrimping states of Nigeria. Data was collected from both artisanal producers and processors. Case-specific information for the research design was gathered during a pre-study that included three focus group discussions (FGD) and 21 face-to-face interviews with key actors such as producers, processors, and experts.

\subsubsection{Sampling}

For the sampling, a multi-stage design was used. Initially, three states representing different socio-cultural settings- Lagos, Akwa-Ibom and Ondo- were purposively selected based on their high level of shrimping activities. From these states, four shrimping local government areas (LGA) - Badagry and Eti-Osa in Lagos, Ibeno in Akwa-Ibom and Ilaje in Ondo state - were purposively selected based on the population of artisanal producers and processors and concentration of shrimping activities in the areas. A two-stage cluster sampling technique was used to randomly pick 20 shrimping communities and the sampling units (-artisanal producers and processors) within the four LGA. Lists of shrimping communities as a basis for random sampling were constructed with the help of experts during the interviews. In this study, producers are defined as business owners (those that own shrimping inputs) and shrimpers (those that lead canoes) while processors process and/or market shrimp and prawn. Overall, 643 smallholders were sampled and surveyed representing 405 artisanal producers and 238 processors/marketers to assess organizational SC network structures across two tiers.

\subsubsection{Data and Sources}

The data were collected using standardized questionnaires for producers and processors designed based on a thorough literature review and the qualitative data from the pre-study. The questionnaires were pretested with 22 randomly selected producers and processors in two shrimping communities. The final versions were applied via face-to-face interviews by 10 intensively trained local enumerators, using tablets with "Sawtooth Software". The producers' and processors' questionnaires comprised eleven and six sections, respectively from which information on contingencies, organizational relationships, and performance constructs was requested. 5-point Likert-scale ranging from "strongly disagree" to "strongly agree", continuous and dummy variables were used for these constructs. Table A3.1 and Table A3.2 present construct items used in producer and processor models. 
Performance indicators have been categorized into financial and non-financial/operational measurements (Aramyan et al., 2007), capturing four indicators: "efficiency", "flexibility", "responsiveness" and "food quality". These measures are crucial to assess the success of activities and decisions, yet there is no consensus on performance metrics in the literature (Aramyan et al., 2007). Smallholders often aim at achieving own marketing performance standards depending on product and marketing strategy, making operationalization of their performances also very complex. Most relevant studies have focused on single and/or diverse

performance measures (Johnston et al., 2004; Kayser et al., 2015; Otter et al., 2014), which limits the reliability and generalizability of findings across tiers and SCs. This research uses multiple "efficiency" indicators, namely; quantity caught/processed, gross margin, profit and cash at hand (business liquidity) as measures of smallholders' long-term and temporal performances, thereby increasing the reliability and validity of our analysis (Zeithaml et al., 1988) and allowing for comparison across tiers.

\subsubsection{Analytical method}

We take advantage of a second generational research approach by employing a variance-based SEM to analyze the disaggregated data. Variance-based SEM is generally suitable to test complex explorative research models with several latent variables/constructs relationships compared to Covariance-based SEM (Hair et al., 2018). Although the approach is subject to potential bias and inconsistent estimations, it offers the methodological robustness to explore the interplay between underlying conceptual models and theory (Hair et al., 2018, 2014). The structural models were analyzed using SmartPLS Version 3.2.8 software and subjected to several measurement reliability and validity tests using item loadings and signs, internal consistency reliability, convergent validity and discriminant validity (Hair et al., 2018, 2012).

The reliability tests require all factor loadings to be logically correlated and above $0.4-$ the threshold for exploratory research (Hair et al., 2012). Factors' internal consistency is measured by composite reliability (CR) values and should be within the range of 0.70 and 0.94 (Hair et al., 2018) while the convergent validity captured by average variance extracted (AVE) should be 0.50 or higher (Hair et al., 2014). Discriminant validity test is done by checking the cross-loading which must load highest on the construct it is intended to measure (Hair et al., 2018, 2014, 2012). Further, the Fornell-Larcker criterion is used to test discriminant validity. The criterion is fulfilled if AVE of each construct is greater than the squared correlation with all other constructs in the 
structural model (Table A3.4 and Table A3.5) (Fornell \& Larcker, 1981). Other quality criteria measures such as multicollinearity using inner and outer VIF values and more efficient heterotrait-monotrait ratio (HTMT) (Table A3.6) were checked (Hair et al., 2018, 2014).

\subsection{Results}

\subsubsection{Descriptive statistics}

The descriptive results for producers and processors presented in Table 3.1 indicate that they share similar socioeconomic characteristics. The majority of fisher folks are settlers in the shrimping communities, with more than $70 \%$ having no access to tarmacked roads. An exception is fisher folks in Akwa-Ibom state where most (98\%) have access to tarmacked roads. They both have relatively low start-up capital for the season, $\$ 153343.20$ (425 USD) for the producers and \#188000 (522USD) for processors.

Information on producers' internal contingencies indicates that most of the producers are young (mean 39 years; minimum 18; maximum 85) with an average of 16.41 years of experience and little education (average of eight schooling years). With only $21.73 \%$ of the subsample having access to credit, credit and huge capital-base are rare for producers. The production tier is dominated by men although there are few women producers (3.5\% of the subsample) who own production inputs and employ men as shrimpers (Table 3.1 Column 2). Producers sell more than $50 \%$ of their products to an average of two processors/marketers (minimum 1; maximum 8), through informal agreements. This reflects the characteristics of tighter vertical relationships rather than open market transactions which are often characterized by numerous trading partners (Barrett et al., 2012). 24.44\% of the producers belong to producer groups in which they have participated averagely for 10 years and collaborated with 5 group members. Only $4.69 \%$ of

producers forge lateral relationships with extension agents and stakeholders who are reportedly making fewer visits to shrimping communities (SE5_1) (Table 3.1 and Table A3.1).

Descriptive information on production shows that $96 \%$ of producers use plank canoes equipped with outboard engines (OBE), with an average capacity of 40 Horse-power (HP). On average, producers shrimp four days/week during the peak season and spend about nine hours/day at sea (Table 3.1 Column 4). Generally, they shrimp more during the peak season, spending an average of 23 weeks as compared to 11 weeks during the offseason. The overall catch is about $1928.43 \mathrm{~kg} /$ week and $343 \mathrm{~kg} /$ week during the peak and offseason, respectively while the average 
gross margin earned by producers is $\$ 9.87 . \mathrm{million} /$ annum $^{10}$ (27420USD/annum; minimum 204.41; maximum 248888.88).

Table 3.1: Producer and processor descriptive statistics

\begin{tabular}{|c|c|c|c|c|c|}
\hline \multirow{3}{*}{ Variable } & \multirow{3}{*}{ Units } & \multicolumn{2}{|c|}{ Producers } & \multicolumn{2}{|c|}{ Processors } \\
\hline & & Number & $\begin{array}{c}\text { Mean } \\
(\mathrm{N}=405)\end{array}$ & Number & $\begin{array}{c}\text { Mean } \\
(\mathrm{N}=238)\end{array}$ \\
\hline & & (1) & (2) & (3) & (4) \\
\hline \multicolumn{6}{|l|}{ Socioeconomics } \\
\hline Indigene & $\begin{array}{l}\text { Dummy: } 1=\text { indigene } \\
0=\text { otherwise }\end{array}$ & & $\begin{array}{c}0.22 \\
(0.42)\end{array}$ & & $\begin{array}{c}0.23 \\
(0.42)\end{array}$ \\
\hline Age & Years & & $\begin{array}{c}39.00 \\
(11.25)\end{array}$ & & $\begin{array}{c}39.96 \\
(10.81)\end{array}$ \\
\hline Gender & $\begin{array}{l}\text { Dummy: } 1=\text { Female } \\
0=\text { Male }\end{array}$ & & $\begin{array}{c}0.03 \\
(0.18)\end{array}$ & & $\begin{array}{c}1.00 \\
(0.00)\end{array}$ \\
\hline Tarmacked road & $\begin{array}{l}\text { Dummy: } 1=\text { access } \\
0=\text { otherwise }\end{array}$ & & $\begin{array}{c}0.26 \\
(0.44)\end{array}$ & & $\begin{array}{c}0.18 \\
(0.39)\end{array}$ \\
\hline Producer/processing group & $\begin{array}{l}\text { Dummy: } 1=\text { If a member } \\
0=\text { otherwise }\end{array}$ & & $\begin{array}{c}0.24 \\
(0.43)\end{array}$ & & $\begin{array}{c}0.21 \\
(0.41)\end{array}$ \\
\hline Years in group & Year & & $\begin{array}{l}10.20 \\
(7.23)\end{array}$ & & $\begin{array}{l}11.00 \\
(8.61)\end{array}$ \\
\hline Number of members collaborated with & Continuous & & $\begin{array}{c}5.01 \\
(6.56)\end{array}$ & & $\begin{array}{l}5.41 \\
(6.18)\end{array}$ \\
\hline Credit & $\begin{array}{l}\text { Dummy: } 1=\text { access } \\
0=\text { otherwise }\end{array}$ & & $\begin{array}{c}0.22 \\
(0.41)\end{array}$ & & $\mathrm{x}$ \\
\hline Start-up capital & $\#$ & & $\mathrm{x}$ & & $\begin{array}{c}188000 \\
(183000)\end{array}$ \\
\hline Extension service & $\begin{array}{l}\text { Dummy: } 1=\text { access } \\
0=\text { otherwise }\end{array}$ & & $\begin{array}{c}0.05 \\
(0.21)\end{array}$ & & $\begin{array}{c}0.02 \\
(0.14)\end{array}$ \\
\hline Labor & Hours/day & & $\begin{array}{c}8.99 \\
(2.51)\end{array}$ & & - \\
\hline Number of trading partners & Continuous & & $\begin{array}{c}2.49 \\
(1.79)\end{array}$ & & $\begin{array}{c}6.53 \\
(5.85)\end{array}$ \\
\hline \multicolumn{6}{|l|}{ Production and processing activities } \\
\hline Shrimping/processing days (Peak season) & Days & & $\begin{array}{c}3.51 \\
(2.91)\end{array}$ & & $\begin{array}{l}5.96 \\
(0.50)\end{array}$ \\
\hline Shrimping/processing days (Offseason) & Days & & $\begin{array}{c}1.43 \\
(1.85)\end{array}$ & & $\begin{array}{c}2.55 \\
(1.85)\end{array}$ \\
\hline Shrimping weeks (Peak season) & Weeks & & $\begin{array}{l}23.14 \\
(2.08)\end{array}$ & & $\begin{array}{l}23.28 \\
(2.34)\end{array}$ \\
\hline Shrimping weeks (Offseason) & Weeks & & $\begin{array}{l}11.20 \\
(8.27)\end{array}$ & & $\begin{array}{l}11.13 \\
(8.18)\end{array}$ \\
\hline \multirow{3}{*}{$\begin{array}{l}\text { Average total shrimps caught/processed } \\
\text { (Peak season) } \\
\text { Average total shrimps caught/processed } \\
\text { (Offseason) }\end{array}$} & $\mathrm{kg} /$ week & & $\begin{array}{c}1928.43 \\
(1387.59)\end{array}$ & & $\begin{array}{c}518.28 \\
(341.27)\end{array}$ \\
\hline & $\mathrm{kg} /$ week & & $\begin{array}{c}343.02 \\
(392.49) \\
\end{array}$ & & $\begin{array}{c}123.97 \\
(130.93) \\
\end{array}$ \\
\hline & \multicolumn{5}{|c|}{ Percentages } \\
\hline Education & $\begin{array}{l}\text { Non-formal education } \\
\text { Little education }\end{array}$ & $\begin{array}{c}55 \\
319\end{array}$ & $\begin{array}{l}13.58 \\
78.77\end{array}$ & $\begin{array}{c}69 \\
157\end{array}$ & $\begin{array}{l}28.99 \\
65.97\end{array}$ \\
\hline
\end{tabular}

${ }^{10} \#$ denotes Nigerian Naira currency. Averagely, 1USD=\$360 between May and August 2018. Shrimp is a high-valued products, however variable costs on engines, canoes and piracy which producers sometimes incurred several times per annum due to accidents and piracy were not accounted for while calculating this value. 


\begin{tabular}{|c|c|c|c|c|c|}
\hline & Higher education & 31 & 7.65 & 12 & 5.04 \\
\hline \multirow[t]{2}{*}{ Major buyer for producers } & Processors/Marketers & 395 & 97.53 & - & - \\
\hline & More than one type & 10 & 2.47 & & \\
\hline \multirow[t]{3}{*}{ Major buyer for processors } & Processors/Marketers & & & 2 & 0.84 \\
\hline & Traders & & & 233 & 97.90 \\
\hline & More than one options & & & 3 & 1.26 \\
\hline \multirow[t]{2}{*}{ Shrimping equipment } & Plank with OBE & 389 & 96.05 & - & - \\
\hline & Without Canoe & 16 & 3.95 & & \\
\hline \multirow[t]{2}{*}{ Processing equipment } & Dummy: $1=$ oven & - & - & 8 & 3.36 \\
\hline & 0 shed/kitchen & & & 230 & 96.64 \\
\hline \multirow[t]{4}{*}{ Number of OBE owned } & 0 & 99 & 24.44 & - & - \\
\hline & 1 & 170 & 41.98 & & \\
\hline & 2 & 101 & 24.94 & & \\
\hline & $>2$ & 35 & 8.64 & & \\
\hline \multirow[t]{3}{*}{ OBE capacity } & $<40 \mathrm{HP}$ & 8 & 1.97 & - & - \\
\hline & $40 \mathrm{HP}$ & 374 & 92.35 & & \\
\hline & $>40 \mathrm{HP}$ & 7 & 1.73 & & \\
\hline
\end{tabular}

Source: Own elaboration based on PLS-estimations

Notes: $\mathrm{x}$ is presented in Table A3.1 and Table A3.2 while - indicates that variables are not applicable for the corresponding respondent. Standard deviations are reported in parentheses.

The second subsample consists of processors/marketers. Generally, processors/marketers have similar socio-economic and institutional characteristics compared to the producers since most reside close or are even related. The processors are also young (mean $\approx 40$ years; minimum 15 ; maximum 75) with 15 years of experience and little to no formal education. Similar to producers, credit access to processors is rare, with only $24.44 \%$ having access. A clear distinction is that the processing/marketing tier is dominated by women (Table 3.1 Column 4). The result also shows that processors/marketers sell to 6 major buyers (minimum 1; maximum 50), suggesting that they seldom sell more than half of their products to several trading partners. $21 \%$ of the processors participate in women unions with most already participating for an average of 11 years and collaborating with 5 union members. Only $0.02 \%$ of the processors forge closer lateral relationships with extension agents and other stakeholders who find it hard to channel fisher folks' grievance easily to the right authority (SE1_5). Overall, processors forge relatively loose vertical relationships, horizontal and lateral relationships compared to the producers.

Information on processing activities indicates that processors spend an average of six days/week to process during the peak season and two days/week during the offseason. Similar to the producers, processors process for an average of 23 weeks during the peak season and 11 weeks during the offseason (Table 3.1 Column 4). The average quantity processed by the processors is $518.28 \mathrm{~kg} /$ week and $123.97 \mathrm{~kg} /$ week during the peak and off-season, respectively. The quantity difference observed between the production and processing tiers ensues because products are 
fried and/or dried at the processing tier. However, with production and processing durations and associated quantities following the same trend indicates the existence of strategic dependencies between the tiers. The average gross margin for processors/marketers is $\$ 3.79$ million/annum $(\approx 10500$ USD/annum; minimum 253 ; maximum 43756.25$)$, confirming that shrimp as a highvalue product.

\subsubsection{PLS-estimations}

All quality criteria depicted in Table A3.1, Table A3.2, and Table A3.3 indicate that the structural models are reliable and valid. An exception is vertical relationships in the producer model with AVE value of 0.40 . Nevertheless, we keep the construct because it satisfies other reliability and validity tests and is important for interpretation of the model. To test the hypotheses, the coefficient of determination $\left(\mathrm{R}^{2}\right)$, path coefficients and significance levels of the inner models are taken into account. In both models, all items significantly load on all constructs while endogenous constructs such as financial resources, vertical relationships, horizontal relationships, and lateral relationships all show $\mathrm{R}^{2}$-values of $0.068,0.345,0.149$ and 0.136 , respectively (Figure 3.4). Similarly, the endogenous constructs in the processor model indicate corresponding $\mathrm{R}^{2}$ values: financial resources (0.167), vertical relationships (0.270), horizontal relationships (0.153) and lateral relationships (0.220). Using the threshold of 0.25 (Hair et al., 2018), these $\mathrm{R}^{2}$-values are considered low to medium. The complexity of the models, dependency on human perceptions and overall explorative nature of the analysis could be the reasons for these $\mathrm{R}^{2}$ values. However, they are larger than what was obtained in extant literature thus, can be considered satisfactory.

\section{Hypothesis testing for production tier}

The results from the producer model show that external environments largely influence organizational structures in the Nigerian shrimp and prawn SC. All external environments significantly influence tighter vertical relationships: perceived market turbulence (H1a confirmed: $0.347 * * *)$, technological progress ( $\mathrm{H}_{1} \mathrm{~b}^{1}$ confirmed: $\left.0.102 * *\right)$, and power asymmetry (H1c confirmed: $0.301 * * *)$. Contrarily, internal resources (H1d and H1e) do not significantly influence producers' vertical relationships. Furthermore, while contingency factors such as perceived market turbulence $\left(\mathrm{H} 2 \mathrm{a}:-0.113^{*}\right)$ and power asymmetry $(\mathrm{H} 2 \mathrm{c}:-0.117 *)$; and internal financial resources $(\mathrm{H} 2 \mathrm{e}$ : $-0.090 * *)$ decreases the closeness of horizontal relationships, human resources ( $\mathrm{H} 2 \mathrm{~d}$ confirmed: $0.362 * * *)$ positively increase its closeness. No significant influence was found for tighter vertical relationships and perceived technological advancement on 
horizontal relationships. The closeness of producers' lateral relationships is positively influenced by external environments such as perceived technological advancement $\left(\mathrm{H} 3 \mathrm{~b}^{1}\right.$ confirmed: $0.100^{* *}$ ) and power asymmetry (H3c confirmed: $0.205^{* * *}$ ), and closer horizontal relationships (H7 confirmed: $0.174 * * *)$. Conversely, financial resources significantly influenced by inherent human resources ( $\mathrm{H} 4$ confirmed: $0.261^{* * *}$ ) were observed to negatively influence the tightness of lateral relationships (H3e: $-0.205^{* * *}$, while no significant influence was found from perceived market dynamism and human resources.

We observed that producers' shrimping performance is directly positively influenced by access to and utilization of different strategic resources- human (H5a confirmed: $0.249^{* * *}$ ) and financial resources ( $\mathrm{H} 5 \mathrm{~b}$ confirmed: $0.320^{* * *}$ ). Organizationally, the formation of tighter vertical relationships by producers with their trading partners (H8 confirmed: 0.091**) ensures the attainment of competitive advantage. This indicates that the highest influence on small-scale producers' shrimping performances ensue when producers can access and combine valuable and rare resources, and complemented by a positive performance effect when external contingencies are addressed with tighter vertical relationships. Overall, these endogenous constructs contribute $22.7 \%$ of the variance in producers' shrimping performances. No significant influence was found from horizontal and lateral relationships.

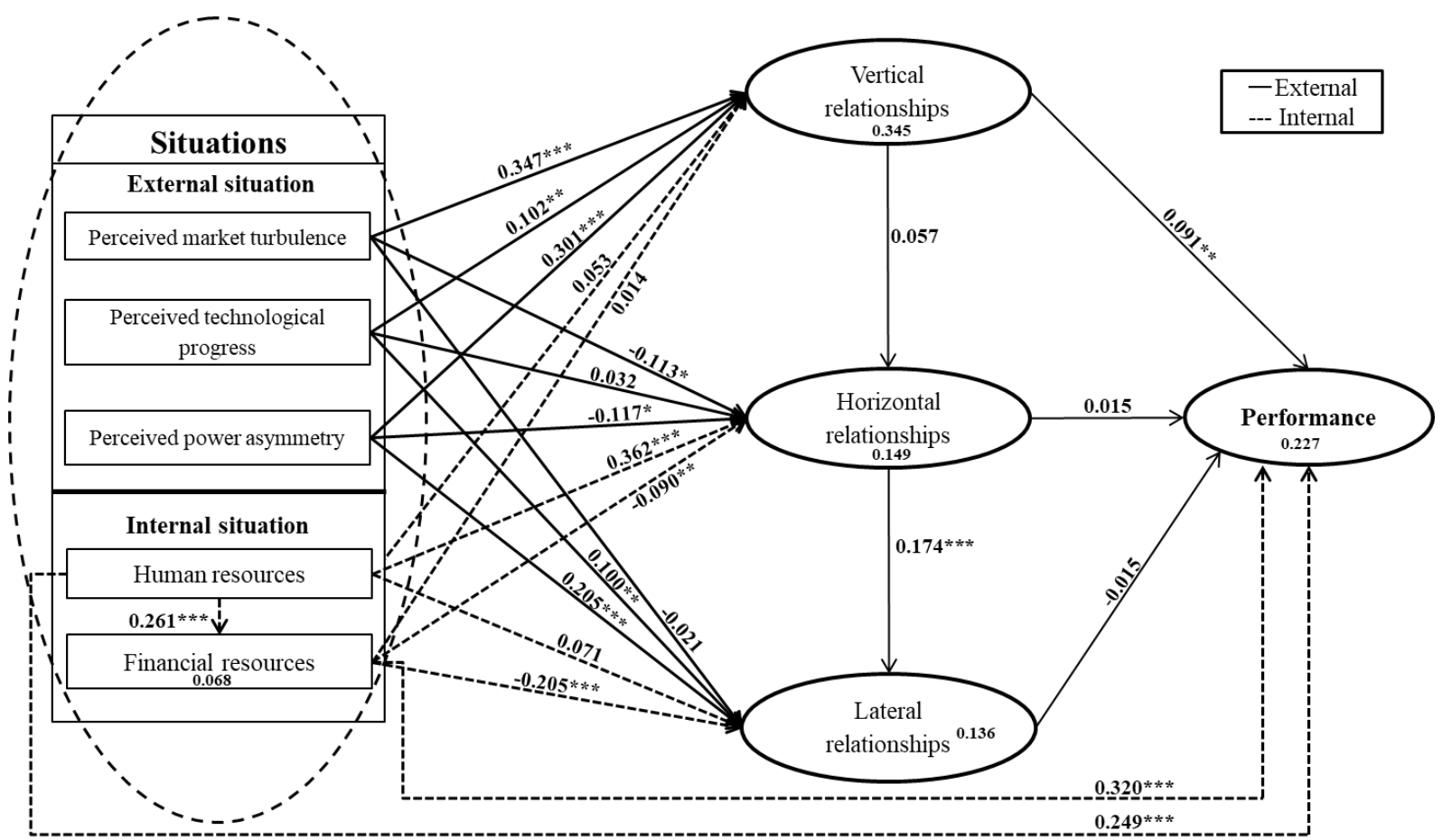

Figure 3.4: Producer model showing path coefficients

Source: Estimated from survey data. Significance level: $* * * \mathrm{P}<0.01 ; * * \mathrm{P}<0.05 ; * \mathrm{P}<0.1$. 


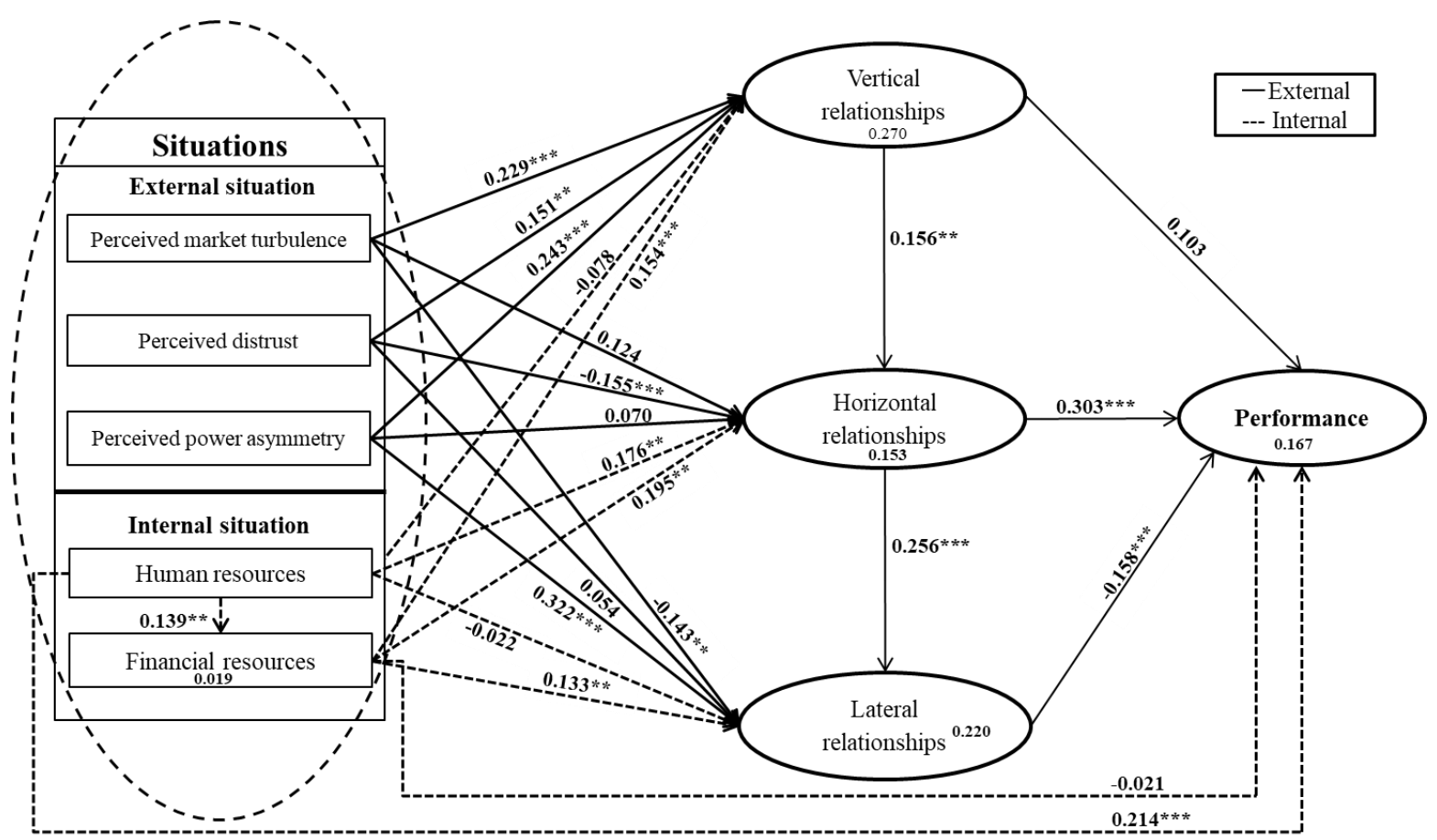

Figure 3.5: Processor model showing path coefficients

Source: Estimated from survey data. Significance level: ${ }^{* * *} \mathrm{P}<0.01 ; * * \mathrm{P}<0.05 ; * \mathrm{P}<0.1$.

\section{Hypothesis testing for processor tier}

According to the results from the processor model in Figure 3.5, external contingency factors have greater significant influence on processors' organizational SC network structures. Perceived market turbulence (H1a confirmed: $0.229 * *$ ), distrust (H2a confirmed: $0.151 * *$ ), power asymmetry (H3a confirmed: $0.243 * * *$ ) significantly increase the tightness of vertical relationships. While access to financial resources increases the tightness of vertical relationships (H1e confirmed: $0.154^{* * *}$ ) in this case, no significant influence was found from human resources. Additionally, perceived distrust $\left(\mathrm{H} 2 \mathrm{~b}^{2}:-0.155^{* *}\right)$ decreases the closeness of horizontal relationships while internal contingencies such as human (H2d confirmed: $\left.0.176^{* *}\right)$ and financial resources (H2e confirmed: $\left.0.195^{* *}\right)$ and tighter vertical relationships (H6 confirmed: 0.156**) increase its tightness. No significant influence was found from perceived market turbulence and power asymmetry on horizontal relationships. However, lateral relationships are found to be positively influenced by closer horizontal relationships (H7 confirmed: 0.256***), external contingencies such as perceived market turbulence (H3a: $-0.143 * *)$, power asymmetry $(\mathrm{H} 3 \mathrm{c}$ confirmed: $0.332 * * *)$ and internal contingencies such as financial resources (H3e confirmed: $\left.0.133^{* *}\right)$. Contingencies such as distrust and human resources do not significantly influence the formation of closer lateral relationships. Conversely, human resources (H4 confirmed: 0.139**) positively influence processors' access to and utilization of financial resources. 
Results from the structural model indicate that processors' processing performances are directly influenced by closer horizontal relationships (H9 confirmed: $0.303 * * *)$, lateral relationships (H10: $-0.158 * * *)$ and human resources (H5a confirmed: $0.214 * * *)$ whereas direct significant influence from vertical relationships and financial resources were not found. For the processors, the highest direct influence on processing performance is from closer horizontal relationships indicating the importance of organizational relationships in attaining competitive advantage. Overall, these endogenous constructs contribute $16.70 \%$ of the variance in performance ${ }^{11}$.

\subsection{Discussion}

\subsubsection{External contingencies and organizational SC network relationships}

The study examines how four external contingencies influence organizational SC network relationships and performance. The results offer several important theoretical implications, particularly regarding actors' contingency organizational adaptation process. Interestingly, our findings found that tighter vertical relationship is a critical factor for producers and processors to cope with all external contingencies. Such a result may be explained by the fact that external contingencies create different levels of operational uncertainties that require improved knowledge and information flow, by enhancing operational routine and coordination through tighter supplier-buyer relationships (Donaldson, 2001; Flynn et al., 2016). Furthermore, the influence of external contingencies on horizontal and lateral relationships are rather mixed across tiers but indicates the need for fit from both hierarchical coordination and network structures. A potential explanation for the mixed finding could be that the type, stability and significance of external contingencies differ across tiers, suggesting that smallholders would require different levels and types of organizational change to successfully cope with all external contingencies (Donaldson, 2001; Lawrence \& Lorsch, 1967; Zeithaml et al., 1988). Besides, market and technological turbulence, power asymmetry and distrust arise due to lack of information and unclear or ambiguous business environment (Flynn et al., 2016). Hence, smallholders would forge closer relationships with competitors and extension agents to earn better knowledge and information, and innovative support needed to successfully cope with these external contingencies. Surprisingly, we found a loose effect of market turbulence on horizontal relationships in the producer model. Such a result can be intuitively explained by the fact that better-informed producers are rationally bound from sharing input and output market information with their

\footnotetext{
${ }^{11}$ Same logical thoughts were found when models were tested for each state, and business owners and shrimpers.
} 
competitors in highly turbulent markets. Also, shrimp stocks are "common goods" which further exacerbate competition among fisher folks in the presence of fluctuating supply and demand. This forces individuals to take faster actions than rivals and avoid information sharing to maximize individual capture and sales (Arora et al., 2016; Wang et al., 2015). In both producer and processor models, power asymmetry tends to lead to closer lateral relationships while market turbulence results in loose lateral relationships. The findings that power asymmetry and distrust lead to loose horizontal but tighter lateral relationships in the processor model is surprising but confirms what Otter et al., (2014) also found. Processors facing high distrust could manage dependency and obtain better information to overcome the contingency by forging tighter vertical interactions with traders and closer relationships with extension agents (Flynn et al., 2016; Kwon $\&$ Suh, 2004). Such an organizational adaptation strategy would also reposition both producers' and processors' bargaining situations by facilitating informal supplier-buyer interactions and build their negotiating power and security through supports from extension agents and NGOs (Otter et al., 2014). Intrinsically, cooperative groups and relationships with extension agents and NGOs allow for efficient knowledge and information exchanges and decentralized decisions for innovation, making them complementary to supplier-buyer relationships in dealing with unstable external contingencies (Donaldson, 2001). Although different predominant external contingencies were considered across tiers, the results highlight that their influence on organizational structures follows the same contingency logic.

\subsubsection{Internal contingencies and organizational SC network relationships}

In line with our hypotheses, we found a direct influence of smallholders' resources on organizational SC network structures. Both human and financial resources resulted in closer organizational SC network structures for processors; for producers, human resources only tighten horizontal relationships while financial resources loosen horizontal and lateral relationships. The levels of financial capital among producers are generally low hence, those with higher financial capital will tend to forge effective organizational strategies that maximize their resource-based values (Wang et al., 2015). Similarly, financial resources loaded by credit access in the processor model involve some levels of covariant risk and information asymmetry, which processors may overcome by pursuing more prudent managerial and organizational strategies. These results support the contingent RBT proponent in that firms' external contingencies and resource-base 
truly matter for the formation of closer organizational SC network structures (Brush \& Artz, 1999).

Furthermore, we found that both human and financial resources are crucial in fostering firms' performance directly in the producer model. Surprisingly, only human resources significantly improve performance in the processor model. This is probably because available credit facilities are costly (interest rates $>10 \%$ ) and processors' investment intensity is lower making credit less valuable for improving processors' margins. Hence, credit access in the processor model may not have fulfilled the VRI conditions of "firm resources" as suggested by RBT (Grant, 1991; Wernerfelt, 1984). Confirming our hypothesis, we found that smallholders with huge resourcebase tend to improve performance by leveraging through their organizational SC network structures, such as horizontal relationships (Verhofstadt \& Maertens, 2014). For example, experienced, older smallholders tend to rely on and forge longer collaborative relationships that enhance their knowledge and information and improve their chances of competitive advantage (Wang et al., 2015).

\subsubsection{Influence among different organizational SC network relationships}

Confirming the netchain proposition, we found that there is influence among the different relationships within organizational SC network structures (Lazzarini et al., 2001). Against what Otter et al., (2014) found, our PLS-estimations suggest that tighter vertical relationships foster closer horizontal relationships in the Nigerian local food system, although no significant influence was found in the producer model. There are several reasons for this result stemming from dynamic organizational and institutional peculiarities of the Nigerian cases. First, fisher folks operate in unregulated and informal markets with relatively lower bargaining power, which buyers generally seek to take advantage of. Hence, fisher folks tend to rely on information and support from cooperative groups to counter bargaining power of influential buyers (Barrett et al., 2012; Verhofstadt \& Maertens, 2014). Second, fisher folks located in isolated coastal areas face high spatial market price differentials, which they overcome by leveraging on economies of scale and positive network externalities of cooperative groups to pool inputs and coordinate shrimping and marketing activities at lower transaction costs (Udong et al., 2010). Third, social ties intensify market information exchange which fisher folks use to complement tighter vertical relationships in overcoming uncertainties from changing market and technological uncertainties (Lazzarini et al., 2001). Fourth, fisher groups allow for collective learning and joint decision- 
making which are crucial for perfecting shrimping routines to effectively utilize available human and financial resources and optimize performance (Grant, 1991). Committed smallholders that are mutually-dependent on buyers tend to reduce associated risks and transaction costs by attaining more market information through collective actions (Fischer \& Qaim, 2012). Furthermore, the significant positive influence of closer horizontal relationships on lateral relationships suggests that smallholders forge horizontal relationships to facilitate more visits by extension agents and NGOs who serve as a medium for them to pass their grievances to the government (Otter et al., 2014). This also confirms the interdependency of different organizatzional relationships (Lazzarini et al., 2001), highlighting the organizational adaptation pathway through which smallholders can cope with changing contingencies (Donaldson, 2001).

\subsubsection{Organizational relationships and performance of mutually-dependent producers and processors}

We found that tighter vertical relationships positively influence producers' shrimping performance, indicating that the contingency theory holds such that there is a fit between the contingencies and the organization variable (Donaldson, 2001; Lawrence \& Lorsch, 1967). This means that the greater degree of "relational governance" between producers and processors fits well with predominant external and internal contingencies in the production segment. The "relational governance" fosters better exchange of implicit product information and consequently allows for effective coordination of producer-processor activities at lower costs. Although the influence is relatively small, the result confirms the effectiveness of tighter supplier-buyer relationships in fitting producers' contingencies and improving performance (Dries et al., 2014; Leuschner et al., 2013). This finding further justifies our rationale for multi-tier analysis that includes the processing tier (Mena et al., 2013).

In the processor model, financial performance is positively influenced by closer horizontal relationships, through processing groups. Consistent with contingency theory, the intermediation of processing groups fits well with processors' contingencies such as turbulent market, power inequality, distrust and resources (section 3.0) and is thus, crucial in improving margins (Mesquita \& Lazzarini, 2008; Otter et al., 2014; Verhofstadt \& Maertens, 2014). The insignificant effect of producers' horizontal relationships on performance might be due to a contingency misfit in which fisher groups are only "production-oriented" and rather than being also "market-oriented". 
Quite surprisingly and contrary to our hypothesis (Figure 3.2 and Figure 3.3), producers' and processors' lateral relationships with external actors are rather ineffective in improving smallholders' performances. Findings in existing literature have been rather mixed for different plausible reasons (Otter et al., 2014; Wang et al., 2015). In line with the contingency theory, this suggests that there is a misfit between fisher folks' external contingency levels and the lateral relationships, resulting in low performance (Donaldson, 2001). Extension agents and public agencies in many African agrifood systems often face several institutional challenges such as inconsistent financial support and training that limit their capacity to support smallholders (Emmanuel et al., 2016). A misfit between smallholders' contingencies and lateral relationships could erupt from these challenges since they inhibit the overall innovation process and knowledge exchanges needed to support smallholders' organizational adaptation process. It is also plausible that the opportunity costs of time spent by smallholders in relating to external actors outweigh associated benefits, especially since fisher folks face high market turbulence that spur competition. This could cause misfit and lower smallholders' performance, particularly their supply, demand and margins which are the dependent variables in this study.

\subsection{Conclusions and implications}

The need to further understand the influence of external and internal contingencies on organizational SC network structures and performance requires a comprehensive framework and analysis. This study presents the "Contingency-Netchain-Performance" (CNP) framework developed from the conceptual integration of contingent RBT (Brush \& Artz, 1999) and the netchain approach (Lazzarini et al., 2001) to comprehensively capture influences between predominant SC contingencies, organizational network structures across multi-tiers and performance.

The empirical application of the CNP framework on large samples of smallholder producers and processors in the Nigerian shrimp and prawn sector indicates its applicability in the context of highly dynamic agrifood systems of a developing country. The research models explain $22.7 \%$ and $16.7 \%$ of the variance of producers' and processors' performance, which is an improvement to the existing study by Otter et al., (2014). We found strong influences from external contingencies on complex organizational SC network structures, in which smallholders tend to forge closer hierarchical coordination and network relationships to cope with their contingencies (Donaldson, 2001). This confirms the contingency paradigm of fit among small-scale producers 
and processors in which they have several organizational adaptation strategies that cut across multi-tiers to deal with their highly dynamic contingencies. Furthermore, the simultaneous integration of smallholders' resource-base (Barney, 2001; Grant, 1991; Wernerfelt, 1984) as internal contingency that influences SC organizational network (Lazzarini et al., 2001) to adapt and fit (Donaldson, 2001; Lawrence \& Lorsch, 1967) and maximize resource-based performances, represents one of the main findings in this study.

The result supports RBT proponent and suggests that the utilization of strategic productive resources under fitting organizational SC network structures are crucial for small-scale producers and processors to attain and sustain competitive advantage (Otter et al., 2014). Additionally, the dawning step to understanding the association among the different organizational relationships, provides evidence that smallholders in developing countries' agrifood systems are responsive and shifting towards complex network structures to fit changing market turbulence, technological progress, power imbalance and distrust (Barrett et al., 2012; Reardon, 2015). Several implications emerged from these results and are addressed to researchers, practitioners, and policymakers involved in developing interventions for the improvement of performances within dynamic industries.

The CNP framework developed in this study offers a valid and richer explanation of the associations among the different constructs thus, it might be important for future applications in comparable industries like textile and retailing industries with dynamic external and internal contingencies, where actors continuously adapt organizational structures to fit and maximize performance. Instead of defining external and internal contingencies as moderator/mediator variables (Arora et al., 2016; Brandon-Jones et al., 2014; De Clercq et al., 2016; Wang et al., 2015), the CNP framework suggests direct link to organizational SC networks (Donaldson, 2001). With this, the empirical model may offer comprehensive results regarding the direct influence of both contingencies on organizational adaptation process. Since smallholders now forge complex network structures, the research framework may further provide a nascent and flexible basis to simultaneously test the influence of different levels of organizational structure variables on smallholders' performance.

Policymakers should focus on stimulating producers and processors to forge tighter informal vertical relationships among themselves as they create best fit for producers' contingencies through synchronization of production and marketing activities. "Relational governance" 
between producers and processors tends to provide effective coordination and information exchanges to deal with some contingencies, however, not enough for certain contingencies such as technological progress and power imbalance which require that both actors form closer complementary relationships with their competitors, extension agents and NGOs. Policymakers and NGOs should, therefore, attach greater importance to organize producers and processors into cooperative groups to ensure joint learning, and effective dissemination of information to fisher folks (Otter et al., 2014). Particularly, processors should simultaneously be encouraged to forge closer horizontal relationships to improve their capabilities and market performance as well as that of producers (Dries et al., 2014; FAO, 2017b; Leuschner et al., 2013; Otter et al., 2014).

Also, policymakers and NGOs would need to provide producers and processors with necessary productive resources such as capital and training to improve the competitiveness of fisher folks in Nigeria. Even though credit access is generally seen by researchers and policymakers as strategic for smallholders, our research findings suggest that the stringent and unfavorable repayment conditions attached to both formal and informal credit access and use in developing countries are too costly (Reardon, 2015; Udong et al., 2010). While the role of external actors to support smallholders has been highlighted, the negative effects of lateral relationships suggest that external actors are inefficient in upgrading smallholders' activities to improve performance. Public policymakers should, therefore, take the results as new proofs that public institutions still need institutional overhaul and resetting (Emmanuel et al., 2016).

The scope of this study could have been limited by its reliance on perceived assessment of concepts thus; future studies can obtain real-time data to make an objective assessment of the concepts. Although the CNP framework was successfully developed and tested, explanatory power of performance captured by $\mathrm{R}^{2}$-values is still relatively low based on Hair et al., (2018). Future studies should further develop the framework by considering intangible resources such as capabilities to find out if intangible resources lead to organizational adaptation and consequently better performance. Also, to capture different institutional settings across sectors and countries, the framework can be applied to other sectors and industrialized countries characterized by different levels of contingency dynamism and types of internal and external contingencies such as labor constraints, and more formalized value chains. The organizational structures in this framework can be further extended to include both supporting and pressuring stakeholders, to 
examine the simultaneous influence on each other and different performance measures such as food quality and sustainability.

To understand whether organizational strategies in one tier simultaneously influence organizational decisions in subsequent SC tiers, multi-tier SC management theory (Mena et al., 2013) can be integrated into the CNP framework to link and simultaneously test mutually dependent tiers, using for instance simulation modeling. Lastly, PLS-SEM applied in this study cannot adequately control for the endogenous influence of internal contingencies on performance. Thus, the associations between contingencies, organizational structures and performance should be further investigated using different research methods such as AMOS and LISREL and other statistically stringent approaches.

\section{Appendix 3}

Table A3.1: Reliability and discriminant validity for the producer model

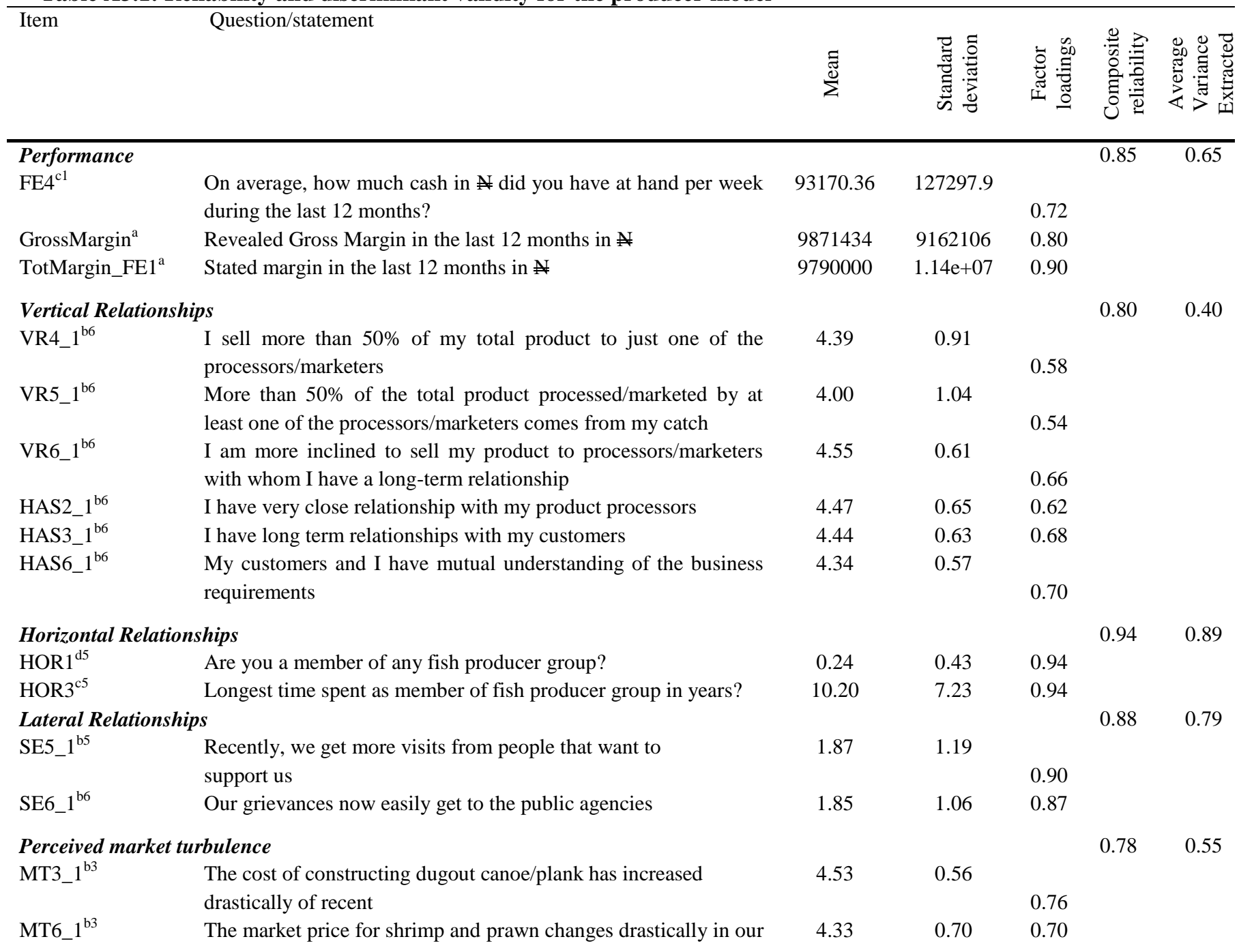




\begin{tabular}{|c|c|c|c|c|c|c|}
\hline \multicolumn{7}{|c|}{ sector } \\
\hline MT7_1 $1^{\mathrm{b} 3}$ & Cost of fuel has been unstable of recent & 3.70 & 1.20 & 0.76 & & \\
\hline \multicolumn{5}{|c|}{ Perceived technological advancement } & 0.84 & 0.51 \\
\hline \multicolumn{4}{|c|}{$\begin{array}{l}\text { ASS1_1 } 1^{\text {b6 }} \begin{array}{l}\text { Shrimpers now need outboard engine before they can shrimp at } \\
\text { the high-sea }\end{array}\end{array}$} & 0.80 & & \\
\hline ASS2_1 $1^{\mathrm{b} 6}$ & Shrimpers now need outboard engine to quickly land catches & 4.66 & 0.54 & 0.67 & & \\
\hline TA1_1 ${ }^{\mathrm{b} 2}$ & $\begin{array}{l}\text { Recently, outboard engine has become more important for } \\
\text { shrimping in our industry }\end{array}$ & 4.67 & 0.55 & 0.80 & & \\
\hline TA2_1 $1^{\mathrm{b} 6}$ & $\begin{array}{l}\text { To catch large quantities of shrimp and prawn, I now need to use } \\
\text { outboard engines }\end{array}$ & 4.61 & 0.59 & 0.73 & & \\
\hline TA3_1 $1^{\mathrm{b} 2}$ & $\begin{array}{l}\text { There are higher outboard engine capacities compared to the } \\
\text { one am using now }\end{array}$ & 4.55 & 0.65 & 0.52 & & \\
\hline \multicolumn{4}{|c|}{ Perceived power asymmetry } & & 0.87 & 0.57 \\
\hline PA1_1 $1^{\text {b5 }}$ & $\begin{array}{l}\text { Certain shrimpers often supply the largest quantity of products } \\
\text { to the market }\end{array}$ & 4.24 & 0.83 & 0.82 & & \\
\hline \multirow{2}{*}{$\begin{array}{l}\text { PA2_1 } 1^{\text {b5 }} \\
\text { PA3_1 } 1^{\text {b5 }}\end{array}$} & Certain producers have very high reputation in our industry & 4.24 & 0.78 & 0.65 & & \\
\hline & $\begin{array}{l}\text { Certain producers are more knowledgeable about the business in } \\
\text { our industry }\end{array}$ & 4.34 & 0.72 & 0.76 & & \\
\hline PA4_1 $1^{\mathrm{b} 6}$ & $\begin{array}{l}\text { Certain processors/marketers understand the business inter- } \\
\text { relationship with producers more }\end{array}$ & 4.24 & 0.67 & 0.77 & & \\
\hline PA6_1 ${ }^{\mathrm{b} 5}$ & $\begin{array}{l}\text { Certain processors/marketers can attract more buyers than } \\
\text { others }\end{array}$ & 4.20 & 0.74 & 0.77 & & \\
\hline \multicolumn{2}{|l|}{ Human Resources } & & & & 0.82 & 0.61 \\
\hline $\mathrm{AGE}^{\mathrm{d} 4}$ & Age of respondent (in years)? & 39.00 & 11.25 & 0.77 & & \\
\hline EMPFISH $^{\mathrm{d} 4}$ & Did you employ other fishers in the last 12 months? & 0.60 & 0.49 & 0.76 & & \\
\hline SHRIMPYEAR $^{\mathrm{c} 4}$ & How many years has respondent been shrimping? & 16.41 & 10.84 & 0.81 & & \\
\hline \multicolumn{2}{|c|}{ Financial Resources } & & & & 1.00 & 1.00 \\
\hline CAPITAL $^{\mathrm{c} 4}$ & What was the start-up capital before the start of the season? & 153343.20 & 166074.40 & 1.00 & & \\
\hline
\end{tabular}

Source: Own elaboration based on PLS-estimations

Note: ${ }^{\mathrm{a} C a l c u l a t e d}$ from direct measures; ${ }^{\mathrm{b}}$ Statements scaled from $1=$ strongly disagree to $5=$ strongly agree; ${ }^{\mathrm{c}}$ Continuous; ${ }^{\mathrm{d}} \mathrm{Dummy}$.

Based on ${ }^{1}$ (Aramyan et al., 2007); ${ }^{2}$ (Autry et al., 2010); ${ }^{3}$ (De Clercq et al., 2016); ${ }^{4}$ (Grant, 1991); ${ }^{5}$ (Otter et al., 2014); ${ }^{6}$ (Pre-study)

Table A3.2: Reliability and discriminant validity for the processor model

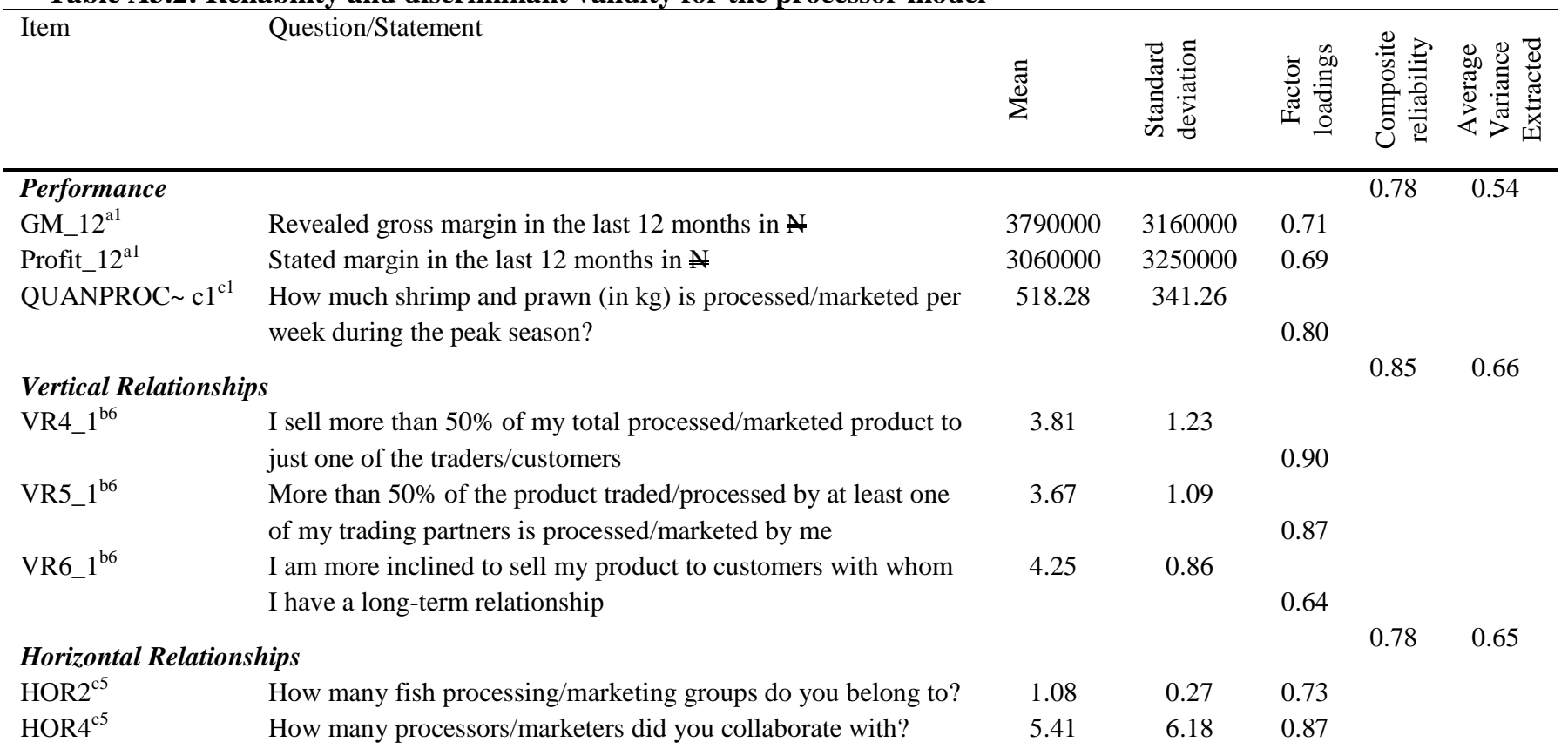


Lateral Relationships

SE5_1 $1^{\mathrm{b}}$

SE6_1 $1^{\text {b6 }}$

Recently, we get more visits from people who want to support us

Our grievances now easily get to the public agencies

\section{Perceived market turbulence}

MT1_1 ${ }^{\mathrm{b} 3}$

Sometimes our customer's demand increases

unpredictably in our market

MT5_1 $1^{\mathrm{b} 3}$

MT6_1 $1^{\mathrm{b} 3}$

Our competitors in nearby villages do reduce the price

of their product to attract our customers

The market price for "crayfish" drastically changes in our sector

Perceived distrust

T3_1 ${ }^{\text {b5 }}$

T6_1 $1^{\mathrm{b} 5}$

People who buy shrimp and prawn from me do not trust the product information I provide them

People who buy shrimp and prawn from me believe I do cheat them

\section{Perceived power asymmetry}

PA1_1 ${ }^{\text {b5 }}$

PA3_1 $1^{\mathrm{b} 5}$

PA4_1 $1^{\text {b5 }}$

PA10_1 $1^{\text {b5 }}$

\section{Human Resources}

$\mathrm{AGE}^{\mathrm{c} 4}$

EMPPROCESS $^{\mathrm{d} 4}$

PROCESSYEAR ${ }^{\mathrm{c} 4}$
Certain processors/marketers often sell the largest quantity of shrimp and prawn in our market

Certain processors/marketers are more knowledgeable about the business of processing and marketing in my area

Certain processors/marketers understand the business organizational relationship with producers better than others

To me, customers who buy shrimp and prawn from me are more influential along the supply chain than me

What is respondent's age (in years)?

Did you employ other processors in the last 12 months?

How many years has respondent been processing/marketing shrimp and prawn?
0.88

$\begin{array}{lll}1.69 & 1.05 & \\ & & 0.92 \\ 1.82 & 0.96 & 0.86\end{array}$

1.82

0.86

0.81

$4.25 \quad 0.78$

$3.37 \quad 1.28$

$4.21 \quad 0.78$

0.77

0.75

0.60

$2.91 \quad 1.18$

$2.93 \quad 1.24$

0.70

0.82

$4.19 \quad 0.82$

0.69

$4.25 \quad 0.73$

0.73

$4.22 \quad 0.58$

0.79

$\begin{array}{lll}3.52 & 1.01 \quad 0.70\end{array}$

$0.78 \quad 0.55$

$\begin{array}{lll}39.96 & 10.81 & 0.84\end{array}$

$\begin{array}{lll}0.65 & 0.48 & 0.50\end{array}$

$\begin{array}{lll}15.12 & 9.74 & 0.85\end{array}$

Financial Resources CREDIT $^{\mathrm{d} 4}$ Could you obtain credit if you needed it?

0.24

0.43 1.00

Source: Own elaboration based on PLS-estimations

Note: ${ }^{\mathrm{a} C a l c u l a t e d}$ from direct measures; ${ }^{\mathrm{b}}$ Statements scaled from $1=$ strongly disagree to 5 strongly agree; ${ }^{\mathrm{c}}$ Ratio; ${ }^{\mathrm{d}} \mathrm{Dummy}$.

Based on ${ }^{1}$ (Aramyan et al., 2007); ${ }^{2}$ (Autry et al., 2010); ${ }^{3}$ (De Clercq et al., 2016); ${ }^{4}$ (Grant, 1991); ${ }^{5}$ (Otter et al., 2014); ${ }^{6}$ (Pre-study)

Table A3.3: Summary of the reflective measurement models

\begin{tabular}{|c|c|c|c|c|c|}
\hline $\begin{array}{c}\text { Reflective } \\
\text { measurement models }\end{array}$ & $\begin{array}{l}\text { Item loadings } \\
\text { and signs }\end{array}$ & $\begin{array}{l}\text { Composite } \\
\text { reliability }\end{array}$ & $\begin{array}{l}\text { Average Variance } \\
\text { Extracted (AVE) }\end{array}$ & $\begin{array}{c}\text { Fornell-Larcker } \\
\text { criterion }\end{array}$ & HTMT \\
\hline Producer model & Passed & Passed & $\begin{array}{c}\text { Passed, except } \\
\text { vertical relationships }\end{array}$ & Passed & Passed \\
\hline Processor model & Passed & Passed & Passed & Passed & Passed \\
\hline
\end{tabular}

Source: Own elaboration based on PLS-estimations

Table A3.4: Inter-construct correlations for the producer model

\begin{tabular}{|c|c|c|c|c|c|c|c|c|c|}
\hline & 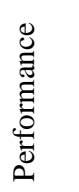 & 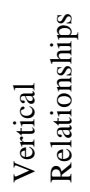 & 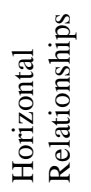 & 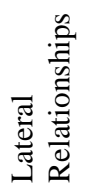 & 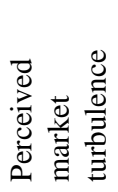 & 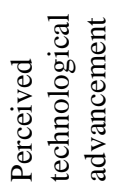 & 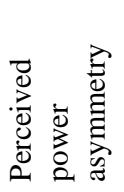 & 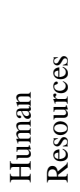 & 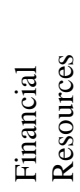 \\
\hline Market Performance & 0.81 & & & & & & & & \\
\hline Vertical Relationships & 0.14 & 0.63 & & & & & & & \\
\hline Horizontal Relationships & 0.09 & -0.02 & 0.94 & & & & & & \\
\hline
\end{tabular}


Lateral Relationships

Perceived market turbulence

Perceived technological advancement

Perceived power asymmetry

Human Resources

Financial Resources

$\begin{array}{cc}-0.03 & 0.13 \\ 0.13 & 0.47 \\ 0.01 & 0.35 \\ 0.03 & 0.47 \\ 0.34 & 0.08\end{array}$

0.18

$-0.12$

$-0.02$

$-0.11$

0.34

0.40

$-0.02$

0.89
0.02
0.21
0.21
0.09
-0.17

0.74

0.24

0.31

0.03

0.12

0.55

0.07

0.00

0.76

$0.02 \quad 0.78$

$0.12 \quad 0.26$ 1.00

Table A3.5: Inter-construct correlations for the processor model

\begin{tabular}{|c|c|c|c|c|c|c|c|c|c|}
\hline & 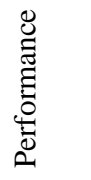 & 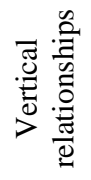 & 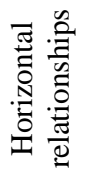 & 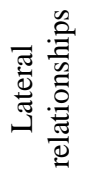 & 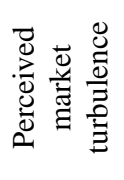 & 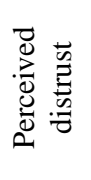 & 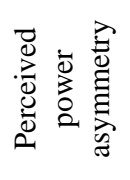 & 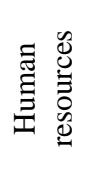 & 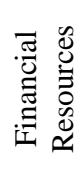 \\
\hline Market Performance & 0.73 & & & & & & & & \\
\hline Vertical relationships & 0.13 & 0.81 & & & & & & & \\
\hline Horizontal relationships & 0.31 & 0.22 & 0.8 & & & & & & \\
\hline Lateral relationships & -0.04 & 0.17 & 0.32 & 0.89 & & & & & \\
\hline Perceived market turbulence & 0.24 & 0.4 & 0.17 & 0.08 & 0.77 & & & & \\
\hline Perceived distrust & 0.00 & 0.3 & -0.02 & 0.09 & 0.34 & 0.78 & & & \\
\hline Perceived power asymmetry & 0.09 & 0.41 & 0.19 & 0.34 & 0.49 & 0.21 & 0.73 & & \\
\hline Human resources & 0.26 & -0.05 & 0.2 & 0.06 & 0.00 & 0.01 & 0.03 & 0.74 & \\
\hline Financial Resources & 0.06 & 0.2 & 0.24 & 0.25 & -0.01 & 0.13 & 0.14 & 0.14 & 1.00 \\
\hline
\end{tabular}

Source: Own elaboration based on PLS-estimations

Table A3.6: HTMT values for producer and processor models

\begin{tabular}{|c|c|c|c|c|c|c|c|c|c|}
\hline & 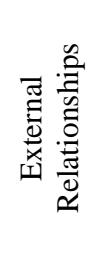 & 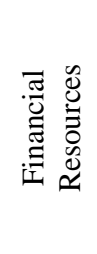 & 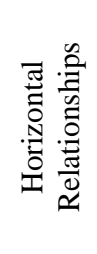 & 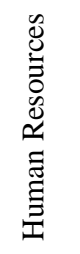 & 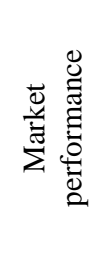 & 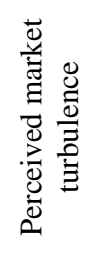 & 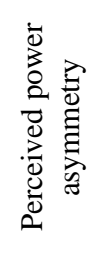 & 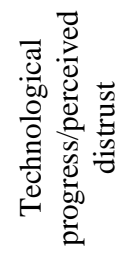 & 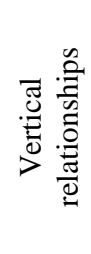 \\
\hline \multicolumn{10}{|l|}{ Producer model } \\
\hline External Relationships & 0.00 & & & & & & & & \\
\hline Financial Resources & 0.19 & & & & & & & & \\
\hline Horizontal Relationships & 0.22 & 0.02 & & & & & & & \\
\hline Human Resources & 0.15 & 0.29 & 0.45 & & & & & & \\
\hline Market performance & 0.08 & 0.46 & 0.11 & 0.44 & & & & & \\
\hline Perceived market turbulence & 0.08 & 0.15 & 0.16 & 0.15 & 0.22 & & & & \\
\hline Perceived power asymmetry & 0.26 & 0.14 & 0.14 & 0.14 & 0.07 & 0.48 & & & \\
\hline Technological progress & 0.26 & 0.05 & 0.07 & 0.15 & 0.08 & 0.40 & 0.78 & & \\
\hline Vertical relationships & 0.17 & 0.15 & 0.09 & 0.18 & 0.22 & 0.70 & 0.58 & 0.47 & 0.00 \\
\hline \multicolumn{10}{|l|}{ Processor model } \\
\hline External Relationships & 0.00 & & & & & & & & \\
\hline Financial Resources & 0.29 & & & & & & & & \\
\hline Horizontal Relationships & 0.53 & 0.34 & & & & & & & \\
\hline Human Resources & 0.13 & 0.18 & 0.40 & & & & & & \\
\hline Market performance & 0.13 & 0.08 & 0.62 & 0.45 & & & & & \\
\hline Perceived market turbulence & 0.17 & 0.23 & 0.21 & 0.14 & 0.11 & & & & \\
\hline Perceived power asymmetry & 0.17 & 0.10 & 0.34 & 0.16 & 0.37 & 0.71 & & & \\
\hline Perceived distrust & 0.46 & 0.15 & 0.31 & 0.15 & 0.14 & 0.50 & 0.71 & & \\
\hline Vertical relationships & 0.23 & 0.21 & 0.31 & 0.18 & 0.20 & 0.57 & 0.54 & 0.57 & 0.00 \\
\hline
\end{tabular}

Source: Own elaboration based on PLS-estimations 


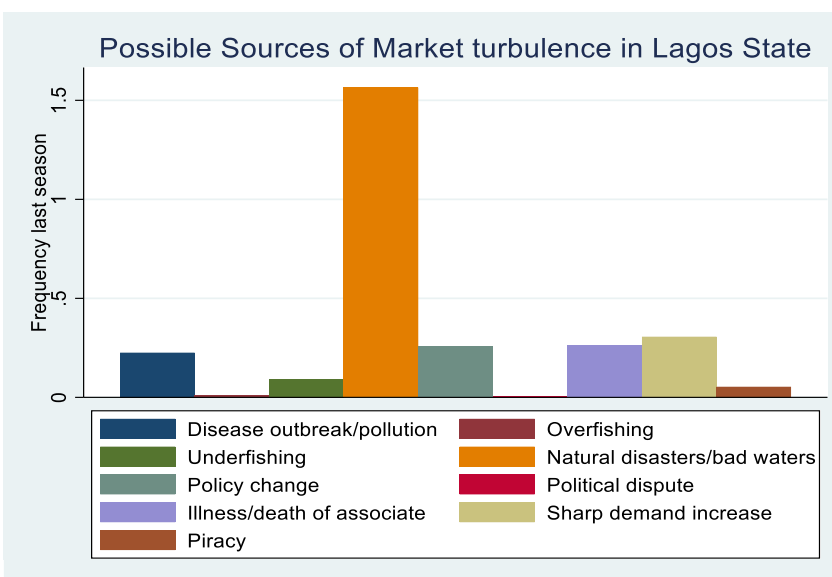

Possible Sources of Market turbulence in Ondo State

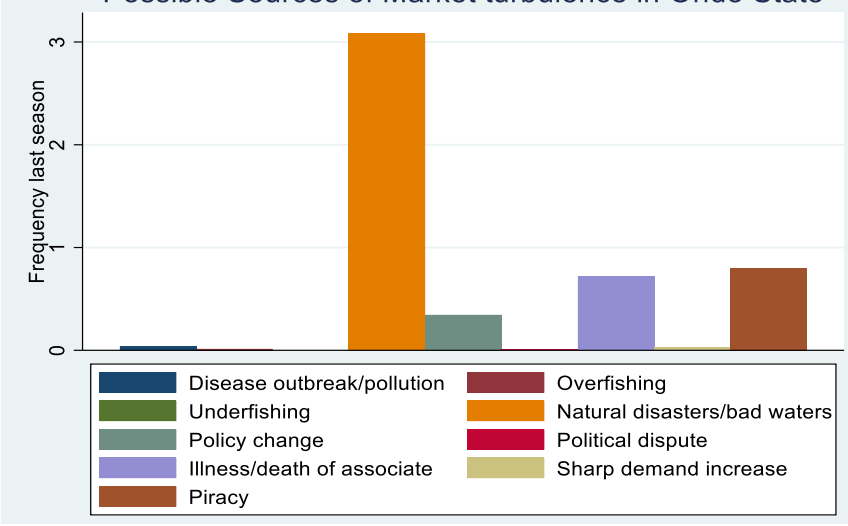

Possible Sources of Market turbulence in Akwa-lbom State

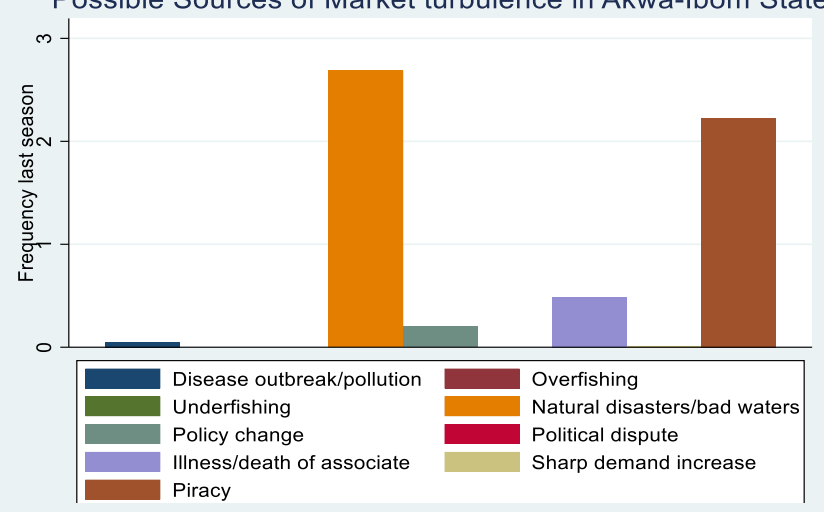

Type of information from external actors

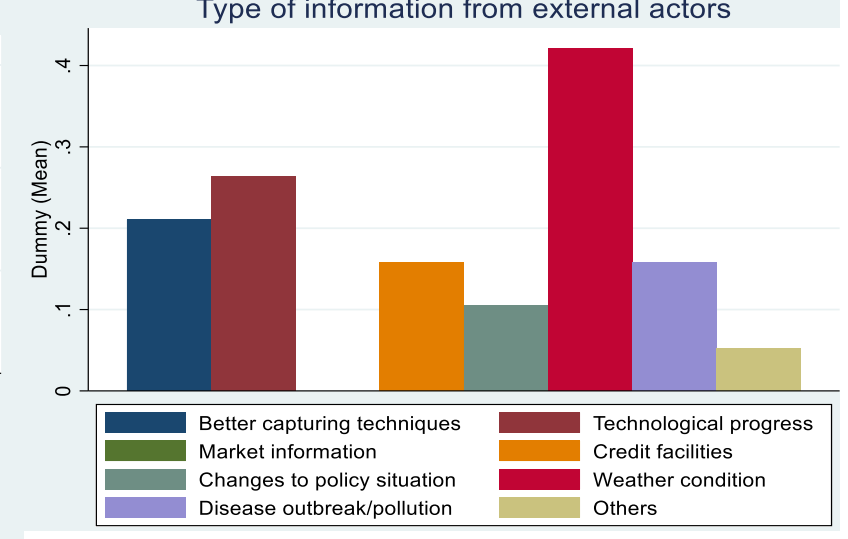

Figure A3.1: Sources of market turbulence and type of information from external actors 


\title{
4 Can producer groups improve technical efficiency among artisanal shrimpers in Nigeria? A study accounting for observed and unobserved selectivity ${ }^{*}$
}

\begin{abstract}
Over the last two decades, scholars and governments in developing countries have widely recognized the formation of producer groups as a valuable institutional arrangement for smallholders to deal with complex production and marketing constraints and dynamic business environments. With scarce evidence from fishery subsectors and self-selection into producer groups, we examine the selectivity-corrected role of fisher groups in improving shrimpers' capture and technical efficiency, using recent survey data from artisanal shrimpers in Nigeria. We apply Greene's (2010) stochastic production frontier model and propensity score matching to account for selection bias from both observable and unobservable factors. The empirical results reveal that technical efficiency scores remain consistently higher for members regardless of how biases were corrected. Although technical efficiency scores for members and nonmembers tend to be overestimated if selectivity is not appropriately controlled, our findings suggest that participation in fisher groups is positively related to increases in capture and technical efficiency.
\end{abstract}

Keywords: Technical efficiency, Greene's Stochastic Production Frontier, Propensity Score Matching, Selection bias, Nigerian fisher group

JEL codes: C21, D24, O12, Q13 Q22

\footnotetext{
*This chapter is co-authored with Dr. Verena Otter. The authors' contributions are as follows: Ayobami Adetoyinbo (AA) conceptualized, designed the research and collected the data. AA analyzed and interpreted the data. VO assisted in the interpretation of the results. AA wrote the paper. VO commented at various stages of the research and revising of the paper.

Acknowledgments: The authors are grateful to the German Research Foundation (DFG) for providing financial support to this research through the GlobalFood Research Training Group (GRK 1666). We are also grateful to Dr. Awal Abdul-Rahaman for sharing his code for this model.
} 


\subsection{Introduction}

Over the last two decades, smallholders in developing countries have increasingly faced significant transactional and contingency challenges in food supply chains due to complex production and marketing constraints and changes in economic, financial, environmental and sociopolitical structures (Chagwiza et al., 2016; Ma \& Abdulai, 2016; Orsi et al., 2017). The formation of producer groups/cooperatives is widely viewed as a valuable institutional arrangement for smallholders to cope with or overcome such production and market inefficiencies (Bernard \& Spielman, 2009; Markelova et al., 2009; Markelova \& Mwangi, 2010; Verhofstadt \& Maertens, 2014). This is grounded in the growing scientific evidence that producer groups have positive effects on smallholder's economic performance and welfare (Ainembabazi et al., 2017; Chagwiza et al., 2016; Fischer \& Qaim, 2012; Mojo et al., 2017; Ochieng et al., 2018; Verhofstadt \& Maertens, 2014). Smallholders that act collectively can reduce the transaction costs of accessing input and output markets and technologies, mitigate entry barriers to high-value markets, enhance their negotiating and marketing power, and obtain necessary market information (Markelova et al., 2009).

Despite several empirical studies promoting collective action among smallholders, only a few studies have empirically investigated the productivity and technical effectiveness of producer groups. It remains unclear if smallholders can channel these advantages to improve their immediate production and technical abilities, which are the keystones for several other aspects of economic performance. Furthermore, producer groups have also been documented to have insignificant and negative effects in other studies (Bernard \& Taffesse, 2012; Bernard et al., 2008; Chagwiza et al., 2016; Fischer \& Qaim, 2012; Hellin et al., 2009). The mixed findings are attributable to producer groups' heterogeneity, as well as biased and inconsistent estimations as a result of selectivity. Concerns over selectivity have been stressed in productivity and empirical economics literature over the last two decades (Greene, 2010). However, many studies ${ }^{12}$ published on productivity and efficiency neglect selection bias (Abate et al., 2014; Gedara et al., 2012; Hailu et al., 2015). Only Abdul-Rahaman and Abdulai (2018) and Ma and colleagues (2018) have applied this approach in the context of group membership effects on productivity and efficiency in farm-based subsectors. Empirical evidence on the effect of group membership in

\footnotetext{
${ }^{12}$ Other studies account for selection bias by employing propensity score matching (PSM) and counterfactual endogenous switching regression (ESR) methods. However, solely using these approaches is marred by their inability to capture unobservable characteristics and produce consistent estimates due to misspecifications of the error term (Alene \& Manyong, 2007; Ma \& Abdulai, 2016).
} 
nonfarm-based subsectors is relatively scarce, particularly in the fishing subsector. Until now, the proportion of fishing households in formal producer groups remains relatively low, while artisanal fishers remain one of the most socially disadvantaged within African's agricultural sector (FAO, 2007). Consequently, most African fishery subsectors become relatively underdeveloped and non-commercialized, finding it hard to connect with profitable, high-value markets (Kobayashi et al., 2015). So far, little is known about the role of fisher group membership in improving the technical abilities and economic performance of artisanal fishers.

On this account, the objective of this study is to examine the selectivity-corrected role of fisher groups on the capture and technical efficiency (TE) of artisanal shrimpers in Africa. This article contributes in two ways to the literature: First, we estimate an unbiased effect of group membership on the capture and TE of artisanal fishers using an approach that combines Greene's (2010) stochastic production frontier (SPF) method and propensity score matching (PSM) to correct for selection bias. This method allows us to account for: (i) different technological sets for members and nonmembers; and (ii) sample selection bias from observed and unobserved factors. Consequently, unbiased TE and technical change effects attributable to group membership are estimated (Bravo-Ureta et al., 2012). Second, we identify factors that influence artisanal shrimpers' decisions to belong to fisher groups using recent data obtained from treatment $(\mathrm{n}=$ $95)$ and control $(n=258)$ groups of shrimpers in the Nigerian shrimp and prawn ${ }^{13}$ subsector.

The Nigerian shrimp subsector is a primary example of a fishery sector that remains underdeveloped and with low participation in fisher groups. Despite the government's strong political will to encourage agricultural cooperatives and collective action through various policy instruments, ${ }^{14}$ no cross-cutting program has been proposed to specifically encourage groups among fishing smallholders (WorldFish, 2018). Enhanced fishing efficiency through fisher groups could help to improve artisanal fishers' competitiveness to concurrently commercialize, target profitable high-value markets and deal with adverse economic conditions. Thus, findings from this kind of study are long overdue and crucial to provide implementable policy insights for governments, stakeholders, agribusiness firms and policy analysts who seek to support artisanal fishers in the case country and other similar African countries.

\footnotetext{
${ }^{13}$ Generally, known as shrimp (Kobayashi et al., 2015).

${ }^{14}$ Basically introduced to propagate farmer groups through the Farm Settlement Scheme, National Accelerated Food Production, Agricultural Development Projects, Agricultural Transformation Agenda in 2011-12 and recently, the Agriculture Promotion Policy (FMARD, 2016).
} 
The rest of the study is organized as follows: Section 2 gives an overview of shrimp production and artisanal fisher groups in Nigeria. Section 3 presents the conceptual framework and empirical specification. The data and model used, as well as the results and discussion, are presented in sections 4 and 5, respectively. The last section presents the concluding remarks and policy implications of the study.

\subsection{Shrimp production and artisanal fisher groups in Nigeria}

In Nigeria, shrimp is the most valuable fish product, with an average of 30 metric tonnes annual production, accounting for about 37.2\% of total agricultural export in the third quarter of 2016 and contributing about $3-5 \%$ to the agriculture share of the gross domestic product (GDP) (Achoja, 2019; NBS, 2016; Olaoye \& Ojebiyi, 2018). The continental shelf cuts across the southern part of Nigeria and consists of nine coastal states (Ogun, Lagos, Ondo, Edo, Delta, Bayelsa, Rivers, Akwa-Ibom and Cross River), located along the Atlantic Ocean (Olaoye \& Ojebiyi, 2018). These states represent the main shrimp producing areas in the country. Of these, Ondo State has the longest coastline, spanning about 180km, while Akwa-Ibom boasts huge wholesaling and retailing markets. Shrimp supply is under two production systems, namely, capture and aquaculture. The latter is underdeveloped, accounting for less than $5 \%$ of total domestic production (Achoja, 2019; Zabbey et al., 2010). Capture fishery involves harvesting naturally occurring fishery products from the wild by smallholder fishers (artisans) or industrial trawlers (fishing companies). While industrial trawlers largely export shrimp products, artisanal fishers are important domestically, contributing up to $90 \%$ of the total domestic supply (Olaoye \& Ojebiyi, 2018; Zabbey et al., 2010). Thus, the subsector is dominated by numerous and poor artisanal fishermen who dwell in the rural coastal areas of the country.

The shrimp subsector plays a critical role in economic development in Nigeria and is integral in ensuring food security among rural and urban households. Fish, including shrimp, supplies about $22 \%$ of the protein intake and $13 \mathrm{~kg}$ per capita consumption, consequently dubbed as "rich food for the poor" in the country (Olaoye \& Ojebiyi, 2018; WorldFish, 2018). However, an increasing human population, the spiraling per capital demand for fish resources and the use of traditional methods has created a demand-supply gap (Achoja, 2019; Oluwatayo \& Adedeji, 2019). To increase production and domestic supply and ensure a paradigm shift from the traditional subsistence production to market-oriented production, the Nigerian government has implemented 
various policies tailored to increase productivity and efficiency by encouraging fishers to form viable fisher groups.

Historically, western-type groups/cooperatives were introduced to the Nigerian fishery sector by both the government and foreign stakeholders in the 1970s and 1980s during the "Green Revolution," when state-sponsored credit and technical assistance were distributed through cooperatives. Thereafter, the National Fadama ${ }^{15}$ Development Project (NFDP) was implemented in the 1990s to promote low-cost technology under the World Bank financing program. The highlight of this project was the implementation of the second and third NFDP in 2004 and 2008, respectively, under a tripartite financial structure that includes the World Bank and federal and participating state governments. These projects aim to increase the incomes of farmers and fishers ${ }^{16}$ through a community-driven development approach (Alawode \& Oluwatayo, 2019; Olaoye \& Ojebiyi, 2018).

The political will by the national government to solely aggregate fishers into groups for selfsufficient production and marketing began in earnest a decade ago. In 2011-2012, the fisheries transformation plan was implemented under the Agricultural Transformation Agenda (ATA). ATA was a five-year (2011-2015) project designed to attain self-sufficiency in fishery production through aquaculture value chain development, thus reducing net import. ATA's objective was to create an enabling environment for small-scale fish farmers to form clusters and to be part of the aquaculture value chain, develop various products along the aquaculture value chain, link up markets to consumers and establish, maintain and enforce quality standards. Recently, Agriculture Promotion Policy - a five-year (2016-2020) project - was intended to refresh strategies adopted in ATA. However, these policies had no concrete national plan to form artisanal fishers into groups/clusters, because the focus was on the development of modern export chains and the popularization of aquaculture (FMARD, 2011, 2016; Kobayashi et al., 2015). As a result, artisanal fishery through capture and localized value chains was neglected.

Due to a lack of extant literature on Nigerian fisher groups, information about fisher groups is obtained from a pre-field study using focus group discussions (FGD) and interviews. The information reveals that most of today's fisher groups in Nigeria are indigenous organizations

\footnotetext{
${ }^{15}$ Fadama is a Hausa word which means low-lying and flood plain areas characterized by shallow aquifers and found along Nigeria's waterways (Alawode \& Oluwatayo, 2019).

16 This is the first time fishers will be targeted under the project.
} 
with little or no external support, which are sometimes intertwined, but different from groups of extended families (clans), tribes and religious bodies (Zabbey et al., 2010). There are several prominent local fisher groups in different fishing communities, particularly in the Lagos and Ondo States. These fisher groups are mostly "production-oriented" and inactive in members' marketing activities. The groups have at least four executive members - Chairperson, ViceChairperson, Secretary and Treasurer - any one of whom could organize and manage group activities. Most shrimpers belong to the Artisanal Fishers Association of Nigeria (ARFAN), a national association that has been in existence for over 20 years. This suggests that the ARFAN was formed under previous interventions when foreign stakeholders were active in the Nigerian fishery sector. ARFAN serves as an important source of information and is active in supporting members' production activities. Similar to other local groups, ARFAN links members to input markets and ensures smooth production and transition of products to the processing segment.

Additionally, the groups advocate for policy supports and interventions for their members by engaging government agencies, private businesses and other stakeholders through meetings and media. Various stakeholders collaborate with ARFAN to tackle issues such as low capture, water pollution from oil companies' activities and piracy in the Niger-Delta region. However, there is no indication that members receive technological assistance through fisher groups. With open membership, shrimpers can participate in fisher groups by registering and subsequently paying registration and annual dues that differ with locations and groups. Information from the FGDs reveals several reasons for shrimpers to participate in fisher groups, which include commitment to fishery, learning from experienced shrimpers, obtaining necessary production inputs and credit facilities and getting external supports and interventions.

\subsection{Conceptual framework and empirical specifications}

In this section, we present a multi-stage framework to evaluate the effect of group membership on capture and TE levels of the members. We start with the determinants of artisanal fishers' decisions to participate in fisher groups. Next, we generate comparable treatment and control groups and, thereafter, account for potential sample selection bias in the SPF model. With this, we intend to control for both sources of bias: observed and unobserved characteristics.

\subsubsection{Artisanal fishers' decisions to participate in producer group}

Membership in producer groups is under the presumption that artisanal producers choose between a binary decision, that is, whether to be a member or nonmember. We assume that 
shrimpers are risk-neutral and take into account their possible net benefits $\left(B_{M}^{*}\right)$ derived from being a member of producer group and the expected net benefit $\left(B_{N}^{*}\right)$ derived from not being a member. Shrimpers are further assumed to be rational and would make a choice that would maximize their benefits (i.e. higher shrimping performance). Thus, shrimpers will choose to belong to a producer group if $B_{i}^{*}=B_{M}^{*}-B_{N}^{*}>0$. $B_{i}^{*}$ cannot be observed but can be expressed as a function of some observed characteristics that influence membership decisions, such as shrimping and individual characteristics. We express $B_{i}^{*}$ as a function of observable variables as:

$$
B_{i}^{*}=\alpha^{\prime} z_{i}+w_{i}, B_{i}=1\left[B_{i}^{*}>0\right]
$$

where $B_{i}$ is a dichotomous variable indicating producer group participation, with a value equal to 1 and zero otherwise; $\alpha^{\prime}$ is a vector of parameters to be estimated; $\boldsymbol{z}_{i}$ is a vector of observable shrimping and household characteristics that influence artisan's decision to participate in a producer group; and $w_{i}$ is the error term of the latent variable framework, normally distributed at zero mean and variance $\sigma^{2}$. The probability of participating in a producer group is given as:

$$
\operatorname{Pr}\left(B_{i}=1\right)=\operatorname{Pr}\left(B_{i}^{*}>0\right)=\operatorname{Pr}\left(w_{i}>-\alpha^{\prime} \boldsymbol{z}_{i}\right)=1-F\left(\alpha^{\prime} \boldsymbol{z}_{i}\right)
$$

where $F$ is the cumulative distribution function for $w_{i}$. Here, we assume and expect that a shrimper's participation in a producer group is associated with higher capture and TE, compared to shrimpers who are nonmembers (Abdul-Rahaman \& Abdulai, 2018; Ma \& Abdulai, 2016).

\subsubsection{Stochastic production frontier model}

An SPF model, which was simultaneously introduced by Aigner and colleagues (1977) and Meeusen and van Den Broeck (1977), is employed to determine the relationship between singleoutput $\left(y_{i}\right)$ captured by individual shrimper $i$ using a vector of production inputs $\left(x_{i}\right)$. The approach measures TE by depicting deviation of an individual shrimper's capture from the bestpractice production frontier. Our general SPF model is defined as:

$$
Y_{i j}=f\left(X, B_{M}\right)+\varepsilon_{i}, \varepsilon_{i}=v_{j i}-u_{j i}
$$

where $Y_{i j}$ is the quantity captured by the $i$ th shrimper; $X$ depicts a vector of variables on inputs and production characteristic; $B_{M}$ is a binary variable that captures the effect of group membership (MEMBERSHIP); $v_{j i}$ reflects the measurement error, omitted variables and statistical noise; $u_{j i}$ is assumed to be a one-sided random variable that captures technical inefficiency; and the subscript $j$ depicts membership groups, that is, $B_{M}$ for group membership and $B_{N}$ for nonmembership. 


\subsubsection{Sample selection bias in stochastic production function model}

Several past studies have corrected for sample selection bias arising from observed and unobserved attributes in SPF models (Greene, 2010; Kumbhakar et al., 2009; Rahman et al., 2009; Rao et al., 2012; Wollni \& Brümmer, 2012). Kumbhakar and colleagues (2009) and Rahman and colleagues (2009) assume that selectivity bias arises from the endogeneity of TE with the decision of whether to belong to a producer group. This reflects that the error term $w_{i}$ in the selection equation (4) is correlated with the error term $\varepsilon_{i}$ in the SPF model. However, BravoUreta and colleagues (2012) and Greene (2010) assume that selection bias comes from unobservable attributes captured by $w_{i}$ in the selection model and is correlated with the error term in the SPF model $v_{i}$. Greene (2010) suggests an approach that is an extension of Heckman's specification for the linear regression model to correct for selection bias in SPF models. The approach is based on simulated log likelihood functions, and it is computationally less demanding when compared with the likelihood functions suggested and used by Kumbhakar and colleagues (2009).

First, in line with Bravo-Ureta and colleagues (2012) and De los Santos-Montero and BravoUreta (2017), we used PSM to match the members (MEM) and control (CONN) producers to eliminate bias from all relevant time-invariant observable variables. Specifically, PSM involves a two-step matching estimation. For the first step, we construct a suitable control group with observed characteristics that are similar to those of the members. PSM uses a probit or logit model to predict "propensity scores," which are the probabilities of belonging to the treatment group based on a specified set of predetermined covariates (Bravo-Ureta et al., 2012). In the second step, the resulting "scores" are used to match similar producers in the control and treatment groups. The approach requires that the common support, overlap condition and balancing property are satisfied. Based on matching balance tests between members and nonmembers, ease of interpretation and intuitiveness (Bravo-Ureta et al., 2012; De los SantosMontero \& Bravo-Ureta, 2017), we implement PSM using the "1-to-1 nearest neighbor without replacement" matching algorithm. ${ }^{17}$ Overall, even though it does not eliminate biases completely, PSM is commonly used and reliable when panel and experimental data are unavailable, as in this case (Fischer \& Qaim, 2012).

\footnotetext{
${ }^{17}$ Kernel matching resulted in higher standardized biases.
} 
Second, we account for biases by estimating the standard and sample selection SPFs and metafrontier models to compare TE for MEM and CONN. First, we estimate the SPF model using the pooled unmatched samples, in which the binary variable MEM is included as an explanatory variable to account for group membership. Next, two SPF models are estimated with unmatched data, one for MEM and another for CONN. The significance of MEMBERSHIP on the production frontier and a likelihood ratio (LR) test was done to test for equality of the pooled versus disaggregated models. If the null hypothesis cannot be rejected, then the estimated model from pooled samples is supported. If rejected, two separate SPF models are re-estimated, but corrected for selectivity bias as suggested by Bravo-Ureta and colleagues (2012) and Greene (2010). The aforementioned processes are repeated for matched samples, that is, one SPF model for pooled matched sample, two SPF models for MEM and CONN and two SPF models for MEM and CONN, controlling for sample selection bias. With this approach, selection bias from both observed and unobserved characteristics is controlled for (De los Santos-Montero \& BravoUreta, 2017). The sample selection and SPF models, with their error structures, are expressed as:

$$
\begin{array}{ll}
\text { Sample selection: } & B_{i}^{*}=1\left[\alpha^{\prime} \boldsymbol{z}_{i}+w_{i}>0\right], w_{i} \sim N[0,1] \\
\text { Stochastic production frontier: } & y_{i}=\beta^{\prime} \boldsymbol{x}_{i}+\varepsilon_{i}, \varepsilon_{i} \sim N\left[0, \sigma_{\varepsilon}^{2}\right] \\
& \left(y_{i}, \boldsymbol{x}_{i}\right) \text { observed only when } B_{i}=1 \\
& \varepsilon_{i}=v_{i}-u_{i} \\
& u_{i}=\sigma_{u} U_{i}=\sigma_{u}\left|U_{i}\right|, \text { where } U_{i} \sim N[0,1] \\
& v_{i}=\sigma_{v} V_{i}=\sigma_{v}\left|V_{i}\right|, \text { where } V_{i} \sim N[0,1] \\
& \left(w_{i}, u_{i}\right) \sim N_{2}\left[(0,1),\left(1, \rho \sigma_{u}, \sigma_{v}^{2}\right)\right]
\end{array}
$$

where $B_{i}$ is a binary variable equal to 1 for MEM and 0 for CONN; $y$ is the output variable; $\boldsymbol{z}$ is a vector of control variables in the sample selection equation; $\boldsymbol{x}$ is a vector of inputs in the stochastic production frontier; $\alpha^{\prime}$, and $\beta^{\prime}$ are parameters to be estimated and the depiction in the error structure corresponds to that in the stochastic frontier model. More importantly, parameter $\rho$ captures sample selection bias. ${ }^{18}$

\subsection{Data and model specification}

The data used in the study was obtained from a survey conducted from May to August 2018 in 20 shrimping communities located in three states (Lagos, Akwa-Ibom and Ondo) that represent

\footnotetext{
${ }^{18}$ Further details of the model are presented in Bravo-Ureta et al. (2012) and Greene (2010).
} 
different socio-cultural regions (Figure 4.1). A multistage sampling technique, that purposively selected states and local shrimping areas and randomly selected 405 producers, was employed.

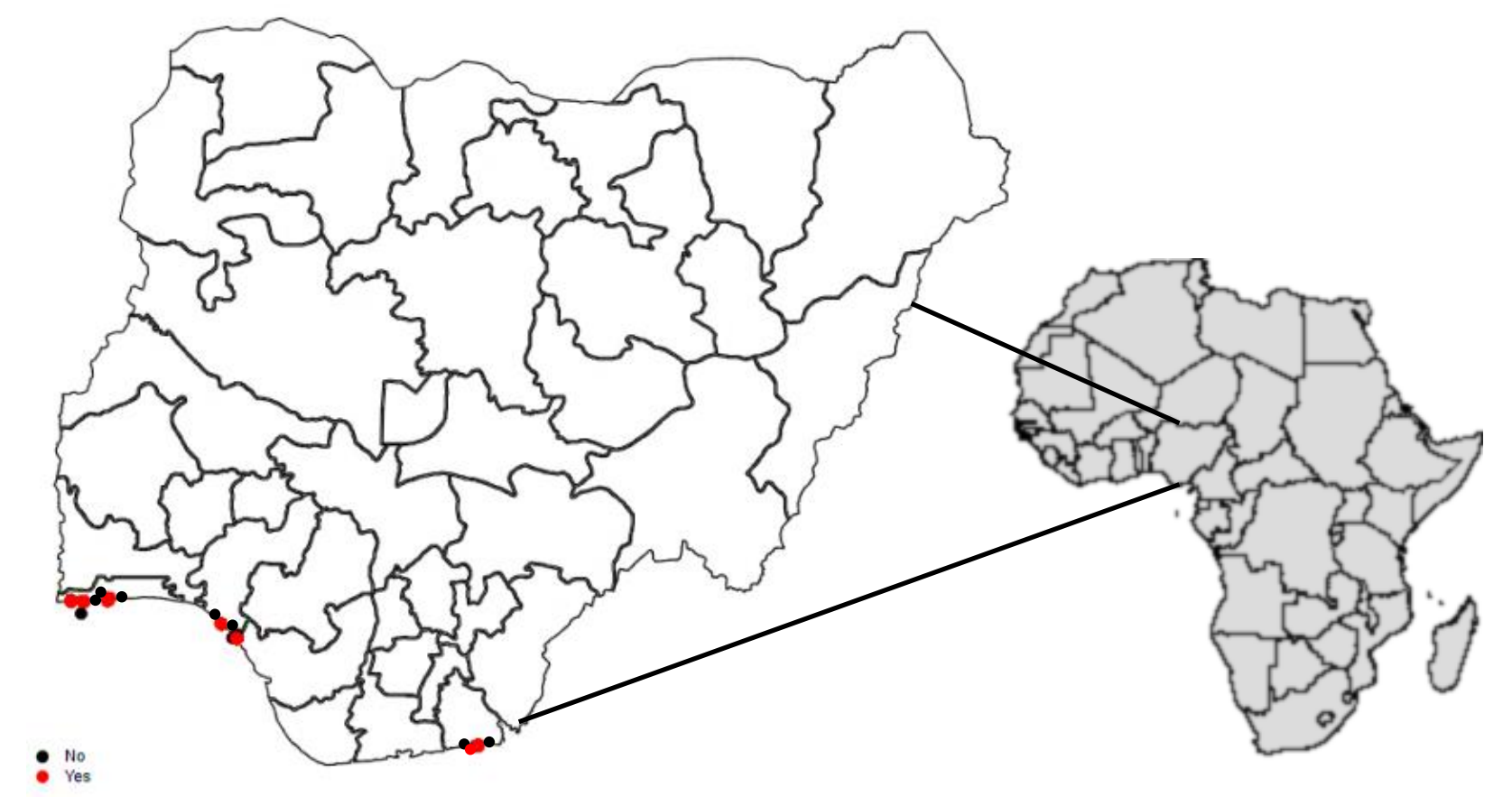

Figure 4.1: Map of Nigeria showing shrimping communities and membership distribution

The sampling procedure was guided by the information obtained from preliminary focus group discussions done with supply actors in 2017 and from extension workers and officials of national research institutes. The sample size compares favorably well with other shrimping surveys in Nigeria and Sub-Saharan Africa. Both the Ondo and Akwa-Ibom States have one shrimping area each, Ilaje and Ibeno, respectively, which were selected. In Lagos, two shrimping areas, Badagry and Eti-osa, were both selected based on the prevalence of shrimping activities. Information was collected using a pre-tested standardized questionnaire. Information collected includes data on shrimping and marketing activities and individual-level characteristics. Although information on the full season was obtained, only data on the peak season was used for the analysis. We rely on peak season data because it is generally characterized by high shrimping activities and efficiency values relative to the offseason. Additionally, producer observations that do not use engines were dropped because they have a different technological set and would operate on different frontiers and production functions. The final dataset contains 353 observations: 95 group members and 258 nonmembers. The approach requires a second dataset obtained using a procedure that matches members and nonmembers based on household and shrimping characteristics in the initial dataset (see Table 4.1). Observations for which a suitable match between members and 
nonmembers is achieved are used as the second dataset. Table 4.1 presents the definition of the variables used in the matching procedure, as well as in the estimation of probit and SPF models.

Table 4.1: Definition of selected variables

\begin{tabular}{|c|c|}
\hline Variable & Description \\
\hline \multicolumn{2}{|c|}{ Dependent variables } \\
\hline TOTALCAP $^{\mathrm{a}}(\mathrm{kg})$ & Shrimp caught in peak season $(\mathrm{kg})$ \\
\hline MEMBERSHIP & 1 if farmer belong to a producer group, 0 otherwise \\
\hline \multicolumn{2}{|c|}{ Input variables used in SPF model } \\
\hline ENGINEOPER & Number of outboard engines operated \\
\hline QUANTFUEL & Quantity of fuel used (liters) \\
\hline LEADERSEMP & Number of skippers employed \\
\hline HELPERSEMP & Number of helpers employed \\
\hline USEFULSEINE & Useful life of Seine net (years) \\
\hline SHOCK & 1 if respondent had a shock, 0 otherwise \\
\hline \multicolumn{2}{|c|}{ Independent variables } \\
\hline AGE & Age of respondent (years) \\
\hline AGESQUARE & Square of respondent's age \\
\hline EXPERIENCE & Years of shrimping experience \\
\hline EDUCYEAR & Years of education \\
\hline REPEAT & Number of times classes were repeated \\
\hline CUSTOMERS & Number of major customers \\
\hline FEMLABSHR & $\begin{array}{l}1 \text { if household female laborer engages in shrimping activities, } 0 \\
\text { otherwise }\end{array}$ \\
\hline FEMASS & 1 if household female laborer belongs to a shrimping group, 0 otherwise \\
\hline AKWA-IBOM ${ }^{b}$ & 1 for Lagos State, 0 otherwise \\
\hline $\mathrm{ONDO}^{\mathrm{b}}$ & 1 for Ondo State, 0 otherwise \\
\hline MOBILE & 1 for mobile phone ownership, 0 otherwise \\
\hline EXTENSION & 1 if respondent had access to extension, 0 otherwise \\
\hline CREDIT & 1 if respondent had access to credit, 0 otherwise \\
\hline LEADER & 1 if respondent is a skipper, 0 otherwise \\
\hline TAROAD & 1 if respondent had access to tarmacked road, 0 otherwise \\
\hline COOP & 1 if respondent participate in financial cooperative society, 0 otherwise \\
\hline
\end{tabular}

Note: ${ }^{a}$ The dependent variable is log form of total capture measured in kg. ${ }^{b}$ The reference state is Lagos

The matching procedure generated a total of 89 pairs, representing 89 members out of 95 with 258 nonmembers. Following Bravo-Ureta and colleagues (2012) and De los Santos-Montero and Bravo-Ureta (2017), we ran a balance $t$-test before and after matching to check the distribution of the covariates and evaluate the null hypotheses that the means of observed characteristics of members and nonmembers are equal. The results indicate that the "1-to-1 nearest neighbor without replacement" matching procedure generated insignificant differences between the groups, suggesting that the balancing property is satisfied (Figure A4.1).

Table 4.2 presents the descriptive statistics of the variables before and after matching. The data shows that shrimpers in the sample are smallholders with an average of 1.48 outboard engines. The average age and experience of producers are 40.20 and 17.39 years, respectively. Education is measured as the number of completed formal schooling years. The mean value of 8.5 years of 
education among the producers is equivalent to the level of primary school completed. Producers have at least one female household laborer who is also engaged in shrimping activities. Table 4.2 further presents the significant mean differences in the characteristics of group members and nonmembers. Only $27 \%$ of the shrimpers belonged to a producer group during the 2017/2018 peak season. Differences in age and experience means show that members tend to be significantly 5.04 years older and 5.07 years more experienced than nonmembers, respectively. Members also have a higher chance of having one of their female household members participating in shrimprelated groups, representing an important source of information.

Overall, more members have access to physical and financial infrastructures: 94\% of the members have access to mobile phones relative to $88 \%$ of the nonmembers. Compared to only $2 \%$ among nonmembers, $14 \%$ of the members have links to extension agents. Likewise, more members had access to credit (33\%) and tarmacked roads (36\%) relative to $21 \%$ and $33 \%$ for nonmembers, respectively. In terms of input endowments, members tend to employ significantly more engines and employees than nonmembers, suggesting higher wealth and larger scales of operation. The average outputs for members are significantly higher than those of nonmembers during the peak season. Total capture for members was 11,299.56kg higher than associated nonmembers. The significant differences provide an initial indication that group membership might play an important role in enhancing shrimping output and margins. To provide proof of this, a sophisticated approach is needed to account for both endogenous membership decisions arising from observed factors such as age, experience and asset endowments; as well as unobserved characteristics.

Table 4.2: Shrimping and socio-economic characteristics

\begin{tabular}{|c|c|c|c|c|c|}
\hline \multirow{2}{*}{ Variable } & \multicolumn{2}{|c|}{ Pooled } & \multirow{2}{*}{$\begin{array}{l}\text { Members } \\
\text { Mean } \\
\end{array}$} & \multirow{2}{*}{$\begin{array}{l}\text { Nonmembers } \\
\text { Mean } \\
\end{array}$} & \multirow{2}{*}{ Diff. } \\
\hline & Mean & Std. Dev. & & & \\
\hline \multicolumn{6}{|l|}{ Unmatched sample } \\
\hline TOTALCAP (kg) & 48003.93 & 34213.76 & 44942.97 & 35042.01 & $11299.56^{* * *}$ \\
\hline MEMBERSHIP & 0.27 & 0.44 & - & - & - \\
\hline ENGINEOPER & 1.48 & 0.79 & 1.63 & 1.43 & $0.20 * *$ \\
\hline QUANTFUEL & 1145.31 & 748.83 & 1223.52 & 1116.50 & 107.02 \\
\hline LEADERSEMP & 0.69 & 0.91 & 0.95 & 0.60 & $0.35 * * *$ \\
\hline HELPERSEMP & 1.03 & 1.02 & 1.34 & 0.91 & $0.43 * * *$ \\
\hline SHOCK & 0.68 & 0.47 & 0.64 & 0.69 & -0.05 \\
\hline USEFULSEINE & 2.18 & 1.41 & 2.28 & 2.14 & 0.14 \\
\hline AGE & 40.20 & 11.01 & 43.87 & 38.83 & $5.04 * * *$ \\
\hline AGE SQUARE & 1736.37 & 1017.46 & 2011.33 & 1635.13 & $376.19 * * *$ \\
\hline EXPERIENCE & 17.39 & 10.75 & 21.11 & 16.03 & $5.07 * * *$ \\
\hline EDUCYEAR & 8.50 & 4.53 & 8.67 & 8.10 & 0.56 \\
\hline REPEAT & 0.096 & 0.47 & 0.042 & 0.12 & 0.074 \\
\hline FEMLABSHR & 1.33 & 1.49 & 1.27 & 1.35 & -0.08 \\
\hline \multicolumn{6}{|c|}{81} \\
\hline
\end{tabular}




\begin{tabular}{|c|c|c|c|c|c|}
\hline FEMASS & 0.22 & 0.42 & 0.41 & 0.15 & $0.26 * * *$ \\
\hline AKWA-IBOM & 0.18 & 0.39 & 0.18 & 0.18 & 0.007 \\
\hline ONDO & 0.33 & 0.47 & 0.11 & 0.42 & -0.31 \\
\hline MOBILE & 0.89 & 0.31 & 0.94 & 0.88 & 0.06 \\
\hline EXTENSION & 0.05 & 0.22 & 0.14 & 0.02 & $0.12 * * *$ \\
\hline CREDIT & 0.24 & 0.43 & 0.33 & 0.21 & $0.12 * *$ \\
\hline LEADER & 0.13 & 0.33 & 0.08 & 0.14 & -0.06 \\
\hline CUSTOMERS & 2.53 & 1.83 & 2.38 & 2.58 & 0.20 \\
\hline TAROAD & 0.26 & 0.44 & 0.36 & 0.22 & $0.14 * * *$ \\
\hline COOP & 0.11 & 0.02 & 0.24 & 0.07 & $0.18 * * *$ \\
\hline Observations & 353 & & 95 & 258 & \\
\hline \multicolumn{6}{|l|}{ Matched sample } \\
\hline TOTALCAP (kg) & 46454.49 & 30479.26 & 52787 & 46730 & 6057 \\
\hline MEMBERSHIP & 2.57 & 0.44 & - & - & - \\
\hline ENGINEOPER & 1.45 & 0.75 & 1.56 & 1.54 & 0.02 \\
\hline QUANTFUEL & 1128.18 & 712.27 & 1173.40 & 1159.50 & 13.90 \\
\hline LEADERSEMP & 0.65 & 0.87 & 0.87 & 0.79 & 0.08 \\
\hline HELPERSEMP & 0.97 & 0.97 & 1.24 & 1.11 & 0.13 \\
\hline SHOCK & 0.69 & 0.685 & 0.64 & 0.65 & -0.01 \\
\hline USEFULSEINE & 2.15 & 1.40 & 2.25 & 2.18 & 0.07 \\
\hline AGE & 39.79 & 11.03 & 43.65 & 42.64 & 1.01 \\
\hline AGE SQUARE & 1704.71 & 1021.46 & 1995.20 & 1915.20 & 80.00 \\
\hline EXPERIENCE & 17.021 & 10.73 & 20.46 & 20.80 & -0.34 \\
\hline EDUCYEAR & 8.205 & 4.604 & 8.56 & 8.35 & 0.21 \\
\hline FEMLABSHR & 1.326 & 1.502 & 1.25 & 1.26 & -0.01 \\
\hline FEMASS & 0.20 & 0.40 & 0.37 & 0.27 & 0.10 \\
\hline AKWA-IBOM & 0.19 & 0.39 & 0.19 & 0.23 & -0.04 \\
\hline ONDO & 0.35 & 0.48 & 0.11 & 0.17 & -0.06 \\
\hline MOBILE & 0.89 & 0.31 & 0.93 & 0.90 & 0.03 \\
\hline EXTENSION & 0.027 & 0.16 & 0.10 & 0.05 & 0.05 \\
\hline CREDIT & 0.23 & 0.42 & 0.32 & 0.28 & 0.04 \\
\hline LEADER & 0.13 & 0.34 & 0.09 & 0.09 & 0.00 \\
\hline CUSTOMERS & 2.54 & 1.84 & 2.33 & 2.25 & 0.08 \\
\hline TAROAD & 0.25 & 0.44 & 0.36 & 0.33 & 0.03 \\
\hline COOP & 0.10 & 0.30 & 0.23 & 0.16 & 0.07 \\
\hline Observations & 347 & & 89 & 258 & \\
\hline
\end{tabular}

To analyze the SPF of shrimpers and determine its effect on their capture and technical efficiency, we apply the parametric approach described in section 2, based on Greene (2010) and Bravo-Ureta and colleagues (2012). In the first step of the approach, a probit model of group membership, described as the sample selection model (4), is conducted to estimate the probability of belonging to a producer group. The model is expressed as a function of exogenous shrimping and individual characteristics ( $\mathbf{z}$ ) that influence group membership. The probit model is expressed as:

$$
B_{i}=\gamma_{0}+\sum_{j=1}^{16} \alpha^{\prime} z_{i}+w_{i}
$$

where $B_{i}$ is a binary variable equal to 1 for MEM and 0 otherwise; $\gamma$ are unknown parameters to be estimated; $w$ is the error term distributed as in (3); and $\boldsymbol{z}$ includes AGE, SHRIMPYEAR, 
LEADER, EDUCYEAR, FEMLABSHR, FEMASS, ONDO, AKWA, MOBILE, EXTENSION, CREDIT, CUSTOMERS, TAROAD and COOP (Table 4.1). These control variables have been identified in previous studies as main determinants of membership in farmer groups (AbdulRahaman \& Abdulai, 2018; Chagwiza et al., 2016; Fischer \& Qaim, 2012; Mojo et al., 2017).

The second step involves the estimation of separate SPF models for MEM and CONN to account for different technological sets. An LR test in line with Bravo-Ureta and colleagues (2012) was conducted to compare whether the pooled (unrestricted model) or MEM and CONN models (restricted) are appropriate for both matched and unmatched samples. The LR test is expressed as:

$$
L R=2\left(\ln L_{P}-\left(\ln L_{M}+\ln L_{C}\right)\right),
$$

with $\ln L_{P}, \ln L_{M}$ and $\ln L_{C}$ exhibiting the $\log$-likelihood function values gained for the pooled, MEM and CONN samples, respectively. We assume a Cobb-Douglas (CD) SPF model to estimate a shrimper's efficiency after preliminary LR tests led to the acceptance of the translog functional form for MEM and CD for CONN (Table A4.1). The translog and CD models are generally defined as:

$\ln y_{i}=\beta_{0}+\sum_{j=1}^{5} \beta_{j} \ln \left(\boldsymbol{x}_{j i}\right)+\frac{1}{2} \sum_{k=1}^{5} \sum_{j=1}^{5} \beta_{j k} \ln \left(\boldsymbol{x}_{k i}\right) \ln \left(\boldsymbol{x}_{j i}\right)+\sum_{k=1}^{7} \delta_{k} D_{k i}+\left(v_{i}-u_{i}\right)$, iff $B=1$

$$
\ln y_{i}=\beta_{0}+\sum_{j=1}^{5} \beta_{j} \ln \left(\boldsymbol{x}_{j i}\right)+\sum_{k=1}^{7} \delta_{k} D_{k i}+\left(v_{i}-u_{i}\right), \text { iff } B=1
$$

where $y_{i}$ denotes output of shrimper $i$ during the peak season; $\left(\boldsymbol{x}_{i j}\right)$ is the quantity of input; $\beta$ and $\delta$ are unknown parameters to be estimated; while $v_{i}$ and $u_{i}$ are the elements of error term $\varepsilon_{i}$ that assume half-normal distributions, respectively. The vector $\boldsymbol{x}$ entails conventional shrimping inputs such as ENGINE ${ }^{19}$, FUEL, SKIPPER, HELPER and SEINE. The number of inputs operated during the peak season was used for the SPF estimation while seine (net) was measured using its useful life, depicting its quality. Previous studies on the SPF model have identified these variables as the classical inputs in the fishery subsectors (Esmaeili, 2006; Lokina, 2009; Sesabo $\&$ Tol, 2007). We add dummies $D_{k}$ to control for shrimping characteristics such as location (Ondo and Akwa-Ibom States), shocks and high engine capacity. As done by Wollni and Brümmer (2012) and Rao and colleagues (2012), we also correct for zero values in input variables by creating and including a dummy which is equal to one if input variables are equal to

\footnotetext{
${ }^{19}$ Canoe was excluded as it is correlated with the number of engines used, i.e. canoes are operated with engines.
} 
zero. Thus, we created dummies for SKIPPER and HELPER to control for 187 and 124 observations that do not use these inputs, respectively.

\subsection{Empirical results and discussions}

\subsubsection{Estimates of producer group participation decisions}

Table 4.3 and Table A4.2 show estimates of factors influencing shrimpers' decisions to participate in producer groups for both matched and unmatched samples. Marginal effects are also computed to allow for easy interpretation of the coefficients. The chi-square test statistics reveal that the parameter estimates are jointly significant at the 1\% level in both models (LR chi2 $(16)=126.61$ and 111.65$)$. Table 4.3 reports that AGE plays a positive and significant role in a shrimper's decision to participate in a producer group, a finding that is consistent with the results reported in previous studies (Abdul-Rahaman \& Abdulai, 2018; Bernard \& Spielman, 2009; Bernard et al., 2008; Fischer \& Qaim, 2012; Mojo et al., 2017). However, we found this effect to be non-linear, suggesting that there is a threshold beyond which shrimpers are $0.1 \%$ less likely to participate in producer groups. It could be that shrimpers make shrimping decisions based on prior experiences and information received from trading partners as they grow older instead of ARFAN. In line with what Abdul-Rahaman and Abdulai (2018) and Ma and Abdulai (2016) found, the result shows that EDUCYEAR, EXPERIENCE, FEMASS, COOP and TAROAD play positive and significant roles in shrimpers' group membership decisions in Nigeria. EDUCYEAR and EXPERIENCE exhibit positive effects, suggesting that higher training and experience facilitate participation in fisher groups.

The results on female household members are interesting in that shrimpers with a larger proportion of FEMLABSHR and FEMASS were 3.8\% less likely and 16.6\% more likely to join ARFAN, respectively. These results are associated with alternative sources of shrimper's information and further clarify the finding by Chagwiza and colleagues (2016), in which the proportion of females in the household was found to insignificantly explain participation. Women who engage in shrimping activities serve as source for information for shrimpers, thus making shrimpers' participation in ARFAN less likely. Conversely, shrimpers that have female household members in shrimp-related associations are consequently motivated to join related producer groups.

Contrary to what Fischer and Qaim (2012) found, COOP shows a positive effect, suggesting that social networks and participation in other community groups drive participation in fisher groups. 
The result that TAROAD positively explains participation in fisher groups is intuitive in that access to tarmacked roads (reflecting close distance to roads) reduces associated transaction costs to organize and participate in producer groups. Similar results have been reported by Chagwiza and colleagues (2016) and Fischer and Qaim, (2012) who found negative and non-linear relationships between distance to collection centers (and roads) and group membership, respectively. However, location variables such as AKWA-IBOM and ONDO (reference to Lagos) depict negative effects, implying significant state, agro-climatic and environmental effects on ARFAN membership. In terms of business relationships, CUSTOMERS show a negative effect, indicating that the intensity and tightness of supplier-buyer relationships influence participation in fisher groups. Lastly, insignificant effects were found from variables such as LEADER, REPEAT, MOBILE, EXTENSION and CREDIT, indicating that they play less of a role in shrimpers' membership decisions. These results were fairly consistent for matched samples in Table A4.2 and after addressing potential endogeneity in Table A4.3.

Table 4.3: Probit model estimates of the determinant of membership in producer group (unmatched sample)

\begin{tabular}{|c|c|c|c|c|}
\hline \multirow{2}{*}{ MEMBERSHIP } & \multicolumn{2}{|c|}{ Probit coefficients } & \multicolumn{2}{|c|}{ Marginal effects } \\
\hline & Coef. & St. Err. & Coef. & St. Err. \\
\hline AGE & $0.223 * * *$ & 0.062 & $0.051 * * *$ & 0.014 \\
\hline AGESQUARE & $-0.002 * * *$ & 0.001 & $-0.001 * * *$ & 0.0001 \\
\hline EXPEREIENCE & $0.020 *$ & 0.011 & $0.004 *$ & 0.002 \\
\hline LEADER & -0.261 & 0.280 & -0.059 & 0.064 \\
\hline EDUCYEAR & $0.034 *$ & 0.020 & $0.008 *$ & 0.005 \\
\hline REPEAT & -0.241 & 0.331 & -0.054 & 0.075 \\
\hline FEMLABSHR & $-0.140 * *$ & 0.065 & $-0.031^{* *}$ & 0.015 \\
\hline FEMASS & $0.652 * * *$ & 0.198 & $0.147 * * *$ & 0.043 \\
\hline AKWA-IBOM & $-0.943 * * *$ & 0.344 & $-0.212 * * *$ & 0.075 \\
\hline ONDO & $-1.152 * * *$ & 0.230 & $-0.260 * * *$ & 0.048 \\
\hline MOBILE & 0.103 & 0.301 & 0.023 & 0.068 \\
\hline EXTENSION & 0.564 & 0.388 & 0.127 & 0.088 \\
\hline CREDIT & 0.325 & 0.200 & 0.073 & 0.046 \\
\hline CUSTOMERS & $-0.134 * * *$ & 0.050 & $-0.030 * * *$ & 0.011 \\
\hline TAROAD & $0.619 * *$ & 0.298 & $0.139 * *$ & 0.066 \\
\hline COOP & $0.616 * *$ & 0.256 & $0.139 * *$ & 0.056 \\
\hline Constant & $-5.959 * * *$ & 1.421 & & \\
\hline Log-likelihood & -142.275 & & & \\
\hline LR chi2(15) & 126.610 & & & \\
\hline Number of obs. & 353 & & & \\
\hline
\end{tabular}

The results in the model are estimated using equation (5). 


\subsubsection{Stochastic production frontier estimates}

Table 4.4 and Table 4.5 present the parameter estimates of the conventional and sample selection SPF models for the unmatched and matched samples, each for MEM and CONN, respectively ${ }^{20}$. The LR tests in equation (7) reject the null hypothesis of homogenous technology between MEM and CONN at less than 5\% level for unmatched and matched samples (Table A4.1). Additionally, the significance of MEMBERSHIP parameters in Table 4.4 and Table 4.5 confirm that MEM and CONN display different frontiers, thereby supporting the estimation of separate SPF models. A similar positive effect of MEMBERSHIP on outputs has been found in previous studies (Chagwiza et al., 2016; Ma \& Abdulai, 2016; Ma et al., 2018; Mojo et al., 2017).

As expected, the results in Table 4.4 and Table 4.5 show that all estimated pooled models present positive partial production elasticities, which depict the percentage contribution of each input to percentage changes in output. Overall, in the pooled models, the result indicates that four conventional inputs (ENGINE, QUANTFUEL, LEADER and SEINE) contribute significantly to an increasing TOTALCAP. However, ENGINE and SKIPPER contribute the most for both members and nonmembers, suggesting that shrimpers rely more on these inputs for shrimp capture. This is in line with what has been documented in previous studies (Esmaeili, 2006; Lokina, 2009). While seine and fuel quantity play minor roles, no significant contribution was found from HELPERSEMP. The location fixed-effect parameters, AKWA-IBOM and ONDO (reference to Lagos), which account for environmental, shrimping and other socio-economic characteristics play positive and significant roles for both members and nonmembers.

Finally, we add a shock dummy to account for shocks such as natural disasters and human activities that might disrupt shrimping activities. We found that shock also plays a minor role, especially for nonmembers. As this is an unregulated sector, this result is meaningful because shocks naturally regulate shrimping activities, keeping shrimpers away from the waters and allowing for the rejuvenation of fish resources. As shown in Table 4.4 and Table 4.5, the null hypothesis of no TE $(\lambda=0)$ is rejected with a probability value of less than $1 \%$. This implies that technical inefficiency is an important contributor to the variation in TOTALCAP for both MEM and CONN.

\footnotetext{
${ }^{20}$ A prior LR test suggested the presence of inefficiency (Table A4.1).
} 
Table 4.4: Parameter estimates for conventional and sample selection SPF models: Unmatched sample

\begin{tabular}{|c|c|c|c|c|c|c|c|c|c|c|}
\hline \multirow{3}{*}{$\operatorname{lnTOTALCAP}$} & \multicolumn{6}{|c|}{ Conventional SPF } & \multicolumn{4}{|c|}{ Sample selection SPF } \\
\hline & \multicolumn{2}{|c|}{ Pooled } & \multicolumn{2}{|c|}{ MEM } & \multicolumn{2}{|c|}{ CONN } & \multicolumn{2}{|c|}{ MEM } & \multicolumn{2}{|c|}{ CONN } \\
\hline & Coef. & St.Err. & Coef. & St.Err. & Coef. & St.Err. & Coef. & St.Err. & Coef. & St.Err. \\
\hline lnENGINEOPER & $0.800 * * *$ & 0.064 & $1.079 * * *$ & 0.306 & $0.824 * * *$ & 0.076 & $1.125 * * *$ & 0.423 & $0.822 * * *$ & 0.090 \\
\hline InQUANTFUEL & $0.088 * * *$ & 0.025 & $0.195 * * *$ & 0.062 & $0.078 * * *$ & 0.028 & $0.186 * *$ & 0.078 & $0.078 * * *$ & 0.020 \\
\hline InLEADERSEMP & $0.189 * *$ & 0.076 & $0.669 * *$ & 0.311 & $0.238 * *$ & 0.099 & 0.622 & 4.489 & $0.236 * *$ & 0.110 \\
\hline InHELPERSEMP & -0.044 & 0.074 & -0.373 & 0.297 & -0.133 & 0.093 & -0.356 & 4.634 & -0.132 & 0.112 \\
\hline lnUSEFULSEINE & $0.058 * *$ & 0.027 & -0.209 & 0.307 & 0.048 & 0.033 & -0.249 & 0.498 & 0.047 & 0.041 \\
\hline lnENGINEOPER2 & & & -0.404 & 0.334 & & & -0.317 & 0.414 & & \\
\hline InLEADERSEMP2 & & & -0.300 & 0.233 & & & -0.230 & 2.244 & & \\
\hline InHELPERSEMP2 & & & 0.074 & 0.156 & & & 0.076 & 2.314 & & \\
\hline lnUSEFULSEINE2 & & & 0.099 & 0.148 & & & 0.117 & 0.243 & & \\
\hline InENGINEOPERxLEADER & & & -0.215 & 0.258 & & & -0.309 & 0.293 & & \\
\hline InENGINEOPERxHELPER & & & $0.566 *$ & 0.316 & & & 0.502 & 0.386 & & \\
\hline lnLEADERxSEINE & & & $0.171 * *$ & 0.078 & & & $0.191 * *$ & 0.931 & & \\
\hline ONDO & $0.089 * *$ & 0.037 & 0.119 & 0.084 & $0.075^{*}$ & 0.042 & 0.033 & 0.142 & 0.057 & 0.055 \\
\hline AKWA-IBOM & $0.082 *$ & 0.043 & $0.127 *$ & 0.076 & 0.046 & 0.053 & 0.081 & 0.111 & 0.043 & 0.063 \\
\hline SHOCK & $0.063^{*}$ & 0.033 & 0.013 & 0.058 & $0.086^{*}$ & 0.040 & 0.028 & 0.081 & $0.091 * *$ & 0.046 \\
\hline HighEngCap & -0.108 & 0.100 & $-0.383 * * *$ & 0.137 & 0.028 & 0.130 & $-0.397 *$ & 0.234 & 0.031 & 0.198 \\
\hline Leadercontrol & -0.043 & 0.044 & 0.278 & 0.220 & -0.073 & 0.055 & 0.230 & 1.565 & -0.071 & 0.060 \\
\hline Helpercontrol & 0.021 & 0.043 & -0.047 & 0.132 & 0.031 & 0.052 & -0.062 & 1.611 & 0.027 & 0.062 \\
\hline MEMBERSHIP & $0.109 * * *$ & 0.036 & - & - & - & - & - & - & - & - \\
\hline Constant & $9.826 * * *$ & 0.182 & $9.058 * * *$ & 0.432 & $9.930 * * *$ & 0.190 & $9.128 * * *$ & 1.917 & $9.948 * * *$ & 0.164 \\
\hline$\lambda$ & $1.01 * * *$ & 0.14 & $0.852 * * *$ & 0.238 & $1.100 * * *$ & 0.087 & - & - & - & - \\
\hline$\sigma^{2}$ & $0.113^{* * *}$ & 0.021 & $0.068 * * *$ & 0.044 & $0.126^{* * *} *$ & 0.024 & - & - & - & - \\
\hline$\sigma_{u}$ & - & - & - & - & - & - & $0.234 *$ & 0.128 & $0.251 * * *$ & 0.083 \\
\hline$\sigma_{v}$ & - & - & - & - & - & - & $0.196^{* * *}$ & 0.051 & $0.246^{* * * *}$ & 0.034 \\
\hline$\rho_{(w, v)}$ & - & - & - & - & - & - & 0.612 & 0.533 & -0.240 & 0.298 \\
\hline Number of obs. & 353 & & 95 & & 258 & & 95 & & 258 & \\
\hline L. likelihood & -48.040 & & 7.859 & & -42.932 & & -75.297 & & -110.30 & \\
\hline
\end{tabular}

$* * * p<0.01, * * p<0.05, * p<0.1$

The results for pooled and CONN models are estimated using equation (9) and MEM models using equation (8). 
Table 4.5: Parameter estimates for conventional and sample selection SPF models: Matched sample

\begin{tabular}{|c|c|c|c|c|c|c|c|c|c|c|}
\hline \multirow{3}{*}{ lnTOTALCAP } & \multicolumn{6}{|c|}{ Conventional SPF } & \multicolumn{4}{|c|}{ Sample selection SPF } \\
\hline & \multicolumn{2}{|c|}{ Pooled } & \multicolumn{2}{|c|}{ MEM } & \multicolumn{2}{|c|}{ CONN } & \multicolumn{2}{|c|}{ MEM } & \multicolumn{2}{|c|}{ CONN } \\
\hline & Coef. & St.Err. & Coef. & St.Err. & Coef. & St.Err. & Coef. & St.Err. & Coef. & St.Err. \\
\hline lnENGINEOPER & $0.793 * * *$ & 0.065 & $1.226 * * *$ & 0.352 & $0.824 * * *$ & 0.076 & $1.295 * * *$ & 0.422 & $0.821 * * *$ & 0.089 \\
\hline lnQUANTFUEL & $0.088^{* * *}$ & 0.025 & $0.227 * * *$ & 0.068 & $0.078 * * *$ & 0.028 & $0.219 * * *$ & 0.078 & $0.080 * * *$ & 0.019 \\
\hline lnLEADERSEMP & $0.194 * *$ & 0.079 & $0.793 * *$ & 0.333 & $0.238 * *$ & 0.099 & 0.790 & 0.602 & $0.222 * *$ & 0.110 \\
\hline InHELPERSEMP & -0.060 & 0.076 & -0.462 & 0.313 & -0.133 & 0.093 & -0.471 & 0.667 & -0.131 & 0.112 \\
\hline lnUSEFULSEINE & $0.057 * *$ & 0.027 & -0.190 & 0.322 & 0.048 & 0.033 & -0.259 & 0.521 & 0.048 & 0.040 \\
\hline lnENGINEOPER2 & & & -0.617 & 0.415 & & & -0.540 & 0.440 & & \\
\hline InLEADERSEMP2 & & & -0.301 & 0.251 & & & -0.253 & 0.338 & & \\
\hline lnHELPERSEMP2 & & & 0.049 & 0.163 & & & 0.039 & 0.351 & & \\
\hline lnUSEFULSEINE2 & & & 0.093 & 0.155 & & & 0.123 & 0.255 & & \\
\hline lnENGINEOPERxLEADER & & & -0.235 & 0.278 & & & -0.361 & 0.299 & & \\
\hline lnENGINEOPERxHELPER & & & $0.670 *$ & 0.374 & & & 0.694 & 0.421 & & \\
\hline lnLEADERxSEINE & & & $0.177 * *$ & 0.086 & & & $0.202 * *$ & 0.090 & & \\
\hline ONDO & $0.092 * *$ & 0.037 & 0.142 & 0.086 & $0.075^{*}$ & 0.042 & 0.036 & 0.127 & 0.054 & 0.054 \\
\hline AKWA-IBOM & $0.088 * *$ & 0.043 & $0.155^{*}$ & 0.091 & 0.046 & 0.053 & 0.082 & 0.097 & 0.040 & 0.023 \\
\hline SHOCK & $0.061 *$ & 0.033 & 0.014 & 0.068 & $0.086^{* *}$ & 0.040 & 0.021 & 0.082 & $0.091 * *$ & 0.045 \\
\hline HighEngCap & -0.102 & 0.101 & $-0.361 * * *$ & 0.145 & 0.028 & 0.130 & $-0.382 *$ & 0.180 & 0.031 & 0.200 \\
\hline Leadercontrol & -0.047 & 0.044 & 0.295 & 0.234 & -0.073 & 0.055 & 0.261 & 0.289 & -0.074 & 0.060 \\
\hline Helpercontrol & 0.018 & 0.043 & -0.034 & 0.137 & 0.031 & 0.052 & -0.045 & 0.252 & 0.028 & 0.061 \\
\hline MEMBERSHIP & $0.104 * * *$ & 0.036 & - & - & - & - & - & - & - & - \\
\hline Constant & $9.830 * * *$ & 0.184 & $8.860 * * *$ & 0.487 & $9.930 * * *$ & 0.190 & $8.849 * * *$ & 0.590 & $9.945 * * *$ & 0.138 \\
\hline$\lambda$ & $1.002 * * *$ & 0.081 & $1.322 * * *$ & 0.280 & $1.100 * * *$ & 0.087 & - & - & - & - \\
\hline$\sigma^{2}$ & $0.114^{* * *} *$ & 0.021 & $0.086 * * *$ & 0.054 & $0.126^{* * *}$ & 0.024 & - & - & - & - \\
\hline$\sigma_{u}$ & - & - & - & - & - & - & $0.238 * * *$ & 0.077 & $0.257 * * *$ & 0.054 \\
\hline$\sigma_{v}$ & - & - & - & - & - & - & $0.206^{* * *}$ & 0.049 & $0.245^{* * *} *$ & 0.028 \\
\hline$\rho_{(w, v)}$ & - & - & - & - & - & - & $0.715^{* * *}$ & 0.065 & -0.250 & 0.338 \\
\hline Number of obs. & 347 & & 89 & & 258 & & 89 & & 258 & \\
\hline L. likelihood & -48.514 & & 6.468 & & -42.932 & & -75.832 & & -109.542 & \\
\hline
\end{tabular}

The results for pooled and CONN models are estimated using equation (9), and MEM models using equation (8). 
The result of the sample selection SPF, as revealed by the significance of the $\rho(w, v)$ parameter $^{21}$ in Table 4.4 and Table 4.5, shows statistical support for the presence of selection bias arising from unobserved factors in the matched samples. This implies that the TE values estimated in the conventional model are biased and inconsistent. This also justifies the estimation of separate SPF models for MEM and CONN to correct for selection bias and supports several recent studies that have highlighted the importance of accounting for the presence of selection bias arising from unobserved variables in the estimation of the group membership effect (Abdul-Rahaman \& Abdulai, 2018; Ma et al., 2018; Mojo et al., 2017). The interpretation of $\rho(w, v)$ directions indicates that shrimpers choose to belong to ARFAN based on their comparative advantage and those with a below-average catch have a higher probability of participating in fisher groups. This finding is plausible, since producer groups are expected to enhance the performance and ability of fishing members (Table A4.4). This is consistent with some extant studies (Fischer \& Qaim, 2012; Ma \& Abdulai, 2016; Markelova et al., 2009), but differs with Bernard and Spielman (2009).

\subsubsection{Catch and technical efficiency levels}

The summary of the mean TE scores for the pooled sample, group members and nonmembers derived from the conventional and sample selection SPF models is summarized in Table 4.6 and Table A4.5. We also present reports of the statistical $t$-test of mean differences between MEM and CONN groups. For the unmatched sample in the conventional SPF model, Table 4.6 shows that ARFAN members and nonmembers operate at an average TE level of $0.878 \%$ and $0.821 \%$, respectively, relative to their group frontiers. The sample selection SPF model results in slightly lower average TE levels of $0.835 \%$ and $0.822 \%$ for members and nonmembers, respectively, relative to their group frontiers. For the matched sample, the results show that ARFAN members operate at average TE levels of $0.838 \%$ relative to $0.821 \%$ for nonmembers in the conventional SPF model, and $0.831 \%$ relative to $0.819 \%$ for nonmembers in the sample selection SPF model. The TE values reported in this study are generally higher when compared to what is found in African's fishery sector (Sesabo \& Tol, 2007), although similarly high TE scores have been reported for small-scale fishers in Tanzania and Nigeria (Lokina, 2009; Oluwatayo \& Adedeji, 2019). It is important to recall that the data used in this study are for the peak season, for which comparatively higher TE values have been recorded in the literature.

\footnotetext{
${ }^{21}$ Prior linear regression tests have indicated the presence of selection bias in both matched and unmatched samples.
} 
In general, the results suggest that the TE for shrimp capture tends to be overestimated if selection bias is not accounted for properly. The results in Table 4.6 indicate that lower TE scores are related to the implementation of the sample selection SPF model, compared to the conventional SPF model. In particular, the mean TE values in the unmatched sample decreased for the pooled model and members by about $3.13 \%$ and $5.15 \%$, respectively. However, it increased for nonmembers by about $0.12 \%$ when sample selection SPF was implemented. A decreasing trend was observed for the matched sample in which average TE values decreased in the pooled model, for both member and nonmember groups, when sample selection SPF is implemented. These results are meaningful, in that accounting for selection bias has allowed us to estimate parameters efficiently, but lead to lesser share of fishers operating close to the group production frontier. This could be due to the lack of a national government plan and stakeholder support for ARFAN and other local fisher groups, thus inhibiting groups' potentials in improving artisanal fishers' performance 22 (Markelova \& Mwangi, 2010).

Conversely, the TE scores for ARFAN members remain consistently and significantly higher than those of nonmembers in both conventional and selectivity SPF models. The stochastic metafrontier model (SMF) in Table A4.5 also indicates that members consistently have higher metafrontier TE values, although both members and nonmembers operate close to the metafrontier. Therefore, this suggests that group membership plays an important role in improving member's knowledge, technical performance and economies of scale (Markelova et al., 2009).

Table 4.6: Technical efficiency levels across the SPF models

\begin{tabular}{|c|c|c|c|c|c|c|c|c|}
\hline \multirow{2}{*}{ SPF model } & \multicolumn{2}{|c|}{ Pooled } & \multicolumn{2}{|c|}{ Members } & \multicolumn{2}{|c|}{ Nonmembers } & \multirow{2}{*}{ Change (\%) } & \multirow{2}{*}{ Test of means } \\
\hline & Mean & St. Err. & Mean & St. Err. & Mean & St. Err. & & \\
\hline \multicolumn{9}{|l|}{ Unmatched } \\
\hline Conventional & 0.857 & 0.003 & 0.878 & 0.040 & 0.821 & 0.068 & 6.943 & $7.708 * * *$ \\
\hline Sample selection & 0.831 & 0.037 & 0.835 & 0.071 & 0.822 & 0.064 & 1.458 & $1.670 * *$ \\
\hline TE difference (\%) & -3.129 & & -5.150 & & 0.122 & & & \\
\hline \multicolumn{9}{|l|}{ Matched } \\
\hline Conventional & 0.835 & 0.059 & 0.838 & 0.071 & 0.821 & 0.067 & 2.071 & $1.967 * *$ \\
\hline Sample selection & 0.822 & 0.004 & 0.831 & 0.008 & 0.819 & 0.004 & 1.465 & $1.412 *$ \\
\hline TE difference (\%) & -0.973 & & -6.482 & & -0.244 & & & \\
\hline
\end{tabular}

$* * * p<0.01, * * p<0.05, * p<0.1$

We also compare the effect of MEMBERSHIP on TOTALCAP assuming all shrimpers' operations are efficient. For this, we use the mean predicted frontier catch generated from the unmatched and matched conventional and selectivity SPF models. Thus, the differentials in

\footnotetext{
${ }^{22}$ Additionally, the matching procedure could have dropped high-performing members of fisher groups.
} 
TOTALCAP measured, which are distances between the group production frontiers for MEM and CONN (i.e. technological gap), are presented in Table 4.7, alongside the respective $t$-tests. Table 4.7 shows that without correcting for observed differences and selection bias, ARFAN members attain a higher catch than nonmembers, with an average predicted frontier of 62.82 tons compared to about 53 tons, respectively. This comes with a highly statistically significant technical change of about $18.53 \%$. However, the technical change fades off to $11.03 \%$ and $1.27 \%$ after controlling for observed and unobserved differences, respectively. Still, these differentials remain consistently higher for members ${ }^{23}$ suggesting that participation in ARFAN and other local fisher groups contributes to improving shrimp catches.

Table 4.7: Predicted frontier output for unmatched and matched samples

\begin{tabular}{lccccc}
\hline \multicolumn{1}{c}{ SPF model } & Pooled & Members & Nonmembers & $\begin{array}{c}\text { Technical } \\
\text { change (\%) }\end{array}$ & Test of means \\
\hline $\begin{array}{l}\text { Unmatched conventional } \\
\text { Mean }\end{array}$ & 55422.65 & 62820.67 & 52998.10 & 18.53 & $2.45^{* * *}$ \\
Minimum & 19684.96 & 24421.24 & 19684.96 & & \\
Maximum & 234011.80 & 332576.90 & 234011.80 & & \\
Matched conventional & & & & & \\
Mean & 53841.56 & 58846.39 & 52998.10 & 11.03 & \\
Minimum & 19684.96 & 26533.19 & 19684.96 & & \\
Maximum & 234011.80 & 171894.10 & 234011.80 & & \\
Matched sample selection & & & & & \\
Mean & 53971.80 & 54480.06 & 53796.47 & 1.27 & \\
Minimum & 19912.85 & 22886.43 & 19912.85 & & \\
Maximum & 238923.70 & 174172.20 & 238923.70 & & \\
\hline$* * * p<0.01 * * p<0.05 * p<0.1$ & & & & & \\
\end{tabular}

\subsection{Concluding remarks and policy implications}

In this study, we used a selectivity correcting model to examine the role of fisher groups in improving artisanal fishers' capture and technical efficiency in Africa. Using recent crosssectional survey data collected from 353 artisanal shrimpers in the major shrimping communities in southern Nigeria, we contribute empirically by identifying factors that influence shrimpers' decisions to belong to producer groups. Additionally, we employ an approach that combines PSM and Greene's (2010) sample selection correction stochastic production frontier to estimate unbiased effects of group membership on artisanal shrimpers' productivity and TE. This approach allows for the correction of potential selection bias arising from both observed and unobserved factors.

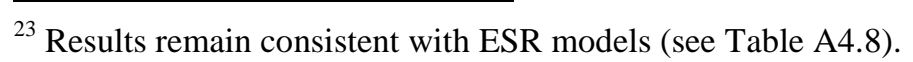


The probit models reveal that shrimpers' age, experience and education; female household members' participation in shrimp-related groups; access to tarmacked roads; and participation in financial cooperatives are the main determinants of shrimpers' participation in fisher groups. Of these, female household members, tarmacked roads and financial cooperatives have the highest positive marginal effects on group membership decisions, reiterating the importance of women and infrastructural facilities in the African fishery subsector (Oluwatayo \& Adedeji, 2019; WorldFish, 2018). The SPF likelihood ratio test indicates that the estimation of separate production frontiers for members and nonmembers is preferred in both unmatched and matched samples. As in other African fishery subsectors, conventional inputs such as engine, fuel and skipper are the main factors of production for members and nonmembers in the Nigerian shrimp subsector.

Furthermore, the estimates show the presence of selection bias, implying that the selectivitycorrection procedures adopted in this study were relevant to mitigating the effect of unobserved attributes. The empirical results from separate SPF models revealed that fisher groups such as ARFAN tend to improve shrimpers' capture and TE. Although values are over-estimated without selectivity models, TE and capture remain consistently higher for members in both conventional and selectivity models. TE for members ranges from 0.831 to 0.878 and from 0.819 to 0.822 for nonmembers, subject to how biases were corrected. Against previous non-selectivity correcting studies, these results show the importance of accounting for selectivity from both observed and unobserved attributes, to avoid over-estimation of group membership effects on fishery capture and TE. The selectivity results further show the inclusiveness of fisher groups, in that shrimpers with below-average performance tend to participate more in ARFAN.

Our results have several policy implications. The finding that fisher groups play an important role in improving the capture and TE of artisanal shrimpers spurs the need for increased policy support from the governments, private agribusiness firms and development stakeholders. Such policy support is needed to: (i) encourage the formation of fisher groups in areas in which they are nonexistent and/or malfunctioning; (ii) align the objectives of fisher groups to enhance the members' comparative advantage beyond current production-oriented activities; (iii) stimulate nonmember shrimpers to join fisher groups; and (iv) implement far-reaching agricultural and value chain development interventions through fisher groups.

According to our results, government and development agencies can facilitate shrimpers' 
participation in fisher groups by investing in female empowerment and infrastructures such as schools/training centers, tarmacked roads and integrative cooperative schemes (Abdul-Rahaman \& Abdulai, 2018; Chagwiza et al., 2016; Ma \& Abdulai, 2016). In particular, state governments and development stakeholders in Ondo and Akwa-Ibom would need concentrated policy measures and public-private partnerships to incentivize formation of and participation in fisher groups.

Furthermore, the presence of selection bias provides policy insights on the equity effects of fisher groups in Nigeria. Our result that shrimpers with below-average capture have a higher probability of participating in ARFAN indicates that fisher groups may lead to a more even distribution of economic performance and wealth in Nigeria and other similar African countries. Hence, the current Nigerian Agriculture Promotion Policy should seek to support the operations and dynamics of fisher groups to foster the attainment of inclusive agricultural and economic growth. Policy instruments, like research and development and training, would build the technical capability of fisher groups and enhance members' skillsets and, consequently, motivate nonmembers to participate in fisher groups. This can be coupled with effective government and private extension services that target technology transfer, enhance sustainable production and marketing activities and coordinate business relationships (FAO, 2007; FMARD, 2011, 2016).

This study is limited by its inability to capture large samples and variations in shrimpers' sociodemographic characteristics over time. Thus, future research could use panel data to provide more insights into the effect of group membership on productivity. Although this study has focused on the productivity effect of fisher groups, future research can determine whether the positive effects translate into better welfare for artisanal shrimpers in Nigeria and other developing countries.

\section{Appendix 4}

Table A4.1: Hypothesis testing for Stochastic Production Frontier Models

\begin{tabular}{lcccl}
\hline Null Hypothesis $H_{0}$ & $\chi^{2}$ statistics & $\begin{array}{c}\text { Degree of } \\
\text { freedom }\end{array}$ & $\begin{array}{c}\chi^{2} \\
\text { Critical }\end{array}$ & Decision \\
\hline $\begin{array}{l}\text { Unmatched conventional } \\
\text { Cobb-Douglas (CD) is appropriate: } \beta_{i j}=0\end{array}$ & 11.95 & 6 & 9.99 & Reject $\mathrm{H}_{0}:$ CD is inadequate \\
Members & 6.89 & 6 & 9.99 & Accept $\mathrm{H}_{0}: \mathrm{CD}$ is adequate \\
Nonmembers & 11.55 & 6 & 9.99 & ${\text { Reject } \mathrm{H}_{0}: \mathrm{CD} \text { is inadequate }}_{\text {Matched conventional }}$ \\
Members & 6.89 & 6 & 9.99 & Accept $\mathrm{H}_{0}: \mathrm{CD}$ is adequate \\
Nonmembers & & & & \\
\hline
\end{tabular}

Homogenous technology across channels 


\begin{tabular}{|c|c|c|c|c|}
\hline $\begin{array}{l}\text { Unmatched conventional } \\
\text { Matched conventional }\end{array}$ & $\begin{array}{l}35.20 \\
32.26\end{array}$ & $\begin{array}{l}19 \\
19\end{array}$ & $\begin{array}{l}32.24 \\
32.24\end{array}$ & $\begin{array}{l}\text { Reject } \mathrm{H}_{0}: \text { No homogenous technology } \\
\text { Reject } \mathrm{H}_{0}: \text { No homogenous technology }\end{array}$ \\
\hline $\begin{array}{l}\text { Unmatched conventional } \\
\text { No technical efficiency effects: } \gamma=0\end{array}$ & z statistics & $p$-value of $\mathrm{z}$ & & \\
\hline Members & 2.99 & 0.00 & & Reject $\mathrm{H}_{0}$ : Frontier not OLS \\
\hline Nonmembers & 6.54 & 0.00 & & Reject $\mathrm{H}_{0}$ : Frontier not OLS \\
\hline Matched conventional & & & & \\
\hline Members & 3.49 & 0.00 & & Reject $\mathrm{H}_{0}$ : Frontier not OLS \\
\hline Nonmembers & 6.54 & 0.00 & & Reject $\mathrm{H}_{0}$ : Frontier not OLS \\
\hline
\end{tabular}

Table A4.2: Probit model estimates of determinant of membership in producer group (matched sample)

\begin{tabular}{|c|c|c|c|c|}
\hline \multirow{2}{*}{ MEMBERSHIP } & \multicolumn{2}{|c|}{ Probit coefficients } & \multicolumn{2}{|c|}{ Marginal effects } \\
\hline & Coef. & St. Err. & Coef. & St. Err. \\
\hline AGE & $0.22 * * *$ & 0.064 & $0.051 * * *$ & 0.014 \\
\hline AGESQUARE & $-0.002 * * *$ & 0.0007 & $-0.0005 * * *$ & 0.0002 \\
\hline EXPEREIENCE & $0.020 *$ & 0.011 & $0.005^{*}$ & 0.002 \\
\hline LEADER & -0.251 & 0.282 & -0.056 & 0.064 \\
\hline EDUCYEAR & 0.033 & 0.028 & 0.008 & 0.005 \\
\hline REPEAT & -0.240 & 0.330 & -0.055 & 0.075 \\
\hline FEMLABSHR & $-0.140 * *$ & 0.066 & $-0.032 * *$ & 0.015 \\
\hline FEMASS & $0.631 * * *$ & 0.203 & $0.144 * * *$ & 0.045 \\
\hline AKWA-IBOM & $-0.931^{* * *}$ & 0.347 & $-0.213^{* * *}$ & 0.077 \\
\hline ONDO & $-1.141 * * *$ & 0.234 & $-0.261 * * *$ & 0.049 \\
\hline MOBILE & 0.103 & 0.303 & 0.024 & 0.069 \\
\hline EXTENSION & 0.509 & 0.411 & 0.116 & 0.093 \\
\hline CREDIT & 0.315 & 0.206 & 0.072 & 0.047 \\
\hline CUSTOMERS & $-0.134 * *$ & 0.052 & $-0.031 * * *$ & 0.012 \\
\hline TAROAD & $0.615^{* *}$ & 0.302 & $0.140 * *$ & 0.068 \\
\hline COOP & $0.612 * *$ & 0.260 & $0.138 * *$ & 0.058 \\
\hline Constant & $-5.862 * * *$ & 1.419 & & \\
\hline Log-likelihood & -141.740 & & & \\
\hline LR chi2(15) & 111.65 & & & \\
\hline Number of obs. & 347 & & & \\
\hline
\end{tabular}

The results in the model are estimated using equation (5).

Table A4.3: Probit model addressing potential endogeneity (pooled and matched samples)

\begin{tabular}{lllll|lllr}
\hline \multirow{2}{*}{ MEMBERSHIP } & \multicolumn{4}{c}{ Pooled } & \multicolumn{4}{c}{ Matched } \\
\cline { 2 - 9 } & \multicolumn{2}{l}{ Probit coefficients } & \multicolumn{2}{c}{ Marginal effects } & \multicolumn{1}{c}{ Probit coefficient } & \multicolumn{2}{c}{ Marginal effects } \\
\cline { 2 - 8 } & Coef. & St. Err. & Coef. & St. Err. & \multicolumn{1}{c}{ Coef. } & St. Err. & Coef. & St. Err. \\
\hline AGE & $0.220^{* * *}$ & 0.064 & $0.224^{* * *}$ & 0.014 & $0.220^{* * *}$ & 0.064 & $0.220^{* * *}$ & 0.064 \\
AGESQUARE & $-0.002^{* * * *}$ & 0.001 & $-0.002^{* * *}$ & 0.0002 & $-0.002^{* * *}$ & 0.001 & $-0.002^{* * *}$ & 0.001 \\
EXPEREIENCE & $0.019^{*}$ & 0.011 & $0.019^{*}$ & 0.002 & $0.019^{*}$ & 0.011 & $0.019^{*}$ & 0.011 \\
LEADER & -0.256 & 0.283 & -0.256 & 0.064 & -0.248 & 0.282 & -0.248 & 0.282 \\
EDUCYEAR & $0.033^{*}$ & 0.020 & $0.033^{*}$ & 0.005 & 0.033 & 0.020 & 0.033 & 0.020 \\
REPEAT & -0.253 & 0.336 & -0.253 & 0.075 & -0.251 & 0.333 & -0.251 & 0.333 \\
FEMLABSHR & $-0.136^{* *}$ & 0.066 & $-0.136^{* *}$ & 0.015 & $-0.136^{* *}$ & 0.066 & $-0.136^{* *}$ & 0.066 \\
FEMASS & $0.630^{* * *}$ & 0.203 & $0.630^{* * *}$ & 0.045 & $0.618^{* * *}$ & 0.204 & $0.618^{* * *}$ & 0.204 \\
AKWA-IBOM & $-0.909^{* * *}$ & 0.346 & $-0.909^{* * *}$ & 0.077 & $-0.899^{* *}$ & 0.349 & $-0.899^{* *}$ & 0.349
\end{tabular}




\begin{tabular}{lllll|llll} 
ONDO & $-1.132 * * *$ & 0.235 & $-1.132^{* * *}$ & 0.049 & $-1.123^{* * *}$ & 0.235 & $-1.123^{* * *}$ & 0.235 \\
MOBILE & 0.100 & 0.302 & 0.100 & 0.069 & 0.096 & 0.302 & 0.096 & 0.302 \\
EXTENSION & $0.833^{*}$ & 0.488 & 0.833 & 0.093 & 0.780 & 0.495 & 0.780 & 0.495 \\
CREDIT & 0.336 & 0.204 & 0.336 & 0.047 & 0.319 & 0.205 & 0.319 & 0.205 \\
CUSTOMERS & $-0.135^{* * *}$ & 0.051 & $-0.135^{* * *}$ & 0.012 & $-0.135^{* *}$ & 0.052 & $-0.135^{* *}$ & 0.052 \\
TAROAD & $0.599^{* *}$ & 0.300 & $0.599^{* *}$ & 0.068 & $0.593^{*}$ & 0.304 & $0.593^{*}$ & 0.304 \\
COOP & $0.601 * *$ & 0.256 & $0.601 * *$ & 0.058 & $0.598^{* *}$ & 0.259 & $0.598^{* *}$ & 0.259 \\
Constant & $-5.923^{* * *}$ & 1.415 & & & $-5.828^{* * *}$ & 1.414 & & \\
Log-likelihood & 159.899 & & & & 198.320 & & & \\
LR chi2(15) & 87.15 & & & & 80.26 & & & \\
Number of obs. & 353 & & & & 347 & & &
\end{tabular}

$* * * p<0.01, * * p<0.05, * p<0.1$.

The results in the model are estimated using equation (5). We use distance to tarmacked roads and fishers' perception of extension usefulness as instruments to address potential endogeneity (Abdul-Rahaman \& Abdulai, 2018). With Wald $\chi^{2}=1.06$, the null hypothesis of exogeneity cannot be rejected so we rely on Table A4.2 estimates.

Table A4.4: Roles and reasons for participating in fisher groups

\begin{tabular}{ll}
\hline Indicator & \% Yes \\
\hline Roles & \\
Do you sell shrimp products through a fisher group? & 2.13 \\
Do you get inputs through a fisher group? & 14.89 \\
Were you trained through a fisher group? & 21.28 \\
Did you obtain public assistance since joining the fisher group? & 10.64 \\
Reasons & \\
To learn from experienced members & 62.77 \\
To jointly access input markets at lower cost & 39.36 \\
To receive high market prices & 19.15 \\
To collaborate when not having necessary inputs & 69.15 \\
To increase profit & 30.85 \\
To get government support & 77.66 \\
To market product easily & 32.98 \\
To access credit facilities & 78.72 \\
To feel a sense of belonging in the village & 70.21 \\
\hline So : Aus'
\end{tabular}

Source: Authors' illustration based on field survey

Table A4.5: Metafrontier levels across the stochastic metafrontier (SMF) models

\begin{tabular}{lcccc}
\hline \multirow{2}{*}{ SPF model } & \multicolumn{3}{c}{ Members } & \multicolumn{2}{c}{ Nonmembers } \\
\cline { 2 - 5 } & Mean & St. Err. & Mean & St. Err. \\
\hline Unmatched Conventional & & & & \\
Technological gap ratio (TGR) & 0.99 & 0.01 & 0.99 & 0.002 \\
Metafrontier technical efficiency (MTE) & 0.87 & 0.04 & 0.82 & 0.07 \\
$\begin{array}{l}\text { Unmatched Selection corrected } \\
\text { Technological gap ratio (TGR) }\end{array}$ & 1.00 & 0.05 & 1.00 & 0.04 \\
Metafrontier technical efficiency (MTE) & 0.83 & 0.08 & 0.82 & 0.07 \\
Matched Conventional & & & & \\
Technological gap ratio (TGR) & 1.00 & 0.01 & 1.00 & 0.002 \\
Metafrontier technical efficiency (MTE) & 0.84 & 0.07 & 0.82 & 0.07 \\
Matched Selection corrected & & & & \\
Technological gap ratio (TGR) & 1.00 & 0.04 & 1.00 & 0.04 \\
Metafrontier technical efficiency (MTE) & 0.83 & 0.09 & 0.82 & 0.07 \\
\hline
\end{tabular}

Calculated following Huang et al.'s (2014) two-step SMF regression method that applies, first, the conventional maximum likelihood method to estimate parameters of SMF regression and second, the SMF method to directly estimate technology gaps by treating them as a conventional one-sided error term. 
Table A4.6: Endogenous switching regression for unmatched sample

\begin{tabular}{|c|c|c|c|c|c|c|}
\hline & \multicolumn{4}{|c|}{ Capture } & \multirow{3}{*}{$\begin{array}{l}\text { Coef. } \\
\text { Selection } \\
\end{array}$} & \multirow[b]{2}{*}{ Std.Err. } \\
\hline & Coef. & Std.Err. & Coef. & Std.Err. & & \\
\hline & \multicolumn{2}{|c|}{ Members } & \multicolumn{2}{|c|}{ Nonmembers } & & \\
\hline AGE & 0.011 & 0.028 & 0.007 & 0.012 & 0.106 & 0.090 \\
\hline AGESQUARE & -0.000 & 0.000 & -0.000 & 0.000 & -0.001 & 0.001 \\
\hline SHRIMPYEAR & -0.005 & 0.004 & 0.003 & 0.003 & 0.014 & 0.015 \\
\hline LEADER & 0.117 & 0.121 & $0.207 * * *$ & 0.073 & 0.015 & 0.435 \\
\hline EDUCYEAR & -0.001 & 0.008 & 0.004 & 0.005 & -0.004 & 0.030 \\
\hline FEMLABSHR & 0.041 & 0.034 & $0.027 *$ & 0.015 & -0.164 & 0.108 \\
\hline FEMASS & 0.084 & 0.073 & -0.043 & 0.067 & 0.426 & 0.299 \\
\hline Akwa_STATE & $0.335 * * *$ & 0.120 & 0.159 & 0.122 & 0.484 & 0.791 \\
\hline Ondo_STATE & 0.061 & 0.110 & $0.270 * * *$ & 0.061 & $-1.020 * *$ & 0.398 \\
\hline MOBILE & $-0.558 * * *$ & 0.141 & 0.007 & 0.072 & 0.117 & 0.421 \\
\hline SE1 & 0.083 & 0.101 & 0.037 & 0.169 & $0.837 *$ & 0.501 \\
\hline CREDIT & $-0.168 * *$ & 0.076 & 0.016 & 0.059 & 0.349 & 0.306 \\
\hline VR1 & 0.018 & 0.019 & 0.015 & 0.013 & -0.012 & 0.071 \\
\hline SHOCK & 0.023 & 0.067 & 0.068 & 0.052 & -0.007 & 0.283 \\
\hline TAROAD & -0.105 & 0.092 & 0.135 & 0.113 & $-1.103 *$ & 0.640 \\
\hline COOP & -0.124 & 0.086 & $0.105 * * *$ & 0.094 & 0.605 & 0.387 \\
\hline SHRIMPLABOR_r1_c1 & $0.201 * * *$ & 0.066 & $0.221 * * *$ & 0.055 & 0.070 & 0.278 \\
\hline SHRIMPLABOR_r2_c1 & $0.170 * * *$ & 0.061 & $0.153 * * *$ & 0.048 & 0.108 & 0.241 \\
\hline NeighmemberAsso & & & & & $3.221 * * *$ & 0.366 \\
\hline ProdgroupNumber & & & & & $0.281 * *$ & 0.142 \\
\hline _cons & $10.588 * * *$ & 0.627 & $9.748 * * *$ & 0.270 & $-4.674 * *$ & 2.073 \\
\hline /lns1 & $-1.240 * * *$ & 0.072 & & & & \\
\hline /r1 & $-0.443 * *$ & 0.221 & & & & \\
\hline$/ \operatorname{lns} 2$ & & & $-1.053 * * *$ & 0.045 & & \\
\hline /r2 & & & 0.153 & 0.399 & & \\
\hline LR test of indep. eqns.: & $4.71 * *$ & & & & & \\
\hline Log likelihood & -172.251 & & & & & \\
\hline Observations & 353 & & 353 & & 353 & \\
\hline
\end{tabular}

$* * * p<0.01, * * p<0.05, * p<0.1$.

Table A4.7: Endogenous switching regression for matched sample

\begin{tabular}{|c|c|c|c|c|c|c|}
\hline & \multicolumn{4}{|c|}{ Capture } & \multirow{3}{*}{$\begin{array}{l}\text { Coef. } \\
\text { Selection }\end{array}$} & \multirow[b]{2}{*}{ Std.Err } \\
\hline & Coef. & Std.Err. & Coef. & Std.Err. & & \\
\hline & \multicolumn{2}{|c|}{ Members } & \multicolumn{2}{|c|}{ Nonmembers } & & \\
\hline AGE & 0.008 & 0.028 & 0.007 & 0.012 & 0.099 & 0.089 \\
\hline AGESQUARE & -0.000 & 0.000 & -0.000 & 0.000 & -0.001 & 0.001 \\
\hline SHRIMPYEAR & -0.005 & 0.004 & 0.003 & 0.003 & 0.013 & 0.015 \\
\hline LEADER & 0.123 & 0.122 & $0.206 * * *$ & 0.073 & 0.020 & 0.432 \\
\hline EDUCYEAR & -0.003 & 0.009 & 0.004 & 0.005 & -0.012 & 0.031 \\
\hline FEMLABSHR & 0.045 & 0.035 & $0.027 *$ & 0.015 & -0.163 & 0.107 \\
\hline FEMASS & 0.074 & 0.076 & -0.042 & 0.067 & 0.414 & 0.298 \\
\hline Akwa_STATE & $0.361 * * *$ & 0.127 & 0.158 & 0.122 & 0.510 & 0.787 \\
\hline Ondo_STATE & 0.066 & 0.111 & $0.268 * * *$ & 0.061 & $-1.005 * *$ & 0.395 \\
\hline MOBILE & $-0.566 * * *$ & 0.143 & 0.006 & 0.072 & 0.141 & 0.423 \\
\hline SE1 & 0.098 & 0.113 & 0.036 & 0.167 & 0.695 & 0.521 \\
\hline CREDIT & $-0.152 *$ & 0.079 & 0.017 & 0.059 & 0.371 & 0.308 \\
\hline VR1 & 0.012 & 0.020 & 0.015 & 0.013 & -0.013 & 0.071 \\
\hline SHOCK & -0.010 & 0.070 & 0.067 & 0.052 & -0.011 & 0.285 \\
\hline TAROAD & -0.118 & 0.099 & 0.136 & 0.114 & $-1.126^{*}$ & 0.636 \\
\hline COOP & -0.140 & 0.088 & 0.106 & 0.094 & 0.553 & 0.393 \\
\hline SHRIMPLABOR_r1_c1 & $0.203 * * *$ & 0.068 & $0.220 * * *$ & 0.055 & 0.078 & 0.276 \\
\hline
\end{tabular}


SHRIMPLABOR_r 2 c1

NeighmemberAsso

ProdgroupNumber

_cons

/lns 1

/r1

$/ \operatorname{lns} 2$

$/ \mathrm{r} 2$

LR test of indep. eqns.:

Log likelihood

Observations
$0.141 * *$

$-1.236 * * *$

$-0.463 * *$

$5.02 * *$

$-171.087$
0.063

0.074

0.224

$* * * p<0.01, * * p<0.05, * p<0.1$.

$0.154 * * *$

$-1.052 * * *$

0.184

347
0.048

0.105

$3.219 * * *$

0.241

$0.297 * *$

0.366

0.142

0.269

$-4.483 * *$

2.073

Table A4.8: Endogenous switching regression showing effects of fisher group on capture

\begin{tabular}{llcrc}
\hline Output $^{\mathrm{a}}$ & Members & Nonmembers & ATT & t-value \\
\hline Unmatched & 10.771 & 10.686 & 0.085 & $3.766^{* * *}$ \\
Matched & 10.735 & 10.604 & 0.132 & $5.617^{* * *}$
\end{tabular}

Note: ATT, average treatment effect on the treated. ${ }^{\mathrm{a}}$ Log of capture in peak season is used as dependent variable for ESR. ATT is also given in $\log$ form.

$* * * p<0.01, * * p<0.05, * p<0.1$.

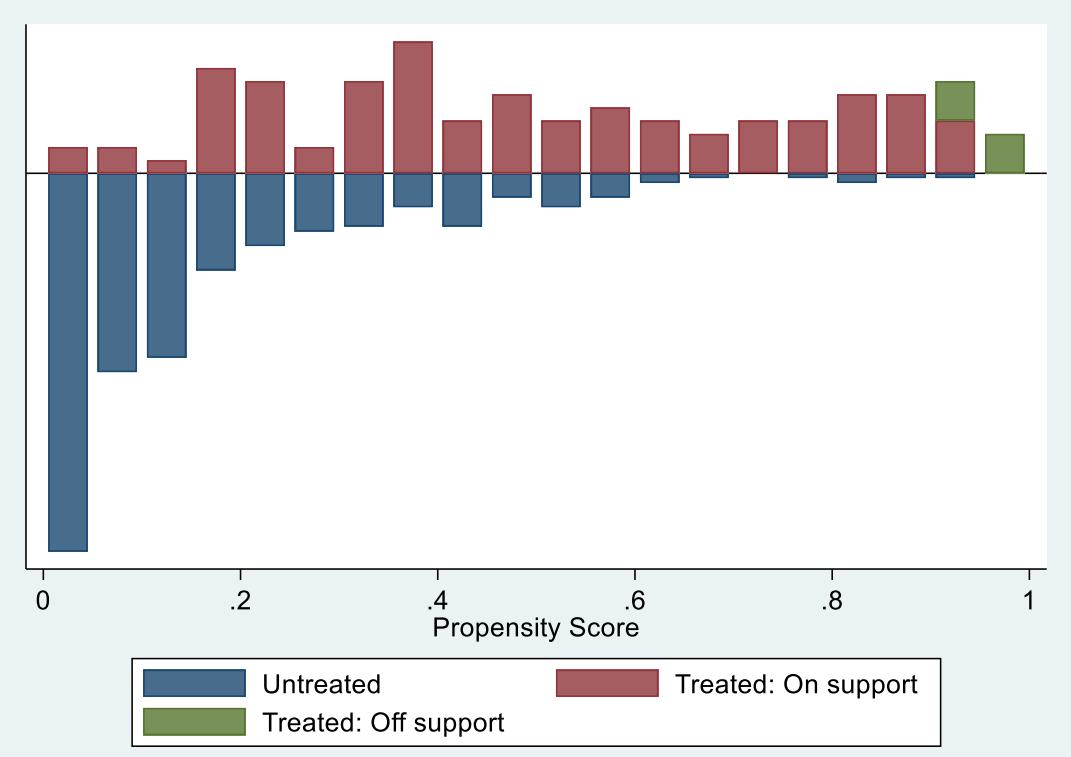

Figure A4.1: Common support property for the PSM model 


\section{General conclusions}

The emergence of modern value chains (MVC) with stringent governance mechanisms and private standards in developing countries' agrifood systems has several implications for smallholders and women, particularly regarding their exclusion and economic marginalization. As a response to these contingencies, excluded smallholders and women develop alternative markets and modify their organizational relationships to form local value chains (LVC), which are often within their reach. LVCs' upgrading can, therefore, be an alternative development model to reduce poverty and economic marginalization for numerous smallholders and women in developing countries (Lie et al., 2012; Markelova et al., 2009). Though there are few emerging studies on LVCs, it is still important to understand the organizational structures of LVCs to suggest possible upgrading strategies that will improve smallholders' and women's performance (Lie et al., 2012; Mani et al., 2018). This is particularly important for neglected smallholders in dualistic agrifood systems in which LVCs function parallel to MVCs. While there are indications that smallholders update their organizational structures to fit changing contingencies, there is no consensus about the association among their business contingencies, organizational structures and performance in the literature. With a focus on the Nigerian shrimp and prawn sector, this dissertation aims at bridging these gaps by exploring the association between smallholders' organizational structures and performance in the neglected LVCs of developing countries.

\subsection{Main findings}

In the first paper, we uncovered how LVCs in dualistic systems are organized along their predominant governance themes and gender roles to come up with necessary upgrading strategies for smallholders. By doing this, we map LVCs distinctively from MVCs and consider all predominant governance mechanisms along the chain. We also make a conceptual contribution by extending and suggesting a framework that includes global value chain (GVC) and gendered value-web approaches. This framework is relevant as it allows for the simultaneous analysis of the roles of governance themes and hidden gender-relations in LVCs.

Results from the Net-map indicate that the most important and predominant LVC marketing channel is long and includes in this case, producer-women processors/marketer-trader-retailerconsumer link. A long chain has ensued because most producers are located in secluded coastal areas that are far from local markets and cities. Thus, the system relies on intermediaries' activities to move products from the supply base to local markets. The results also highlight the 
emergence of regional markets and industrial firms, suggesting that the LVC has developed over time. However, smallholders continue to target final consumers in the local retail markets due to the presence of huge demand that transmits into higher product value.

Against the pre-notion that LVCs are unstructured in developing countries, this LVC was found to be structured, with coordinated activities and trading partners and target markets. Analysis of the governance themes according to the GVC framework suggests that the LVC is buyer-driven such that competitive traders at the midstream are the lead actors and main drivers of the chain. Traders engage in a "hub and spoke business model" by continuously sourcing and consolidating products from landing sites and marketing them in different markets. Traders dominate because they have access to rich market information and higher purchasing and bargaining power. To deal with the product characteristics such as high perishability and counter traders' power along the LVC, fishers, and processors evolve their activities and governance mechanisms. Fishers and processors, based on their gender comparative advantages, have become specialized and shifted from open-market transactions to relational governance, managed by reputation, social ties, and proximity.

Additionally, analysis of the gendered value-web highlights the vital role that women, particularly processors play in ensuring value addition and effective flow of products along the LVC. Aside from their processing activities that increase product's shelf life and marketing opportunities, women processors act as a financial cushion for fishermen, point of contact for the supply base and precursor to all midstream and industrial value additions. However, benefits were found to be distributed inequitably to both fishermen and women processors at the supply base because of several organizational and infrastructural constraints that suggest the need to critically focus on the production and processing segments.

The second paper comprehensively analyzes the influence between external and internal contingencies, organizational SC network structures and performance across multi-tiers. Based on the results and implications of the first paper, a variance-based structural equation model was employed to analyze quantitative data from mutually dependent producers and women processors. This paper contributes to the existing literature by taking a cue from contingent resource-based theory and netchain approach to suggest the "Contingency-NetchainPerformance" (CNP) framework that comprehensively depicts the influence of both external and internal contingencies on smallholders' organizational SC network relationships and 
performance. The resulting CNP framework was empirically tested on the production and processing tiers to derive valid and rich evidence comparable across tiers. Our results indicate that both external and internal business environments significantly influence smallholders' organizational SC network relationships in both producer and processor models.

Against what holds in some extant literature, all external contingencies (such as market turbulence, technological progress, distrust, and power asymmetry) positively influence the formation of tighter vertical coordination. However, the influence and significance of external contingencies were found to be different for horizontal and lateral relationships across the tiers. This confirms vertical and network relationships as complementary, such that there are several organizational adaptation strategies for smallholders to deal with highly dynamic contingencies. The influence of internal contingencies (such as human and financial resources) on organizational SC network structures represents one of the main findings in this paper. This result highlights the importance of organizational reconfiguration to adapt and fit to changes in smallholders' internal contingencies. Our result that SC vertical relationships positively influence horizontal and consequently, lateral relationships, indicates the organizational adaptation pathways in which smallholders tend to forge complex organizational SC networks when dealing with higher contingencies.

Further, we found that internal contingencies and organizational SC network structures influence smallholders' performance. The consistent positive association between internal contingencies and performance indicates that smallholders' performances are resource-based. Besides, vertical and horizontal relationships positively influence producers' and processors' performance, respectively, confirming the contingency paradigm of fit for smallholder producers' and processors' facing highly dynamic contingencies.

We estimate stochastic production frontier (SPF) models that correct for selectivity in the third paper to understand the role of producer groups in improving artisanal fishers' productivity and technical efficiency. With this, we empirically determined the factors that influence fisher's decision to participate in fisher groups and analyzed the effect of group membership on fishers' productivity and technical efficiency. We employed an approach that combines Propensity Score Matching (PSM) and Greene's SPF model to account for different technological sets and correct for selectivity biases from observed and unobserved variables. Our results indicate that shrimpers' socioeconomic characteristics such as age, education, and experience; female 
household members; and infrastructural facilities such as access to tarmacked roads and social participation in local financial cooperatives have significantly positive influences on shrimpers' decision to participate in fisher groups. Of these, female household members, access to tarmacked roads and participation in financial cooperatives have the highest positive marginal effects on group membership. However, number of females participating in shrimping activities, Ondo and Akwa-Ibom location effects, and number of major trading partners exhibit significantly negative effects on group membership. Institutional factors such as extension and credit access did not exhibit significant influences on group membership.

The SPF likelihood ratio test indicates the presence of different technological sets and supports the estimation of separate production frontiers for members and nonmembers. Our results show that conventional inputs such as engine, fuel, and skipper exhibit significantly positive effects on members' and nonmembers' capture. Prior linear regression tests and estimates in our SPF models indicate the presence of selection bias, implying that the selectivity-correction procedures adopted in this study were relevant to mitigate biased effects from unobserved attributes. The empirical results from separate SPF models revealed that fisher groups tend to improve capture and TE. Values are over-estimated without selectivity models, although TE and productivity values remain consistently higher for members in both conventional and selectivity models. Similarly, we find from our stochastic metafrontier model (SMF) that metafrontier technical efficiency (MTE) values are consistently higher for members, though both members and nonmembers function close to the metafrontier. This suggests that the TE values of nonmembers pull their mean MTE values down. Overall, these results indicate the importance of selectivity correcting SPF to estimate the effect of group membership on fishers' capture and TE.

\subsection{Policy implications}

Several policy insights are derived from this dissertation for policymakers regarding how smallholders can be organized to develop and upgrade their activities and improve overall smallholder competitiveness within LVCs. These implications aim at upgrading existing policies and motivating the formation of new encompassing interventions and programs to support smallholders in LVCs.

Our findings suggest that the development of LVCs holds several opportunities that can contribute to poverty reduction, attainment of economic equality and propagation of gendered opportunities among smallholders in developing countries (Lie et al., 2012; Markelova et al., 
2009). However, our results in the first paper suggest that smallholders at the LVCs' supply base are constrained by limited technical skills, market access, innovative resources, physical infrastructure and institutions (Trienekens, 2011). These factors were later found to be crucial in improving smallholders' competitiveness in the second paper. Policy interventions should, therefore, provide an enabling physical and financial environment for smallholders, particularly in areas where basic physical and financial infrastructures are limited.

Besides, private firms' activities were found to be limited in the subsector, which consequently restricts entrepreneurial innovativeness and market development along the LVC. Thus, policymakers need to provide an enabling environment for private firms to act and formulate inclusive interventions that can reposition and involve smallholders progressively along the LVC. More importantly, well-coordinated public-private partnerships are imminent to improve entrepreneurial efficacy and smallholders' operational efficiency and effectively link them to the growing local and regional demands (AUC/OECD, 2019; Trienekens, 2011). Only after these policies and smallholder's process upgrading are achieved can product upgrading begin. The fact that these policies might take time to implement implies that actors along the LVCs should continue to target domestic and regional markets. With this, smallholders at the supply base can reap from LVCs' emerging opportunities and gather experiences needed to deal with MVCs' contingencies.

Results from the analysis of the gendered value-web suggest that fishers and women processors are mutually dependent. This further indicates that they both face almost similar contingencies and problems. Thus, policies for effective process and product upgrading at the upstream and LVC development should simultaneously consider the two segments and be tailored to target smallholders' differentiated gender roles. Our results generally indicate that women processors are important to accrue benefits to the supply base, counter traders' bargaining and negotiating power, obtain information and determine producers' participation in fisher groups (AUC/OECD, 2019; FAO, 2016a; Kamau \& Ngigi, 2013; Schumacher, 2014; Udong et al., 2009; Udong et al., 2010). As a result, policy interventions that provide complementary assets, financial support, training, and technologies are needed to further empower women both along LVCs and within households, reduce their drudgery and improve technical ability.

Several policy implications emerged from the results on the role of organizational structures on smallholders' performance in the second paper. The fact that all external contingencies 
significantly influence smallholders' organizational SC network structures implies that policymakers need to postulate protective policies that shield smallholders from external contingencies such as market turbulence and power asymmetry.

Although smallholders have tried to independently organize themselves by forming "relational governance" to deal with some contingencies, the producer-processor interface still lacks coordination to overcome certain contingencies such as technological turbulence and power asymmetry. Complementarily, smallholders would need to deal with all external contingencies in several ways, particularly by coordinating transactions with their trading partners and forging closer networks with competitors, extension agents and NGOs. Therefore, policymakers and NGOs should attach greater importance to stimulate and support the optimization of producerprocessor and processor-trader relationships by encouraging efficient information sharing through digitalization, and nudging smallholders to make concrete business strategies and plan (Hobbs \& Young, 2000; Trienekens, 2011). The diverse influences of organizational relationships on performance across tiers reiterate that policy interventions should not be a "one-size-fit-all". While the formation of tighter vertical relationships is crucial for producers as it fit their contingencies and improve shrimping performance, policymakers should stimulate women processors to forge closer horizontal relationships.

While the role of external actors to support smallholders to adapt to certain contingencies has been highlighted, the negative influence of lateral relationships on smallholders' production and gross margins is surprising. This result should serve as a new proof to policymakers and NGOs that public institutions in developing countries need to be overhauled to ensure that opportunity costs of interacting with external actors do not outweigh its benefits (Emmanuel et al., 2016). Policymakers need to ensure that public institutions' capacities are revamped, staff well trained and budgets consistent to foster the invention and effective dissemination of knowledge and technologies to smallholders.

The positive influence of horizontal relationships on catches, gross margins, productivity and technical efficiency in the third and fourth chapters suggests that collective action plays an important role in improving smallholders' economic performance and welfare in neglected LVCs. Thus, policymakers at federal and state levels should encourage the formation of fisher groups in areas where they are non-existing or functional so far, strategically align group objectives to support members and encourage artisans to join producers. Important lessons can be 
derived from the factors that determine smallholders' participation in fisher groups. Besides the needed provision and improvement in physical infrastructure, the results from path analysis (Chapter 3) and probit models (Chapter 4) show that smallholders' internal contingencies are important determinants of group membership for fisher folks. For instance, policies aimed at training producers, building tarmacked roads and supporting financial institutions should be encouraged. Nevertheless, the study warns that not all rare resources are valuable to create and sustain smallholders' competitiveness. For instance, credit access is generally considered strategic in developing countries, however stringent and unfavorable repayment conditions could make it costly for smallholders. Policymakers should establish and encourage less stringent and more favorable formal and informal financial services for smallholders.

\subsection{Limitations and suggestions for future research}

Some research limitations are acknowledged in this dissertation. The first paper in the second chapter is based on qualitative data obtained from focus group discussions and key informant interviews. Although we triangulated and validated our findings with several sources, relying on respondents' qualitative perceptions could have skewed obtained data. Additionally, the snowball selection of experienced respondents from just three States could have biased our findings and omitted important socio-cultural concepts and contingencies, which affect smallholders' LVC activities. Overall, we posited several upgrading strategies for smallholders based on their gender roles but without cost implications. Future studies can determine the most cost-effective upgrading choices for smallholders, particularly at the supply base. Furthermore, we analyzed the LVC following the dimension suggested by Gereffi \& Fernandez-Stark (2016) and Kaplinsky \& Morris (2001), however, several key dimensions such as the geographic scope, local institutional and stakeholder analyses were not done. This might have limited our understanding and implications regarding how to attain smallholders' upgrading and LVC development in the subsector. Other studies can focus on the analyses of these dimensions.

The scope of the second paper may have been limited by its reliance on perceived assessment of key concepts by respondents. The objective assessment of the data in capturing real-time situations may be questioned, even though statistical tests indicate that the data are considered reliable and valid. Also, although PLS analysis best suits our complex models, it presents several disadvantages. PLS analysis employs a non-parametric approach to evaluate the adequacy of model structure hence, no causal inference can be made. Further concerns border on parameter 
estimates, which are subject to bias and inconsistency. Other studies can employ a covariancebased structural equation modeling to determine causal associations between these concepts (Hair et al., 2012).

Our proposed conceptual framework was successfully developed and tested, although the explanatory power of performance constructs, captured by $\mathrm{R}^{2}$-values, was relatively low based on Hair et al., (2018). Besides, the construct, vertical relationship in the producer model, had a low average variance extracted implying that it has more than 50 percent error. Thus, conclusions from the construct need to be taken with caution. To improve the measures and explanatory power, future studies can further develop our framework by considering intangible resources such as capabilities to find out if intangible resources lead to organizational adaptation and consequently better performance. Differeces in institutional set-up across sectors and countries can be captured by apply the CNP framework to other sectors and industrialized with different type and levels of predominant contingencies, organizational structures and performance measures. Likewise, the organizational structures in this framework can be further extended to include both supporting and pressuring stakeholders, to examine the simultaneous influence on each other and different performance measures such as food quality and sustainability. To understand whether organizational strategies in one tier simultaneously influence organizational decisions in subsequent SC tiers, multi-tier SC management theory (Mena et al., 2013) can be integrated into the CNP framework to link and simultaneously test mutually dependent tiers, using for instance simulation modeling.

A few limitations are further acknowledged regarding the measurement of our dependent variables such as quantities produced and gross margins in the second and third papers. We measured these by subjecting respondents to data recall procedure. While measures of these variables were validated, directly and indirectly, such procedure could lead to recall bias. Besides, we only focused on shrimping activities during the peak season in the third paper. By neglecting activities during the offseason, important productivity decisions for the whole season might have been omitted. Furthermore, focus was placed only on smallholders' productivity and technical efficiency in the third paper; it might be interesting to determine if the positive effects of group membership also translate into better welfare for smallholders. Evidence suggests that producer group membership can positively affect household income and welfare in farm-based 
sectors (Ainembabazi et al., 2017; Ma et al., 2018; Ochieng et al., 2018; Orsi et al., 2017). Thus, other studies can analyze the effect of fisher groups on fishers' income and welfare.

Endogeneity is other possible limitations. The conceptual frameworks in the second study might have resulted in the modeling of internal situations that are endogenous to smallholders' performance while links between internal contingencies could have gone in either direction. We account for this by relying on sound theoretical frameworks, yet inability to correct for bias and inconsistent path estimations are likely disadvantages of PLS-method. Besides, producers could receive extension services due to their membership in fisher groups. This makes access to extension services to be endogenous in predicting group membership. However, we assume no endogeneity in the third paper after exogeneity tests could not be rejected. Since the PLS-method cannot appropriately deal with endogeneity, future research can apply more statistically stringent approaches to account for endogeneity and simultaneously analyze the models.

Further peculiar limitations pertain to the static view obtained by the cross-sectional study design, which does not capture changes over time. This may also bring up some concerns over selectivity and unobserved heterogeneity. It might have been important to explore the dynamism in shrimping and organizational practices in the second paper. For instance, a more robust finding might have been obtained if seasonal variations in smallholders' business contingencies, organizational structures, and performance were accounted for. Similarly, dynamic changes in producer group membership in terms of crowding in and out of members, location-based factors and seasonal agro-climatic conditions such as drought could have had different effects on productivity in the third paper. Additionally, the geographical scope of these studies in three states may have limited the generalizability of obtained results. Although we tried to capture socio-economic differences across different geographical regions, shrimping states omitted might have been facing different contingencies and performance measures. Besides, our analysis on 95 and 89 producer group members in the third paper may be characterized by a lack of variation in socio-demographic characteristics that might not capture the reality. Future research can conduct this analysis using a large variety of panel data that captures these changes over time to provide more insights into the effect of group membership on fishers' productivity and technical efficiency. 


\section{References}

Abate, G. T., Francesconi, G. N., \& Getnet, K. (2014). Impact of agricultural cooperatives on smallholders' technical efficiency: Empirical evidence from Ethiopia. Annals of Public and Cooperative Economics, 85(2), 257-286.

Abdul-Rahaman, A., \& Abdulai, A. (2018). Do farmer groups impact on farm yield and efficiency of smallholder farmers? Evidence from rice farmers in northern Ghana. Food Policy, 81(June), 95-105.

Abdulai, A., \& Huffman, W. (2014). The adoption and impact of soil and water conservation technology: An endogenous switching regression application. Land Economics, 90(1), 2643.

Achoja, F. O. (2019). Analysis of profitability of shrimp value chain in Delta State, Nigeria. Ege Journal of Fisheries and Aquatic Sciences, 36(2), 125-133.

Adekambi, S. A., Dabade, D. S., Kindji, K., den Besten, H. M. ., Faure, M., \& Nout, M. J. R. (2016). Quality and innovation in food chains. In J. Bijman \& V. Bitzer (Eds.), Quality and Innovation in food chains.

AfDB. (2019). African Economic Outlook 2019-Macroeconomic Performance and Prospects. Côte d'Ivoire.

Agbo, F. U., \& Usoroh, B. B. (2015). Marketing of Estuarine Shrimps in Akwa Ibom State, Nigeria. Journal of Marketing and Consumer Research, 15, 63-71.

Aigner, D., Lovell, C. A. K., \& Schmidt, P. (1977). Formulation and estimation of stochastic frontier production function models. Journal of Econometrics, 6(1), 21-37.

Ainembabazi, J. H., van Asten, P., Vanlauwe, B., Ouma, E., Blomme, G., Birachi, E. A., ... Manyong, V. M. (2017). Improving the speed of adoption of agricultural technologies and farm performance through farmer groups: evidence from the Great Lakes region of Africa. Agricultural Economics (United Kingdom), 48(2), 241-259.

Alawode, O. O., \& Oluwatayo, I. B. (2019). Development Outcomes of Fadama III among Fish Farmers in Nigeria: Evidence from Lagos State. Evaluation and Program Planning, 75(April 2018), 10-19.

Alene, A. D., \& Manyong, V. M. (2007). The effects of education on agricultural productivity under traditional and improved technology in northern Nigeria: An endogenous switching regression analysis. Empirical Economics, 32(1), 141-159.

AUC/OECD. (2019). Africa's development Dynamics 2019: Achieving Productive Transformation.

Barrett, C. B., Bachke, M. E., Bellemare, M. F., Michelson, H. C., Narayanan, S., \& Walker, T. F. (2012). Smallholder participation in contract farming: Comparative evidence from five countries. World Development, 40(4), 715-730.

Barrientos, S., Dolan, C., \& Tallontire, A. (2003). A gendered value chain approach to codes of 
conduct in African horticulture. World Development, 31(9), 1511-1526.

Bassett, T. J., Koné, M., \& Pavlovic, N. R. (2018). Power Relations and Upgrading in the Cashew Value Chain of Côte d'Ivoire. Development and Change, 49(5), 1223-1247.

Bellemare, M. F. (2012). As You Sow, So Shall You Reap: The Welfare Impacts of Contract Farming. World Development, 40(7), 1418-1434.

Bernard, T., \& Spielman, D. J. (2009). Reaching the rural poor through rural producer organizations? A study of agricultural marketing cooperatives in Ethiopia. Food Policy, $34(1), 60-69$.

Bernard, T., \& Taffesse, A. S. (2012). Returns to scope? Smallholders' commercialisation through multipurpose cooperatives in Ethiopia. Journal of African Economies, 21(3), 440464.

Bernard, T., Taffesse, A. S., \& Gabre-Madhin, E. (2008). Impact of cooperatives on smallholders' commercialization behavior: Evidence from Ethiopia. Agricultural Economics, 39(2), 147-161.

Bondad-Reantaso, M. G., Subasinghe, R. P., Josupeit, H., Cai, J., \& Zhou, X. (2012). The role of crustacean fisheries and aquaculture in global food security: Past, present and future. Journal of Invertebrate Pathology, 110(2), 158-165.

Bravo-Ureta, B. E., Greene, W., \& Solís, D. (2012). Technical efficiency analysis correcting for biases from observed and unobserved variables: An application to a natural resource management project. Empirical Economics, 43(1), 55-72.

Brush, T. H., \& Artz, K. W. (1999). Toward a contingent resource-based theory: The impact of information asymmetry on the value of capabilities in veterinary medicine. Strategic Management Journal, 20(3), 223.

Carbone, A., Galli, F., \& Sorrentino, A. (2009). Coordination Mechanisms along the Supply Chain: a Key-Factor for Competitiveness. In 113th EAAE Seminar: A resilient European food industry and food chain in a challenging world.

Chagomoka, T., Afari-sefa, V., \& Pitoro, R. (2013). Value Chain Analysis of Indigenous Vegetables from Malawi and Mozambique. Commercializing Agriculture in Africa: Social, Economic and Environmental Impacts, 44.

Chagwiza, C., Muradian, R., \& Ruben, R. (2016). Cooperative membership and dairy performance among smallholders in Ethiopia. Food Policy, 59, 165-173.

Codjo, S. O., Fiamohe, R., Kpenavoun, S., Acclassato, D., \& Biaou, G. (2016). Determinants of the choice of multi-modes of governance by producers and processors of paddy in Benin. 149th EAAE Seminar "Structural Change in Agri-Food Chains: New Relations between Farm Sector, Food Industry and Retail Sector" Rennes, France.

Corsi, S., Marchisio, L. V., \& Orsi, L. (2017). Connecting smallholder farmers to local markets: Drivers of collective action, land tenure and food security in East Chad. Land Use Policy, 68(June), 39-47. 
De los Santos-Montero, L. A., \& Bravo-Ureta, B. E. (2017). Productivity effects and natural resource management: econometric evidence from POSAF-II in Nicaragua. Natural Resources Forum, 41(4), 220-233.

De Marchi, V., Di Maria, E., \& Micelli, S. (2013). Environmental Strategies, Upgrading and Competitive Advantage in Global Value Chains. Business Strategy and the Environment, 22(1), 62-72.

Dolan, C., \& Humphrey, J. (2000). Governance and Trade in Fresh Vegetables: The Impact of UK Supermarkets on the African Horticulture Industry. Journal of Development Studies, $37(2), 147-176$.

Dürr, J. (2015). Global value chains and traditional supply chains: Evidence from Guatemala. Development Policy Review, 36(October 2015), O857-0879.

Elomri, A. (2015). Cooperation in supply chain networks: Motives, outcomes, and barriers. International Journal of Supply Chain Management, 4(1), 12-24.

Emmanuel, D., Owusu-Sekyere, E., Owusu, V., \& Jordaan, H. (2016). Impact of agricultural extension service on adoption of chemical fertilizer: Implications for rice productivity and development in Ghana. NJAS - Wageningen Journal of Life Sciences, 79(2016), 41-49.

Esmaeili, A. (2006). Technical efficiency analysis for the Iranian fishery in the Persian Gulf. ICES Journal of Marine Science, 63(9), 1759-1764.

FAO. (2007). Fishery Profile of The Federal Republic of Nigeria.

FAO. (2014). Developing sustainable food value chains-Guiding principles.

FAO. (2016a). Developing gender-sensitive value chains: A guiding framework. Rome.

FAO. (2016b). The State of World Fisheries.

FAO. (2017). Fishery and Aquaculture Country Profiles. Retrieved from FAO website:

FAO. (2018). Small family farms country factsheet.

Fayet, L., \& Vermeulen, W. J. V. (2014). Supporting Smallholders to Access Sustainable Supply Chains: Lessons from the Indian Cotton Supply Chain. Sustainable Development, 22(5), 289-310.

Fischer, E., \& Qaim, M. (2012). Linking Smallholders to Markets: Determinants and Impacts of Farmer Collective Action in Kenya. World Development, 40(6), 1255-1268.

FMARD. (2011). Agricultural Transformation Agenda: We Will Grow Nigeria's Agricultural Sector. Abuja, Nigeria.

FMARD. (2016). The Agriculture Promotion Policy (2016-2020): Building on the Successes of the ATA, Closing Key Gaps.

Forsman, S. (2004). How do small rural food-processing firms compete? A resource-based approach to competitive strategies. Agricultural and Food Science, 13(SUPPL. 1), 1-156. 
Gedara, K. M., Wilson, C., Pascoe, S., \& Robinson, T. (2012). Factors Affecting Technical Efficiency of Rice Farmers in Village Reservoir Irrigation Systems of Sri Lanka. Journal of Agricultural Economics, 63(3), 627-638.

Gereffi, G., \& Fernandez-Stark, K. (2016). Global Value Chain Analysis: A Primer. In Duke CGGC (Center on Globalization, Governance \& Competitiveness).

Gereffi, G., Humphrey, J., \& Sturgeon, T. (2005). The governance of global value chains. Review of International Political Economy, 12(1), 78-104.

GIZ, G. I. Z. (2013). Gender and Value Chains. In Deutsche Gesellschaft für Internationale Zusammenarbeit (GIZ) GmbH. Bonn and Eschborn.

Gnizy, I., Cadogan, J. W., Oliveira, J. S., \& Nizam, A. (2017). The empirical link between export dispersion and export performance: A contingency-based approach. International Business Review, 26(2), 239-249.

Gramzow, A., Batt, P. J., Afari-Sefa, V., Petrick, M., \& Roothaert, R. (2018). Linking smallholder vegetable producers to markets - A comparison of a vegetable producer group and a contract-farming arrangement in the Lushoto District of Tanzania. Journal of Rural Studies, 63(July 2017), 168-179.

Greene, W. (2010). A stochastic frontier model with correction for sample selection. Journal of Productivity Analysis, 34(1), 15-24.

Hailu, G., Weersink, A., \& Minten, B. (2015). Rural Organizations, Agricultural Technologies and Production Efficiency of Teff in Ethiopia. In International Conference of Agricultural Economists.

Hair, J. F., Sarstedt, M., Ringle, C. M., \& Mena, J. A. (2012). An assessment of the use of partial least squares structural equation modeling in marketing research. Journal of the Academy of Marketing Science, 40(3), 414-433.

Handayati, Y., Simatupang, T. M., \& Perdana, T. (2015). Agri-food supply chain coordination: the state-of-the-art and recent developments. Logistics Research, 8(1), 1-15.

Hellin, J., Lundy, M., \& Meijer, M. (2009). Farmer organization, collective action and market access in Meso-America. Food Policy, 34(1), 16-22.

Herring, R. J. (2015). The Oxford Handbook of Food, Politics, and Society. In Oxford University Press (Vol. 34).

Hichaambwa, M., \& Tschirley, D. (2010). How Are Vegetables Marketed Into Lusaka? The Structure of Lusaka's Fresh Produce Marketing System and Implications for Investment Priorities. In Policy Synthesis (Vol. 40).

Hobbs, J. E., \& Young, L. M. (2000). Closer vertical co-ordination in agri-food supply chains: a conceptual framework and some preliminary evidence. Supply Chain Management: An International Journal, 5(3), 131-143.

Huang, C. J., Huang, T. H., \& Liu, N. H. (2014). A new approach to estimating the metafrontier 
production function based on a stochastic frontier framework. Journal of Productivity Analysis, 42(3), 241-254.

Kamau, P., \& Ngigi, S. (2013). Potential for Women Fish Traders to Upgrade within the Fish Trade Value Chain: Evidence from Kenya. DBA Africa Management Review, 3(2), 93-107.

Kaplinsky, R. (2000). Globalisation and Unequalisation: What Can Be Learned from Value Chain Analysis? Journal of Development Studies, 37(2), 117-146.

Kaplinsky, R., \& Morris, M. (2001). A Handbook For Value Chain. In Institute for Development Studies: Brighton, $U K$.

Kayser, M., Schulte, M., \& Theuvsen, L. (2015). Organizing vegetable supply chains: results of a survey of farmers. Journal on Chain and Network Science, 15(2), 1-12.

Ketema, M., Aman, M., Seifu, E., Getachew, T., Hawaz, E., \& Hailu, Y. (2016). The Dairy Value Chain and Factors Affecting Choice of Milk Channels in Harar and Dire Dawa Areas, Eastern Ethiopia. Review of Agricultural and Applied Economics, 19(2), 10-18.

Kobayashi, M., Msangi, S., Batka, M., Vannuccini, S., Dey, M. M., \& Anderson, J. L. (2015). Fish to 2030: The Role and Opportunity for Aquaculture. Aquaculture Economics \& Management, 19(3), 282-300.

Kumbhakar, S. C., Tsionas, E. G., \& Sipiläinen, T. (2009). Joint estimation of technology choice and technical efficiency: An application to organic and conventional dairy farming. Journal of Productivity Analysis, 31(3), 151-161.

Lawrence, P. R., \& Lorsch, J. W. (1967). Differentiation and Integration in Complex Organizations. Administrative Science Quarterly, 12(1), 1-47.

Lazzarini, S., Chaddad, F. ., \& Cook, M. . (2001). Integrating supply chain and network analyses: the study of netchains. Journal on Chain and Network Analysis, 1(1), 7-22.

Lie, H., Rich, K. M., Kurwijila, L. R., \& Jervell, A. M. (2012). Improving smallholder livelihoods through local value chain development: a case study of goat milk yogurt in Tanzania. International Food and Agribusiness Management Review, 15(3), 55-86.

Lokina, R. B. (2009). Technical efficiency and the role of skipper skill in artisanal Lake Victoria fisheries. Environment and Development Economics, 14(4), 497-519.

Ma, Wangli, \& Abdulai, A. (2016). Does cooperative membership improve household welfare? Evidence from apple farmers in China. Food Policy, 58, 94-102.

Ma, Wanglin, Renwick, A., Yuan, P., \& Ratna, N. (2018). Agricultural cooperative membership and technical efficiency of apple farmers in China: An analysis accounting for selectivity bias. Food Policy, 81(April), 122-132.

Maertens, M. (2012). Welfare effects of the spread of modern food supply chains.

Maertens, M., Bart, M., \& Swinnen, J. (2012). Modern Food Supply Chains and Development: Evidence from Horticulture Export Sectors in Sub-Saharan Africa. Development Policy Review, 30(4), 473-497. 
Maertens, M., \& Swinnen, J. F. M. (2009). Gender and Modern Supply Chains in Developing Countries. In LICOS Discussion Paper Series.

Maertens, M., \& Swinnen, J. F. M. (2012). Gender and Modern Supply Chains in Developing Countries. Journal of Development Studies, 48(10), 1412-1430.

Maertens, M., \& Vande Velde, K. (2017). Contract-farming in Staple Food Chains: The Case of Rice in Benin. World Development, 95, 73-87.

Mani, G., Kundra, A., \& Haque, A. (2018). Kiwi value chain in Arunachal Pradesh: issues and prospects. Agricultural Economics Research Review, 31(1), 123.

Manning, L. (2015). Determining value in the food supply chain. British Food Journal, 117(11), 2649-2663.

Markelova, H., Meinzen-Dick, R., Hellin, J., \& Dohrn, S. (2009). Collective action for smallholder market access. Food Policy, 34(1), 1-7.

Markelova, H., \& Mwangi, E. (2010). Collective action for smallholder market access: Evidence and implications for Africa. Review of Policy Research, 27(5), 621-640.

Mather, C. (2005). The growth challenges of small and medium enterprises (SMEs) in South Africa's food processing complex. Development Southern Africa, 22(5), 607-622.

Mayring, P. (2015). Qualitative Content Analysis: Theoretical Background and Procedures. In Bikner-Ahsbahs A., Knipping C., Presmeg N. (eds) Approaches to Qualitative Research in Mathematics Education. Advances in Mathematics Education (pp. 365-380).

Meeusen, W., \& van Den Broeck, J. (1977). Efficiency Estimation from Cobb-Douglas Production Functions with Composed Error. International Economic Review, 18(2), 435.

Mesquita, L. F., \& Lazzarini, S. G. (2008). Horizontal and vertical relationships in developing economies: Implications for SMEs' access to global markets. Academy of Management Journal, 51(2), 359-380.

Mhlanga, N. (2010). Private sector agribusiness investment in sub-Saharan Africa. In Agricultural Management, Marketing and Finance.

Mojo, D., Fischer, C., \& Degefa, T. (2017). The determinants and economic impacts of membership in coffee farmer cooperatives: recent evidence from rural Ethiopia. Journal of Rural Studies, 50, 84-94.

Mujawamariya, G., D’Haese, M., \& Speelman, S. (2013). Exploring double side-selling in cooperatives, case study of four coffee cooperatives in Rwanda. Food Policy, 39, 72-83.

NBS. (2016). 3rd 2016 Quarter External Trade News: Trade Intensity Index/Re-Exports Analysis.

Neven, D., Odera, M. M., Reardon, T., \& Wang, H. (2009). Kenyan Supermarkets, Emerging Middle-Class Horticultural Farmers, and Employment Impacts on the Rural Poor. World Development, 37(11), 1802-1811. 
Nguyen, T. A. T., Bui, C. T. P. N., \& Jolly, C. M. (2017). The Value Chain Of Exported Whiteleg Shrimp: Case Study In Khanh Hoa Province, Vietnam. International Journal of Food and Agricultural Economics, 5(2), 9-23.

Ochieng, J., Knerr, B., Owuor, G., \& Ouma, E. (2018). Strengthening collective action to improve marketing performance: evidence from farmer groups in Central Africa. Journal of Agricultural Education and Extension, 8622, 1-21.

Olaoye, O. J., \& Ojebiyi, W. G. (2018). Marine Fisheries in Nigeria: A Review. In U. Ö. and A. I. Muhammet Türkoğlu (Ed.), Marine Ecology - Biotic and Abiotic Interactions: Vol. $i$ (p. 13).

Oluwatayo, I. B., \& Adedeji, T. A. (2019). Comparative analysis of technical efficiency of catfish farms using different technologies in Lagos State, Nigeria: A Data Envelopment Analysis (DEA) approach. Agriculture and Food Security, 8(1), 1-9.

Orsi, L., De Noni, I., Corsi, S., \& Marchisio, L. V. (2017). The role of collective action in leveraging farmers' performances: Lessons from sesame seed farmers' collaboration in eastern Chad. Journal of Rural Studies, 51, 93-104.

Otter, V., Engler, a., \& Theuvsen, L. (2014). The influence of the interplay of supply chain network relationships on farmers' performance in the Chilean NTAE sector. Journal on Chain and Network Science, 14(3), 149-169.

Ouma, E., Ochieng, J., Dione, M., \& Pezo, D. (2017). Governance structures in smallholder pig value chains in Uganda: Constraints and opportunities for upgrading. International Food and Agribusiness Management Review, 20(3), 307-319.

Qaim, M. (2017). Globalisation of agrifood systems and sustainable nutrition. Proceedings of the Nutrition Society, 76(01), 12-21.

Rahman, S., Wiboonpongse, A., \& Sriboonchitta, S. (2009). Production efficiency of Jasmine rice producers in Northern and North-eastern Thailand. Journal of Agricultural Economics, 60(2), 419-435.

Rao, E. J. O., Brümmer, B., \& Qaim, M. (2012). Farmer Participation In Supermarket Channels , Production Technology, And Efficiency: The Case Of Vegetables In Kenya. American Journal of Agricultural Economics, 94(February), 891-912.

Reardon, T., Barrett, C. B., Berdegue, J. A., \& Swinnen, J. F. M. (2009). Agrifood Industry Transformation and Small Farmers in Developing Countries. World Development, 37(11), $1717-1727$.

Reardon, T., Pingali, P. L., \& Stamoulis, K. G. (2006). Impacts of Agrifood Market Transformation during Globalization on the Poor's Rural Nonfarm Employment: Lessons for Rural Business Development Programs. Staff Papers.

Scheiterle, L., Ulmer, A., Birner, R., \& Pyka, A. (2018). From commodity-based value chains to biomass-based value webs: The case of sugarcane in Brazil's bioeconomy. Journal of Cleaner Production, 172, 3851-3863. 
Schiffer, E., \& Hauck, J. (2010). Net-Map : Collecting Social Network Data and Facilitating Network Learning through Participatory Influence Network Mapping. SAGE, 22(3), 231249.

Schipmann, C., \& Qaim, M. (2010). Spillovers from modern supply chains to traditional markets: Product innovation and adoption by smallholders. Agricultural Economics, 41(3-4), 361371.

Schumacher, K. P. (2014). Gender relations in global agri-food value chains - A review. Erde, 145(3), 127-134.

Scoones, I., Amanor, K., Favareto, A., \& Qi, G. (2016). A New Politics of Development Cooperation? Chinese and Brazilian Engagements in African Agriculture. World Development, 81, 1-12.

Sesabo, J. K., \& Tol, R. S. J. (2007). Technical efficiency of small-scale fishing households in Tanzanian coastal villages: An empirical analysis. African Journal of Aquatic Science, 32(1), 51-61.

Swinnen, J. F. M., Colen, L., \& Maertens, M. (2013). Constraints to smallholder participation in high-value agriculture in West Africa. Rebuilding West Africa's Food Potential: Policies and Market Incentives for Smallholder-Inclusive Food Value Chains, 289-313.

Teklehaimanot, M. L., Ingenbleek, P. T. M., \& van Trijp, H. C. M. (2017). The Transformation of African Smallholders into Customer Value Creating Businesses: A Conceptual Framework. Journal of African Business, 18(3), 299-319.

The World Bank. (2012). Agricultural Innovation Systems: An Investment Sourcebook. In The World Bank.

The WorldBank. (2013). Growing Africa: Unlocking the Potentials of Agribusiness.

Ton, G., Vellema, W., Desiere, S., Weituschat, S., \& D’Haese, M. (2017). Contract farming for improving smallholder incomes: What can we learn from effectiveness studies? World Development, 104, 46-64.

Trienekens, J. H. (2011). Agricultural Value Chains in Developing Countries A Framework for Analysis. International Food and Agribusiness Management Review, 14(2), 085201.

Udong, E., Niehof, A., \& Tilburg, V. A. (2009). Struggle for Survival: Women fish traders fighting institutional and cultural constraints in fishing communities in the Niger Delta, Nigeria. International Research on Food Security, Natural Resource Management and Rural Development, Tropentag 2009, 1-4.

Udong, Ekaete, Niehof, A., \& Tilburg, A. van. (2010). The livelihood strategies of women fish traders in adapting to cultural and institutional constraints in Ibaka, Nigeria. Mast, 9(2), 6593.

Verhofstadt, E., \& Maertens, M. (2014). Smallholder cooperatives and agricultural performance in Rwanda: do organizational differences matter? Agricultural Economics, 45(S1), 39-52. 
Virchow, D., Denich, M., Kuhn, A., \& Beuchelt, T. (2014). The Biomass-based Value Web as a Novel Perspective on the Increasingly Complex African Agro-food Sector. Tropentag 2014 Conference on International Research on Food Security, Natural Resource Management and Rural Development. Prague, Czech Republic.

Wang, G., Dou, W., Zhu, W., \& Zhou, N. (2015). The effects of firm capabilities on external collaboration and performance: The moderating role of market turbulence. Journal of Business Research, 68(9), 1928-1936.

Watabaji, M. D., Molnar, A., Dora, M. K., \& Gellynck, X. (2016). The influence of value chain integration on performance: An empirical study of the malt barley value chain in ethiopia. International Food and Agribusiness Management Review, 19(4), 79-94.

Wategire, B. B., \& Ike, P. C. (2015). An Analysis of the Technical Efficiency of Non Motorized Small Scale Shrimp Fishers in the Coastal Areas of Delta State, Nigeria. Mediterranean Journal of Social Sciences, 6(1), 285-291.

Wentink, C. R., Raemaekers, S., \& Bush, S. R. (2017). Co-governance and upgrading in the South African small-scale fisheries value chain. Maritime Studies, 16(1).

Williams, J. N. (1995). Economic analysis of crayfish production; processing and marketing amongst rural women in rivers state, Nigeria.

Wollni, M., \& Brümmer, B. (2012). Productive efficiency of specialty and conventional coffee farmers in costa rica: Accounting for technological heterogeneity and self-selection. Food Policy, 37(1), 67-76.

WorldFish. (2018). WorldFish Nigeria Strategy 2018-2022. In WorldFish. Strategy: 2018-09. Penang, Malaysia.

WTO. (2019). Technological Innovation, Supply Chain Trade, and Workers in a Globalized World. Switzerland.

Zabbey, N., Erondu, E. S., \& Hart, A. I. (2010). Nigeria and the prospect of shrimp farming: Critical issues. Livestock Research for Rural Development, 22(11), 1-6. 


\section{General appendix}

Pre-field Artisan Questionnaire, 2017 .............................................................................................117

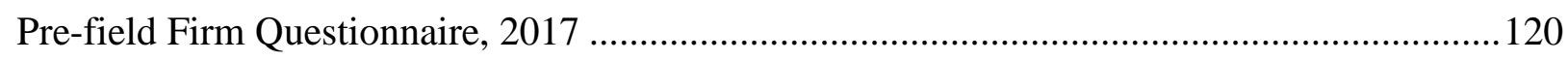

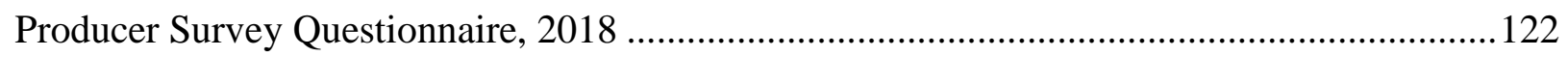

Processor Survey Questionnaire, 2018 ...............................................................................137 


\section{SHRIMP AND PRAWN SUPPLY CHAIN ORGANIZATION IN NIGERIA}

Pre-field Artisan Questionnaire, 2017

\section{Introduction}

Thank you for taking time to participate in a focus group discussion on the shrimp and prawn supply chain in Nigeria. This focus group discussion is part of a larger research process that we are conducting to learn about the different aspects of shrimp and prawn supply chain organizational structure with a focus on identifying some multidimensional characteristics, value additions and key actors within the industry. You are a group that has been purposively selected to participate in this discussion. Your selection is based on your activities along the shrimp and prawn supply chain. Therefore, we will like to hear from you about how shrimp and prawn flow from the point of capture/production until it gets to the last known actors. We will like to uncover details about your attributes, production and distribution activities you are involved in, relationships with and/or among other actors across or along the supply chain, and your supply performances within the industry.

During this discussion, we will ask questions and facilitate conversation about the above-mentioned areas of interest including any other topics that we might find interesting during the discussion. We will use the Net-mapping tool to elicit information about the shrimp and prawn supply chain. You will be asked to represent this information on the cardboard that will be provided. It is, however, important to iterate to you that there are no "right" or "wrong" answers. The main purpose is to stimulate conversation and represent the consensus opinion of everyone represented on the cardboard provided.

Finally, please note that this will be recorded while will take notes during the discussion. This will only ensure the adequate capture of your important contributions, which might be too ambiguous to note off hand. We will conclude by iterating that this discussion is for the purpose of research only and your comments during the discussion will remain confidential while your name will not be attached to any comments you make.

Do you have any questions before we begin? 


\section{VALUE-WEB IN SHRIMP AND PRAWN SUPPLY CHAIN}

- Before we start, let us do a round of introduction.

- Can each of you tell the group your name and your years of experience with capturing and/or processing shrimp and prawn?

\begin{tabular}{|c|c|c|}
\hline Main questions & Additional questions & Clarifying questions \\
\hline $\begin{array}{l}\text { What is the background } \\
\text { information about the } \\
\text { respondents? }\end{array}$ & $\begin{array}{l}\text { - What do you do? } \\
\text { - What are the products you deal in? } \\
\text { - What will you count as your major product? } \\
\text { - To whom do you sell your shrimp and prawn? } \\
\text { - What are the marketing destinations of your shrimp and prawn? } \\
\quad \text { Shat are the levels of respondents' experience in the fishing and } \\
\text { shrimping activities? }\end{array}$ & \multirow{8}{*}{$\begin{array}{l}\text { Do you feel the } \\
\text { same? } \\
\text { - } \quad \begin{array}{l}\text { Can you tell us } \\
\text { anything else apart } \\
\text { from the one already } \\
\text { discussed? }\end{array} \\
\text { - What do you think } \\
\text { about this? } \\
\text { Can you clarify a } \\
\text { little further on this? } \\
\text { Can you provide } \\
\text { some examples } \\
\text { regarding this? }\end{array}$} \\
\hline $\begin{array}{l}\text { What is the necessary } \\
\text { background information } \\
\text { about shrimp and prawn in } \\
\text { your area? }\end{array}$ & $\begin{array}{l}\text { - What are the differences between shrimp and prawn? } \\
\text { - What type of shrimp and prawn species do you have? } \\
\text { - How many shrimping seasons do you have in your area? } \\
\text { - What period is the peak shrimping season in your area? } \\
\text { - When is the ideal time to capture shrimp and prawn? } \\
\text { Where is the ideal place/point to capture shrimp and prawn? }\end{array}$ & \\
\hline $\begin{array}{l}\text { What inputs do you need } \\
\text { for capturing shrimp and } \\
\text { prawn? }\end{array}$ & $\begin{array}{l}\quad \text { How did you obtain these inputs? } \\
\text { - } \quad \text { How much does it cost to obtain these inputs today? } \\
\text { - What are the most important shrimping inputs required? }\end{array}$ & \\
\hline $\begin{array}{l}\text { After capturing shrimp and } \\
\text { prawn with other fish } \\
\text { resources, what value can } \\
\text { you add to them? }\end{array}$ & $\begin{array}{l}\text { - What constitutes your catch on the average? } \\
\text { - What percentage of your total catch is represented by each fish resource? } \\
\text { - What are the different types of value-addition possible for shrimp and } \\
\text { prawn? }\end{array}$ & \\
\hline $\begin{array}{l}\text { Responses should be } \\
\text { represented on the } \\
\text { cardboard provided!! }\end{array}$ & $\begin{array}{l}\text { - What determines the value-adding activities employed at a time? } \\
\text { - What percentage of these fish resources goes into each of the value- } \\
\text { adding activities? } \\
\text { - Are there any by-products from each of these value-adding activities? } \\
\text { What do you do with these by-products? }\end{array}$ & \\
\hline $\begin{array}{l}\text { How does the price of } \\
\text { shrimp and prawn differ } \\
\text { along the supply chain? }\end{array}$ & $\begin{array}{l}\text { - What will be the price of shrimp and prawn per unit if they are sold after } \\
\text { each value-addition? } \\
\text { - What is the price difference at each supply chain tier? } \\
\text { - What are the reasons for such huge/small/no price differences? } \\
\text { - What can be done to maximize the price of shrimp and prawn at each } \\
\text { supply chain tier? }\end{array}$ & \\
\hline $\begin{array}{l}\text { What influence do female } \\
\text { laborers have along the } \\
\text { supply chain in your area? }\end{array}$ & $\begin{array}{l}\text { - How many female laborers are involved in each of these value-adding } \\
\text { activities? } \\
\text { - } \quad \text { Tow important are female laborers in the industry? } \\
\text { resources that can improve their activities? } \\
\text { - To what degree are the female laborers involved in the decision-making } \\
\text { process of each value-adding activity? } \\
\text { To what degree are the female laborers involved in the decision-making } \\
\text { process at each supply chain tier? }\end{array}$ & \\
\hline $\begin{array}{l}\text { What are the perpetual } \\
\text { characteristics of the shrimp } \\
\text { and prawn supply chain in } \\
\text { your area? }\end{array}$ & $\begin{array}{l}\text { - Who are the main actors you interact with and what kind of relationships } \\
\text { - } \quad \text { Whist between you and them? } \\
\text { always have in mind? } \\
\text { - What changes have you observed recently within the industry? } \\
\text { - What brought about such changes? } \\
\text { What can you say about: } \\
\circ \text { the level of trust } \\
\circ \quad \text { power asymmetry } \\
\circ \quad \text { technological advancements } \\
\circ \text { market turbulence } \\
\text { - How do you react and cope with such changes? }\end{array}$ & \\
\hline
\end{tabular}




\section{NET-MAP APPROACH}

1. The researchers first explained to each focus group the objectives and significance of the study. The Net-map steps were described to participants, reiterating confidentiality of identities. Permissions were also taken to record the discussions, stating its essence.

2. Respondents were asked to identify all the important value-adding activities and actors within the sector starting from input procurement until shrimp and prawn get to the final consumers. Each activity and actor was written on stickers with different colors that represent different segment and actors. Thereafter, the stickers were attached to A1 sized cardboard.

3. For the value chain, participants were told to depict the sequential flow of shrimp and prawn by drawing arrows to connect all segments identified in step 2. Uni-directional arrows are used for this step since products flow in one direction in value chains.

4. For the value-web, all value additions possible for each segment listed in step 2 were further identified. Then possible links between the value additions were made across the segments and value chains in step 2 and 3 respectively. In all, two types of net-maps were made, namely: shrimp and prawn value chains depicting product flow and actor relationships, and value-web.

5. After creating the value chains and value-webs, participants were asked if any important elements such as activities, actors or value additions that needed to be added are still missing in the net-maps. Participants were encouraged to probe and discuss whether missing elements should be added.

6. Thereafter, further steps were made to discuss the characteristics of the value chains and value-webs. For the value chains, participants were asked identify the quantity of shrimp and prawn that goes to each segment as well as associated price. For the value-web, participants were nudged to identify value additions in which both men and women are dominant. Using a scale of $0-8^{24}$, participants ranked each value addition using an equally sized flat button-like material. The ranking was done based on perceived gender influence and was determined by counting and noting ${ }^{25}$ the number of materials piled. Decisions about the ranking were left to the respondents. Participants were allowed to argue out their points until they come to a single conclusion. Important information were recorded at the edge of the cardboard and in a reference notebook to increase credibility and reliability of the information obtained.

7. Each session was ended by discussing of the net-maps. With the whole structure now visible, it became easy to raise questions and follow up on important discussions relating to the activities, position, relationships and power ranking of several actors along the chains.

\footnotetext{
${ }^{24} 0$ is the least and 8 , the most influence.

${ }^{25}$ This will represent how influential women are at different tiers. The power rank will basically capture women's participation in the chain, access to and control over resources and benefits.
} 


\section{SHRIMP AND PRAWN SUPPLY CHAIN ORGANIZATION IN NIGERIA Pre-field Firm Questionnaire, 2017}

\section{Introduction}

Thank you for taking time to participate in this interview on the shrimp and prawn supply chain organization in Nigeria. This interview is part of a larger research process that we are conducting to learn about the different aspects of shrimp and prawn supply chain organizational structure with a focus on identifying some multidimensional characteristics of key actors within the industry. Your firm has been purposively selected to participate in this interview. The selection of your firm is based on her activities along the shrimp and prawn supply chain. So, we will like to hear and uncover details about how firms organize themselves and interact along the supply chain, and how the changing characteristics of the industry have affected the firm's operation and performance.

During this interview, we will ask questions and facilitate conversation about the above-mentioned areas of interest including any other topics that we might find interesting during the discussion. It is, however, important to iterate to you that there are no "right" or "wrong" answers. However, we crave for your valid contributions to the above subject. Finally, please note that this discussion will be recorded while

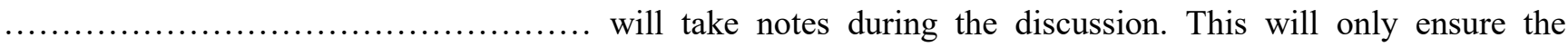
adequate capture of your important contributions, which might be too ambiguous to note off hand. We will conclude by iterating that this discussion is for the purpose of research only and your comments during the discussion will remain confidential while your name will not be attached to any comments you make.

Do you have any questions before we begin? 


\begin{tabular}{|c|c|c|}
\hline Main questions & Additional questions & Clarifying questions \\
\hline $\begin{array}{l}\text { What is the background } \\
\text { information about the } \\
\text { firm and respondents? }\end{array}$ & $\begin{array}{l}\text { - What does the firm do? } \\
\text { - What are the products the deal in? } \\
\text { - What will you count as the firm's major product? } \\
\text { - What are marketing destinations of shrimp and prawn? } \\
\text { - What are the levels of respondents' experience in the fishing and shrimping activities? } \\
\text { - What are the job specifications of the respondents? }\end{array}$ & \multirow{6}{*}{$\begin{array}{l}\text { - Can you tell us } \\
\text { anything else apart } \\
\text { from the one already } \\
\text { discussed? } \\
\text { - What do you think } \\
\text { about this? } \\
\text { - Can you clarify a } \\
\text { little further on this? } \\
\text { - Can you provide } \\
\text { some examples } \\
\text { regarding this? }\end{array}$} \\
\hline $\begin{array}{l}\text { What is the necessary } \\
\text { background information } \\
\text { about shrimp and prawn? }\end{array}$ & $\begin{array}{l}\text { - What are the differences between shrimp and prawn? } \\
\text { - What type of shrimp and prawn species do you have? } \\
\text { - How many shrimping seasons do you have in your area? } \\
\text { - Where and when is the ideal time and place to capture shrimp and prawn? } \\
\text { - What are the potential bycatches you could have? }\end{array}$ & \\
\hline $\begin{array}{l}\text { After capturing shrimp } \\
\text { and prawn with other fish } \\
\text { resources, what value can } \\
\text { you add to them? }\end{array}$ & $\begin{array}{l}\text { - What percentage of your total catch is represented by each fish resource? } \\
\text { - What are the different types of value-addition possible for shrimp and prawn? } \\
\text { - What determines the value-adding activities employed at a time? } \\
\text { - What percentage of these fish resources goes into each of the value-adding activities? } \\
\text { - What do you do with these by-products? }\end{array}$ & \\
\hline $\begin{array}{l}\text { What influence do female } \\
\text { laborers have along the } \\
\text { supply chain? }\end{array}$ & $\begin{array}{l}\text { - How many female laborers are involved in each of these value-adding activities? } \\
\text { - How important are female laborers in the industry? } \\
\text { - How many female executives are there within the industry? }\end{array}$ & \\
\hline $\begin{array}{l}\text { What are the perpetual } \\
\text { characteristics of the } \\
\text { shrimp and prawn supply } \\
\text { chain? }\end{array}$ & $\begin{array}{l}\text { - While dealing with your supply chain partners, what kind of things do you always have to consider? } \\
\text { - What kind of situations is surrounding the shrimp and prawn subsector? } \\
\text { - What changes have you observed recently within the industry? }\end{array}$ & \\
\hline How are firms organized? & $\begin{array}{l}\text { - Who are the firm's major trading partners? } \\
\text { - From which countries are the firms trading partners from? } \\
\text { - Hhat kind of relationships do you have with your supply chain partners? } \\
\text { - How long has the firm been in the relationships } \\
\text { - Hhat is the firm's relationship like with external stakeholders in the supply chain? } \\
\text { - How do you measure the firm's performance in terms of SP supply chain? }\end{array}$ & \\
\hline
\end{tabular}




\section{SHRIMP SUPPLY CHAIN ORGANIZATION IN NIGERIA \\ Producer Survey Questionnaire, 2018}

\section{Introduction}

With this survey, we intend to examine different aspects of shrimp supply chain organization. You have been randomly selected to participate in this interview that covers your characteristics, production and distributing activities on shrimp, as well as your relationships with other actors across or along the supply chain, and market performance.

We are doctoral students affiliated with the University of Goettingen. Thus, the information you will be providing will be used solely for research purposes, while all your responses will be kept confidential and untraceable to individuals. The questionnaire should take about 1 hour and 10 minutes to complete. We therefore crave for your consent to participate in this interview. If you have any question, do not hesitate to contact the undersigned:

\section{Adetoyinbo Ayobami}

adetoyinbo@gwdg.de

\section{IDENTIFICATION}

Details on Supervisor and Enumerator

\section{Supervisor's Name:}

Enumerator's Name:

Time started (STIME):

Date of interview (INDATE):

\section{Contents}

number

IDENTIFICATION

MODULE 1: GENERAL INFORMATION

MODULE 2: SHRIMPING INPUTS AND PRODUCTION COSTS (LAST 12 MONTHS)

MODULE 3: SHRIMP OUTPUT AND MARKETING

MODULE 4: PRODUCER SITUATIONS ALONG THE SHRIMP SUPPLY CHAIN

MODULE 5: PRODUCER ORGANIZATIONAL STRUCTURE AND PERFORMANCE

MODULE 6: HOUSEHOLD ASSET HOLDINGS

MODULE 7: COLLECTIVE ACTION AND PARTICIPATION IN PRODUCER GROUP

MODULE 8: CREDIT

MODULE 9: SHOCKS AND EXTENSION SERVICES

\section{Enumerator's code:}

Signature/date:

Time ended (ETIME):

Page number 


\section{MODULE 1: GENERAL INFORMATION}

1.1 State (STAT) (\{1\} Lagos $\{2\}$ Ondo $\{3\}$ Akwa lbom)

1.2 Local Government Area (LGA)

1.3 Village name (VILL)

1.4 Name of household head (HHNAME)

1.5 Name of respondent (RNAME)

1.6 Do you own a mobile phone? ( $\{1\}$ Yes $\{0\}$ No) (MOBILE)

1.7 Mobile number of respondent?

1.8 Gender of household head (HHGENDER) (\{1\} Male $\{0\}$ Female)

1.9 Distance to the nearest shrimp market in meters? (MDIST)

1.10 Distance to the nearest shrimp market-hub in meters? (HUBDIST)

1.11 How many years has respondent been shrimping? (FISHYEAR)

1.12 What is the distance to the village head's home? (VIHHDIST)

1.13 How many years has the village head ruled? (VIHHREIGN)

1.14 What is the occupation of the village head? (OCCUPHH) (\{1\} Fishing $\{0\}$ others)
1.15 What is the distance to the nearest fishing village in meters? (FVILL)

1.16 Female household in association related to shrimp? (FEMASS) ( $\{1\}$ Yes $\{0\}$ No)

1.17 How many female laborers do you have in your household? (FEMLAB)

1.18 Is any of these females dealing in "crayfish"? (FEMSHR) (\{1\} Yes $\{0\}$ No)

1.19 How many female household laborers deal in "crayfish"? (FEMLABSHR)

1.20 Females in association not related to "crayfish"? (FEMASSO) ( $\{1\}$ Yes $\{0\}$ No)

1.21 Do you have access to credit facilities? (CREDIT) ( $\{1\}$ Yes $\{0\}$ No)

1.22 Do you have access to a tarred road? (TROAD) ( $\{1\}$ Yes $\{0\}$ No)

1.23 Distance between the point of landing and tarred road in meters? (DROAD)

1.24 Are you a Nigerian? (NATIONALITY) ( $\{1\}$ Yes $\{0\}$ No, skip to question 1.26)

1.25 What tribe do you belong to? (TRIBE) ( $\{1\}$ Yoruba $\{2\}$ ljaw $\{3\}$ Igbo $\{4\}$ Others)

1.26 Is respondent an indigene of this village? (INDIG) ( $\{1\}$ Yes $\{0\}$ No)

1.27 If No, where are you from? (COUNT) ( $\{1\}$ Ghana $\{2\}$ Cameroon $\{3\}$ Others)

1.28 How many years has the respondent been resident in the village? (RESIDE)

1.29 Is respondent a member of a cooperative society? (COOP) ( $\{1\}$ Yes $\{0\}$ No)

Note to the Enumerator: A household is defined as a group of people who live and eat together most of the time, i.e. more than six months of the year or 3.5 days of the week.

The household head is defined as the household member who makes most of the economic decisions.

"Crayfish" as commonly known among the locals is a type of small shrimp specie and thus mostly used interchangeably here with shrimp. 
MODULE 2: SHRIMPING INPUT AND PRODUCTION COSTS (LAST 12 MONTHS i.e. April 2017- May 2018)

Questionnaire /HHID

2.1 Kindly fill in all information about the characteristics of gears and canoes used, and their associated costs during the last 12 months (April 2017-May 2018)

\begin{tabular}{|c|c|c|c|c|c|c|c|c|c|c|c|c|c|c|c|c|c|c|c|c|}
\hline \multirow{5}{*}{ 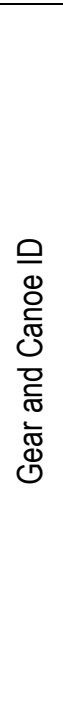 } & 1 & 2 & 3 & 4 & 5 & 6 & \multicolumn{3}{|c|}{7} & \multicolumn{3}{|c|}{8} & 9 & 10 & 11 & 12 & \multicolumn{4}{|c|}{13} \\
\hline & $\begin{array}{l}\frac{\text { How }}{\text { many }} \\
\frac{\text { canoe }}{\text { s are }} \\
\frac{\text { owned }}{\text { by }} \\
\frac{\text { respo }}{\text { ndent }} \\
?\end{array}$ & 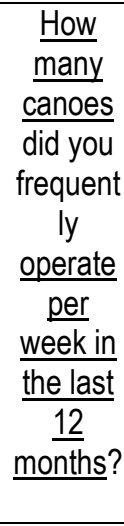 & $\begin{array}{l}\frac{\text { What }}{\frac{\text { type of }}{\text { canoe }}} \\
\frac{\text { did you }}{\text { mainly }} \\
\frac{\text { use for }}{\text { shrimpin }} \\
\frac{\text { gin the }}{\text { last } 12} \\
\text { months? } \\
\text { CODE } \\
\text { A }\end{array}$ & $\begin{array}{l}\frac{\text { How }}{\text { did }} \\
\text { you } \\
\frac{\text { obtain }}{\text { these }} \\
\frac{\text { canoe }}{\underline{\text { s? }}} \\
\text { CODE } \\
\text { B }\end{array}$ & $\begin{array}{l}\frac{\text { Did other }}{\frac{\text { fishers }}{\text { operate }}} \\
\frac{\text { your }}{\text { canoe for }} \\
\frac{\text { you in the }}{\text { last } 12} \\
\text { months? } \\
\text { coDE: } \\
\text { [1] Yes } \\
{[0] \text { No }}\end{array}$ & $\begin{array}{l}\frac{\text { How }}{\text { many }} \\
\frac{\text { canoes }}{\text { did you }} \\
\frac{\text { operate }}{\text { through }} \\
\frac{\text { other }}{\text { fishers }} \\
\frac{\text { per }}{\text { week in }} \\
\frac{\text { the last }}{12} \\
\text { months? }\end{array}$ & \multicolumn{3}{|c|}{$\frac{\text { How many gears are }}{\frac{\text { owned by the }}{\text { respondent? }}}$} & \multicolumn{3}{|c|}{$\begin{array}{l}\text { How many shrimping } \\
\text { gears did you frequently } \\
\frac{\text { use per week in the last }}{12 \text { months? }}\end{array}$} & $\begin{array}{l}\frac{\text { How }}{\text { many }} \\
\frac{\text { Out }}{\text { Board }} \\
\frac{\text { Engin }}{\frac{\text { es }}{(O B E)}} \\
\frac{\text { are }}{\text { owned }} \\
\text { by } \\
\text { your } \\
\text { house } \\
\text { hold? }\end{array}$ & $\begin{array}{l}\frac{\text { How many }}{\text { Out Board }} \\
\frac{\text { Engines }}{\text { (OBE) did }} \\
\frac{\text { you }}{\text { (requently }} \\
\frac{\text { operate }}{\text { per week }} \\
\frac{\text { in the last }}{12} \\
\text { months? }\end{array}$ & $\begin{array}{l}\frac{\text { How much }}{\text { did you buy }} \\
\text { each OBE? }\end{array}$ & $\begin{array}{l}\frac{\text { Wha }}{\underline{t}} \\
\text { year } \\
\frac{\text { did }}{\text { you }} \\
\frac{\text { buy }}{\text { eac }} \\
\frac{\mathrm{h}}{\mathrm{B} E} \\
? \frac{?}{\underline{m}}\end{array}$ & \multicolumn{4}{|c|}{$\begin{array}{l}\text { Since the year of purchase, how } \\
\text { many more years can you use the } \\
\text { following equipment? }\end{array}$} \\
\hline & \multirow{3}{*}{$\begin{array}{l}\text { SHRC } \\
\text { ANO }\end{array}$} & \multirow{3}{*}{$\begin{array}{c}\text { CANOP } \\
\text { ER }\end{array}$} & \multirow{3}{*}{$\underset{\mathrm{H}}{\text { SHRFIS }}$} & \multirow{3}{*}{$\begin{array}{c}\text { INSO } \\
\text { UR }\end{array}$} & \multirow{3}{*}{ EMPFISH } & \multirow{3}{*}{$\begin{array}{c}\text { CANOE } \\
\text { MP }\end{array}$} & \multirow{2}{*}{\multicolumn{3}{|c|}{ SHRGEAR }} & \multirow{2}{*}{\multicolumn{3}{|c|}{ GEAROPER }} & \multirow{3}{*}{ NOBE } & \multirow{3}{*}{$\begin{array}{c}\text { OPEROB } \\
\text { E }\end{array}$} & \multirow{2}{*}{ OBECOST } & \multirow{2}{*}{$\begin{array}{l}\text { OB } \\
\text { EYR }\end{array}$} & \multicolumn{4}{|c|}{ USELIFE } \\
\hline & & & & & & & & & & & & & & & & & Canoe & Seine & Trap & Tester \\
\hline & & & & & & & Seine & Trap & Tester & Seine & Trap & Tester & & & Owned & & & & & \\
\hline PS & & & & & & & & & & & & & & & Owned & & & & & \\
\hline OS & & & & & & & & & & & & & & & Owned & & & & & \\
\hline
\end{tabular}

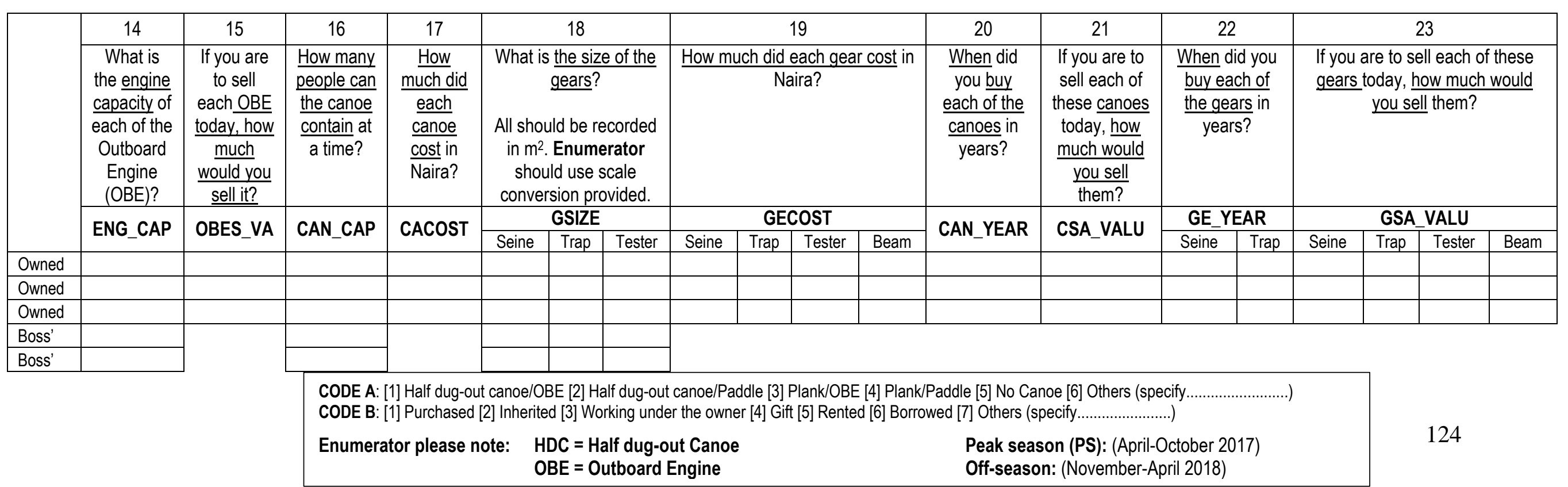


Questionnaire /HHID.

2.2 Kindly fill in all information about the characteristics of other shrimping inputs used and their associated costs during the last 12 months (April 2017-May 2018)

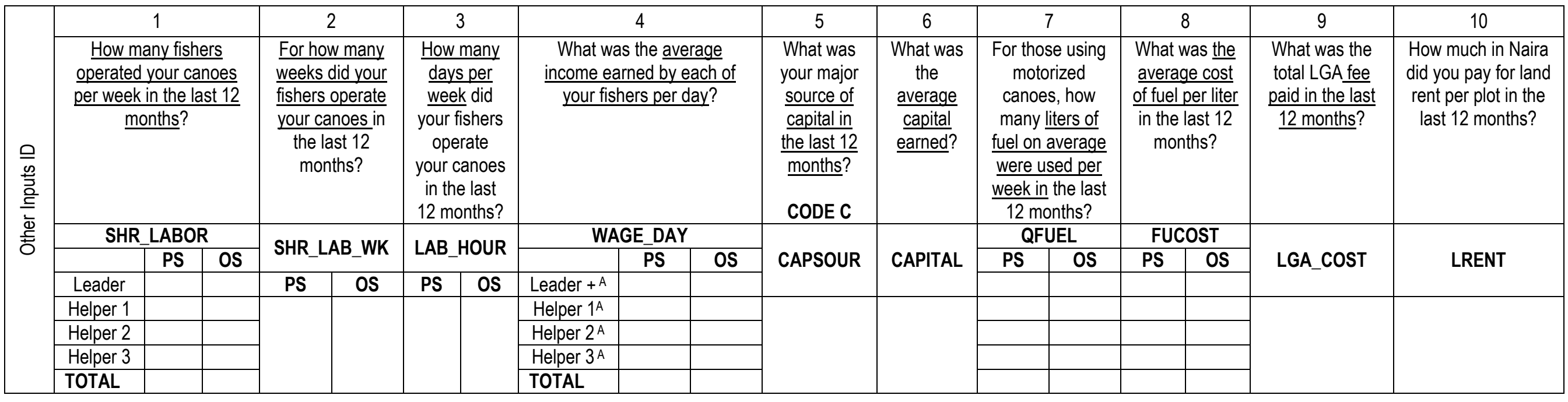

2.3 Kindly fill in all information about shrimping costs incurred during the last 12 months (April 2017-May 2018)

\begin{tabular}{|c|c|c|c|c|c|c|c|c|c|c|c|c|c|c|}
\hline \multirow{4}{*}{ 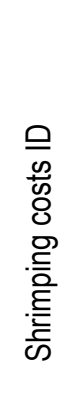 } & \multicolumn{5}{|c|}{1} & \multicolumn{5}{|c|}{2} & 3 & 4 & 5 & 6 \\
\hline & \multicolumn{5}{|c|}{$\begin{array}{l}\text { For those who own both canoes and gears, } \\
\text { how many repairs on the average were made } \\
\text { per month in the last } 12 \text { months? }\end{array}$} & \multicolumn{5}{|c|}{$\begin{array}{c}\text { What was the average cost of a repair per } \\
\text { month in the last } 12 \text { months? }\end{array}$} & $\begin{array}{l}\text { How much did } \\
\text { you spend on } \\
\text { food per week } \\
\text { of fishing in } \\
\text { the last } 12 \\
\text { months? }\end{array}$ & $\begin{array}{l}\begin{array}{l}\text { How much did } \\
\text { you spend on } \\
\text { spare }\end{array} \\
\frac{\text { parts/mainten }}{\text { ance per }} \\
\frac{\text { month in the }}{12 \text { months? }}\end{array}$ & $\begin{array}{l}\text { How much was } \\
\text { spent on other } \\
\text { operation's } \\
\text { miscellaneous } \\
\text { per week in the } \\
\text { last } 12 \text { months? } \\
\text { e.g. rope, }\end{array}$ & $\begin{array}{c}\frac{\text { How much did }}{\text { you spend on }} \\
\frac{\text { transporting }}{\text { your product }} \\
\frac{\text { to the point of }}{\text { sale per }} \\
\text { week? }\end{array}$ \\
\hline & \multicolumn{5}{|c|}{ REPAIR } & \multicolumn{5}{|c|}{ REPAIR_COST } & FOOD COST & SPAR COST & MISC COST & TCOST \\
\hline & Canoe & Engine & Seine & Trap & Tester & Canoe & Engine & Seine & Trap & Tester & & & & \\
\hline
\end{tabular}

CODE C: [1] Personal savings [2] Cooperatives/association [3] Trading partner [4] Friends and relatives [5] Bank credit [6] Others (specify..........)

PS $=$ Peak Season (April-October 2017)

OS = Off season (November 2017-May 2018)

A If no directly payment has been made, enumerators should ask for the value equivalent of goods given to the helpers. 
MODULE 3: SHRIMP OUTPUT AND MARKETING

3.1 Kindly fill in the information about shrimp output and trading during the last 12 months (April 2017-May 2018)

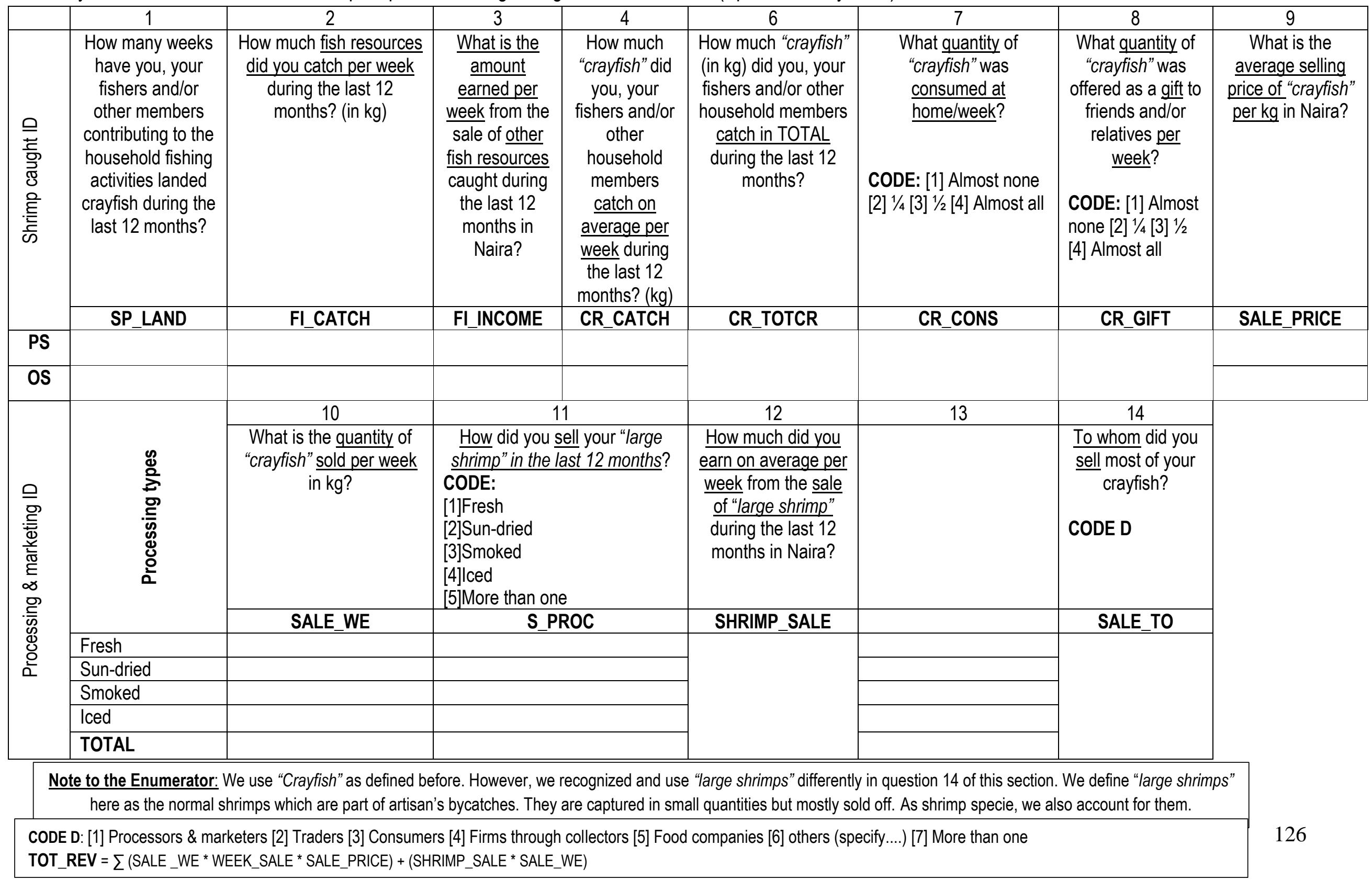




\section{MODULE 4: PRODUCER SITUATIONS ALONG THE SHRIMP SUPPLY CHAIN}

4.1 Kindly state the level at which you concur with statements on the external characteristics of shrimp supply chain organization

\begin{tabular}{|c|c|c|c|}
\hline $\mathrm{S} / \mathrm{N}$ & External contingencies & Items & Response \\
\hline \multirow[t]{8}{*}{1.} & \multirow{8}{*}{ Market turbulence } & MT1: Sometimes our customer's demand increases unpredictably in our market & \\
\hline & & MT2: The volume of crayfish I caught per trip is unpredictable & \\
\hline & & MT3: The cost of constructing dugout canoe/planks has increased drastically of recent & \\
\hline & & MT4: I am not sure of the stage in which my crayfish quality is by the time I deliver them to the processors & \\
\hline & & MT5: Our competitors in nearby villages do reduce the price of their product to attract our customers & \\
\hline & & MT6: The market price of crayfish changes drastically within our market & \\
\hline & & MT7: Cost of fuel has been unstable of recent & \\
\hline & & MT8: It is difficult for me to constantly supply crayfish because of the incessant activities of pirates in my area & \\
\hline \multirow[t]{7}{*}{2.} & \multirow[t]{7}{*}{ Technology } & TA1: Recently, outboard engine has become more important for shrimping in our industry & \\
\hline & & TA2: To catch large quantities of "crayfish" I will need to use outboard engines & \\
\hline & & TA3: There are higher outboard engine capacities compared to what am using now & \\
\hline & & TA4: Recently, there are changes to the type of woods we use to construct our canoes & \\
\hline & & TA5: Recently, I make my boat stronger by constructing it with zinc & \\
\hline & & TA6: The quality of outboard engine I use nowadays is worse than the one I used before & \\
\hline & & TA7: It is hard to predict what technological improvements will emerge in the nearest future & \\
\hline \multirow[t]{8}{*}{3.} & \multirow[t]{8}{*}{ Power } & PA1: Certain fishers often supply the largest quantity of products to the market & \\
\hline & & PA2: Certain fishers have very high reputation in our industry & \\
\hline & & PA3: Certain fishers are more knowledgeable about the business in our industry & \\
\hline & & PA4: Certain processors/marketers understand the business inter-relationship with fishers more & \\
\hline & & PA5: Certain processors/marketers can attain better financial background than others & \\
\hline & & PA6: Certain processors/marketers can attract more buyers than others & \\
\hline & & PA7: We are strongly dependent on processors to process our products & \\
\hline & & PA8: We are strongly dependent on marketers to market our products & \\
\hline
\end{tabular}

4.2 Kindly state the level at which you concur with statements on the internal characteristics of shrimp supply chain organization

\begin{tabular}{|l|l|l|l|}
\hline S/N & Internal contingencies & Items & Response \\
\hline \multirow{5}{*}{1.} & Human resources & HR1: My skills in shrimping are quite huge & \\
\cline { 3 - 5 } & & HR2: My employees are experienced fishers & \\
\cline { 3 - 5 } & & HR3: My employees are able to mend my fishing gears (seine, tester etc.) & \\
\cline { 3 - 5 } & HR4: My employees have closer inter-relationships with my crayfish processors/marketers & \\
\cline { 3 - 5 } & HR5: I have built strong relationships with processors/marketers & \\
\hline
\end{tabular}


Questionnaire /HHID.

\begin{tabular}{|l|l|l|l|}
\hline \multirow{2}{*}{} & & HR6: I keep accurate records of each quantity of "crayfish" I sell to the processors/marketers \\
\cline { 3 - 4 } & & HR7: I keep accurate records of my revenues from "crayfish" & \\
\cline { 3 - 4 } & HR8: I consider myself as being not financially literate \\
\hline \multirow{5}{*}{2.} & Business resources & BR1: Correct forecast of changes in the demand for crayfish is of paramount importance to my business \\
\cline { 3 - 4 } & BR2: I have several sources of financing my business & \\
\cline { 3 - 4 } & BR3: My business is located in an area where I can easily link up to my customers \\
\cline { 3 - 4 } & BR4: Out of 10, what proportion of your customers is linked to other artisanal producers in your area? \\
\hline & BR5: I consider myself as being less creditworthy & \\
\hline & BR6: I have little amount of monetary reserve that can take my shrimping business through periods of struggle & \\
\hline
\end{tabular}

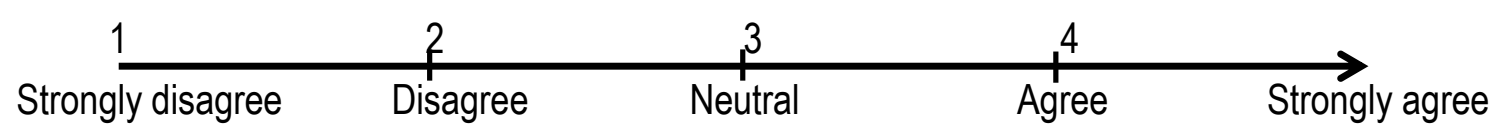

Note for the Enumerator: The respondent of this section should be the most experienced and active fisher in the household 


\section{MODULE 5: PRODUCER ORGANIZATIONAL STRUCTURE AND PERFORMANCE}

5.1 Kindly fill in the necessary information and state the level at which you concur with some statements on the organizational structure of the shrimp supply chain

\begin{tabular}{|c|c|c|c|}
\hline $\mathrm{S} / \mathrm{N}$ & Inter-relationships & Items & Response \\
\hline \multirow[t]{11}{*}{1.} & \multirow[t]{11}{*}{ Vertical relationships } & VR1: How many processors/marketers do you sell your crayfish to? & \\
\hline & & VR2: What kind of agreement did you have with your customer? CODE: [1] Written contracts [0] Non-formal agreements & \\
\hline & & VR3: How many years have you been supplying your longest standing "crayfish"processor? & \\
\hline & & VR4: I sell more than $50 \%$ of my total "crayfish" caught to just one of the processors/marketers & \\
\hline & & VR5: More than $50 \%$ of the crayfish processed/marketed by at least one of the processors/marketers comes from my catch & \\
\hline & & VR6: I am more inclined to sell my product to customers with whom I have a long-term relationship & \\
\hline & & VR7: I sell "crayfish" to as many buyers at a particular open spot & \\
\hline & & VR8: I have to display my "crayfish" before I can get willing buyers & \\
\hline & & VR9: Out of 10, what is the proportion of women among processors/marketers you sell your crayfish to? & \\
\hline & & VR10: Does your main crayfish processor/marketer provide you with cash in order to shrimp? CODE: (\{1\} Yes $\{0\}$ No) & \\
\hline & & VR11: Out of 10, what is the average proportion of each cash received from processors/marketers in your total fuel cost per trip? & \\
\hline \multirow[t]{4}{*}{2.} & \multirow[t]{4}{*}{ Horizontal relationships } & HOR1: Are you a member of any fish producer group? CODE: (\{1\} Yes $\{0\}$ No) & \\
\hline & & HOR2: How many fish producer groups do you belong to? & \\
\hline & & HOR3: Longest time spent as a member of fish producer group in years? & \\
\hline & & HOR4: How many fishers do you collaborate with? & \\
\hline \multirow[t]{6}{*}{3.} & \multirow[t]{6}{*}{ External relationships } & SE1: Do you have access to extension services? CODE: (\{1\} Yes $\{0\}$ No) & \\
\hline & & SE2: How many times do extension agents/supporting personnel visit the community in a year? & \\
\hline & & SE3: I get some vital information about fishing from extension agents & \\
\hline & & SE4: Do you attend trainings organized by actors who are not part of the supply chain? CODE: (\{1\} Yes $\{0\}$ No) & \\
\hline & & SE5: Recently, we get more visits from people that want to support us & \\
\hline & & SE6: Our grievances now easily get to the public agencies & \\
\hline
\end{tabular}

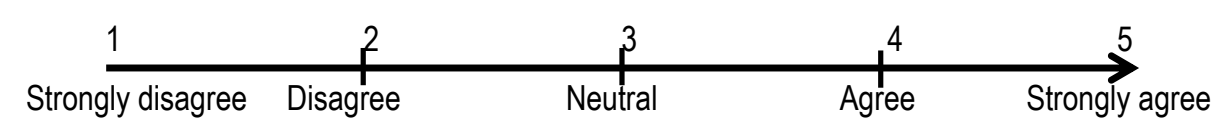


5.2 Kindly fill in the necessary information and state the level at which you concur with some statements on your performance during the last 12 months

\begin{tabular}{|c|c|c|c|c|}
\hline S/N & Performances & Indicators & Items & Response \\
\hline \multirow[t]{8}{*}{1.} & \multirow[t]{8}{*}{ Financial } & \multirow[t]{8}{*}{ Efficiency } & FE1: What is your average profit per week from shrimping during the last 12 months? & \\
\hline & & & FE2: What was your average profit per week from shrimping in 2016, 2015 and $2014 ?$ & \\
\hline & & & FE3: Over the last 3 years my profit from shrimping has been increasing & \\
\hline & & & FE4: On average, how much cash did you have at hand per week during the last 12 months? & \\
\hline & & & FE5: On average, how much cash were you having at hand per week in 2016, 2015 and $2014 ?$ & \\
\hline & & & FE6: Over the last 3 years the cash I have at hand from shrimping has been increasing & \\
\hline & & & FE7: Over the last 3 years the quantity of "crayfish" I catch has been increasing & \\
\hline & & & FE8: Over the last 3 years I have better profit relative to my competitors & \\
\hline \multirow[t]{11}{*}{2.} & \multirow[t]{11}{*}{ Operational } & \multirow[t]{3}{*}{ Customer satisfaction } & OC1: Over the last 3 years I am more competitive in meeting the demand of women processors & \\
\hline & & & OC2: Over the last 3 years many women processors often lay complaints about my product & \\
\hline & & & OC3: Over the last 3 years many women processors continuously patronize me because they are satisfied & \\
\hline & & \multirow[t]{2}{*}{ Responsiveness } & OR1: Over the last 3 years I respond to the orders of women processors on time & \\
\hline & & & OR2: What was your average lead time in 2017, 2016-2014? (Period between when an order is placed and received by buyer in hour) & \\
\hline & & \multirow[t]{2}{*}{ Flexibility } & OF1: Over the last 3 years I am able to quickly respond to unpredictable orders by women processors & \\
\hline & & & OF2: Over the last 3 years I am able to handle late orders from my immediate trading partner & \\
\hline & & \multirow[t]{4}{*}{ Food quality } & OFQ1: Did you carry out thorough sorting of your product over the last 3 years? CODE: (\{1\} Yes $\{0\}$ No) & \\
\hline & & & OFQ2: Over the last 3 years I strive to ensure my product is well sorted before sale to the women processors & \\
\hline & & & OFQ3: The quality of product is an important measure of my market performance & \\
\hline & & & OFQ4: I believe the quality of my product is of paramount importance & \\
\hline \multicolumn{3}{|c|}{ Overall performance } & SCP1: How would you rate the success of your shrimp supply chain in comparison to other fishing supply chains over the last 3 years? & \\
\hline
\end{tabular}

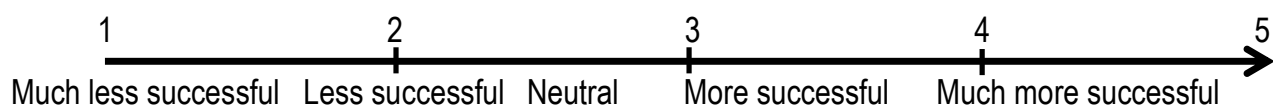

$\underset{\text { Strongly disagree }}{\stackrel{1}{2}} \stackrel{\text { Disagree }}{\stackrel{3}{4}} \underset{\text { Agree }}{\longrightarrow}$




\section{MODULE 6: HOUSEHOLD ASSET HOLDINGS}

Questionnaire /HHID

6.1 Kindly fill in the necessary information about the asset holdings of the household

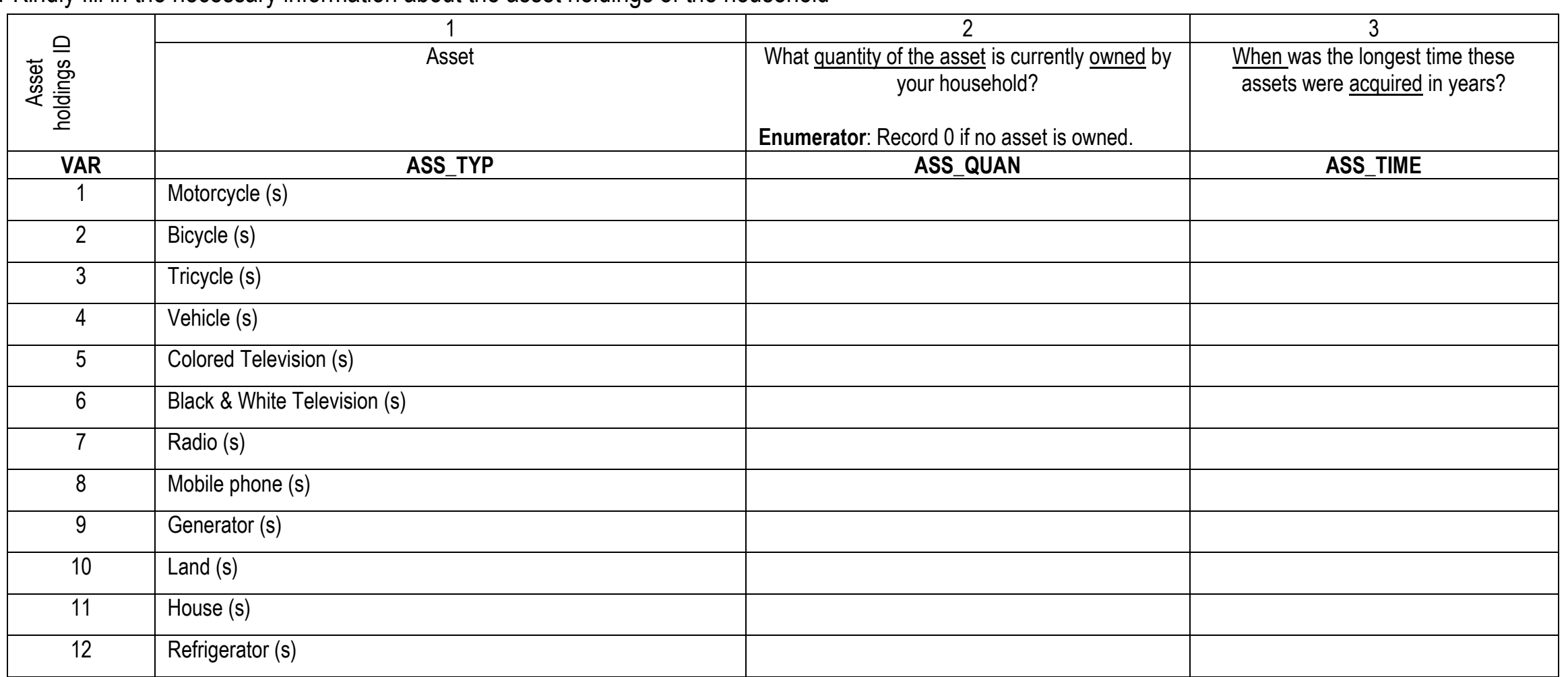

6.2 Do you have access to electricity? (ELECTRIC) CODE: (\{1\} Yes $\{0\}$ No)

6.3 Do you have access to piped borne water? (PIPED_WAT) CODE: (\{1\} Yes $\{0\}$ No)

6.4 Is the floor of your house concreted? (F_CONCRETE) CODE: $(\{1\}$ Yes $\{0\}$ No)

6.5 What type of house is respondent living in? (HOUSE) CODE: (\{1\} Full concreted house $\{0\}$ Sheds made from palm or aluminum) 
MODULE 7: COLLECTIVE ACTION AND PARTICIPATION IN PRODUCER GROUP

7.1 If HOR1 is yes, respondent should provide information about the producer groups they belong to. If No, enumerator should move to question 7.2 .

\begin{tabular}{|c|c|c|c|c|c|c|c|c|c|c|c|c|}
\hline & 1 & 2 & 3 & 4 & 5 & 6 & 7 & 8 & 9 & 10 & 11 & 12 \\
\hline 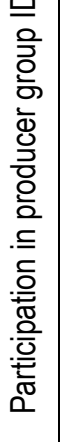 & $\begin{array}{l}\text { What is the } \\
\text { name of } \\
\text { producer } \\
\text { groups } \\
\text { respondent } \\
\text { belong to }\end{array}$ & $\begin{array}{l}\text { How many } \\
\text { members are } \\
\text { there in your } \\
\text { fish producer } \\
\text { group? }\end{array}$ & $\begin{array}{l}\text { What is the } \\
\text { educational status } \\
\text { of the head of your } \\
\text { producer group? } \\
\text { coDE: } \\
\text { [1] Non-formal } \\
\text { [2] Primary } \\
\text { [3] Secondary } \\
\text { [4] University }\end{array}$ & $\begin{array}{c}\text { Please } \\
\text { specify } \\
\text { when you } \\
\text { joined the } \\
\text { group in } \\
\text { years }\end{array}$ & $\begin{array}{l}\text { Have you at } \\
\text { any time left } \\
\text { the producer } \\
\text { group within } \\
\text { the period you } \\
\text { first became a } \\
\text { member? } \\
\text { CODE: } \\
\text { [1] Yes } \\
\text { [0] No }\end{array}$ & $\begin{array}{l}\text { When was } \\
\text { the fish } \\
\text { producer } \\
\text { group } \\
\text { formed in } \\
\text { the village? }\end{array}$ & $\begin{array}{l}\text { How many } \\
\text { times have } \\
\text { you left the } \\
\text { producer } \\
\text { group within } \\
\text { that period? }\end{array}$ & $\begin{array}{l}\text { What is the role } \\
\text { of respondent } \\
\text { in the fish } \\
\text { producer } \\
\text { group? } \\
\text { CODE: } \\
\text { [1] Executive } \\
\text { [0] Ordinary } \\
\text { member }\end{array}$ & $\begin{array}{l}\text { What is the } \\
\text { membership } \\
\text { cost of your } \\
\text { producer group } \\
\text { in a year? }\end{array}$ & $\begin{array}{l}\frac{\text { How often }}{\text { do you pay }} \begin{array}{c}\text { your } \\
\text { membershi }\end{array} \\
\frac{\text { p cost? }}{\text { CODE E }}\end{array}$ & $\begin{array}{l}\begin{array}{l}\text { Is any of your } \\
\text { closest }\end{array} \\
\frac{\text { neighbor part }}{\text { of your fish }} \\
\frac{\text { producer }}{\text { group? }} \\
\text { CODE: } \\
\text { [1] Yes } \\
\text { [0] No }\end{array}$ & $\begin{array}{c}\text { What is the } \\
\text { distance of } \\
\text { your home to } \\
\text { the home of } \\
\text { the head of } \\
\text { the producer } \\
\text { group? }\end{array}$ \\
\hline ID & PGNAME & ASSO_NR & EDU_ASSH & PGYEAR & PGDMEM & ASSO_YR & PGDTIME & MEM_POSIT & MEM_COST & MCOST & NEI_MEM & DIST_ASSH \\
\hline 1 & ARFAN & & & & & & & & & & & \\
\hline 2 & & & & & & & & & & & & \\
\hline 3 & & & & & & & & & & & & \\
\hline
\end{tabular}

7.2 If the response in 7.1 is yes, what is the essence of participating in fish producer group?

Do you agree with any of the statements below?

ROLE1: Did you sell your product through the producer group? [1] Yes [0] No

ROLE2: What share of your product did you sell to the women processors linked to your producer group?

ROLE3: Did you obtain inputs jointly through the producer group? [1] Yes [0] No

ROLE4: Have you been trained through the producer group on the maintenance of either gear or outboard engine? [1] Yes [0] No

ROLE5: Have you obtained any government or public assistance since you joined the producer group? [1] Yes [0] No

PART1: I joined the producer group because I could learn from experienced members

PART2: I joined the producer group because I could jointly access input markets with other members at lower cost

PART3: I joined the producer group because I could receive higher selling price than other fishers who did not join

PART4: I joined the producer group because they could provide opportunity for members who do not have all necessary inputs to fish with someone who has

PART5: I joined the producer group because my profit would increase

PART6: I joined the producer group because I could easily get government support

PART7: I joined the producer group because they would make it easier for me to market my crayfish

PART8: I joined the producer group because they would provide me with the opportunity to easily access credit facilities

PART9: I joined the producer group because I will feel among when I belong to the producer group in my village

7.3 Are you a member of non-fish related association? CODE: [1] Yes [0] No (SOCPAR)

7.4 How many years have you been with other non-fish producing association? (SOPAR_YR)

CODE E: [1] Occasionally [2] Sometimes [3] Regularly

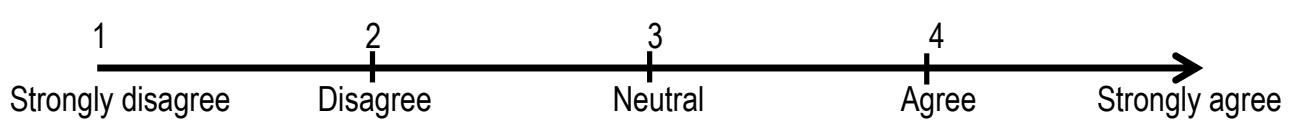


7.5 If the response in 7.1 is no, why is respondent not participating in producer group?

\begin{tabular}{|c|c|c|c|c|c|c|c|c|c|}
\hline \multicolumn{8}{|c|}{ Do you agree with any of the statements below? } & \multicolumn{2}{|c|}{ Response } \\
\hline \multicolumn{10}{|c|}{ NPG1: I do not see the reason to join the producer group } \\
\hline \multicolumn{10}{|c|}{ NPG2: The cost of being a member of the producer group is very high } \\
\hline \multicolumn{10}{|c|}{ NPG3: I will get unsatisfying price for my product if I become a member of the producer group } \\
\hline \multicolumn{10}{|c|}{ NPG4: I did not join the producer group because there is none located close to my village } \\
\hline \multicolumn{10}{|c|}{ NPG5: There are very few full-time fishers in your village } \\
\hline \multicolumn{10}{|c|}{ 7.6 Kindly provide information about the person you often interact and learn from in the group } \\
\hline & 1 & 2 & 3 & 4 & 5 & 6 & 7 & 8 & 9 \\
\hline & $\begin{array}{c}\text { Name of the } \\
\text { person you } \\
\text { interact most } \\
\text { within the group }\end{array}$ & $\begin{array}{l}\text { Gender } \\
\text { of NAME } \\
\text { CODE F }\end{array}$ & $\begin{array}{l}\text { Age of } \\
\text { NAME }\end{array}$ & $\begin{array}{l}\text { Please specify the position } \\
\text { of NAME in the group } \\
\text { CODE G }\end{array}$ & $\begin{array}{l}\text { How long has NAME } \\
\text { been a member of the } \\
\text { group in years? }\end{array}$ & $\begin{array}{l}\text { How often did you talk with NAME } \\
\text { during the last } 12 \text { months } \\
\text { CODE H }\end{array}$ & $\begin{array}{l}\text { Is NAME's market share } \\
\text { larger than yours? } \\
\text { CODE: [1] Yes [0] No }\end{array}$ & $\begin{array}{l}\text { Are you and NAME in } \\
\text { other groups? } \\
\text { CODE: [1] Yes [0] No }\end{array}$ & $\begin{array}{l}\text { Are you and NAME } \\
\text { from the same ethnic } \\
\text { group? } \\
\text { CODE: [1] Yes [0] No }\end{array}$ \\
\hline ID & NAME & NGEND & NAGE & NRELAT & NMEM & INTER & NMAR & NOPG & NETHNIC \\
\hline 01 & & & & & & & & & \\
\hline
\end{tabular}

7.7 Kindly provide information about the transaction attributes of shrimp in your village. Do you agree with any of the statements below? Transaction attributes

\section{agree}

HAS1: I have contact with more processors

HAS2: I have very close relationship with my product processors

HAS3: I have long-term relationships with my customers

HAS4: I often get credit assistance from my customers

HAS5: I often give my products on credit to my customers

HAS6: My customers have mutual understanding of the business requirements

HAS7: My customers respect mutually agreed business arrangements

SIT1: My customers always have to wait at the landing site for my return

SIT2: My customers make great effort to reside close to the landing site

SIT3: Transportation to the processing site is not a problem

SIT4: I made efforts to reside closer to the shore

SIT5: I made efforts to reside where I can easily reach processors and marketers

ASS1: I need outboard engine before I can go to the high-sea

ASS2: I need outboard engine to quickly land my catches

ASS3: We spend little time on the high-sea to meet quality standards

ASS4: Shrimping requires special type of nets

CODE F: [1] Male [0] Female
CODE G: [1] Executive [2] Member
CODE H: [1] Daily [2] Weekly [3] Monthly [4] Quarterly [5] once in a year

CODE F: [1] Male [0] Female

CODE H: [1] Daily [2] Weekly [3] Monthly [4] Quarterly [5] once in a year

\section{Strongly disagree}

(1)
Disagree

(2)
Neutral

(3)
Agree

(4)

\section{Strongly}

(5)

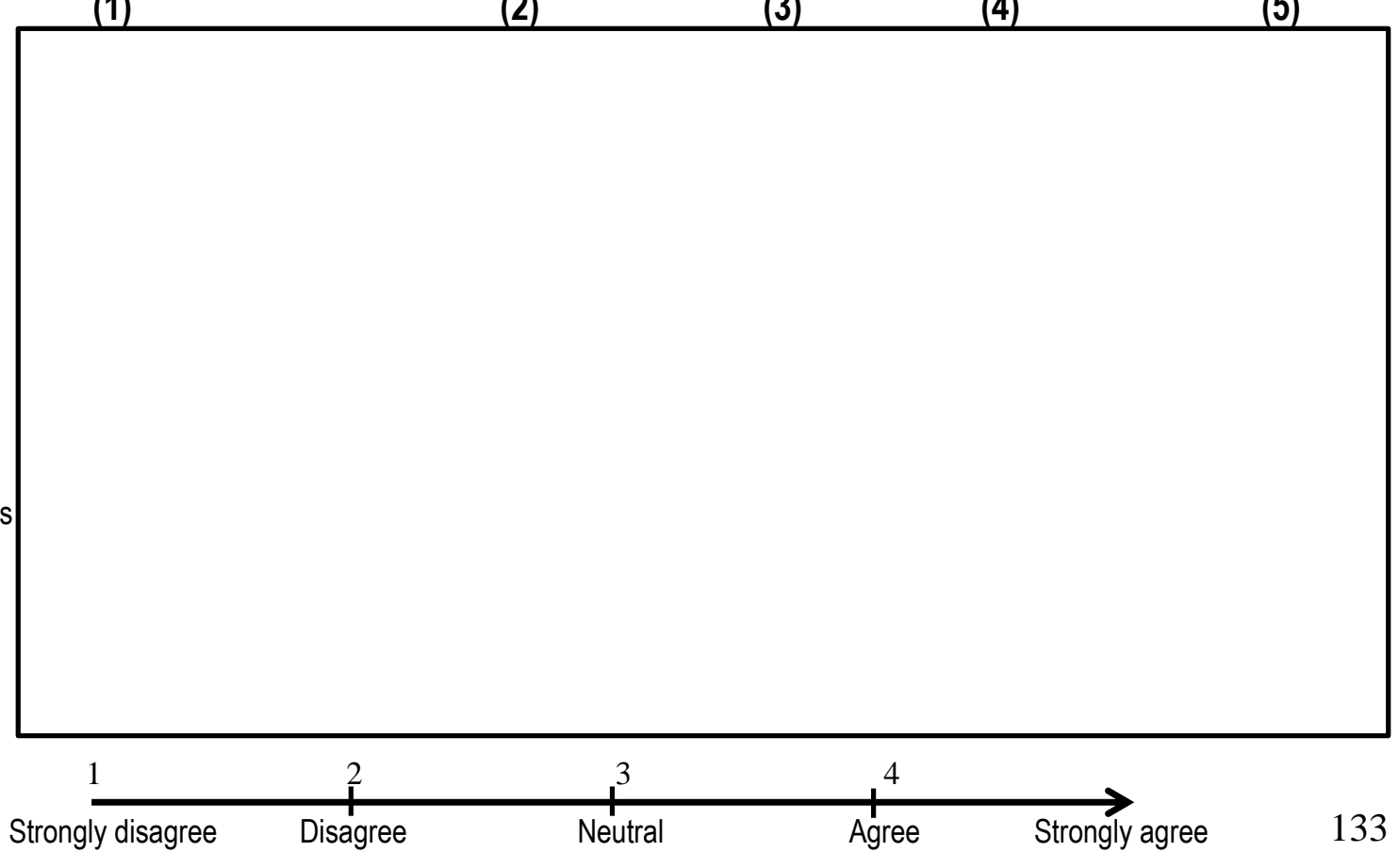




\section{MODULE 8: CREDIT}

To respondents who answered yes to question 1.21 in Module 1, kindly fill in information about the credit facilities accessed.

\begin{tabular}{|c|c|c|c|c|c|c|c|c|}
\hline \multirow{3}{*}{$\begin{array}{l} \\
\text { 음 } \\
\text { 능 }\end{array}$} & 1 & 2 & 3 & 4 & 5 & 6 & 7 & 8 \\
\hline & $\begin{array}{l}\text { What kind of } \\
\frac{\text { credit did you }}{\text { access? }} \\
\text { CODE I }\end{array}$ & $\begin{array}{l}\text { What is the main } \\
\text { source of credit } \\
\text { accessed by } \\
\text { respondent? } \\
\text { CODE J }\end{array}$ & $\begin{array}{l}\text { How often did you } \\
\frac{\text { access these credit }}{\text { facilities? }} \\
\text { cODE: } \\
\text { [1] Occasionally } \\
\text { [2] Sometimes } \\
\text { [3] Everytime }\end{array}$ & $\begin{array}{l}\text { What time did you access these } \\
\text { credit facilities? } \\
\text { CODE: } \\
\text { [1] Beginning of the next } 12 \\
\text { months } \\
\text { [2] During the shrimping season } \\
\text { [3] After the shrimping season }\end{array}$ & $\begin{array}{l}\text { What was the } \\
\text { value of credit } \\
\frac{\text { applied for in }}{\text { Naira? }}\end{array}$ & $\begin{array}{l}\text { How long did you wait on the } \\
\text { average before your request } \\
\text { was granted? } \\
\text { CODE: } \\
\text { [1] Days } \\
\text { [2] Weeks } \\
\text { [3] Months } \\
\text { [4] Years }\end{array}$ & $\begin{array}{l}\text { What was the } \\
\text { value of } \\
\frac{\text { credit granted }}{\text { in Naira? }}\end{array}$ & $\begin{array}{c}\text { What did you } \\
\text { use the credit } \\
\text { for? } \\
\text { CODE K }\end{array}$ \\
\hline & CRED_TYP & CRED_SOUR & CRED_FREQ & CRED_TIME & CRED_APP & CRED_TAPP & CRED_VAL & CRED_PURP \\
\hline
\end{tabular}

\section{MODULE 9: SHOCKS AND EXTENSION SERVICES}

9.1 Was there any kind of shocks during the last 12 months (April 2017-May 2018)? (\{1\} Yes \{0\} No, go to question 5) (SHOCK)

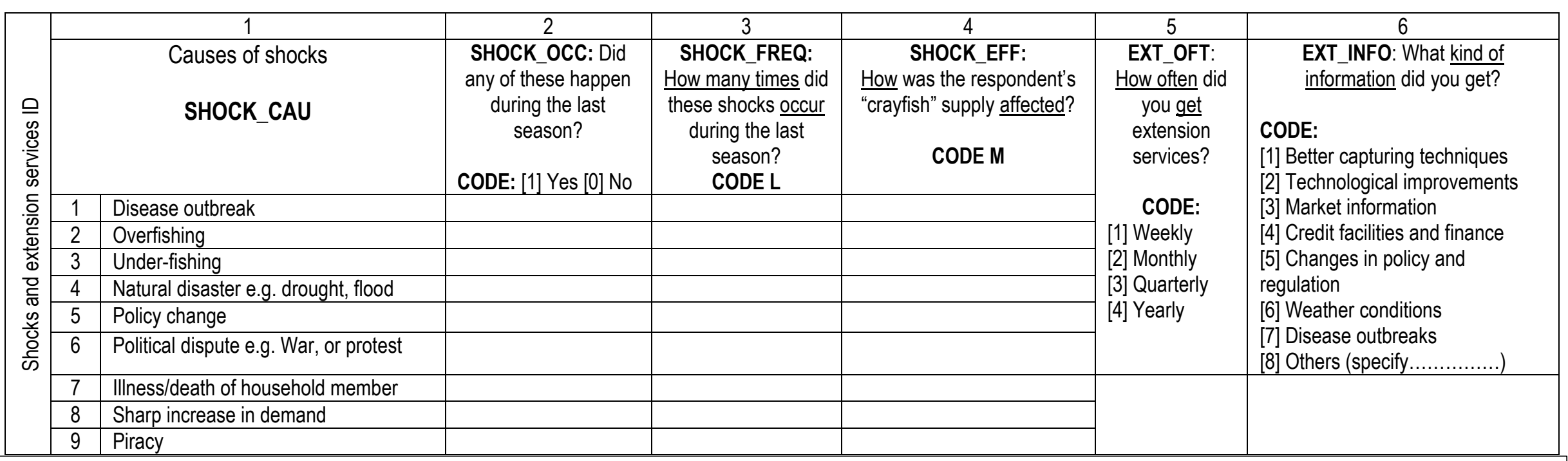

CODE I: [1] Cash loan [2] Input loan [3] Product loan [4] Others (specify..........)

CODE J: [1] Cooperative society [2] Friends/relatives [3] Trading partner [4] Producer group [5] Esusu [6] Commercial Bank [7] Micro-finance Bank [8] Religious bodies

CODE K: [1] Fishing investment [2] Non-fishing investments [3] Educational dues [4] Social activities [5] Saved [6] Health [7] Others (specify)..............

CODE L: [1] Never [2] Once [3] 2-5 [4] More than 5

CODE M: [1] Indifferent [2] Slightly [3] Considerably [4] Severely 


\section{MODULE 10: RESPONDENT'S DEMOGRAPHIC CHARACTERISTICS}

10.1 Kindly fill in the information about the respondent's demographic characteristics

\begin{tabular}{|c|c|c|c|c|c|c|c|c|c|c|}
\hline & 1 & 2 & 3 & 4 & 5 & 6 & 7 & 8 & 9 & 10 \\
\hline 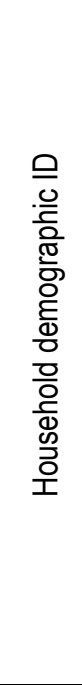 & $\begin{array}{l}\quad \begin{array}{l}\text { What is the } \\
\text { relationship of }\end{array} \\
\text { [RESPONDENT] to } \\
\text { the household head? } \\
\text { CODE: } \\
\text { [1]Head } \\
\text { [2]Spouse } \\
\text { [3]Son/Daughter } \\
\text { [4]Son/Daughter-in- } \\
\text { law } \\
\text { [5]Father/mother } \\
\text { [6]Sister/Brother } \\
\text { [7]Grandchild } \\
\text { [8] Others (......) } \\
\text { [9]Other non-relative } \\
\text { (......) }\end{array}$ & \begin{tabular}{l}
\multicolumn{1}{c}{ Gender of } \\
[RESPONDENT] \\
CODE: \\
[1]Female \\
[0] Male
\end{tabular} & $\begin{array}{l}\frac{\text { Age }}{\text { (in }} \\
\text { years) }\end{array}$ & $\begin{array}{l}\begin{array}{c}\text { What is the } \\
\text { highest level of }\end{array} \\
\frac{\text { education attained }}{\text { by }} \\
\text { [RESPONDENT]? } \\
\text { CODE: } \\
\text { [1]Quranic } \\
\text { [2] Non-formal } \\
\text { education } \\
\text { [3]Primary } \\
\text { [4]Junior School } \\
\text { [5]Senior school } \\
\text { [6]University }\end{array}$ & $\begin{array}{c}\text { What is the } \\
\text { number of years } \\
\text { [RESPONDENT] } \\
\text { spent in school? }\end{array}$ & $\begin{array}{l}\text { What the number } \\
\text { is of times } \\
\text { [RESPONDENT] } \\
\text { repeated classes? }\end{array}$ & 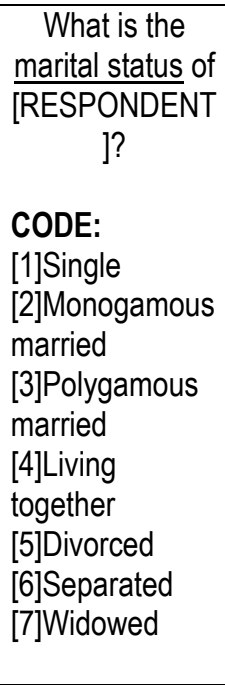 & $\begin{array}{l}\text { What is the main } \\
\text { occupation of } \\
\text { [RESPONDENT] } \\
\text { in the last } 12 \\
\quad \text { months? } \\
\text { CoDE: } \\
\text { [1]Fishing } \\
\text { [2]Processing \& } \\
\text { marketing } \\
\text { [3]1\&2 } \\
\text { [4]Farming } \\
\text { [5]Transport } \\
\text { [6] Wage labor } \\
\text { [7]Trade } \\
\text { [8]Service }\end{array}$ & $\begin{array}{l}\text { Was } \\
\text { [RESPONDENT } \\
\text { ] employed in } \\
\text { non-fishing } \\
\text { activities in the } \\
\text { last } 12 \text { months? } \\
\text { CODE: } \\
\text { [1] Yes } \\
\text { [0] No }\end{array}$ & $\begin{array}{l}\text { Did } \\
\text { [RESPONDENT] } \\
\text { shrimp under } \\
\text { someone in the } \\
\text { last } 12 \text { months? } \\
\text { CODE: } \\
\text { [1] Yes } \\
{[0] \text { No }}\end{array}$ \\
\hline MBID & RELATION & GEND & AGE & EDUC & EDUYR & REPEAT & MARSTAT & OCCUP & NONFISH & APPRE \\
\hline
\end{tabular}




\section{MODULE 11: WOMEN'S PARTICIPATION AND ROLES}

Kindly fill in the information about the participation and roles of female household members along the shrimp supply chain

11.1 Did any female household laborers have access to financial resources/ assistance in the role she played in the last 12 months? CODE: [1] Yes [0] No

11.2 Did any female household laborers have access to information that improved her activities during the last 12 months? CODE: [1] Yes [0] No

11.3 Did any female household laborers have access to technological resources that improved her activities in the last 12 months? CODE: [1] Yes [0] No

11.4 Thinking about the role women perform in the family and shrimp sector, kindly choose the degree of influence you think women have on the decision-making process in the areas highlighted below.

\begin{tabular}{|c|c|c|c|c|c|c|c|c|c|c|c|c|}
\hline \multirow[t]{2}{*}{$\begin{array}{c}\text { Female } \\
\text { Influence } \\
\text { level ID }\end{array}$} & \begin{tabular}{|l|} 
INF1: \\
Equipment \\
purchases \\
\end{tabular} & $\begin{array}{l}\text { INF2: } \\
\text { Product } \\
\text { quality } \\
\end{array}$ & \begin{tabular}{|l|} 
INF3: Introduction of \\
new technologies/ \\
approaches \\
\end{tabular} & $\begin{array}{l}\text { INF4: } \\
\text { Hiring } \\
\text { staff }\end{array}$ & $\begin{array}{l}\text { INF5: } \\
\text { Shrimping } \\
\text { period } \\
\end{array}$ & $\begin{array}{l}\text { INF6: } \\
\text { Quantity } \\
\text { consumed }\end{array}$ & $\begin{array}{l}\text { INF7: } \\
\text { Quantity } \\
\text { gifted }\end{array}$ & $\begin{array}{l}\text { INF8: } \\
\text { Processing } \\
\text { activities } \\
\end{array}$ & $\begin{array}{l}\text { INF9: } \\
\text { Marketing } \\
\text { activities }\end{array}$ & $\begin{array}{l}\text { INF10: Major } \\
\text { investments }\end{array}$ & $\begin{array}{l}\text { INF11: Household } \\
\text { finance management }\end{array}$ & $\begin{array}{l}\text { INF12: } \\
\text { Environmental } \\
\text { management }\end{array}$ \\
\hline & & & & & & & & & & & & \\
\hline
\end{tabular}

11.5 Did any of female household laborers receive any kind of training regarding her role in the last 12 months? (F_TRAIN) (\{1\} Yes $\{0\}$ No)

11.6 What are the problems affecting women processors along the shrimp value/supply chain? CODE: ( $\{1\}$ Yes $\{0\}$ No)

\begin{tabular}{|c|l|l|l|l|l|l|l|l|l|}
\hline $\begin{array}{c}\text { Women } \\
\text { performance } \\
\text { inhibitors ID }\end{array}$ & $\begin{array}{l}\text { SOC1: Lack of } \\
\text { social security }\end{array}$ & $\begin{array}{l}\text { SOC2: } \\
\text { Gender } \\
\text { discrimination }\end{array}$ & $\begin{array}{l}\text { Soc3: Lack of } \\
\text { property right }\end{array}$ & $\begin{array}{l}\text { ECO1: Lack of } \\
\text { capital }\end{array}$ & $\begin{array}{l}\text { INFR1: Lack of } \\
\text { communication } \\
\text { facilities }\end{array}$ & $\begin{array}{l}\text { INFR2: Lack } \\
\text { of power } \\
\text { supply }\end{array}$ & $\begin{array}{l}\text { INFR3: Low } \\
\text { years of } \\
\text { education }\end{array}$ & $\begin{array}{l}\text { MRK1: Poor } \\
\text { bargaining power }\end{array}$ & $\begin{array}{l}\text { MRK2: Lack of } \\
\text { adequate processing } \\
\text { equipment }\end{array}$ \\
\cline { 2 - 8 } \\
\hline
\end{tabular}

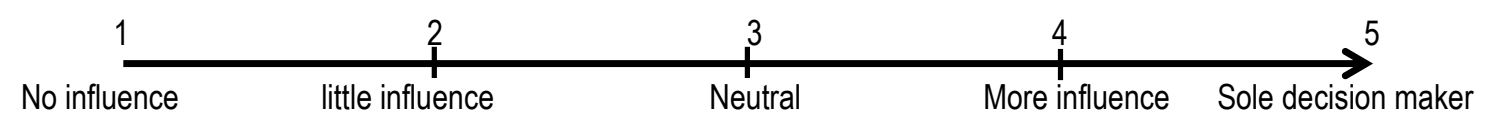

Note for the Enumerator: Female household labourers here are female household members contributing to the household fishing activities in one way. 


\section{SHRIMP SUPPLY CHAIN ORGANIZATION IN NIGERIA}

\section{Processor Survey Questionnaire, 2018}

\section{Introduction}

With this survey, we intend to examine different aspects of shrimp supply chain organization. You have been randomly selected to participate in this interview that covers your characteristics, processing and distributing activities on shrimp, as well as your relationships with other actors across or along the supply chain, and market performance.

We are doctoral students affiliated with the University of Goettingen. Thus, the information you will be providing will be used solely for research purposes, while all your responses will be kept confidential and untraceable to individuals. The questionnaire should take about 30 minutes to complete. We therefore crave for your consent to participate in this interview. If you have any question, do not hesitate to contact the undersigned:

\section{Adetoyinbo Ayobami}

adetoyinbo@gwdg.de

\section{IDENTIFICATION}

Details on Supervisor and Enumerator

\section{Supervisor's Name:}

\section{Enumerator's Name:}

Time started (STIME):

Date of interview (INDATE):

\section{Contents}

IDENTIFICATION

MODULE 1: GENERAL INFORMATION

MODULE 2: PROCESSING INPUTS AND COST

MODULE 3: PROCESSING OUTPUT AND MARKETING

MODULE 4: PROCESSOR SITUATIONS ALONG THE SHRIMP SUPPLY CHAIN

MODULE 5: PROCESSOR ORGANIZATIONAL STRUCTURE AND PERFORMANCE

MODULE 6: RESPONDENT'S DEMOGRAPHIC CHARACTERISTICS
Enumerator's code:

Signature/date:

Time ended (ETIME):

\section{Page number}

1

2

3

5

6 


\section{MODULE 1: GENERAL INFORMATION}

1.1 State (STAT) ( $\{1\}$ Lagos $\{2\}$ Ondo $\{3\}$ Akwa lbom)

1.2 Local Government Area (LGA)

1.3 Village name (VILL)

1.4 Name of household head (HHNAME)

1.5 Name of respondent (RNAME)

1.6 Do you own a mobile phone? ( $\{1\}$ Yes $\{0\}$ No) (MOBILE)

1.7 Mobile number of respondent:

1.8 Gender of household head (HHGENDER) ( $\{1\}$ Male $\{0\}$ Female)

1.9 What is respondent's marital status? (MARR) CODE A

1.10 What is respondent's educational status in years? (EDUC)

1.11 How many years has respondent been processing shrimps? (FISHYEAR)

1.12 What is the distance to the village head's home? (VIHHDIST)

1.13 How many years have the village head ruled? (VIHHREIGN)

1.14 What is the occupation of the village head? (OCCUPHH) (\{1\} Fishing $\{0\}$ others)

1.15 What is the distance to the nearest fishing village in meters? (FVILL)

1.16 What respondent's age in years? (AGE)

1.17 Distance to the nearest shrimp market in meters? (MDIST)
1.18 Is respondent in association related to shrimp processing? (ASSO) ( $\{1\}$ Yes $\{0\}$ No)

1.19 How many years has respondent spent with this association? (YRASSO)

1.20 Do you have access to credit facilities? (CREDIT) $(\{1\}$ Yes $\{0\}$ No)

1.21 Do you have access to a tarred road? (TAROAD) $(\{1\}$ Yes $\{0\}$ No)

1.22 Distance between processing point and tarred road in meters: (DROAD)

1.23 Are you a Nigerian? (NATIONALITY) ( $\{1\}$ Yes $\{0\}$ No, skip to question 1.30)

1.24 What tribe do you belong to? (TRIBE) ( $\{1\}$ Yoruba $\{2\}$ ljaw $\{3\}$ lgbo $\{4\}$ Others)

1.25 Is respondent an indigene of this village? (INDIG) (\{1\} Yes $\{0\}$ No)

1.26 If No, where are you from? (COUNT) ( $\{1\}$ Ghana $\{2\}$ Cameroon $\{3\}$ Others)

1.27 How many years has the respondent been resident in the village? (RESIDE)

1.28 Distance to the nearest shrimp market-hub in meters? (HUBDIST)

1.29 Does respondent belong to other groups not related to "crayfish"? (SOC) (\{1\} Yes $\{0\}$ No)

1.30 How many other groups not related to "crayfish" do you belong to? (SOCNUM)

1.31 Is respondent a member of a cooperative society? (COOP) $(\{1\}$ Yes $\{0\}$ No) 
MODULE 2: PROCESSING INPUT AND COSTS (LAST 12 MONTHS i.e. April 2017-May 2018)

2.1 Kindly fill in all information about the characteristics of processing inputs, and their associated costs during the last 12 months (April 2017-May 2018)

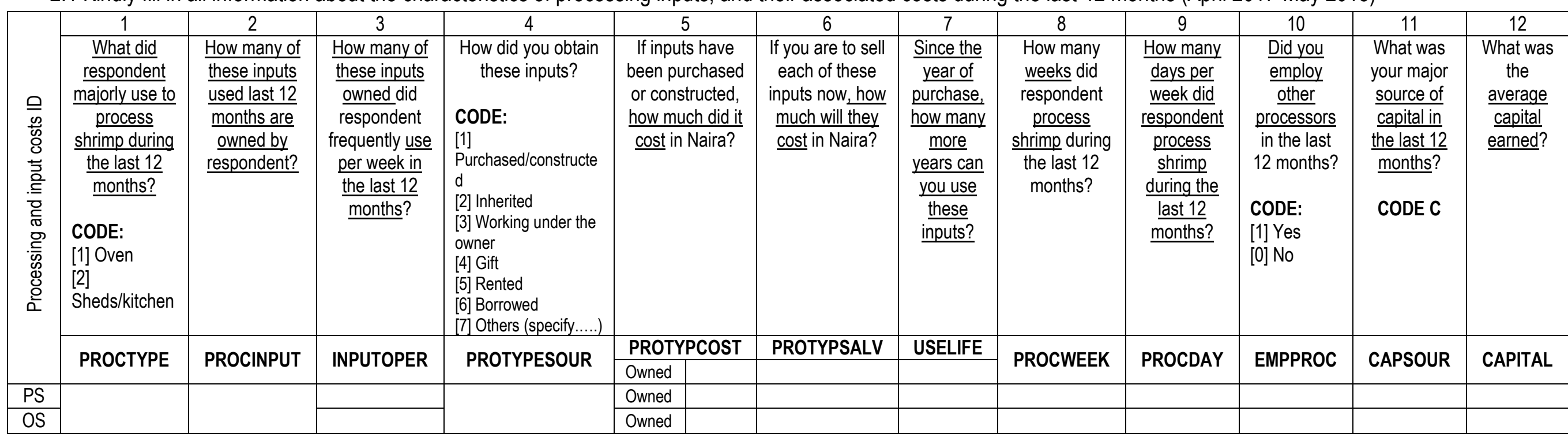

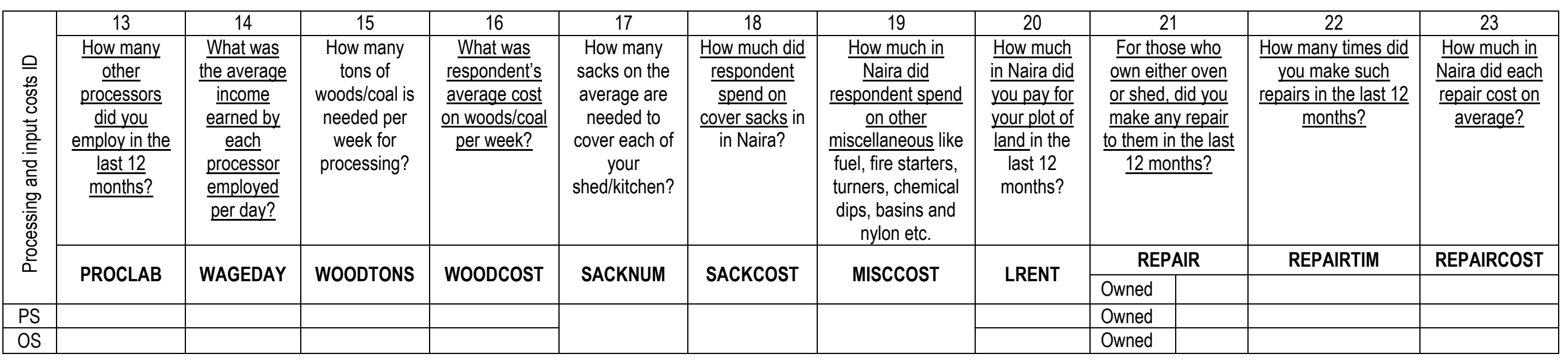

CODE C: [1] Personal savings [2] Cooperatives/association [3] Trading partner [4] Friends and relatives [5] Bank credit [6] Others (specify..........)

PS $=$ Peak Season (April-October 2017)

OS = Off season (November 2017-May 2018) 


\section{MODULE 3: PROCESSING OUTPUT AND MARKETING}

3.1 Kindly fill in the information about processing output and marketing during the last 12 months (April 2017-May 2018)

\begin{tabular}{|c|c|c|c|c|c|c|}
\hline \multirow{3}{*}{ 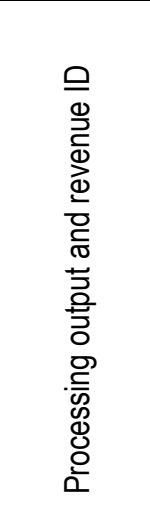 } & 1 & 2 & 3 & 4 & 5 & 6 \\
\hline & $\begin{array}{l}\frac{\text { How much "crayfish" (in }}{\mathrm{kg} \text { ) is processed per }} \\
\frac{\text { week during the last } 12}{\text { months? }}\end{array}$ & $\begin{array}{l}\text { What quantity of processed } \\
\text { "crayfish" was consumed at } \\
\quad \text { home/week? } \\
\text { CODE: [1] Almost none } \\
\text { [2] } 1 / 4 \\
\text { [3] } 1 / 2 \\
\text { [4] Almost all }\end{array}$ & $\begin{array}{l}\text { What quantity of processed } \\
\text { "crayfish" was offered as a } \\
\text { gift to friends and/or } \\
\text { relatives per week? } \\
\text { CODE: [1] Almost none } \\
\text { [2] } 1 / 4 \\
\text { [3] } 1 / 2 \\
\text { [4] Almost all }\end{array}$ & $\begin{array}{l}\text { What is the } \\
\text { average } \\
\text { selling price } \\
\text { of processed } \\
\text { "crayfish" per } \\
\text { kg in Naira? }\end{array}$ & $\begin{array}{l}\frac{\text { To whom did you sell most }}{\text { of your processed }} \\
\text { "crayfish"? } \\
\text { CODE: [1] Traders } \\
\text { [2] Consumers } \\
\text { [3] Firms through collectors } \\
\text { [4] Food companies } \\
\text { [5] Others (specify....) } \\
\text { [6] More than one }\end{array}$ & $\begin{array}{l}\frac{\text { How much did you earn on }}{\text { average per week from the }} \\
\frac{\text { marketing of "large shrimp" }}{\text { in Naira? }}\end{array}$ \\
\hline & SHRIMPROC & SHRIMPCON & SHRIMPGIFT & SALEPRICE & SALETO & SHRIMPSALE \\
\hline$\frac{\text { Peak Seas }}{\text { Offseason }}$ & & & & & & \\
\hline
\end{tabular}

PS $=$ Peak Season $($ April-October 2017)

OS $=$ Off season (November 2017-May 2018) 


\section{MODULE 4: PROCESSOR SITUATIONS IN THE SHRIMP SUPPLY CHAIN}

4.1 Kindly state the level at which you concur with the following statements on the characteristics of shrimp and prawn supply chain organization

\begin{tabular}{|c|c|c|c|}
\hline $\mathrm{S} / \mathrm{N}$ & External contingencies & Items & Response \\
\hline \multirow[t]{8}{*}{1.} & \multirow{8}{*}{ Market turbulence } & MT1: Sometimes my customers` demand increases unpredictably in our market & \\
\hline & & MT2: The cost of woods has drastically increased of recent & \\
\hline & & MT3: My product deteriorate very fast & \\
\hline & & MT4: Am not sure of the stage in which my "crayfish" quality is by the time I deliver them to my trading partners & \\
\hline & & MT5: My competitors in nearby villages do reduce the price of their product to attract our customers & \\
\hline & & MT6: The market price for "crayfish" drastically changes in our market & \\
\hline & & MT7: Cost of constructing processing shed for "crayfish" has been increasing drastically of recent & \\
\hline & & MT8: I do not get a constant supply of "crayfish" from fishers because of incessant activities of pirates in my area & \\
\hline \multirow[t]{11}{*}{2.} & \multirow[t]{11}{*}{ Trust } & T1: People who buy "crayfish" from me often try to hide things which could negatively affect me & \\
\hline & & T2: People who buy "crayfish" from me never give me good advice & \\
\hline & & T3: People who buy "crayfish" from me do not trust me on the product information I provide them & \\
\hline & & T4: Transactions with people who buy "crayfish" from me are closely supervised & \\
\hline & & T5: People who buy "crayfish" from me often avoid taking advantage of me, even if the opportunity arises & \\
\hline & & T6: People who buy "crayfish" from me believe I do cheat them & \\
\hline & & T7: Do you trust the traders who buy "crayfish" from you? ( $\{1\}$ Yes $\{0\}$ No) & \\
\hline & & T8: I believe people who buy "crayfish" from me want to cheat me & \\
\hline & & T9: Generally speaking, I will say that most people along the supply chain cannot be trusted & \\
\hline & & T10: When circumstances change, I believe that people who buy "crayfish" from me will be willing to assist me & \\
\hline & & T11: I need to be very careful in dealing with traders who buy "crayfish" from me & \\
\hline \multirow[t]{10}{*}{3.} & \multirow[t]{10}{*}{ Power } & PA1: Certain processors/marketers often sell the largest quantity of "crayfish" in our market & \\
\hline & & PA2: Certain processors/marketers have very high reputation in the shrimp business & \\
\hline & & PA3: Certain processors/marketers are more knowledgeable about the shrimp processing business in my area & \\
\hline & & PA4: Certain processors/marketers understand the business interrelationship with fishers better than others & \\
\hline & & PA5: Certain processors/marketers do attain better financial background than others & \\
\hline & & PA6: Certain processors/marketers do attract more buyers than others & \\
\hline & & PA7: It is easier for my customers to dictate what price I should sell my product to them & \\
\hline & & PA8: We are strongly dependent on Ibo traders to constantly demand our "crayfish" & \\
\hline & & PA9: Traders who buy "crayfish" from me often dictate what measure they want me to sell my "crayfish" with & \\
\hline & & PA10: To me, traders who buy "crayfish" from me are more influential along the supply chain than me & \\
\hline \multicolumn{4}{|c|}{ 4.2 Kindly state the level at which you concur with statements on the internal characteristics of shrimp supply chain organization } \\
\hline S/N & Internal contingencies & Items & Response \\
\hline \multirow[t]{4}{*}{1.} & \multirow[t]{4}{*}{ Human resources } & HR1: My skills in "crayfish" processing are quite huge & \\
\hline & & HR2: My employees are experienced processors & \\
\hline & & HR3: My employees are experienced crayfish marketers & \\
\hline & & HR4: My employees can mend my processing shed/oven & \\
\hline
\end{tabular}




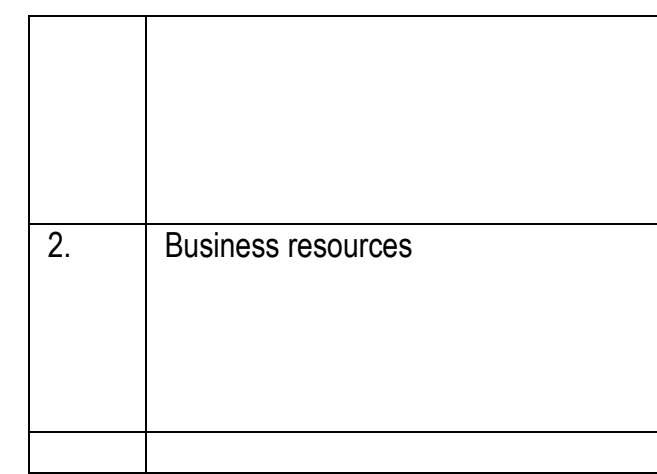

HR5: My employees have closer inter-relationships with traders who buy crayfish from me

HR6: I have built strong relationships with traders who buy "crayfish" from me

HR7: I keep accurate records of each quantity of "crayfish" I sell to traders who buy from me

HR8: I keep accurate records of my revenues from "crayfish" processing

HR9: I consider myself as being not financially literate

BR1: Correct forecast of changes in the demand for crayfish is of paramount importance to my business

BR2: I have several sources of financing my business

BR3: My business is located in an area where I can easily link up to my customers (traders)

BR4: Out of 10 , what proportion of your customers is linked to other artisanal processors in your area?

BR5: I consider myself as being less creditworthy

BR6: I have little amount of monetary reserve that can take my shrimping business through periods of struggle

Strongly disagree Disagre $\stackrel{4}{4}$
Neutral

(n)

\section{$\stackrel{5}{\text { Strongly agree }^{2}}$}




\section{MODULE 5: PROCESSOR ORGANIZATIONAL STRUCTURE AND PERFORMANCE}

5.1 Kindly fill in the necessary information and state the level at which you concur with some statements on the organization of the supply chain

\begin{tabular}{|c|c|c|c|}
\hline $\mathrm{S} / \mathrm{N}$ & Inter-relationships & Items & Response \\
\hline \multirow[t]{8}{*}{1.} & \multirow{8}{*}{ Vertical relationships } & VR1: How many major traders patronized you? & \\
\hline & & VR2: What kind of agreement do you have with your trading partners? CODE: [1] Written contracts [0] Non-formal agreements & \\
\hline & & VR3: How long have you been trading with your longest-standing customer (in years)? & \\
\hline & & VR4: I sell more than $50 \%$ of my total "crayfish" processed to just one of the traders & \\
\hline & & VR5: More than $50 \%$ of the "crayfish" purchased by at least one of the traders is processed by me ${ }^{a}$ & \\
\hline & & VR6: I am more inclined to sell my product to customers with whom I have a long-term relationship ${ }^{a}$ & \\
\hline & & VR7: I sell my "crayfish" to as many buyers at a particular open spot & \\
\hline & & VR8: I have to display my product before I can get willing buyers & \\
\hline \multirow[t]{4}{*}{2.} & \multirow[t]{4}{*}{ Horizontal relationships } & HOR1: Is the respondent a member of fish processing group? $(\{1\}$ Yes $\{0\}$ No) & \\
\hline & & HOR2: How many fish processing group does the respondent belong to? & \\
\hline & & HOR3: Longest time respondent has been a member of a processing group? & \\
\hline & & HOR4: How many fishers did you collaborate with? & \\
\hline \multirow[t]{6}{*}{3.} & \multirow[t]{6}{*}{ External relationships } & SE1: Do you have access to extension services? (\{1\} Yes $\{0\}$ No) & \\
\hline & & SE2: How many times do extension agents/supporting personnel visit the community in a year? & \\
\hline & & SE3: Do executives in your association meet with external actors on your behalf? ( $\{1\}$ Yes $\{0\}$ No) & \\
\hline & & SE4: I get some vital information about our processing from extension agents & \\
\hline & & SE5: Recently, we get more visits from people who want to support us & \\
\hline & & SE6: Our grievances now easily get to the public agenciesa & \\
\hline
\end{tabular}

aUse likert-scale

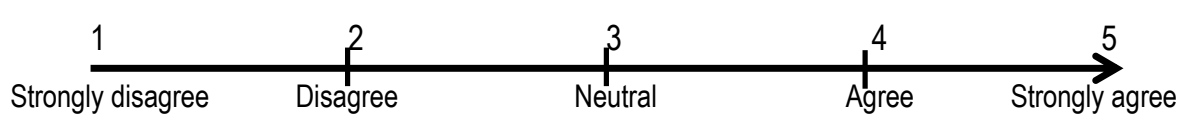




\begin{tabular}{|c|c|c|c|c|}
\hline S/N & Performances & Indicators & Items & Response \\
\hline \multirow[t]{8}{*}{1.} & \multirow[t]{8}{*}{ Financial } & \multirow[t]{8}{*}{ Efficiency } & FE1: What is your average profit per week from processing during the last 12 months? & \\
\hline & & & FE2: What was your average profit per week from processing in 2016, 2015 and $2014 ?$ & \\
\hline & & & FE3: Over the last 3 years my profit from "crayfish" processing has been increasing & \\
\hline & & & FE4: On average, how much cash do you have at hand per week during the last 12 months? & \\
\hline & & & FE5: On average, how much cash were you having at hand per week in 2016, 2015 and 2014 ? & \\
\hline & & & FE6: Over the last 3 years the cash I have at hand from "crayfish" processing has been increasing & \\
\hline & & & FE7: Over the last 3 years the quantity of "crayfish" I process has been increasing & \\
\hline & & & FE8: Over the last 3 years I have better profit relative to my competitors & \\
\hline & \multirow[t]{12}{*}{ Operational } & \multirow[t]{3}{*}{ Customer satisfaction } & OC1: Over the last 3 years I am more competitive in meeting the demand of my major buyers & \\
\hline & & & OC2: Over the last 3 years many buyers often lay complaints about my "crayfish" & \\
\hline & & & OC3: Over the last 3 years many buyers continuously patronize me because they are satisfied & \\
\hline & & \multirow[t]{3}{*}{ Responsiveness } & OR1: Over the last 3 years I respond to the orders of my customers on time & \\
\hline & & & OR2: What is your lead time? (Period between when an order is placed and received by buyer in hour) & \\
\hline & & & OR3: What is your lead time in 2016, 2015, and 2014? (Period between when an order is placed and received by buyer in hour) & \\
\hline & & \multirow[t]{2}{*}{ Flexibility } & OF1: Over the last 3 years I am able to quickly respond to unpredictable demands from buyers & \\
\hline & & & OF2: Over the last 3 years I am able to handle late demands from major buyers & \\
\hline & & \multirow{4}{*}{ Food quality } & OFQ1: Did you carry out thorough sorting of your processed "crayfish" over the last 3 years? ( $\{1\}$ Yes $\{0\}$ No) & \\
\hline & & & OFQ2: Over the last 3 years I strive to ensure my "crayfish" is well sorted before selling to the buyers & \\
\hline & & & OFQ3: The quality of my processed "crayfish" is an important measure of my market performance & \\
\hline & & & OFQ4: I believe the quality of my processed "crayfish" is of paramount importance & \\
\hline
\end{tabular}

5.2 Kindly fill in the necessary information and state the level at which you concur with some statements on your performance during the last 12 months (April 2017-May 2018) 
MODULE 6: RESPONDENT'S DEMOGRAPHIC CHARACTERISTICS

6.1 Kindly fill in the information about the respondent's demographic characteristics

\begin{tabular}{|c|c|c|c|c|c|c|c|c|c|c|}
\hline \multirow[b]{2}{*}{ 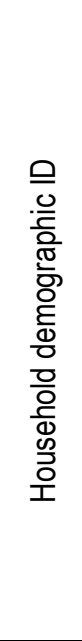 } & 1 & 2 & 3 & 4 & 5 & 6 & 7 & 8 & 9 & 10 \\
\hline & $\begin{array}{l}\text { What is the relationship of } \\
\text { [RESPONDENT] to the } \\
\quad \text { household head? } \\
\text { CODE: } \\
\text { [1]Head } \\
\text { [2]Spouse } \\
\text { [3]Son/Daughter } \\
\text { [4]Son/Daughter-in-law } \\
\text { [5]Father/mother } \\
\text { [6]Sister/Brother } \\
\text { [7]Grandchild } \\
\text { [8] Others (......) } \\
\text { [9]Other non-relative (......) }\end{array}$ & \begin{tabular}{l}
\multicolumn{1}{c}{ Gender of } \\
[RESPONDENT] \\
CODE: \\
[1]Female \\
[0] Male
\end{tabular} & $\frac{\text { Age (in }}{\text { years) }}$ & 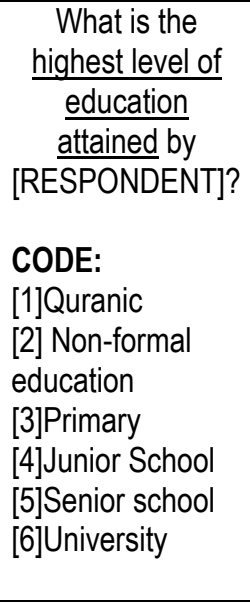 & $\begin{array}{l}\text { What is the } \\
\text { number of } \\
\text { years } \\
\text { [RESPOND } \\
\text { ENT] spent } \\
\text { in school? }\end{array}$ & $\begin{array}{c}\text { What the } \\
\text { number is of } \\
\text { times } \\
\text { [RESPONDENT] } \\
\text { repeated } \\
\text { classes? }\end{array}$ & $\begin{array}{l}\text { What is the } \\
\text { marital status of } \\
\text { [RESPONDENT]? } \\
\text { CODE: } \\
\text { [1]Single } \\
\text { [2]Monogamous } \\
\text { married } \\
\text { [3]Polygamous } \\
\text { married } \\
\text { [4]Living together } \\
\text { [5]Divorced } \\
\text { [6]Separated } \\
\text { [7]Widowed }\end{array}$ & $\begin{array}{l}\text { What is the main } \\
\text { occupation of } \\
\text { [RESPONDENT] } \\
\text { in the last 12 } \\
\quad \text { months? } \\
\text { CODE: } \\
\text { [1]Fishing } \\
\text { [2]Processing \& } \\
\text { marketing } \\
\text { [3]1\&2 } \\
\text { [4]Farming } \\
\text { [5]Transport } \\
\text { [6] Wage labor } \\
\text { [7]Trade } \\
\text { [8]Service }\end{array}$ & $\begin{array}{l}\text { Was } \\
\text { [RESPONDEN } \\
\text { T] employed in } \\
\frac{\text { non-fishing }}{\text { activities in the }} \\
\text { last } 12 \\
\text { months? } \\
\text { CODE: } \\
\text { [1] Yes } \\
\text { [0] No }\end{array}$ & $\begin{array}{l}\text { Did } \\
\text { [RESPONDE } \\
\text { NT] shrimp } \\
\text { under } \\
\frac{\text { someone in }}{\text { the last } 12} \\
\text { months? } \\
\text { CODE: } \\
\text { [1] Yes } \\
\text { [0] No }\end{array}$ \\
\hline MBID & RELATION & GEND & AGE & EDUC & EDUYR & REPEAT & MARSTAT & OCCUP & NONFISH & APPRE \\
\hline 00 & & & & & & & & & & \\
\hline
\end{tabular}

